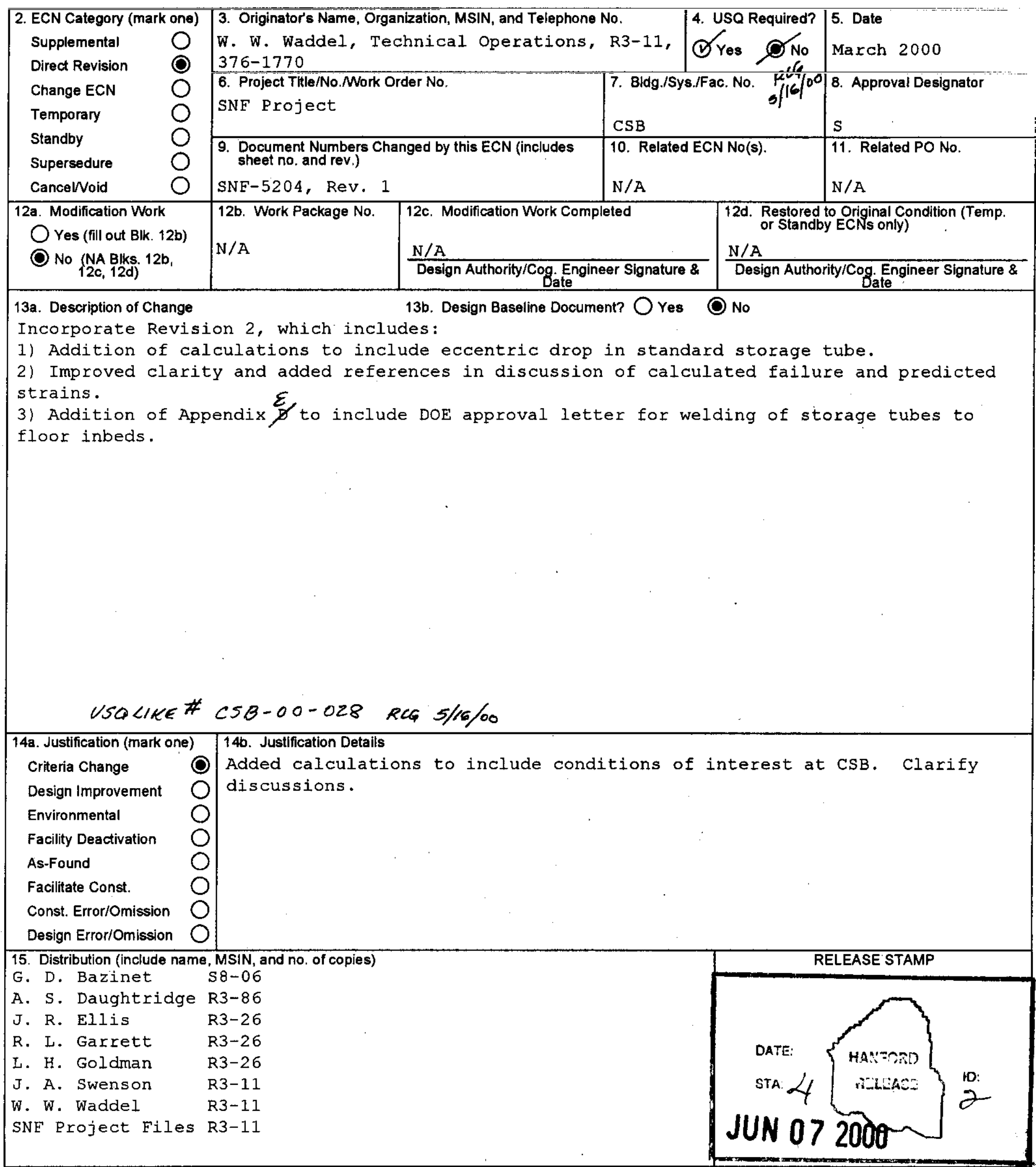




\section{ENGINEERING CHANGE NOTICE}

16. Design Verification

Required
OYes
O No

17. Cost Impact

ENGINEERING

Additional $O \$ N / A$

Savings $\bigcirc$ s
Page 2 of 2

\begin{tabular}{lll} 
& \multicolumn{2}{c}{ CONST } \\
Additional & $\bigcirc$ \\
Savings & $\bigcirc$ & $\$$
\end{tabular}
1. ECN (use no. from pg. 1) 657948

18. Schedule Impact (days)

Improvement

0

19. Change Impact Review: Indicate the related documents (other than the engineering documents identifled on Side 1) that will be affected by the change described in Block 13. Enter the affected document number in Block 20.

$\begin{array}{llll}\text { SDD/DD } & \square & \text { Seismic/Stress Analysis } & \square \\ \text { Functional Design Criteria } & \square & \text { Stress/Design Report } & \square \\ \text { Operating Specification } & \square & \text { Interface Control Drawing } & \square \\ \text { Criticality Specification } & \square & \text { Calibration Procedure } & \square \\ \text { Conceptual Design Report } & \square & \text { Installation Procedure } & \square \\ \text { Equipment Spec. } & \square & \text { Maintenance Procedure } & \square \\ \text { Const. Spec. } & \square & \text { Engineering Procedure } & \square \\ \text { Procurement Spec. } & \square & \text { Operating Instruction } & \square \\ \text { Vendor Information } & \square & \text { Operating Procedure } & \square \\ \text { OM Manual } & \square & \text { Operational Safety Requirement } & \square \\ \text { FSAR/SAR } & \square & \text { IEFD Drawing } & \square \\ \text { Safety Equipment List } & \square & \text { Cell Arrangement Drawing } & \square \\ \text { Radiation Work Permit } & \square & \text { Essential Material Specification } & \square \\ \text { Environmental Impact Statement } & \square & \text { Fac. Proc. Samp. Schedule } & \square \\ \text { Environmental Report } & \square & \text { Inspection Plan } & \square \\ \text { Environmental Permit } & \square & \text { Inventory Adjustment Request } & \square\end{array}$

Tank Calibration Manual Health Physics Procedure Spares Multiple Unit Listing Test Procedures/Specification Component Index ASME Coded Item Human Factor Consideration Computer Software Electric Circuit Schedule ICRS Procedure Process Control Manual/Plan Process Flow Chart Purchase Requisition Tickler File

20. Other Affected Documents: (NOTE: Documents listed below will not be revised by this ECN.) Signatures below indicate that the signing organization has been notified of other affected documents listed below.

$N / A$

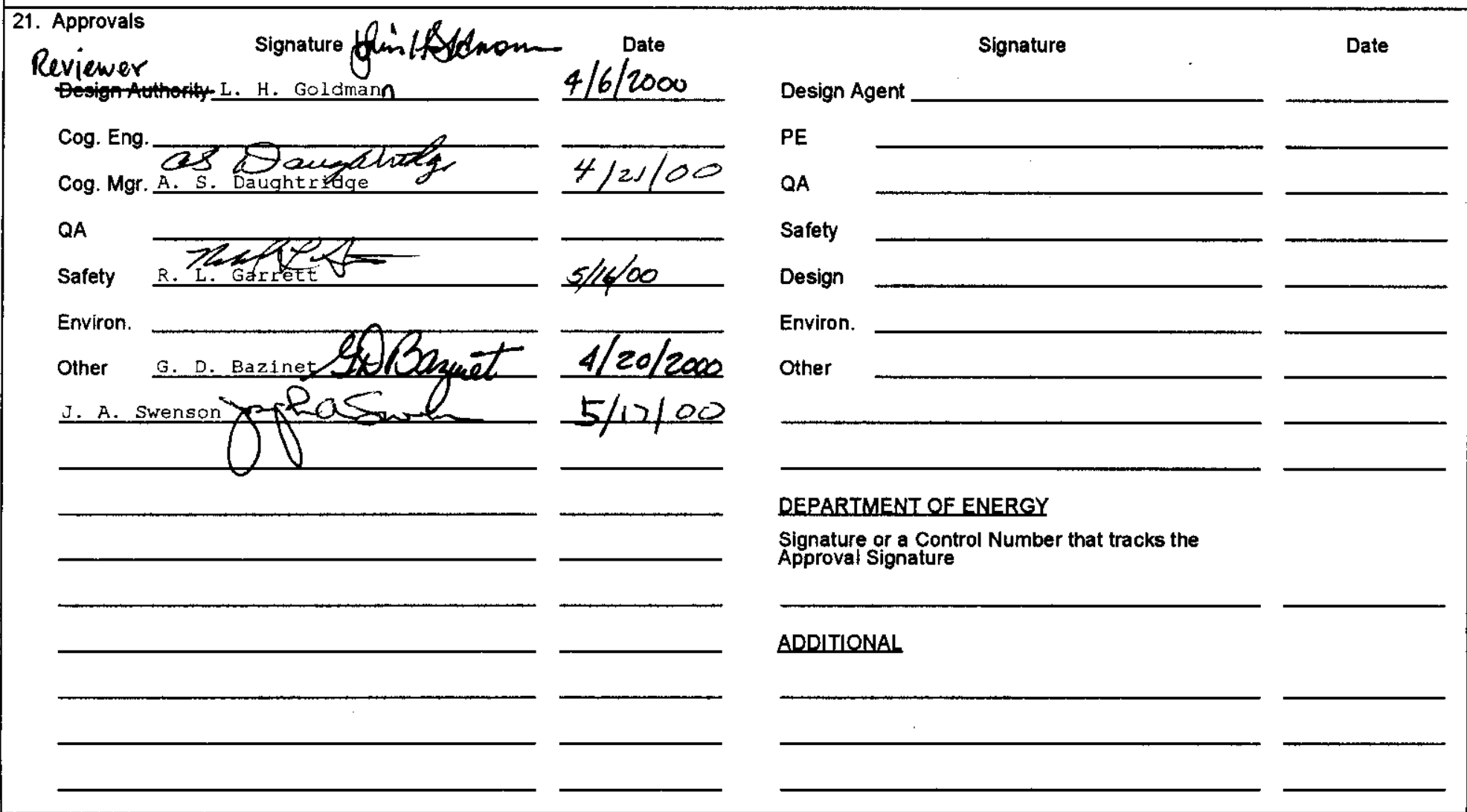


SNF-5204

Revision 2

\section{Analysis for Eccentric Multi-Canister Overpack Drops at the Canister Storage Building}

Prepared for the U.S. Department of Energy

Assistant Secretary for Environmental Management

Project Hanford Management Contractor for the

U.S. Department of Energy under Contract DE-AC06-96RL13200

Fluor Hanford

P.O. Box 1000

Richland, Washington 


\section{Analysis for Eccentric Multi-Canister Overpack Drops at the Canister Storage Building}

R. G. Hollenbeck

K. C. Tu

Fluor Daniel Northwest, Inc.

Date Published

May 2000

Prepared for the U.S. Department of Energy

Assistant Secretary for Environmental Management

Project Hanford Management Contractor for the

U.S. Department of Energy under Contract DE-AC06-96RL13200

Fluor Hanford

P.O. Box 1000

Richland, Washington
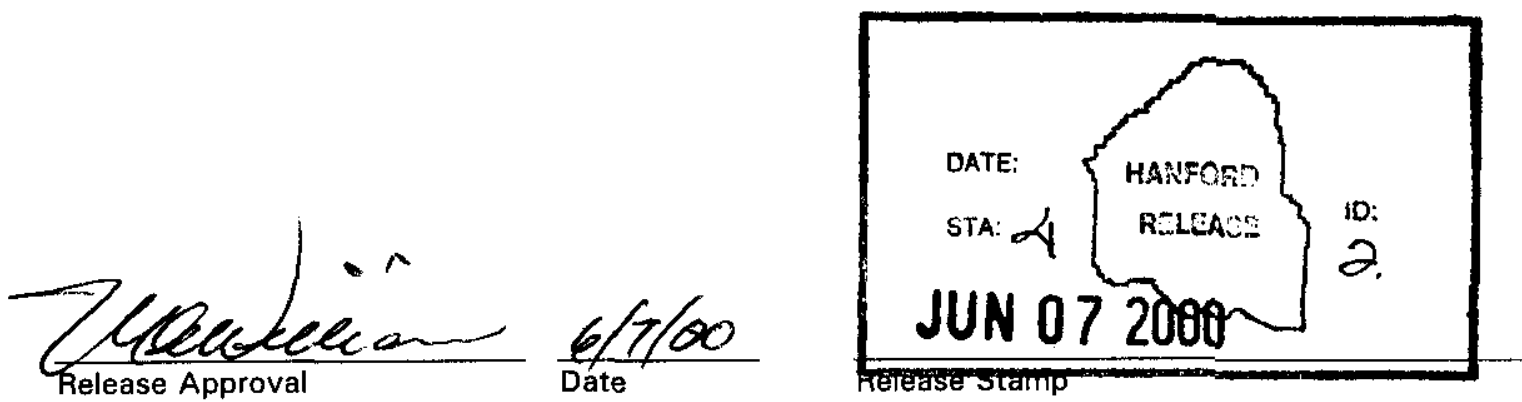


\section{TRADEMARK DISCLAIMER}

Reference herein to any specific commercial product, process,

or service by trade name, trademark, manufacturer, or

otherwise, does not necessarily constitute or imply its

endorsement, recommendation, or favoring by the United

States Government or any agency thereof or its contractors or

subcontractors.

This report has been reproduced from the best available copy.

Printed in the United States of America

Total Pages: 145

Abaqus is a registered trademark of Hibbltt, Karlsson, \& Sorenson, Inc.

Explicit is a registered trademark of Explicit Software, Inc.

SNF-5204, rew 2 


\section{RECORD OF REVISION}

(1) Document Number

$\mathrm{SNE}-5204$

Page

1

(2) Title

Analysis for Eccentric Multi-Canister Overpack Drops at the Canister Storage Building

\section{Change Control Record}

(3) Revision

(4) Description of Change - Replace, Add, and Delete Pages

1) Addition of calculations to include eccentric drop in standard storage tube.

2) Improved clarity and added references in discussion of calculated failure and predicted strains.

3) Addition of Appendix E to include DOE approval letter for welding of storage tubes to floor inbeds.

$E C N-657948$

$276-7.00$ 


\section{ENGINEERING REPORT}

\section{ANALYSIS FOR \\ ECCENTRIC MULTI-CANISTER OVERPACK DROPS \\ AT THE CANISTER STORAGE BUILDING}

FLUOR DANIEL HANFORD, INC.

RICHLAND, WA

SPENT NUCLEAR FUEL PROJECT

CONTRACT 804602101800

February 2000

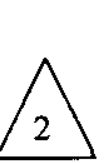

K. C. Tu

R. G. Hollenbeck

Fluor Daniel Northwest, Inc. 


\section{EXECUTIVE SUMMARY}

The Spent Nuclear Fuel (SNF) Canister Storage Building (CSB) is the interim storage facility for the K-Basin SNF at the U.S. Department of Energy (DOE) Hanford Site. The SNF is packaged in multi-canister overpacks (MCOs). The MCOs are placed inside transport casks, then delivered to the service station inside the CSB. At the service station, the MCO handling machine (MHM) moves the MCO from the cask to a storage tube or one of two sample/weld stations. There are 220 standard storage tubes and six overpack storage tubes contained in a below grade reinforced concrete vault. Each storage tube can hold two MCOs.

The purpose of this report is to investigate the potential for damage to the MCO during impact from an eccentric accidental drop onto the standard storage tube, overpack tube, service station or sampling/weld station.

The MCO impacts a 45 degree inclined surface on the lower flange at both the standard storage tube and the overpack storage tube. The standard storage tubes have a smaller gap between the tube and the embedment than the overpack tubes. This limits the tube lateral displacements to a lower value, which means that during a drop more force would be transferred to the MCO causing more potential for damage. The model appropriate for the standard storage tubes with the smaller gap is the basis for the analysis and results reported herein in this SNF-5204, revision 2 report. Revision 1 of this report is based on a model that includes the larger gap appropriate for the overpack tubes.

The shielding rings at the service and sampling/weld station are fixed in place and do not move during impact. The inclinations of the impact surfaces of the shielding rings have been reduced from 45 degrees to 15 degrees from vertical to reduce the impact damage to the MCO. The temporary shielding at the sampling/weld station is less massive than the shield hatch ring at the service station and will cause less damage to the MCO from an accidental drop. Therefore, the receiving service station pit has been chosen to represent the drop for both locations.

The maximum equivalent plastic strain is 40 to $45 \%$. It occurs on the MCO bottom plate near the point of impact. It is in a compressive triaxial stress state. The compressive failure strain for the base material is $48 \%$ to $60 \%$. Some gouging and removal of local surface metal may occur. However, because the maximum principal tensile strain is in the radial direction, through-wall cracking will not occur.

The maximum predicted equivalent plastic strain at the MCO lower weld inner surface is about $4.6 \%$, which is acceptably less than a conservative estimate of failure strain of $8 \%$ for positive triaxiality. The maximum predicted equivalent plastic strain of the MCO lower weld outer surface is about $15 \%$, which is acceptably less than a conservative estimated failure strain of $32 \%$ for negative triaxiality. The maximum tensile principal strain is in a radial direction, therefore, any failure would be by spalling or flaking rather than through-wall cracking.

The deceleration of the MCO baskets are shown to be about $34 \mathrm{~g}$ which is within the design allowable of $35 \mathrm{~g}$ and conservatively less than the calculated design capacity of $54 \mathrm{~g}$ for the basket.

The deformations of the MCO and standard storage tube are less than the tube clearance, therefore, no wedging of the MCO in the tube is expected. 


\section{Table of Contents}

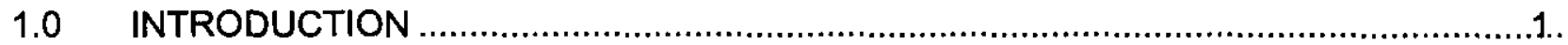

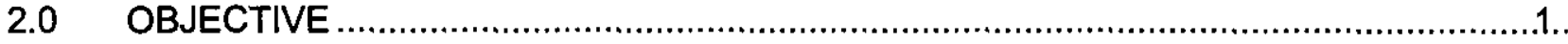

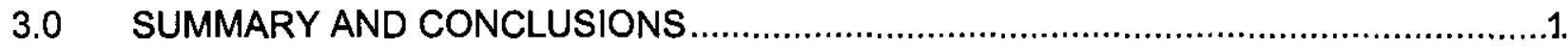

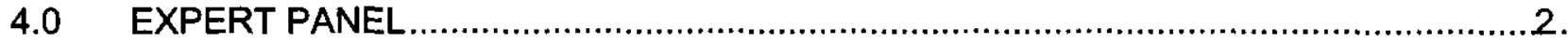

5.0 DESCRIPTION

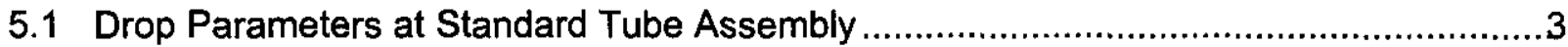

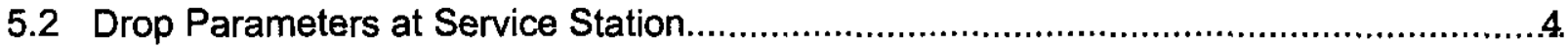

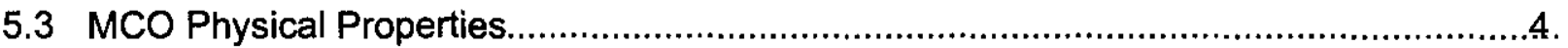

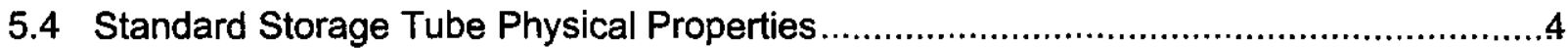

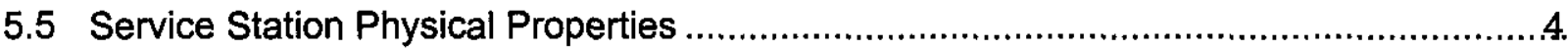

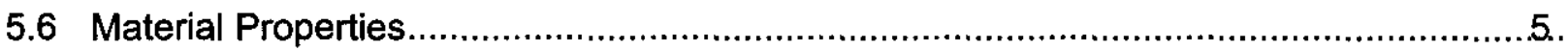

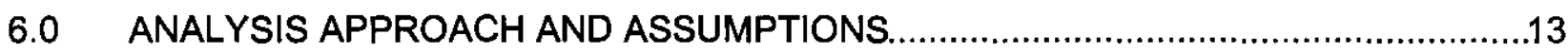

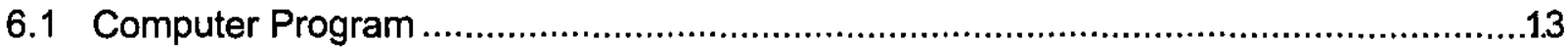

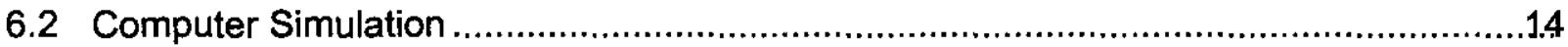

6.3 Computer Modeling of MCO Drops onto Storage Tube Assembly.............................14

6.4 Computer Modeling of MCO Drops onto Service Station.............................................15

7.0 RESULTS

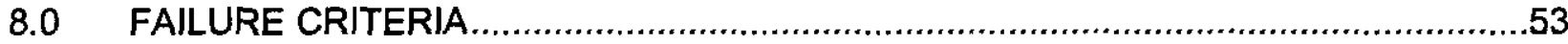

9.0 DISCUSSION

10.0 REFERENCES

\section{Attachment \\ Expert Panel Report}




\section{Appendices}

A Material Properties for ABAQUS/Explicit Input

B Stress, Strain, and Triaxiality Factor Plots

C Computer Input Files

C-1 ABAQUS Input File Section One, MCO Drop on Standard Storage Tube

C-2 ABAQUS Input File Section Two, MCO Drop on Service Station

D Peer Review Comment Record and FDNW Transmittal Record

E RL Letter of Concurrence

\section{List of Table}

7.1 Calculated Failure Strain and Predicted Strain 


\section{List of Figures}

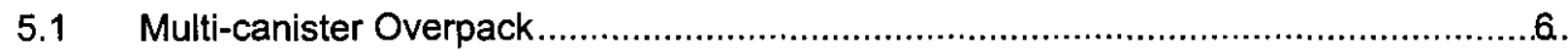

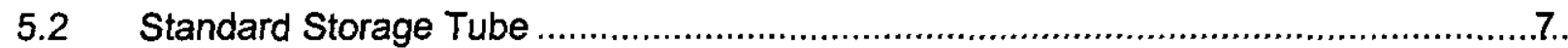

5.3 MCO, MHM and Storage Tube At Time Of Impact................................................

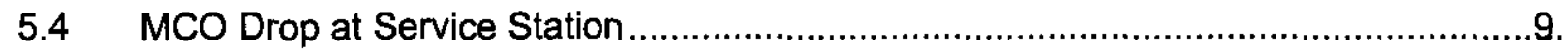

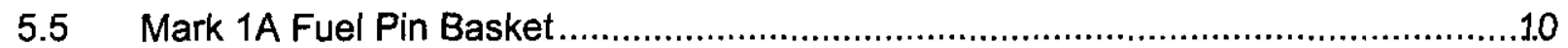

5.6 True Stress-Strain Curves For 304SS Steel.......................................................11

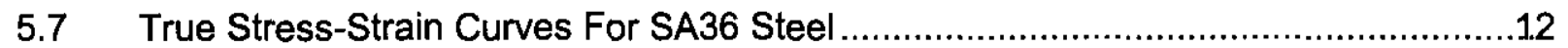

6.1 Computer Model of MCO Drop Onto Storage Tube ..............................................17

6.2 Close-up of Computer Model of MCO Drop Onto Standard Storage Tube................18

6.3 Computer Model of MCO Drop Onto Service Station Shield Hatch Ring..................19

6.4 Close-up Computer Model of MCO Drop Onto Service Station Shield Hatch Ring....20

7.1 Close-up View at 0.03 Second After Impact Onto Storage Tube Assembly..............24

7.2 Equivalent Plastic Strain at MCO Bottom at 0.03 Second After Impact at Storage

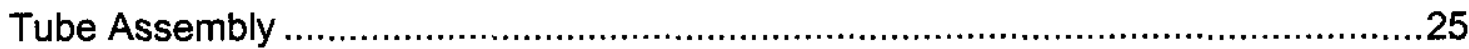

7.3 Equivalent Plastic Strain at MCO Lower Weld at $0.03 \mathrm{Sec}$ After Impact on Storage

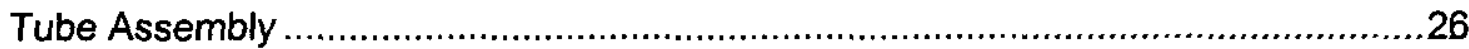

7.4 Equivalent Plastic Strain at 0.028 Second at High Strain Rate for MCO Drop Onto Storage Tube Assembly ..........................................................................27

7.5 Equivalent Plastic Strain at MCO Bottom 0.04 Second After Impact Onto Service Station Shield Hatch Ring..........................................................................28

7.6 Equivalent Plastic Strain Near Lower Weld At 0.04 Second After Impact Onto Service

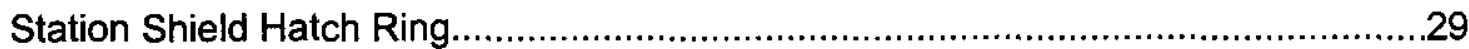

7.7 Basket Velocity vs. Time of MCO Impact Onto Storage Tube Assembly..................30

7.8 Basket Velocity vs. Time of MCO Impact Onto Service Station Shield Hatch Ring...31

7.9 Node Locations for Velocity Plot of MCO Drop onto Service Station.........................32

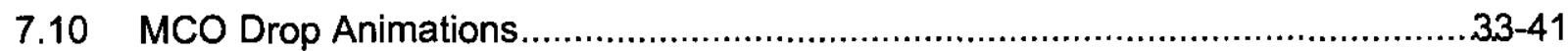

7.11 Mises Equivalent Stress Time History Plot of Element 70159 near Outside Weld.....42

7.12 Mises Equivalent Stress Time History Plot of Element 70019 at MCO bottom Near Impact Location..........................................................................43

7.13 Stress in Radial Direction (direction 1) at Time 0.03 Second...............................44

7.14 Stress in Meridian Direction (direction 2) at Time 0.03 Second ............................45 
7.15 Stress in Hoop Direction (direction 3) at Time 0.03 Second.................................46

7.16 Plastic Strain in Radial in Direction (direction 1) at Time 0.03 Second....................47

7.17 Plastic Strain in Meridian Direction (direction 2) at Time 0.03 Second....................48

7.18 Plastic Strain in Hoop Direction (direction 3) at Time 0.03 Second..........................49

7.19 Total Kinetic Energy Time History of the MCO Drops onto the Standard Storage

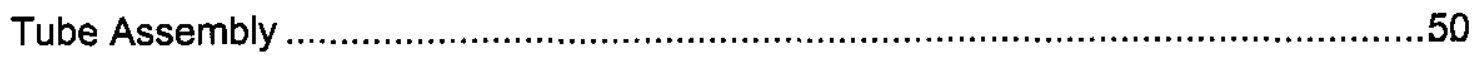

7.20 MCO Deformations ................................................................................ 5.1

7.21 Standard Storage Tube Deformations....................................................52

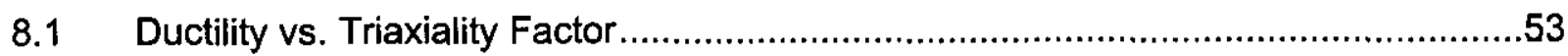




\section{ACRONYM LISTING}

$\begin{array}{ll}\text { CSB } & \text { Canister Storage Building } \\ \text { DESH } & \text { Duke Engineering \& Services Hanford, Inc. } \\ \text { DOE } & \text { U.S. Department of Energy } \\ \text { FDNW } & \text { Fluor Daniel Northwest } \\ \text { MCO } & \text { Multi-canister overpack } \\ \text { MHM } & \text { MCO handling machine } \\ \text { QA } & \text { Quality Assurance } \\ \text { SNF } & \text { Spent Nuclear Fuel }\end{array}$




\title{
ENGINEERING REPORT
}

\author{
ANALYSIS FOR \\ ECCENTRIC MULTI-CANISTER OVERPACK DROPS \\ AT THE CANISTER STORAGE BUILDING
}

\subsection{INTRODUCTION}

The Spent Nuclear Fuel (SNF) Canister Storage Building (CSB) is the interim storage facility for the K-Basin SNF at the U.S. Department of Energy (DOE) Hanford Site. The SNF is packaged in multi-canister overpacks (MCOs). The MCOs are placed inside transport casks, then delivered to the service station inside the CSB. At the service station, the MCO handling machine (MHM) moves the MCO from the cask to a storage tube or one of two sample/weld stations. There are 220 standard storage tubes and six overpack storage tubes in a below grade reinforced concrete vault. Each storage tube can hold two MCOs.

\subsection{OBJECTIVE}

The purpose of this report is to investigate the potential for damage to the MCO during impact from an eccentric accidental drop onto the standard storage tube, overpack storage tube, service station or sampling/weld station. Damage to the storage tube and sample/weld station is beyond the scope of this report. The results of this analysis are required to show the following;

- If a breach resulting in unacceptable release of contamination could occur in the MCO.

- If the dropped MCO could become stuck in the storage tube after the drop.

- Maximum deceleration of the spent nuclear fuel baskets.

The model appropriate for the standard storage tubes with the smaller gap is the basis for the analysis and results reported herein in this SNF-5204, revision 2 report. Revision 1 of this report is based on a model that includes the larger gap appropriate for the overpack tubes.

\subsection{SUMMARY AND CONCLUSIONS}

The maximum equivalent plastic strain is 40 to $45 \%$. It occurs on the MCO bottom plate near the point of impact. It is in a compressive triaxial stress state. The compressive failure strain for the base material is $48 \%$ to $60 \%$. Some

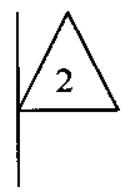


gouging and removal of local surface metal may occur. However, because the maximum principal tensile strain is in the radial direction, through-wall cracking will not occur.

The maximum predicted equivalent plastic strain at the MCO lower weld outside surface is about $15 \%$, during the drop into the standard storage tube. This is well below a $32 \%$ failure strain for a negative triaxiality factor. The maximum predicted plastic strain is about $4.6 \%$ at the lower weld inside surface. The failure strain is about $8 \%$ with a triaxiality factor of 2 . The maximum plastic strains are about $4 \%$ and $12 \%$ at the outside and inside shell base metal areas and the associated failure strains are $15 \%$ and $60 \%$ respectively. The maximum tensile principal strain is in a radial direction, therefore, any failure would be by spalling or flaking rather than through-wall cracking.

The maximum deceleration of the MCO baskets is about $34 \mathrm{~g}$ which is within the design allowable of $35 \mathrm{~g}$ and conservatively less than the calculated design capacity of $54 \mathrm{~g}$ for the basket (Ref.17).

The deformations of the $\mathrm{MCO}$ and target assembly are less than the tube clearance, therefore, wedging of the MCO in the tube is not expected.

The analyses of the standard and overpack storage tube assemblies have been studied in References 1 and 2 . However, the strains found in this report are in agreement with previous analyses and no rupture or through wall cracking is anticipated.

\subsection{EXPERT PANEL}

An expert panel was assembled to oversee this report to verify that appropriate inputs, methods, and assumptions were used and to ensure the findings of this report would be available in a timely manner. The panel was made up of the following members.

- L. D. Blackburn Metallurgy

- R. D. Crow Safety Analysis

- L. H. Goldmann MCO Design Authority

- R. P. Kennedy Structural Analysis

- L. K. Severud Engineering Management \& Structural Analysis

The expert panel report, included as an attachment to this report, was prepared in a review of Revision 1 of this SNF-5204 document. The Expert Panel reviewed Revision 2 and agrees with the conclusion. 
- Standard storage tube assembly

- Overpack storage tube assembly

- Service station

- Sampling/weld station

The MCO is constructed of stainless steel and measures approximately 24 inches in diameter by about 13 feet in length as shown in Figure 5.1 as the shell assembly. The MCOs are maneuvered inside the CSB by the MCO handling machine (MHM). The MCO impacts a 45 degree inclined surface on the lower flange at both the standard storage tube and the overpack storage tube. The damage to the tube assembly has been studied in References 1 and 2 . The standard storage tubes have a smaller gap (1/2") between the tube and the embedment than the overpack tubes $\left(1^{\prime \prime}\right)$. This limits the tube lateral displacements to a lower value, which means that during a drop more force would be transferred to the MCO causing more potential for damage. Therefore, the standard storage tube was chosen to represent the drop for both locations. The standard storage tube is $\mathbf{2 8}$ inches in diameter and approximately 40 feet long and is shown in Figure 5.2. A sketch of the drop onto the standard storage tube is shown in Figure 5.3.

The shielding rings at the service and sampling/weld station are fixed in place and do not move during impact. The inclinations of the impact surfaces of the shielding rings have been reduced from 45 degrees to 15 degrees from vertical to reduce the impact damage to the MCO. The temporary shielding ring at the sampling/weld station is supported on steel posts from the base of the pit. The service station shield hatch ring is more rigidly supported directly on the floor embedment and is more massive than the sampling/weld station shielding ring. A drop on this more rigid and massive ring would cause more damage to the MCO from an accidental drop. Therefore, the service station was chosen to represent the drop for both locations. A sketch of the drop onto the service station is shown on Figure 5.4.

Each MCO has the capacity to contain six Mark 1A baskets (see Figure 5.5) or five Mark IV baskets loaded with fuel pins. The baskets are stacked one on top of the other. At the bottom of the MCO are 6 basket support plates (ribs) in a radial arrangement. These 6 ribs support the entire basket stack. The loaded baskets make up about $70 \%$ of the total MCO weight.

\subsection{Drop Parameters at Standard Tube Assembly}

Loaded MCO weight, without cap

Drop height

Drop velocity

Kinetic energy at impact

Point of impact

Impact distance from inside face

of standard tube assembly
$20,000 \mathrm{lbf}$

90 inches

$263.7 \mathrm{in} / \mathrm{sec}$

$1,800,000$ in-lbf

$45^{\circ}$ inclined surface of lower flange

2.75 inches 
MHM off center dimension

Drop angle
1 inch

$2^{\circ} 21^{\prime}$

\subsection{Drop Parameters at Service Station}

Loaded MCO weight, without cap

Drop height

Drop velocity

Kinetic energy at impact

Point of impact

Impact distance from top inside face of opening

MHM off center dimension

Drop angle
$20,000 \mathrm{lbf}$

90 inches

$263.7 \mathrm{in} / \mathrm{sec}$

$1,800,000$ in-lbf

15 degrees inclined surface of shield hatch ring

1.58 inches

3.63 inches

$1^{\circ} 40^{\prime}$

\subsection{MCO Physical Properties}

Wall thickness

Bottom thickness

Outside diameter

Outside diameter at head
0.5 inches

2.01 inches

24.0 inches

25.3 inches

\subsection{Standard Storage Tube Physical Properties}

Lower flange thickness

Slope of lower flange sealing surface

Tube inner diameter

Wall thickness

\section{5 inches}

45 degrees from vertical

27 inches

0.5 inches

\subsection{Service Station Physical Properties}

Shield hatch ring thickness

10 inches

Slope of shield hatch ring 15 degrees from vertical 


\subsection{Material Properties}

The MCO is constructed from $304 \mathrm{~L}$ stainless steel while the storage tubes are constructed from ASTM A36 steel. The stress-strain curves for these steels are dependent on the applied strain rate. Stress-strain data for a strain rate of 60 inch/inch per second (maximum strain rate observed in an earlier computer run) was calculated (Appendix $A$ ) and is plotted on Figures 5.6 and 5.7 along with the low stress-strain curve for $304 \mathrm{~L}$ and A36 steel, respectively.

The material properties for the MCO and storage tubes are as follows:

MCO MATERIAL

304L stainless steel

(Ref. Drawing no. H-2-828043 for shell wall \& H-2-828044 for shell bottom)

Elastic modulus

Poisson ratio

STANDARD TUBE ASSEMBLY MATERIAL

Elastic modulus

Poisson ratio
$28,000,000$ psi

0.27

ASTM A36

$29,500,000$ psi

0.27 
SNF-5204, Rev. 2 / CSB-S-0073

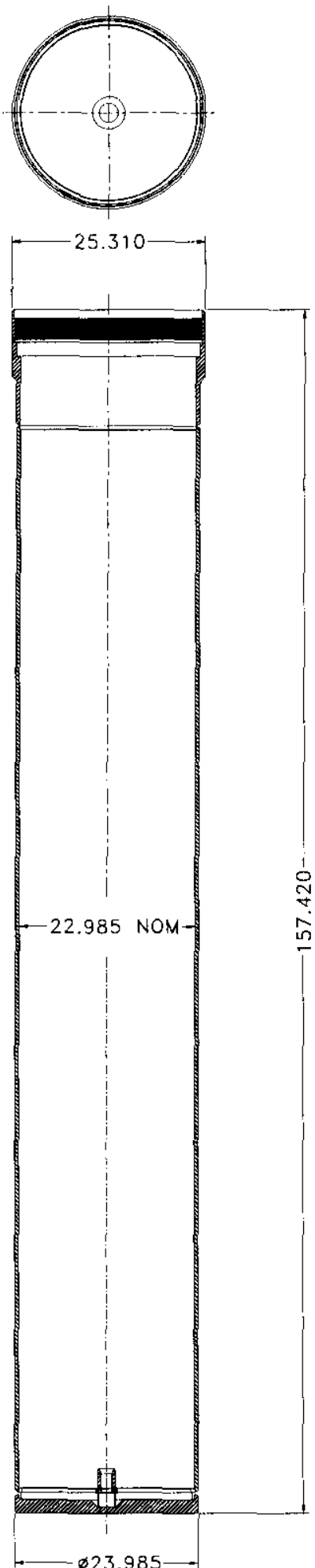

Figure 5.1. Multi-canister Overpack Shell Assembly 

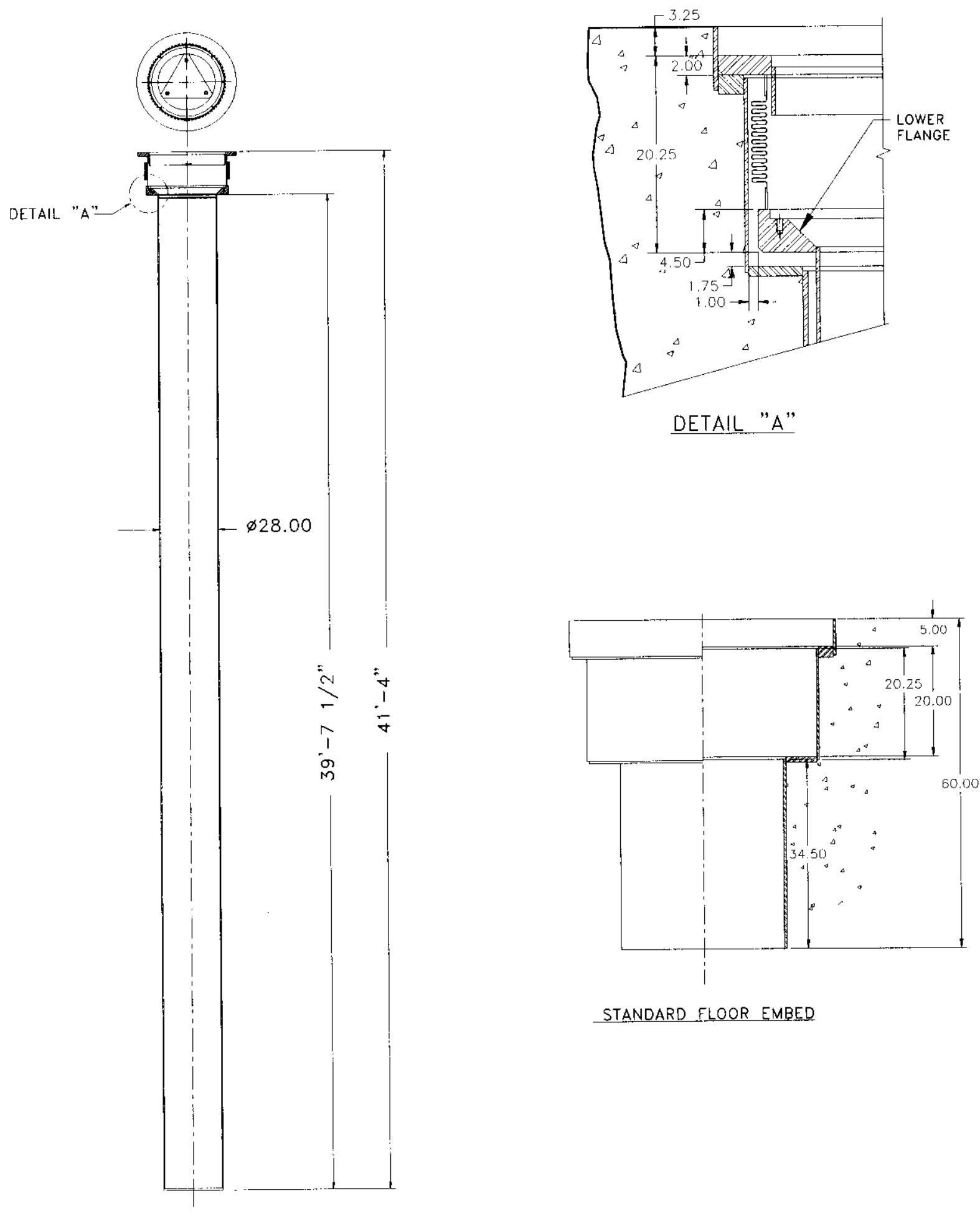

STANDARD FLOOR EMBED

Figure 5.2. Standard Storage Tube. 


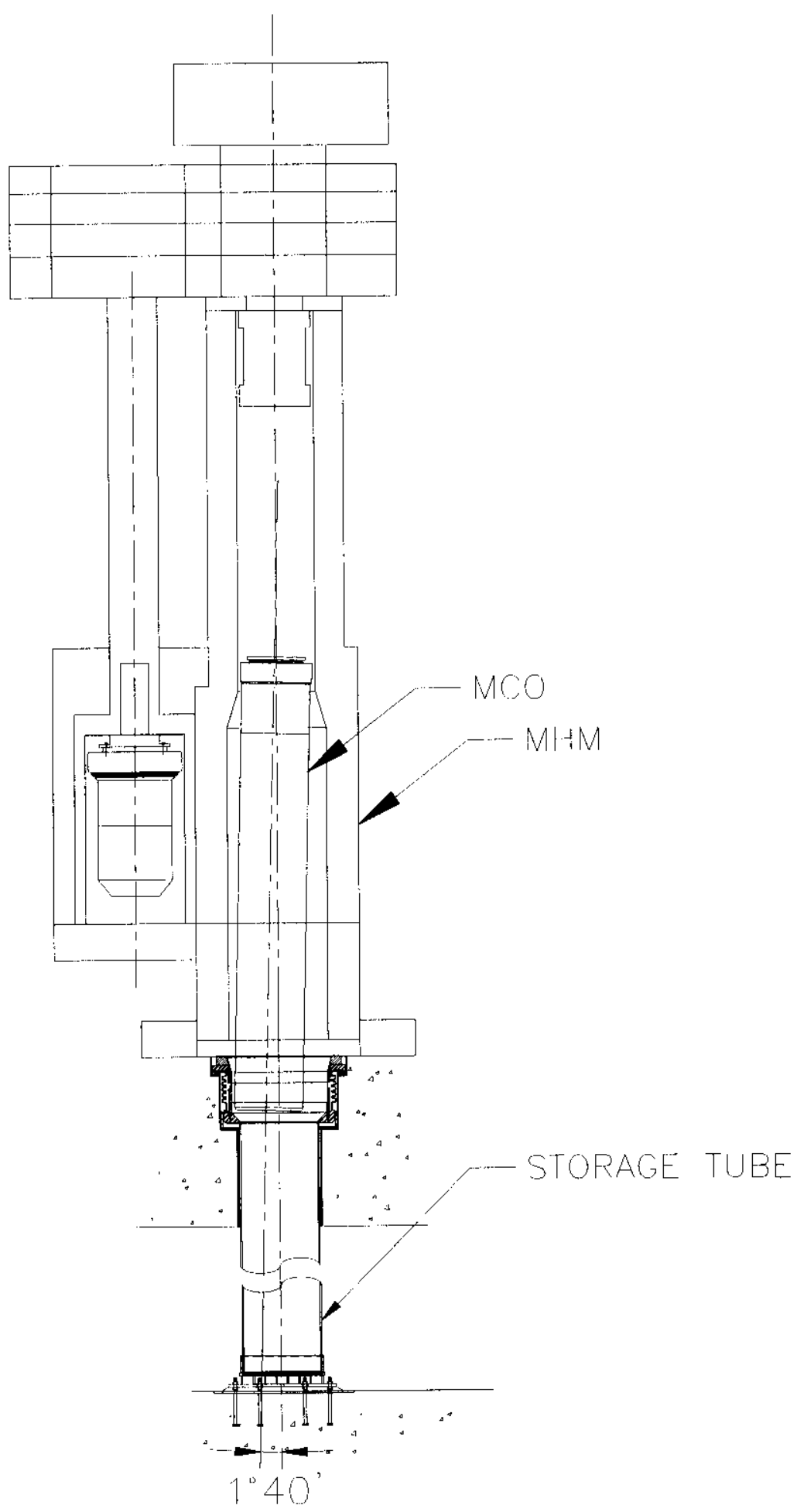

Figure 5.3. MCO, MHM and Storage Tube at Time of Impact. 


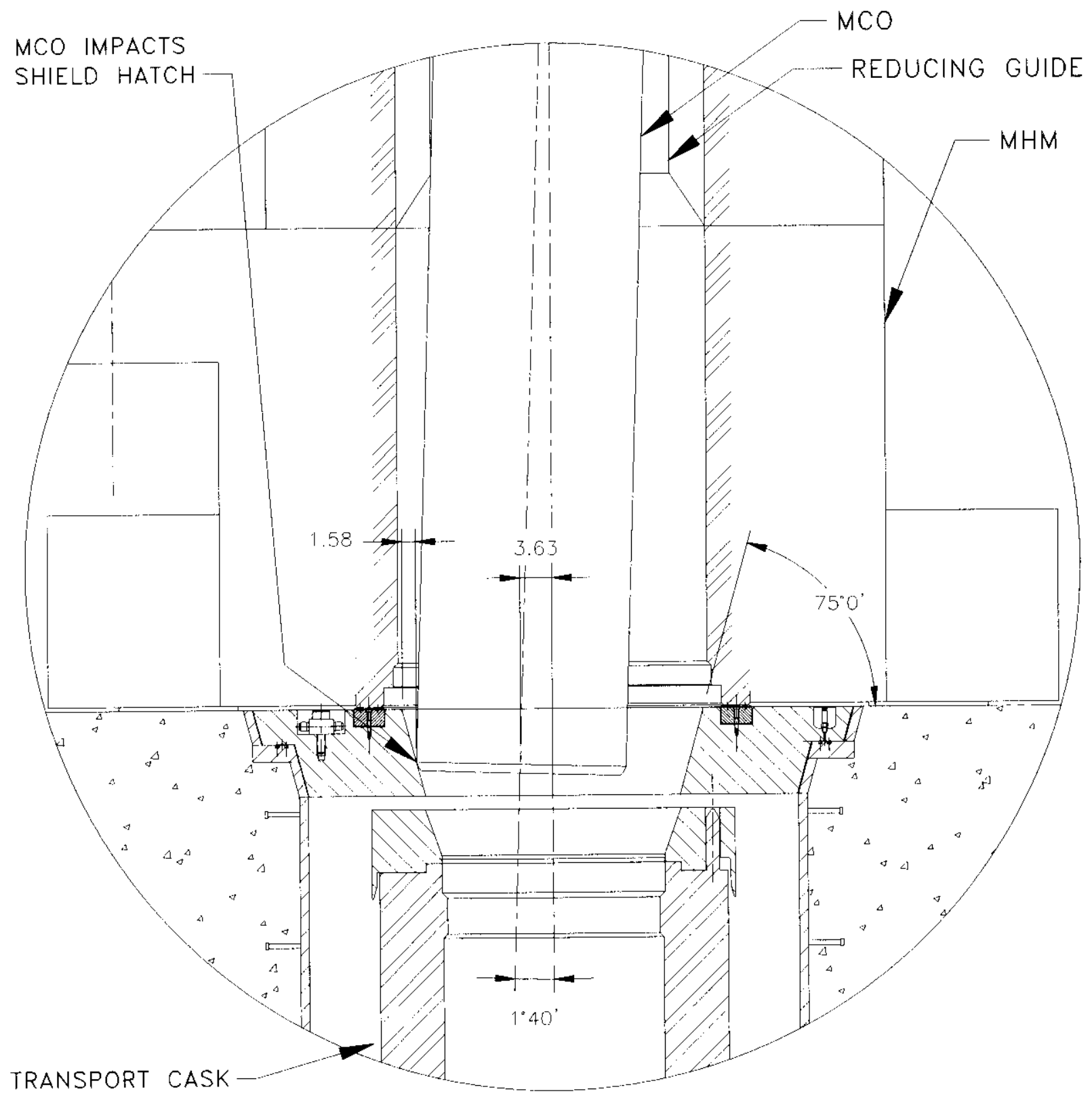

Figure 5.4. MCO Drop at Service Station. 
SNF-5204, Rev. 2 / CSB-S-0073

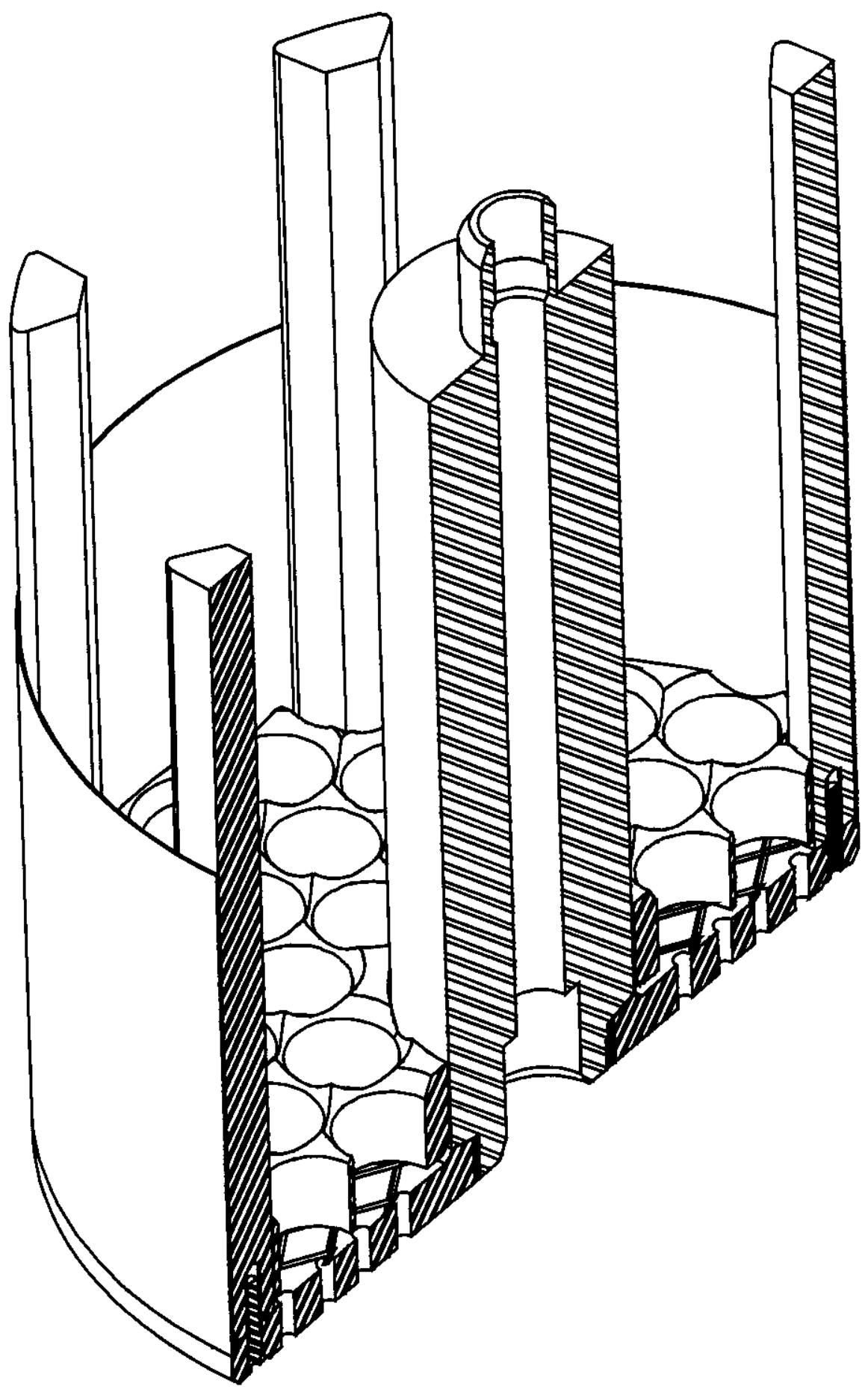

Figure 5.5. Mark 1A Fuel Pin Basket. 


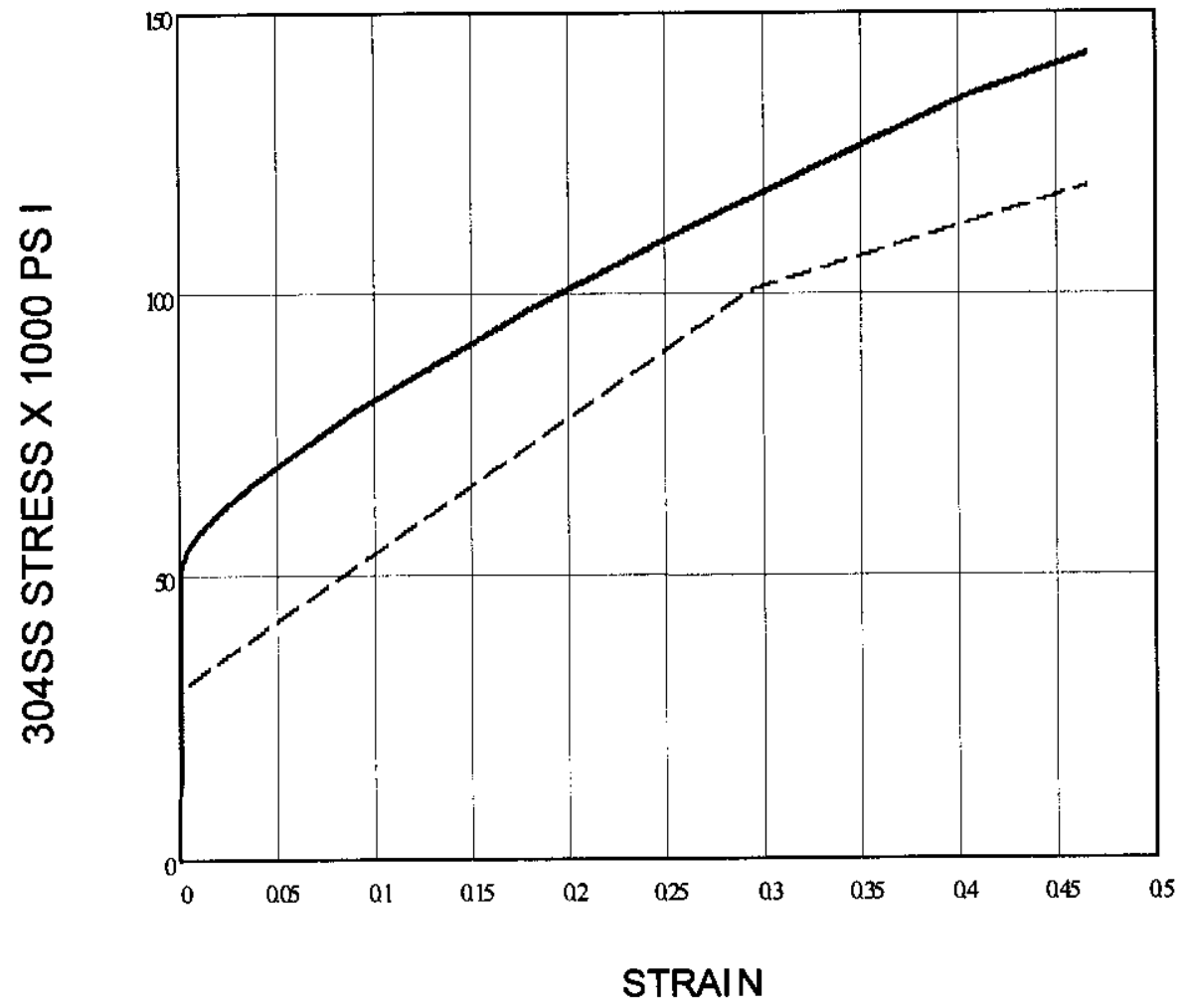

- Strain Rate of $60 \mathrm{in} / \mathrm{in} / \mathrm{sec}$

- Low Strain Rate $\left(3 \times 10^{-5} \operatorname{In} / \mathrm{In} / \mathrm{sec}\right)$

Figure 5.6. True Stress-Strain Curves for 304SS Steel. 


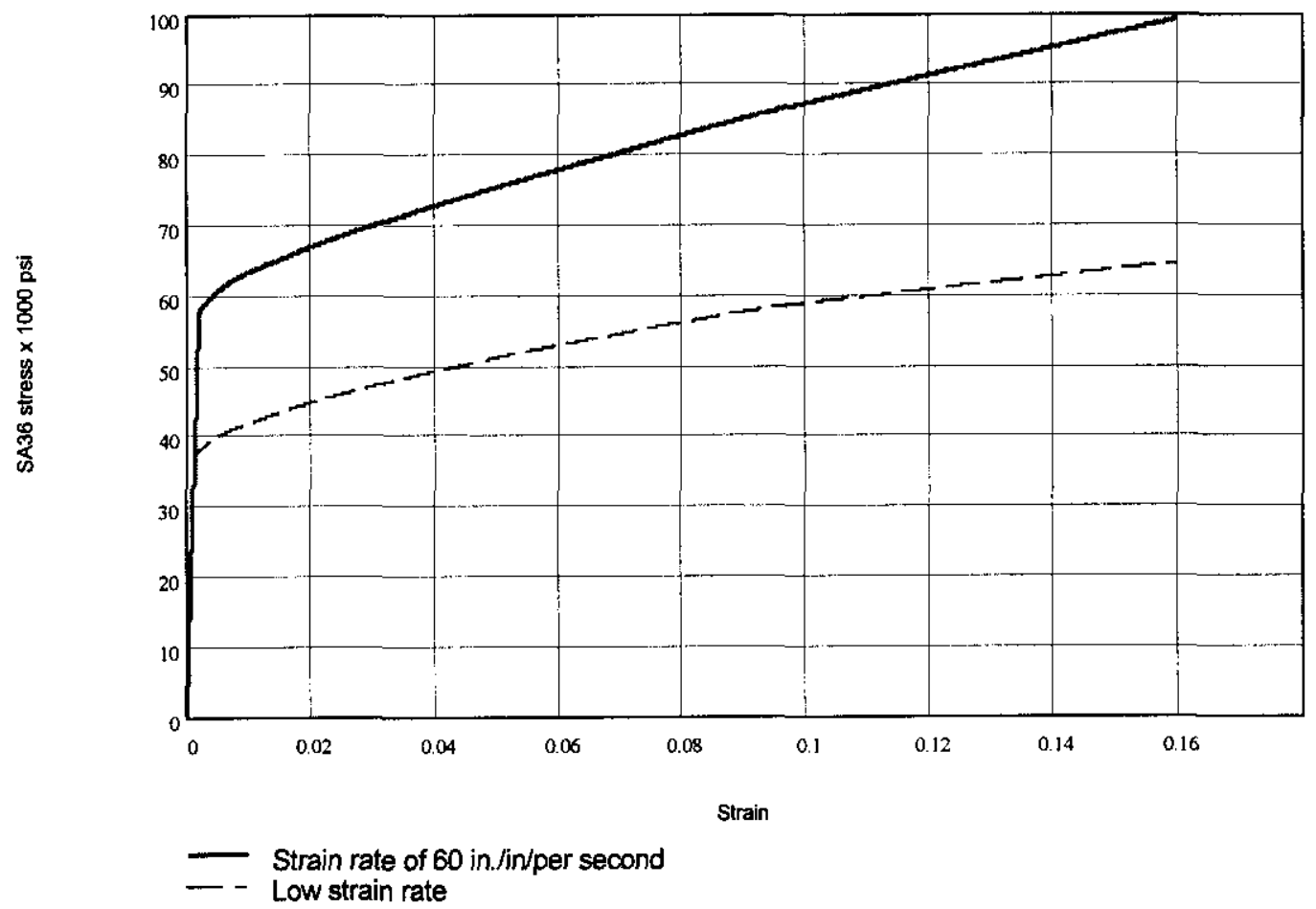

Figure 5.7. True Stress-Strain Curves for SA36 Steel. 


\subsection{ANALYSIS APPROACH AND ASSUMPTIONS}

A finite element computer model is utilized to simulate the MCO impact analysis. The MCO, the standard storage tube assembly and the shielding ring are explicitly modeled so that elastic and plastic strains for both assemblies can be computed to characterize the reactive forces and energy absorption during impact.

Both low and high strain rate material properties were used to study the damage to the MCO.

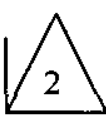

\subsection{Computer Program}

Industry-accepted, quality assurance (QA) approved and efficient computer analysis codes are required to perform sophisticated nonlinear dynamic finiteelement analyses. The ABAQUS/Explicit computer program was selected for this analysis. ABAQUS/Explicit is a well-documented and proven finite-element program. It is a general-purpose finite-element analysis program, which has been used in the nuclear industry for decades. The program has an extensive element library. Nonlinear geometry (contact surfaces, sliding surfaces and large deflections), nonlinear material properties (plasticity and strain hardening), and explicit time integration are specific options that make the program ideal for evaluation of nonlinear dynamic impact evaluations. Contact surfaces allow free movement of two adjacent nontouching surfaces but preclude penetration of one contact surface into another. Sliding surfaces allow free movement of two adjacent nontouching surfaces but resist movement if the two surfaces are in contact. Friction forces that are determined by normal forces and prescribed friction coefficients model the resistance. The program comes with a welldocumented theoretical manual and verification manual. The program has an error reporting system available through the Internet. ABAQUS/Explicit has extensive preprocessing, and graphics capabilities.

ABAQUS/Explicit has previously been used to simulate the puncture-drop tests and drop tests on SNF canisters. Actual test drops were set up and performed to determine how well the simulated drop results and the actual drop results matched. Evaluations of the drop simulations and actual drops are found in References 13 and 14. There was a good match in deformations of the actual dropped canister to those calculated in the model, with the model generally overpredicting the deformations. The model was very good in simulating the actual dropped canister response.

ABAQUS/Explicit has been verified and validated through the FDNW QA program. ABAQUS/Explicit is currently maintained in accordance with these requirements. Use of the program at FDNW is restricted to authorized users administered by the FDNW software administrator. ABAQUS/Explicit version $5.8-10$ is used in this analysis. 


\subsection{Computer Simulation}

Two computer runs using the comprehensive finite-element model were used to determine the effect of an MCO drop onto a standard storage tube assembly for the material properties (low and high strain rate stress-strain curves) and geometry parameters listed in Section 5.0. Another computer run was performed for the MCO drop at the service station using the low strain rate stress-strain curves (without considering the high strain rate effect).

Coefficients of friction for various materials are given in Reference 3 . Sliding coefficients for mild steel on medium steel varied from 0.53 to 0.18 for sliding speeds of $0.0001 \mathrm{in} / \mathrm{sec}$ to $100 \mathrm{in} / \mathrm{sec}$. A coefficient of sliding friction of 0.3 is used throughout this analysis.

\subsection{Computer Modeling of MCO Drops onto Storage Tube Assembly}

The interface surfaces of the MCO and the MHM (MCO handling machine) are modeled with contact surfaces to control the lateral displacement of the falling MCO. The interface surfaces of the standard storage tube assembly lower flange and the concrete deck embedment are modeled with contact surfaces to control the lateral displacement of the deflecting standard tube assembly lower flange resulting from the glancing blow of the MCO onto the inclined surface of the lower flange. The MHM and the concrete deck embedment are modeled with rigid elements.

The interface surfaces of the MCO and the inclined surface of the standard tube assembly lower flange are modeled with contact surfaces to characterize the deformation and sliding at the point of impact. The elements depicting the contact surfaces of the MCO and the standard storage tube assembly are modeled with solid elements having elasto-plastic material properties. Figures 6.1 and 6.2 show the computer model for the drop at the standard storage tube assembly.

Two previous MCO drop analyses were performed to determine the effects of an accidental drop. One analysis (Reference 1) studied the potential damage to the standard storage tubes and the other (Reference 2) studied potential damage to the overpack storage tube. The computer models of these reports are not suitable to study the damage to the MCO.

The improvements in this analysis include better modeling of the MCO internals, accounting for the strain rate effects on the material stress-strain properties, refinement of the finite element model in areas of high strains, and inclusion of appropriate predictions of the failure strain levels. Specifically, the MCO model has been improved in the following ways:

- Mesh Size

A finer mesh was used in the high stress/strain area around the impact location. The finer mesh yields lower results, but requires a longer run time. 
- Shell vs. solid elements

In previous analyses the MCO bottom was made up of solid elements up to the area of the weld between the bottom and the wall. From that point up shell elements were used. The transition from solid to shell elements at the weld could cause undesirable effects on the results. For this analysis the area of solid elements was extended above the high stress area.

- Four elements vs. seven elements through the wall

A model with 7 elements across the thickness of the wall has been developed to compare the results with a 4-element model. The maximum equivalent plastic strain of the 7 -element model is about $20 \%$ less than the results of the 4-element model. Each element in the 7-element model is about 0.07 inches thick. The time required for each iteration of the ABAQUS/Explicit program is controlled by the element size. The 7-element model requires about 60 hours of computer time to run. The final analysis of the drop on the storage tube assembly uses the 7-element model.

- Basket mass

The mass of the basket and its contents was accounted for in previous analyses by placing mass elements in the MCO bottom. This method of modeling did not accurately represent the movement of the baskets that occurs during an impact. For this analysis the basket is modeled with solid elements and beam elements in the proper locations. Contact surfaces are modeled between the baskets and the MCO interior surface. The basket is free to bounce inside the MCO during impact, which more accurately simulates the actual condition. The density of the basket material in this model was increased to include the mass of the fuel pins. This process, known as smearing, provides conservative results.

For the MCO drop on the storage tube assembly, the vertical and horizontal gaps between the tube assembly and the concrete deck are included in the preimpact model configuration to accurately characterize the influence of the impact of the MCO on the inclined surface of the tube assembly lower flange. As the impact occurs the lower flange moves down and away from the point of impact. At the same time the MCO slides down the inclined surface of the lower flange.

\subsection{Computer Modeling of MCO Drops onto Service Station}

The interface surfaces of the MCO and the inclined surface of service station shield hatch ring are modeled with contact surfaces to characterize the deformation and sliding at the point of impact. The elements depicting the contact surfaces of the MCO and shipping cask are modeled with solid elements having elasto-plastic material properties. Figure 6.3 and 6.4 show the computer model for the drop at the service station. 
Basically, the MCO model for the drop onto the service station is similar to the MCO model for the drop onto the storage tube assembly except as follows.

- The number of elements through the wall thickness was reduced from seven to four. The reduction in elements reduces computer run time and gives conservative results.

- A finer vertical mesh was used through the full length of the MCO. A finer horizontal mesh was used near the impact location (as in Standard storage tube assembly drop) and on the opposite side of the impact location.

The finer mesh on the opposite side of the impact location was necessary to yield reasonable results because the basket bounces and impacts the MCO wall at that location. 


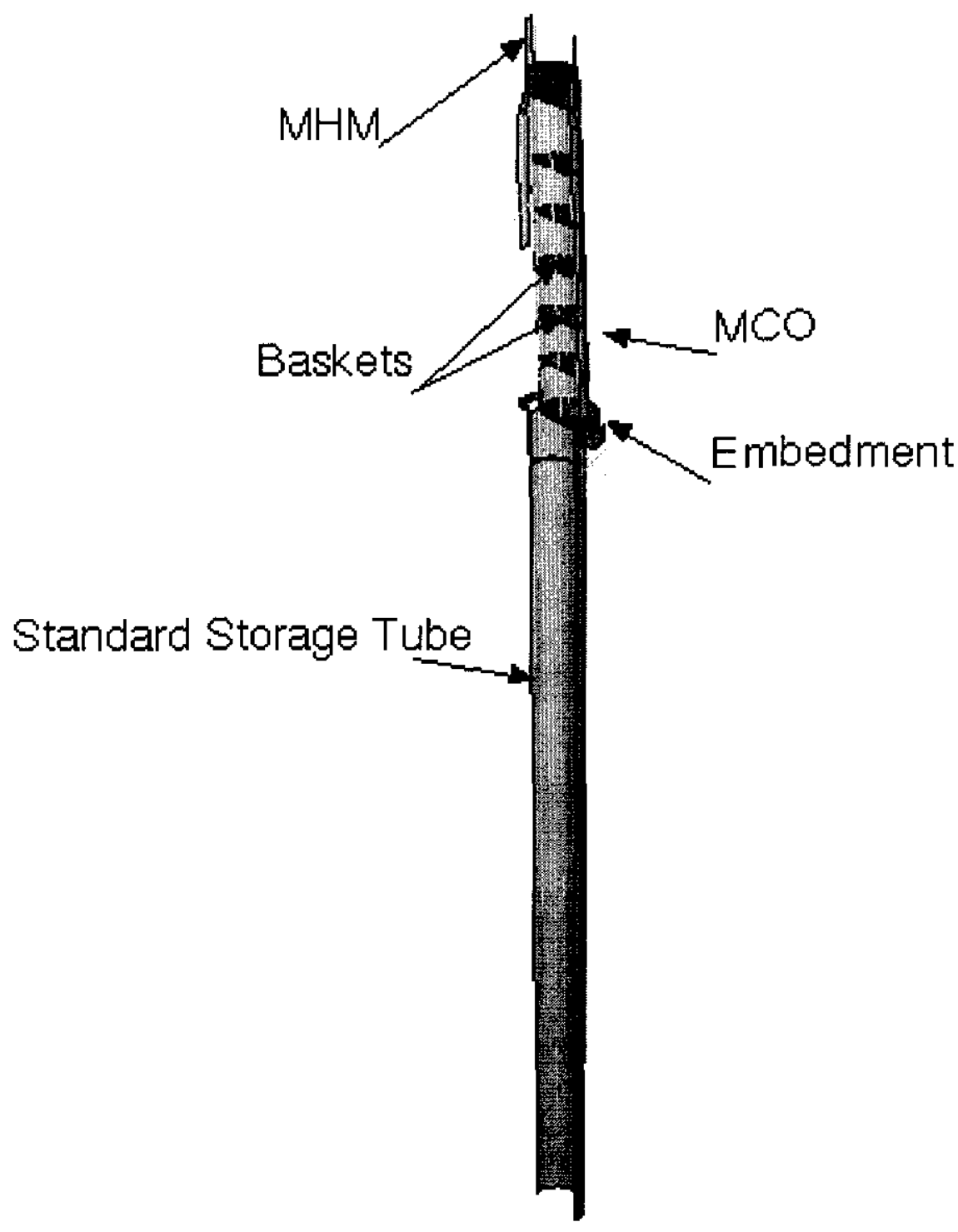

Figure 6.1. Computer Model of MCO Drop onto Storage Tube. 


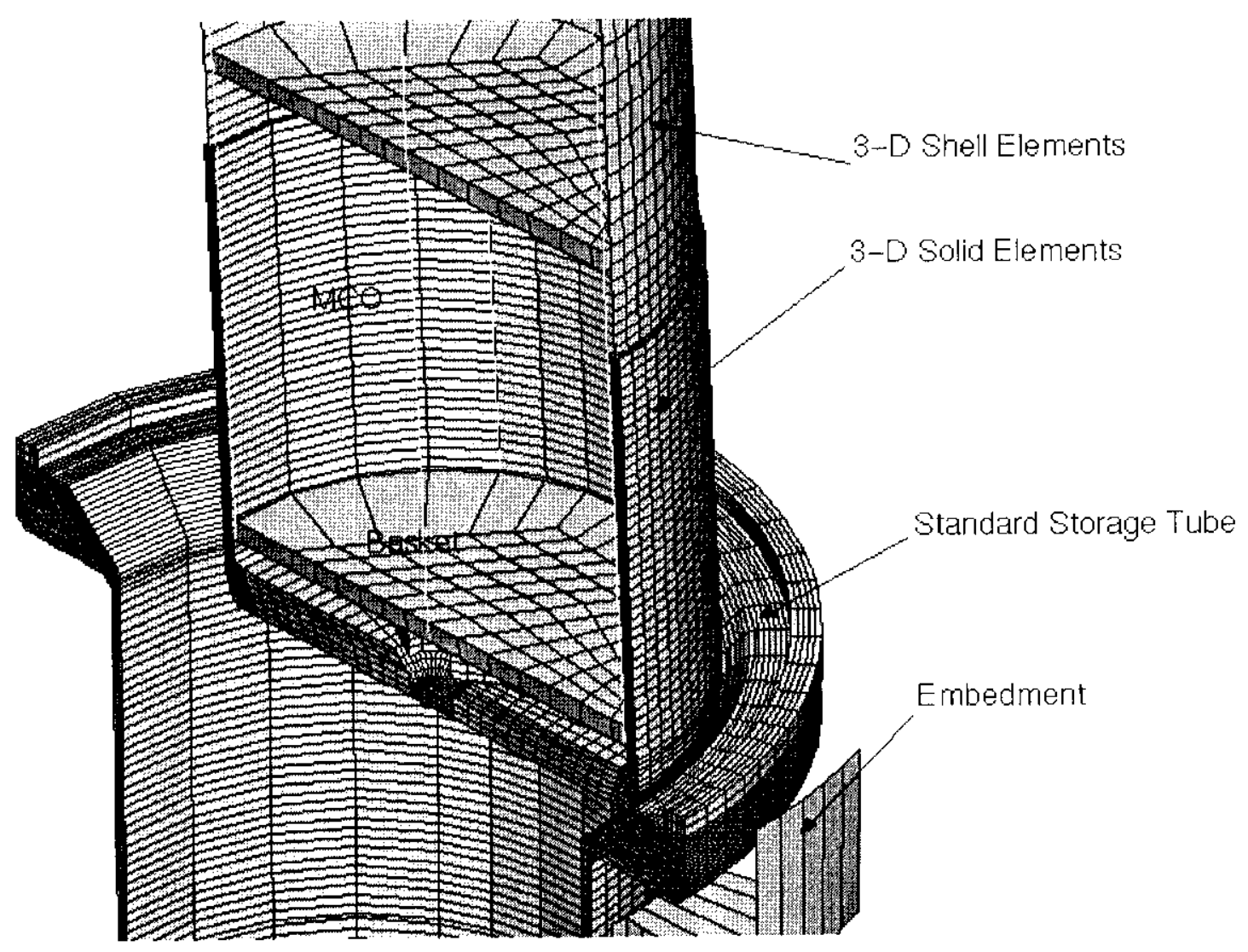

Figure 6.2. Close-up of Computer Model of MCO Drop onto Standard Storage Tube. 


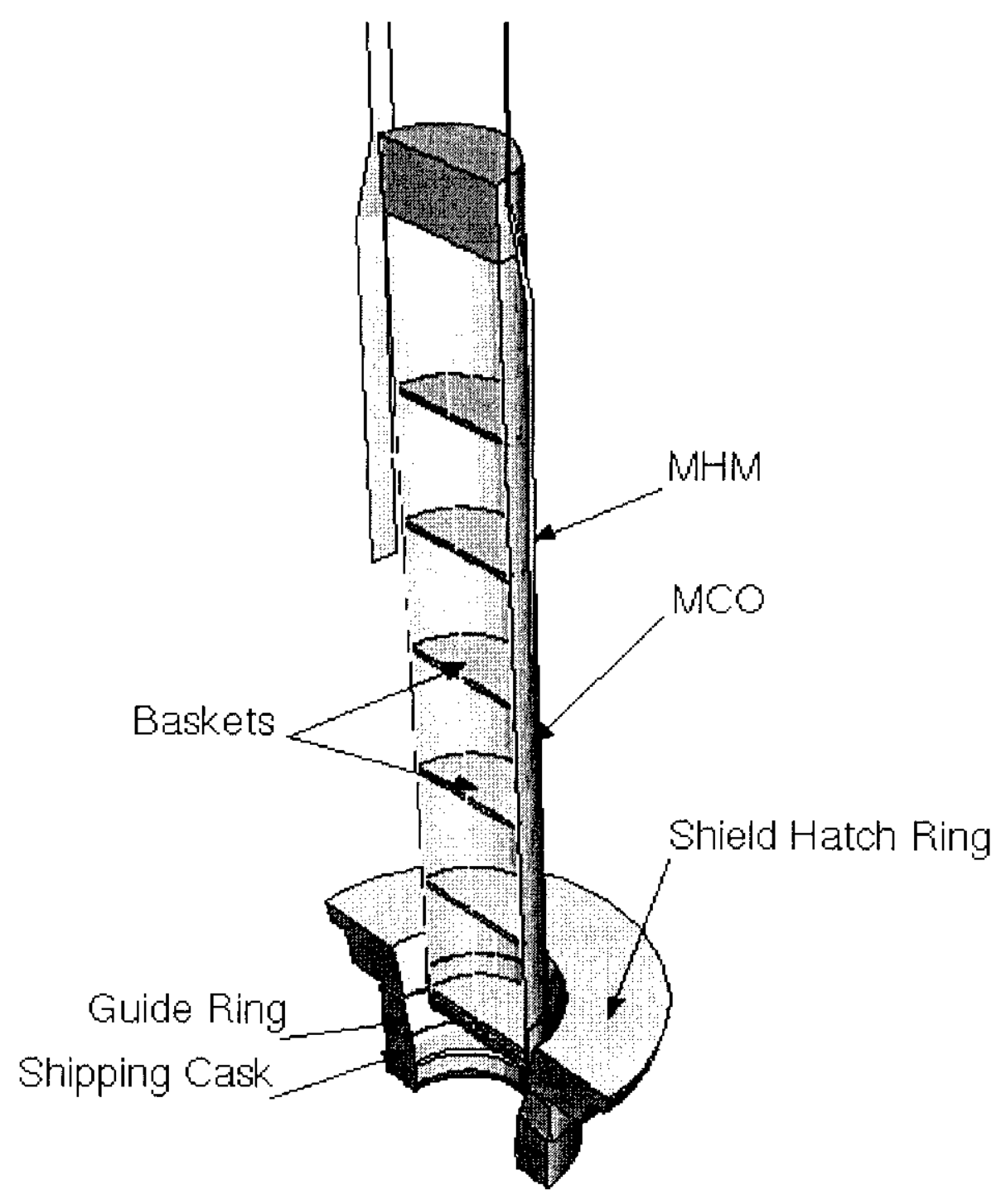

Figure 6.3. Computer Model of MCO Drop onto Service Station Shield Hatch Ring. 


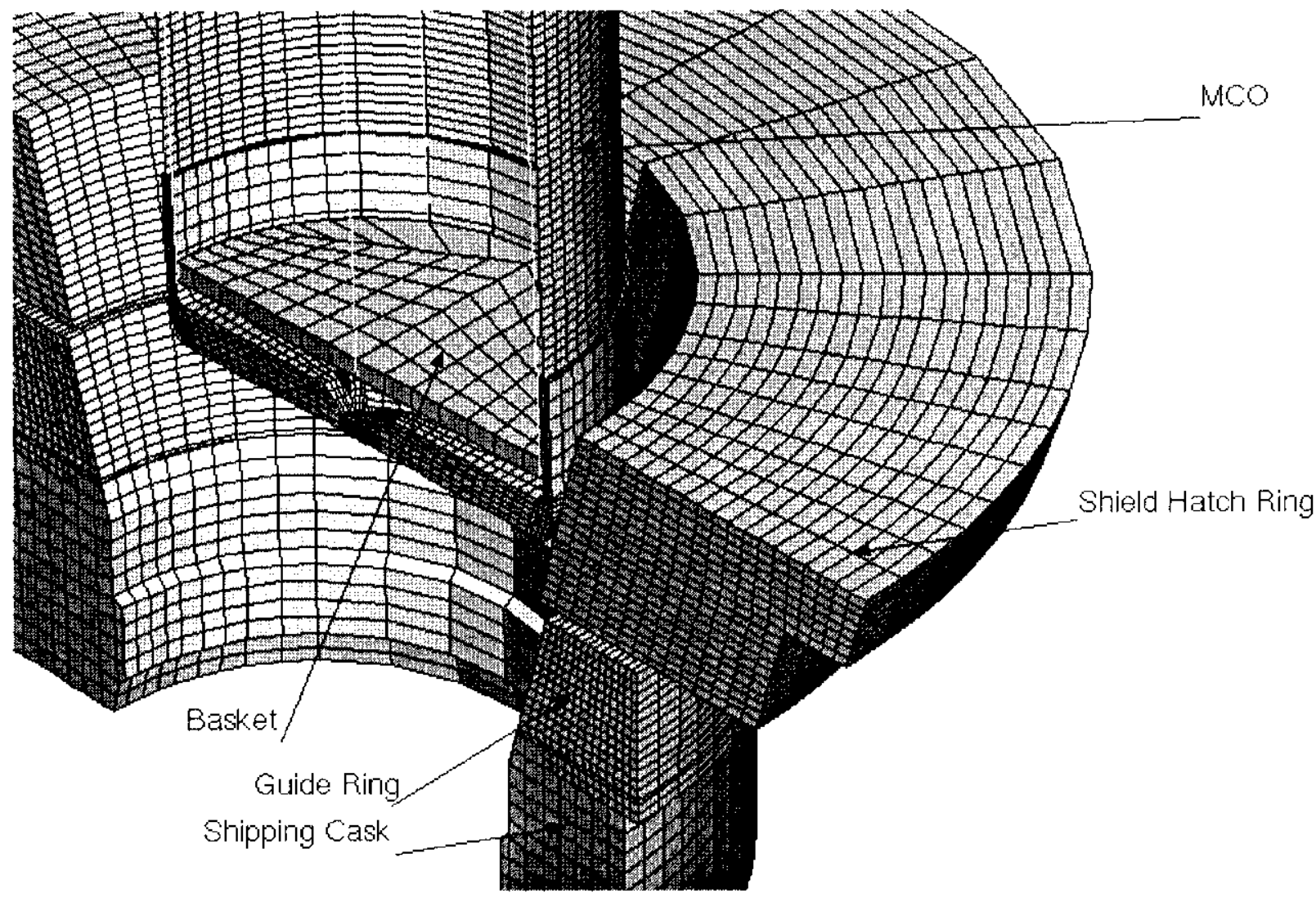

Figure 6.4. Close-up Computer Model of MCO Drop onto Service Station Shield Hatch Ring. 


\subsection{RESULTS}

The equivalent plastic strain (peeq) is calculated from three principal plastic strains, and the value is greater than the maximum absolute value of the three direction strains. It is convenient to measure the magnitude of permanent damage/deformation by using peeq value that is represented by the plastic strain in all directions.

Figure 7.1 shows the deformed shape of the MCO and standard storage tube 0.03 seconds after impact. Figures 7.2 through 7.6 show the deformed shapes and strains of the MCO and storage tube after impact. Deformation strains along with failure strains at the bottom and lower weld on the MCO from the ABAQUS analysis are calculated and documented in Appendix B. These locations represent the areas of highest MCO strains. The failure strains, triaxiality factors and predicted strains at critical locations are summarized in Table 7.1. Note: The plotted results in Appendix B are the values at the center of the elements. The triaxiality factors should be less than or equal to 2 at the surface. At the shell and weld area, the plastic strain increases rapidly from 0.009 second to reach the peak at 0.016 second after impact when the lower storage flange impacts the embedded flange.

Table 7.1. Calculated Failure Strain and Predicted Strain

\begin{tabular}{|c|c|c|c|c|c|c|}
\hline METAL & \multicolumn{2}{c|}{ SHELL } & \multicolumn{2}{c|}{ WELDMENT } & \multicolumn{2}{c|}{ BOTTOM PLATE } \\
\hline Location /strain rate & Inside & Outside & Inside & Outside & Low & High \\
\hline $\begin{array}{c}\text { Uniaxial failure strain } \\
\text { at ambient temperature }\end{array}$ & \multicolumn{2}{|c|}{$40 \%$} & \multicolumn{2}{c|}{$21 \%$} & $40 \%$ & $27 \%^{1}$ \\
\hline $\begin{array}{c}\text { Uniaxial failure strain } \\
\text { at 270 } \text { F }^{2}\end{array}$ & \multicolumn{2}{|c|}{$30 \%$} & \multicolumn{2}{c|}{$16 \%$} & $30 \%$ & $24 \%^{3}$ \\
\hline $\begin{array}{c}\text { Triaxiality } \\
\text { Factor }\end{array}$ & $<0$ & 2 & 2 & $<0$ & $<0$ & $<0$ \\
\hline $\begin{array}{c}\text { Ductility (adjust factor for } \\
\text { multi-axial failure) }\end{array}$ & 2 & 0.5 & 0.5 & 2 & 2 & 2 \\
\hline $\begin{array}{c}\text { Failure strain } \\
\text { with triaxial effect }\end{array}$ & $60 \%$ & $15 \%$ & $8 \%$ & $32 \%$ & $60 \%$ & $48 \%$ \\
\hline $\begin{array}{c}\text { Maximum predicted } \\
\text { Plastic strain }\end{array}$ & $12 \%$ & $3.7 \%$ & $4.6 \%$ & $15 \%$ & $45 \%$ & $40 \%$ \\
\hline $\begin{array}{c}\text { Reference Figure } \\
\text { In Appendix B }\end{array}$ & B-3 & B-4 & B-7 & B-6 & B-8 \& B-9 & B-10 \\
\hline
\end{tabular}

Reference 15.

2 Temperature dependence of stainless steel total elongation from Ref. 10 and Ref. 18.

3 Reference 16.

${ }^{4}$ The failure strain values are reduced to account for the $270^{\circ} \mathrm{F}$ temperature and are based the Manjoine correlation (Reference 4).

The Mises time history plots of the stress near the outer weld surface and the impact location are shown on Figure 7.11 and 7.12, respectively. 
The basket velocity during impact with the standard storage tube is plotted in Figure 7.7. The slope of the velocity curve gives the basket deceleration. The steeper the velocity curve, the greater the deceleration. The steepest portion of the curve is between 200 and 120 inches per second. The time interval between the two points is 0.0061 seconds. The change in speed divided by the time interval is $80 / 0.0061$ or $13114 \mathrm{in} / \mathrm{sec} / \mathrm{sec}$. Since the acceleration from gravity is 386.4 inches per second per second, the $g$ force that the basket experiences is $13114 / 386.4=34 \mathrm{~g}$.

The basket velocity during impact with the service station is plotted in Figure 7.8. Using the method noted above, the basket $\mathrm{g}$ force is about $4 \mathrm{~g}$. The basket nodes used for the $\mathrm{g}$ force calculations are shown in Figure 7.9.

The computer-generated views on Figures 7.10.a through 7.10.i show a timed sequence of the MCO drop onto the standard storage tube.

The ABAQUS/Explicit computer simulation uses global coordinates to describe the stresses and strains in the model. The ABAQUS direction 1 corresponds to stress/strain in the radial direction at the point of impact and $180^{\circ}$ from the point of impact. At other locations around the MCO circumference, the direction 1 stress/strain represents some combination of radial and hoop stress/strain. The hoop stress and strain at the point of impact is shown on Figures 7.15 and 7.18, respectively. The radial stress and strain at the point of impact is shown on Figures 7.13 and 7.16, respectively. The ABAQUS/Explicit direction 2 corresponds to the stress/strain in the meridian (vertical) direction. The ABAQUS direction 3 corresponds to the hoop stress/strain at the point of impact and $180^{\circ}$ from the point of impact. At other locations around the MCO circumference the direction 3 stress represents some combination of hoop and radial stress/strain. The meridian stress and strain at the point of impact is shown on Figures 7.14 and 7.17 , respectively.

The deformations near the point of impact for the MCO and standard storage tube are shown in Figures 7.20 and 7.21, respectively. The clearances between the $\mathrm{MCO}$ and standard storage tube after the drop are calculated below.

\begin{tabular}{ll} 
Cold tube O. D. & $28.0{ }^{\prime \prime}$ \\
tolerance & $-.07^{\prime \prime}$ \\
\hline & $27.93^{\prime \prime}$ \\
Tube Wall Thickness & $-.588^{\prime \prime}$ \\
" & $-.588^{\prime \prime}$ \\
Cold Tube I. D. & $26.754^{\prime \prime}$ \\
MCO top at 270 F* & $-25.33^{\prime \prime}$ \\
Reduction in tube O. D. & $-\frac{.79 "}{.634 "}$ \\
Net Clearance &
\end{tabular}

*The top of the MCO is 25.33 inches in diameter while the maximum deformed barrel diameter is about 24.29 inches; the larger of the two values is used. 
The maximum kinetic energy during the drop is about $1,800,000$ in-lbf. The time history of the kinetic energy for half of the MCO during the drop is plotted in Figure 7.19. 


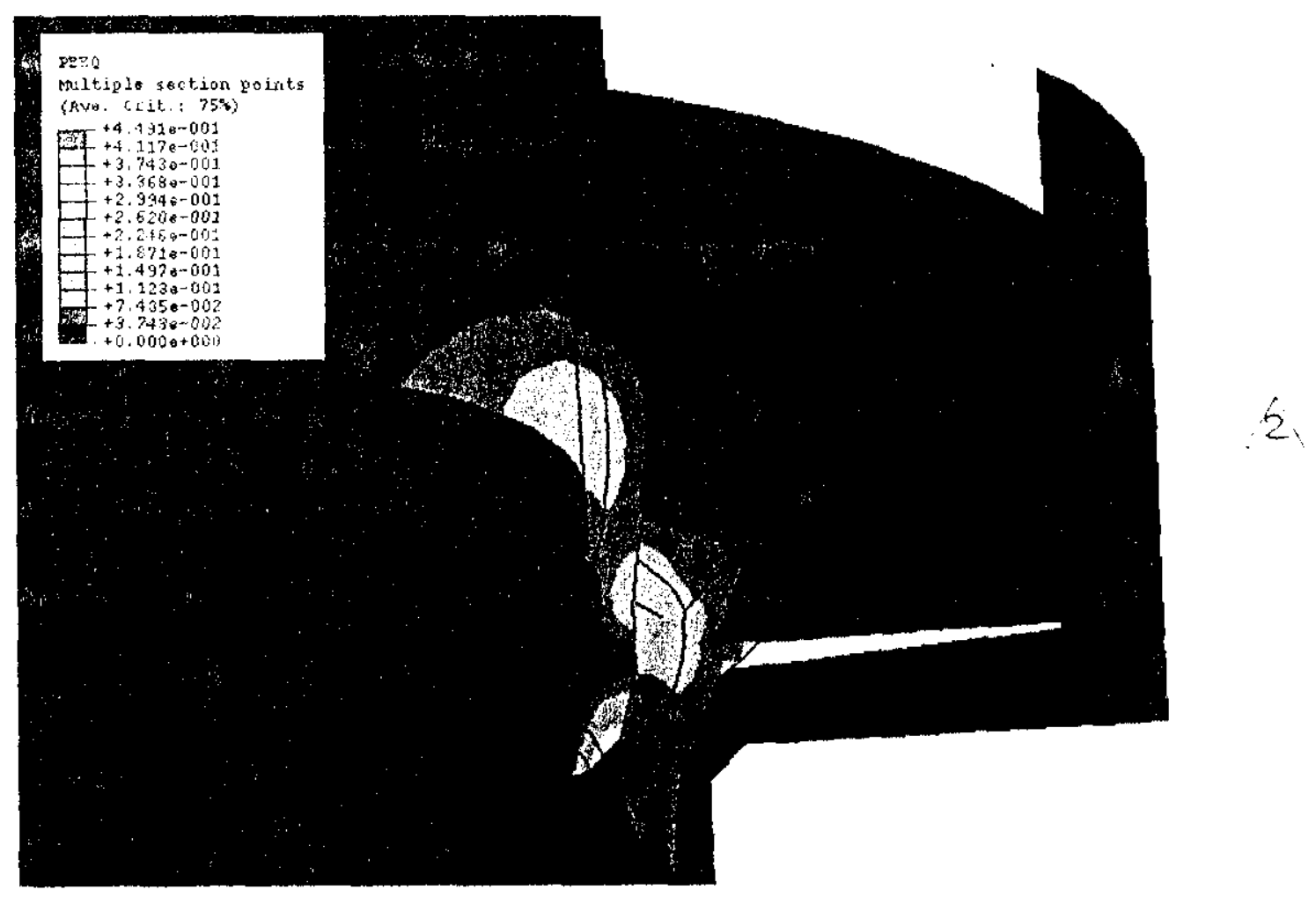

Figure 7.1. Close-up View at 0.03 Seconds After Impact Onto Storage Tube Assembly. 


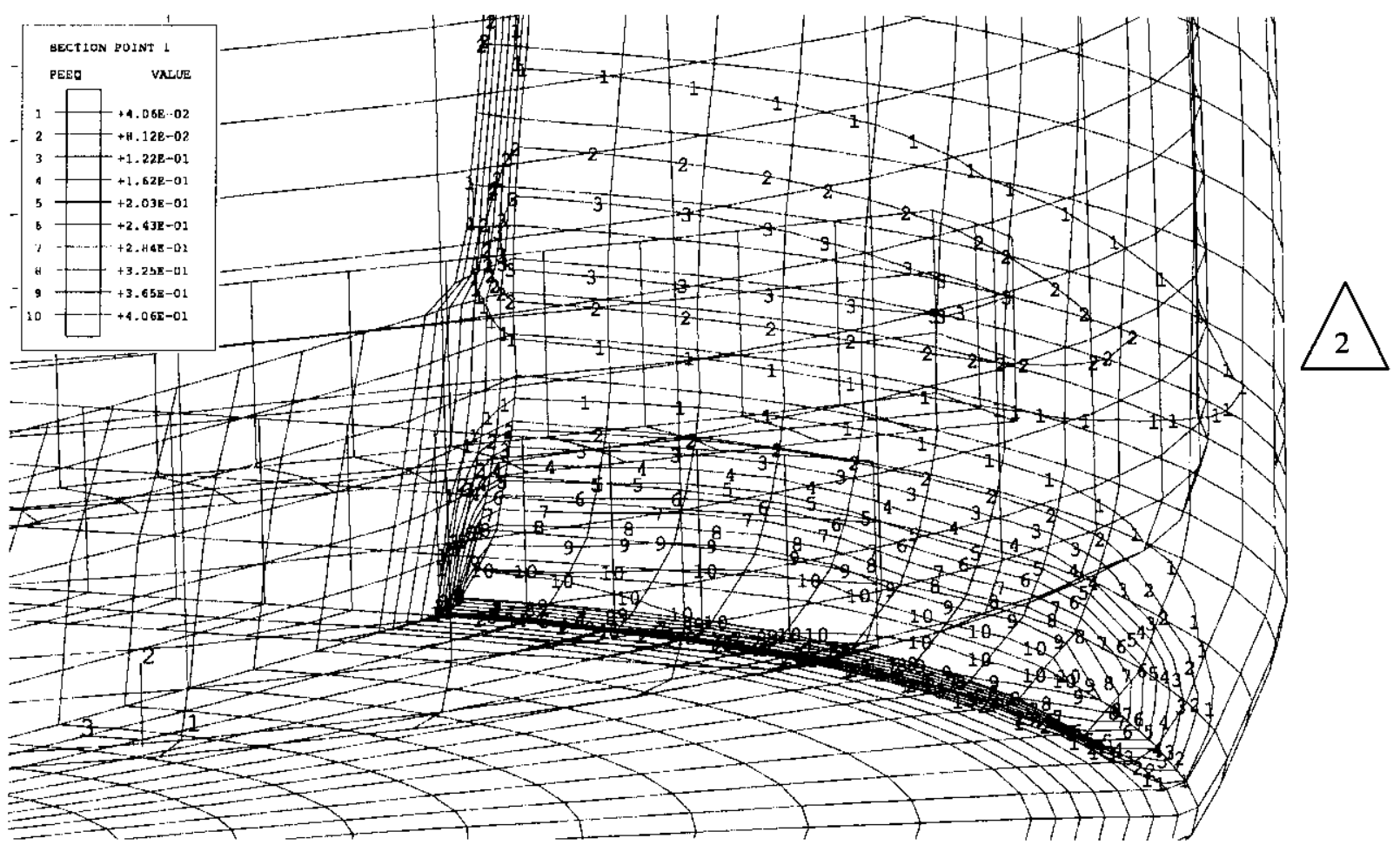

Figure 7.2. Equivalent Plastic Strain at MCO Bottom at $\mathbf{0 . 0 3}$ Second After Impact at Storage Tube Assembly. 


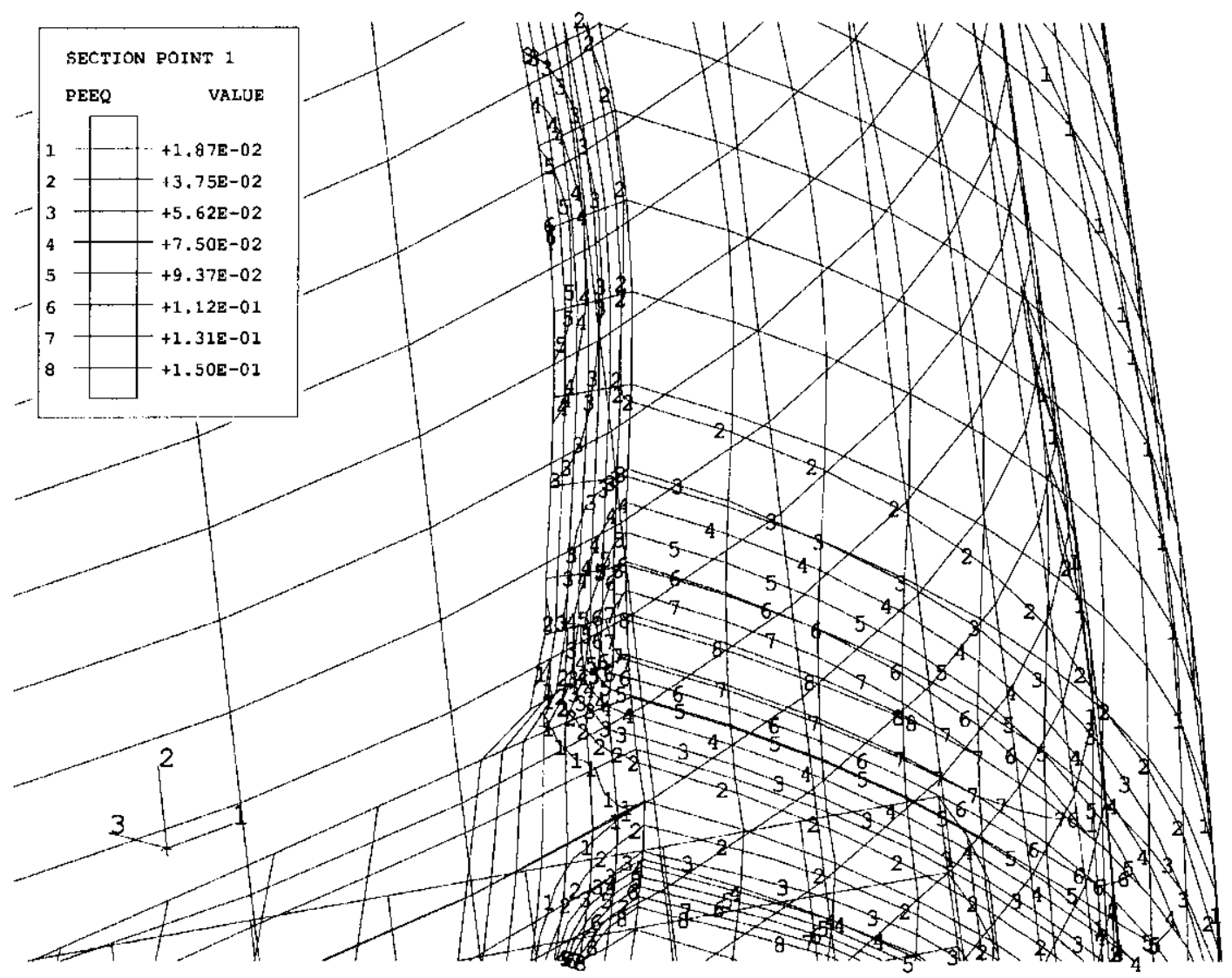

Figure 7.3. Equivalent Plastic Strain at MCO Lower Weld at 0.03 Sec After Impact on Storage Tube Assembly. 


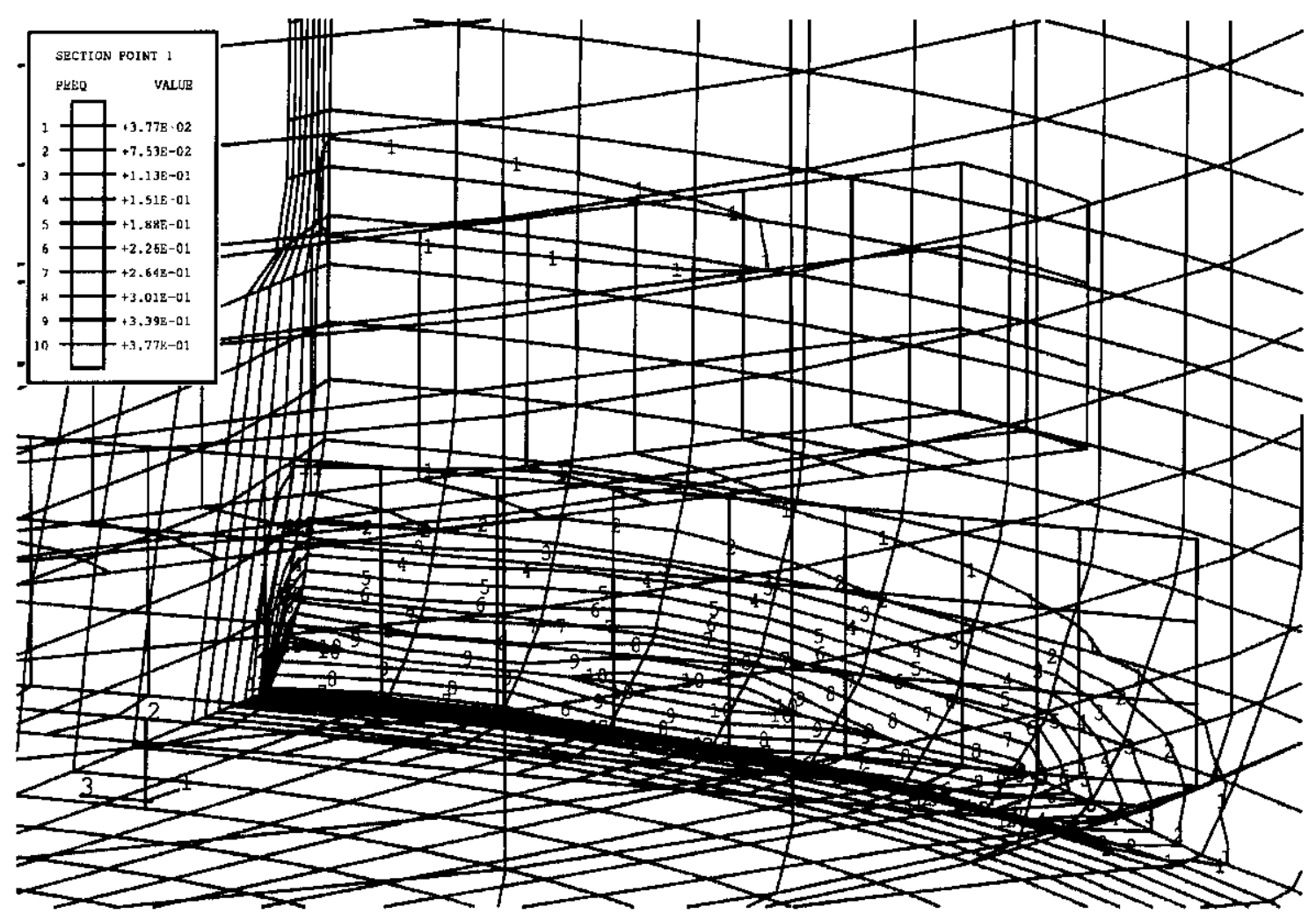

Figure 7.4. Equivalent Plastic Strain at 0.03 Second at High Strain Rate for MCO Drop Onto Storage Tube Assembly. 


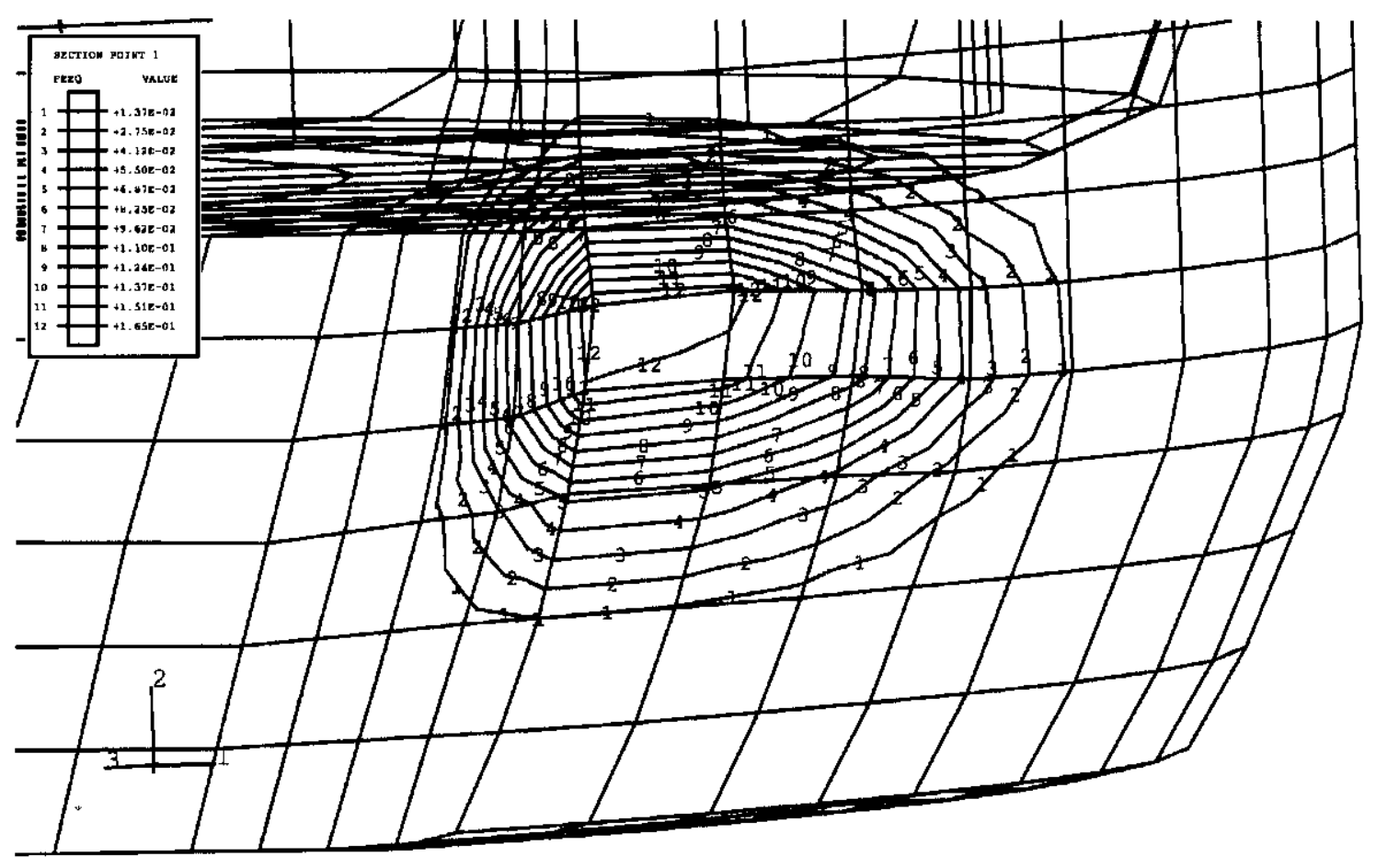

Figure 7.5. Equivalent Plastic Strain at MCO Bottom 0.04 Second After Impact Onto Service Station Shield Hatch Ring. 


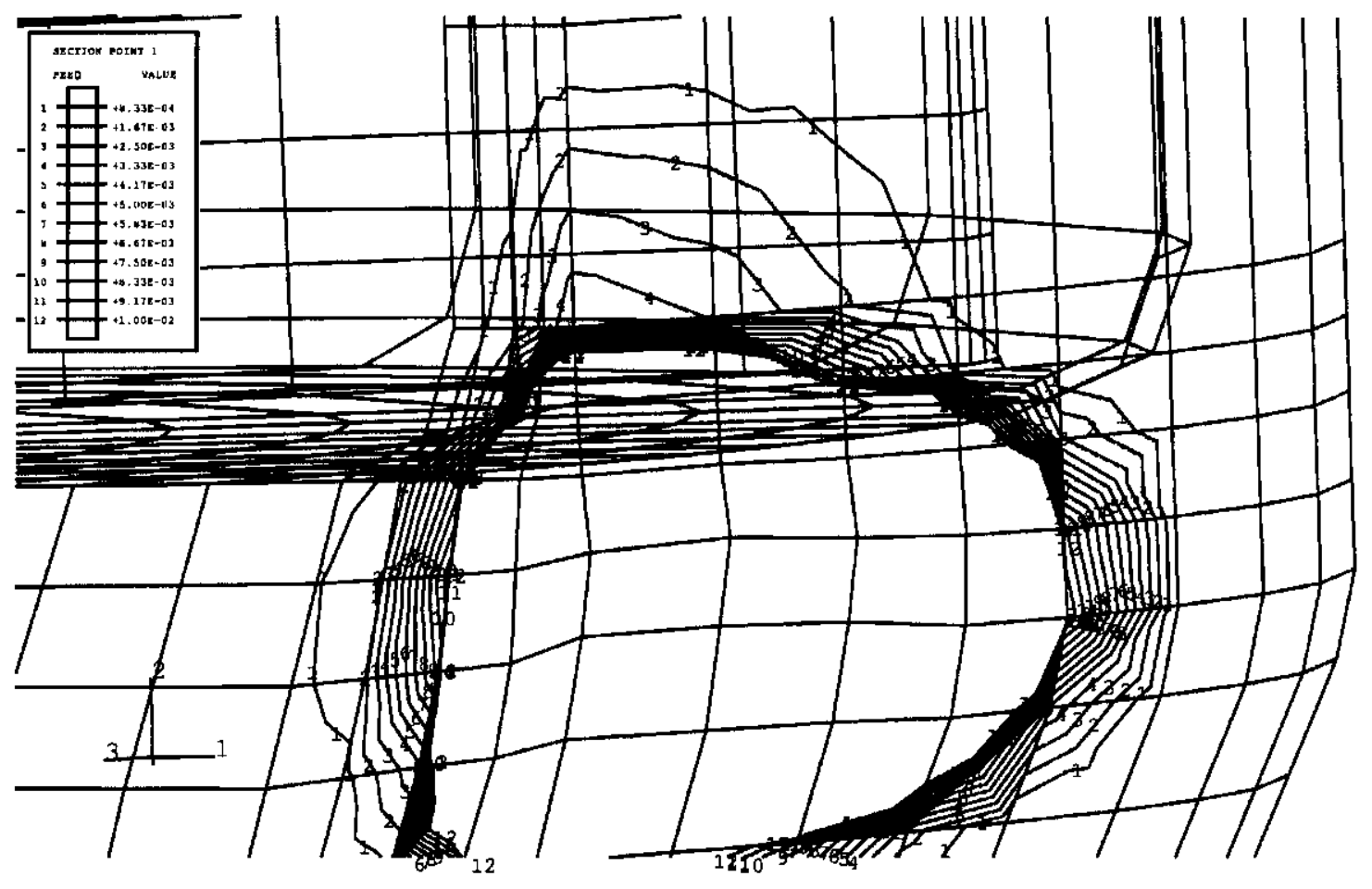

Figure 7.6. Equivalent Plastic Strain Near Lower Weld At 0.04 Second After Impact Onto Service Station Shield Hatch Ring. 


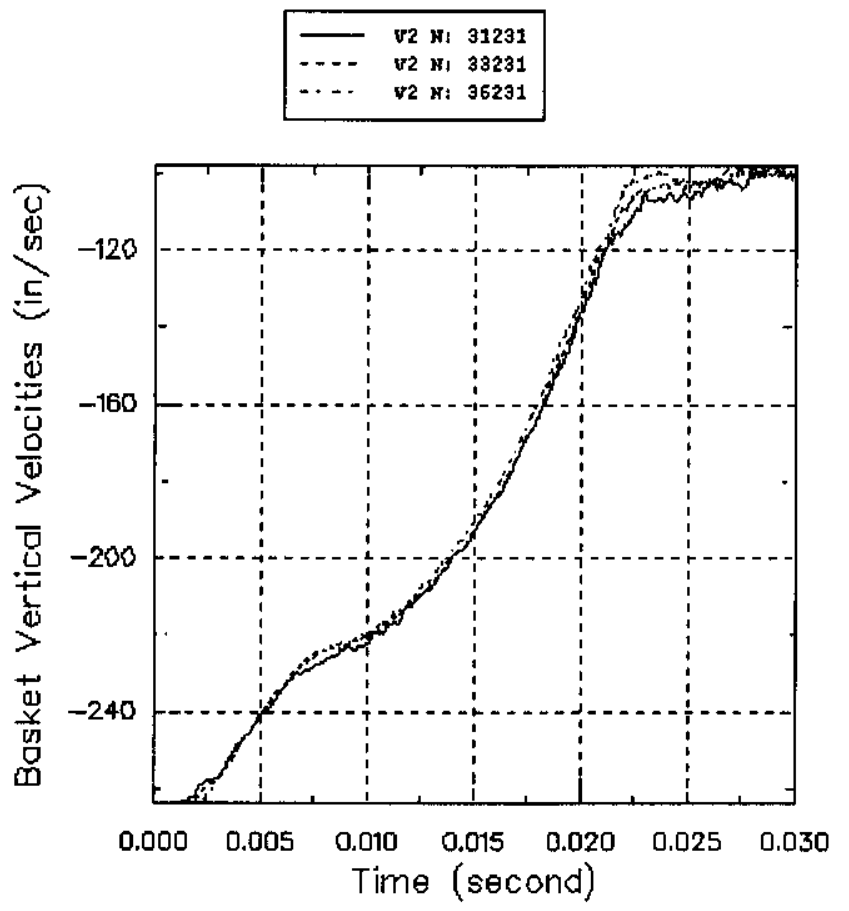

Deceleration of Baskets:

$$
\begin{aligned}
& (200-120) /(.021-.0149) \\
& =13114 \mathrm{in} / \mathrm{sec} / \mathrm{sec} \\
& =34 \mathrm{~g}
\end{aligned}
$$

Figure 7.7. Basket Velocity vs. Time of MCO Impact onto Storage Tube Assembly. 


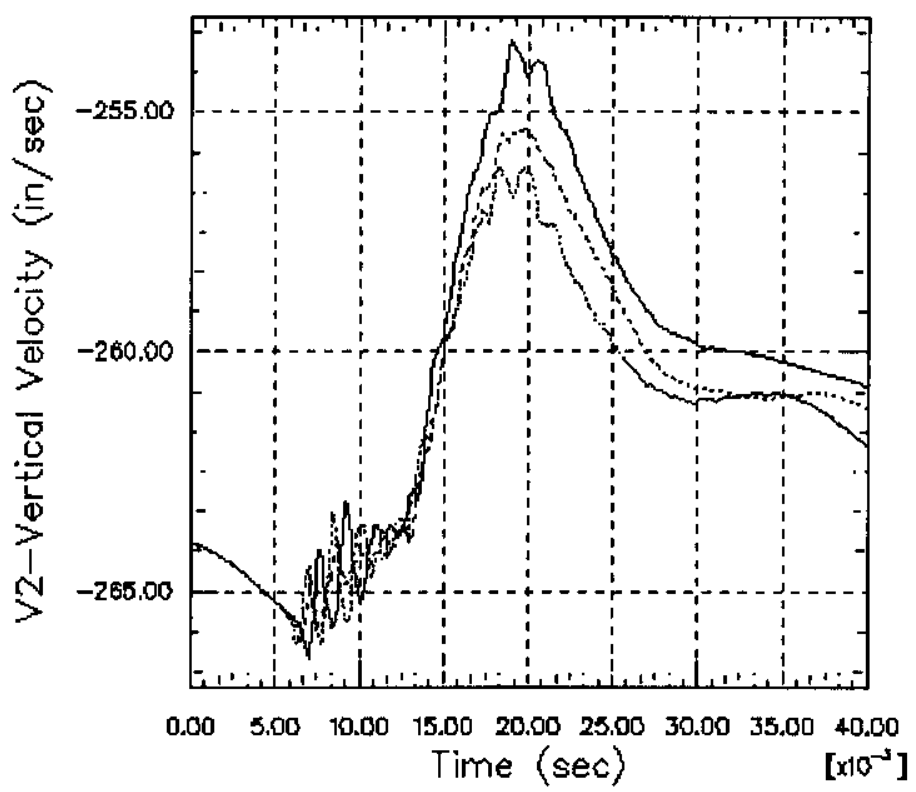

Deceleration of Baskets:

(264-253.5) / (.019-.012)

$=1500 \mathrm{in} / \mathrm{sec} / \mathrm{sec}$

$=3.9 \mathrm{~g}$

say less than $4 \mathrm{~g}$

Figure 7.8. Basket Velocity vs. Time of MCO Impact onto Service Station Shield Hatch Ring. 


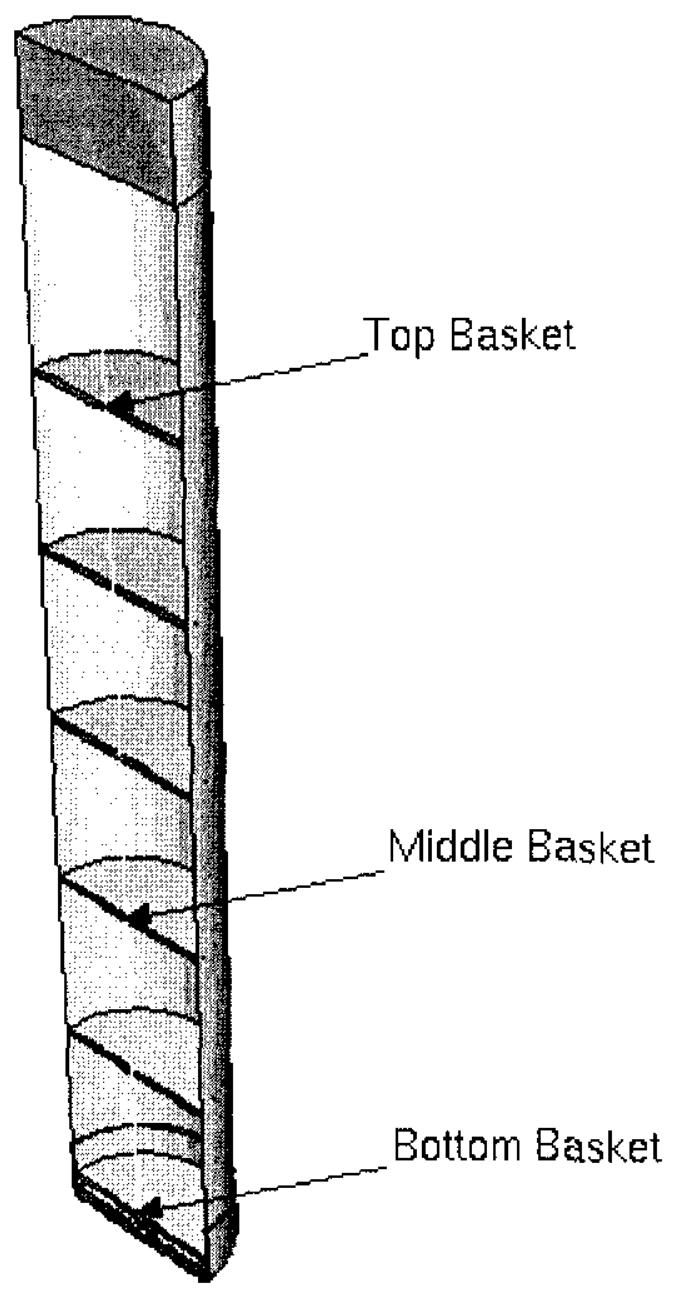

Figure 7.9. Node Locations for Velocity Plot of MCO Drop onto Service Station. 


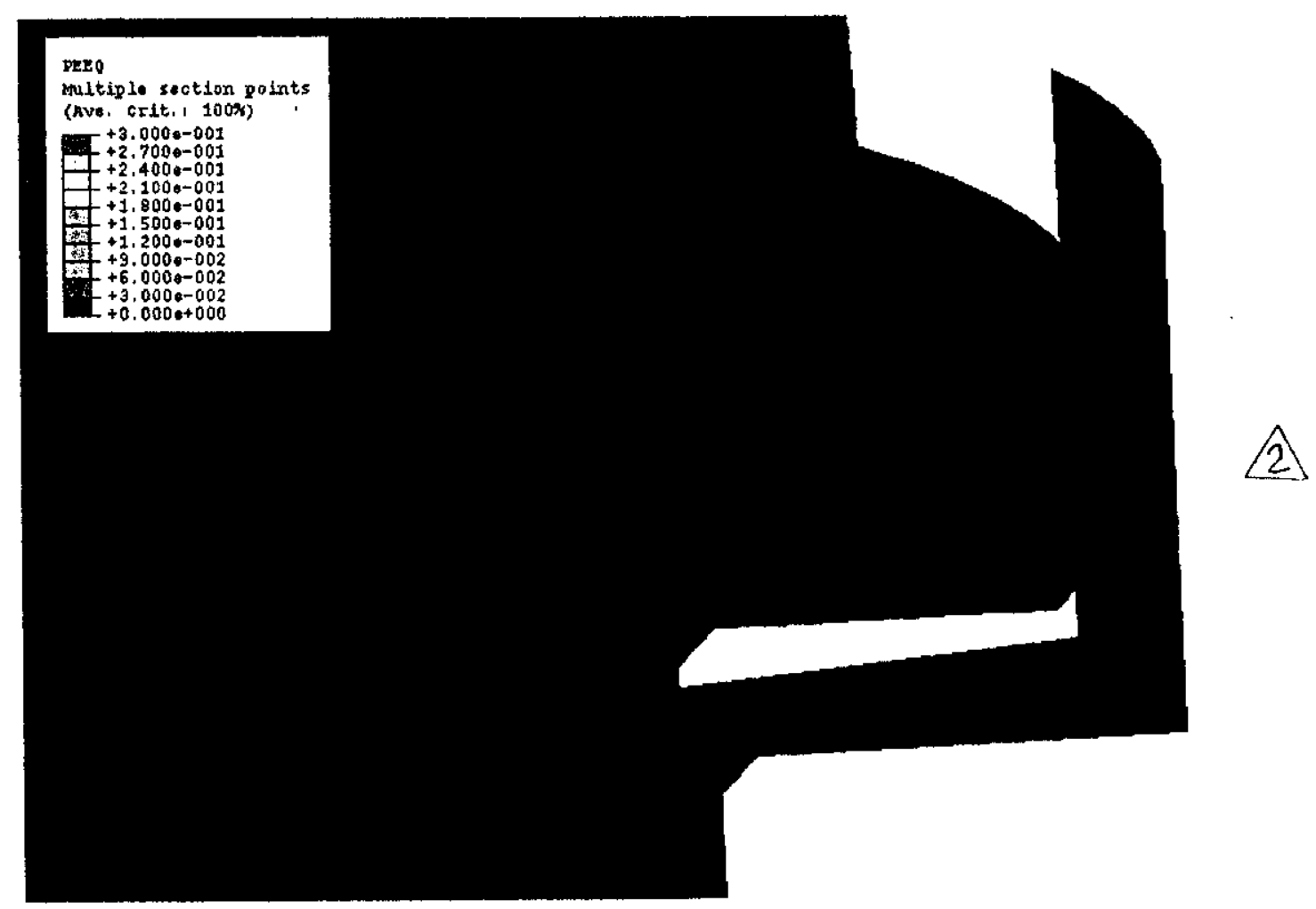

Figure 7.10.a. MCO Drop Animation (Time $=0$ seconds). 


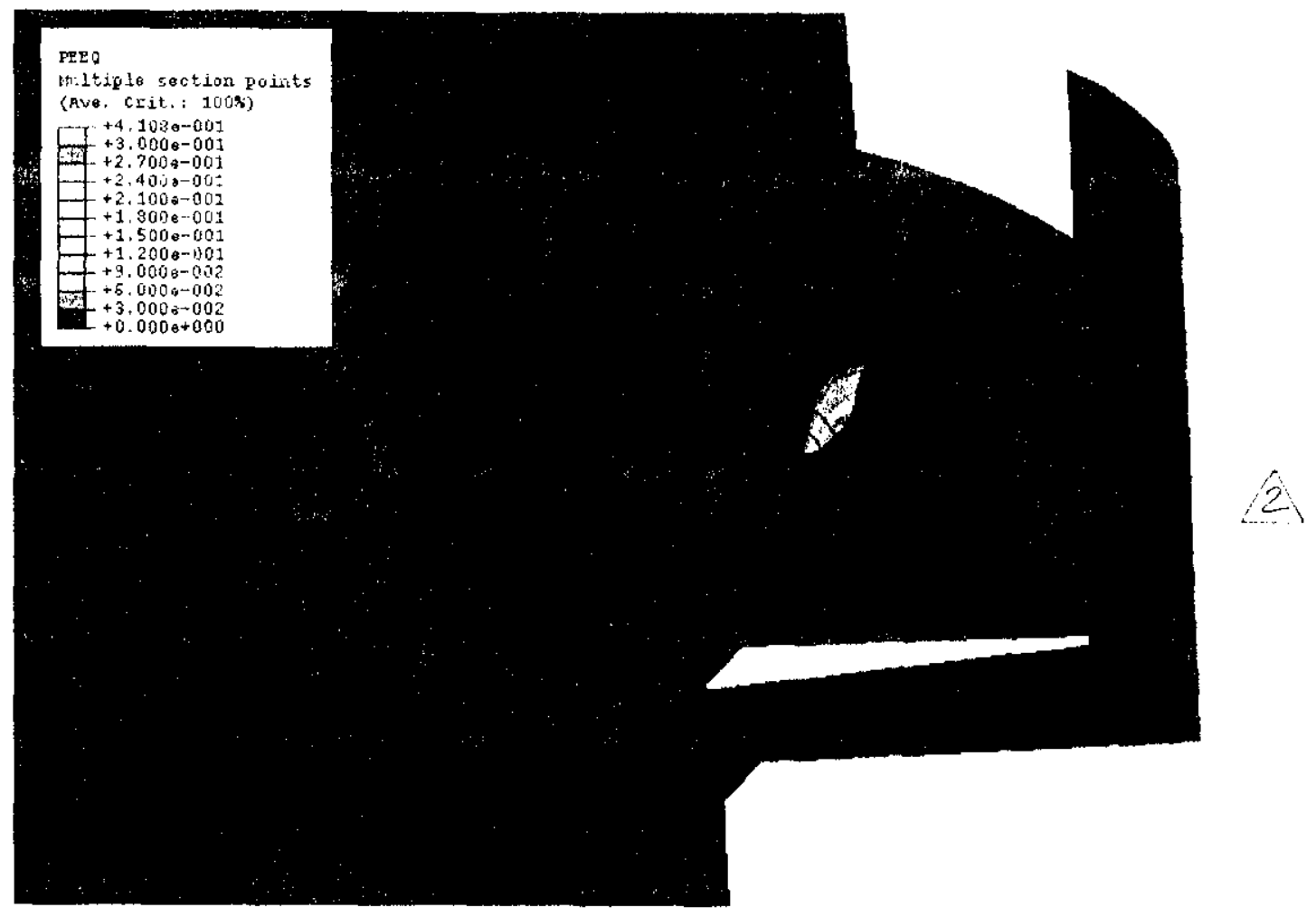

Figure 7.10.b. MCO Drop Animation (Time $=0.00375$ seconds). 


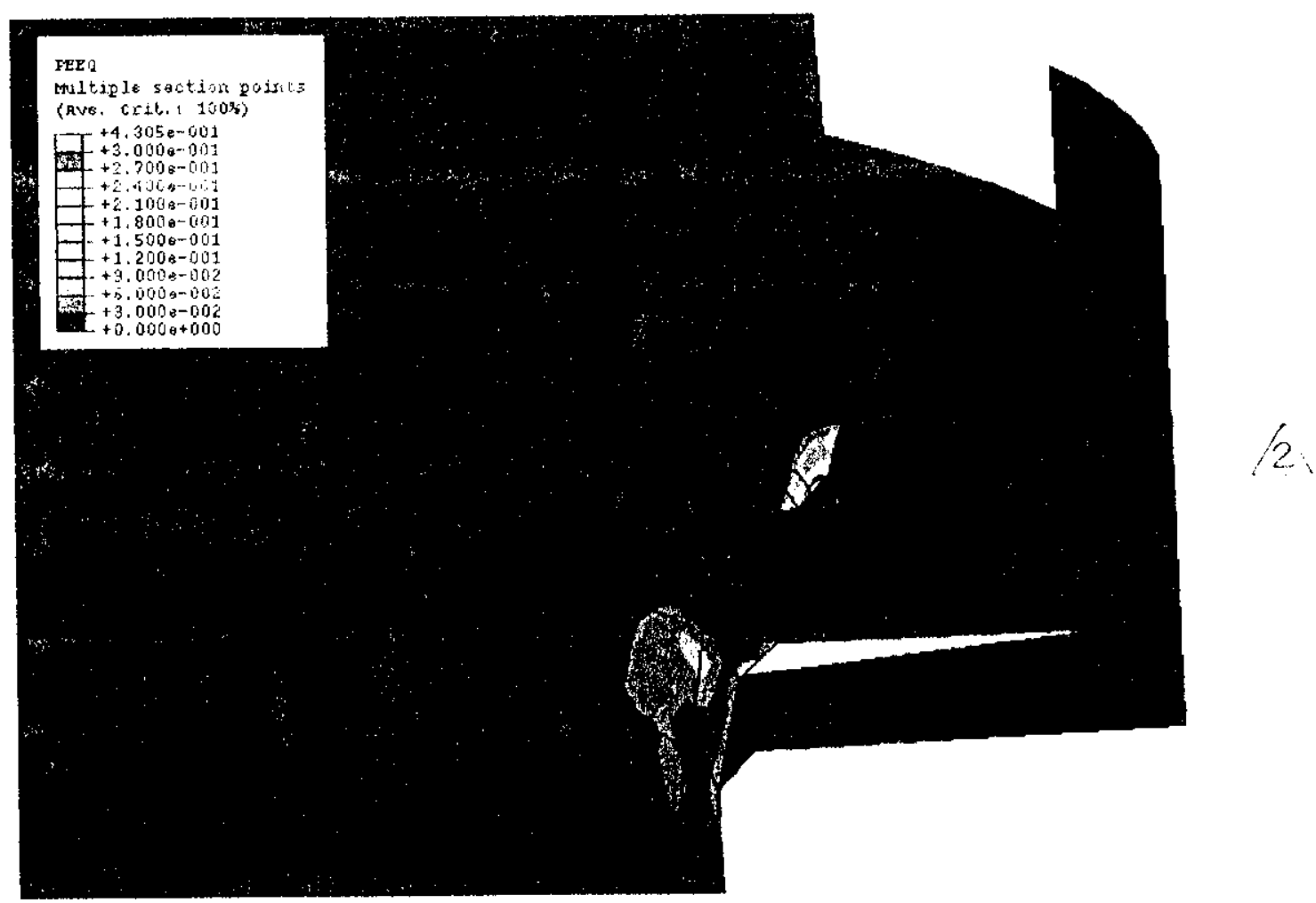

Figure 7.10.c. MCO Drop Animation (Time $=0.0075$ seconds). 


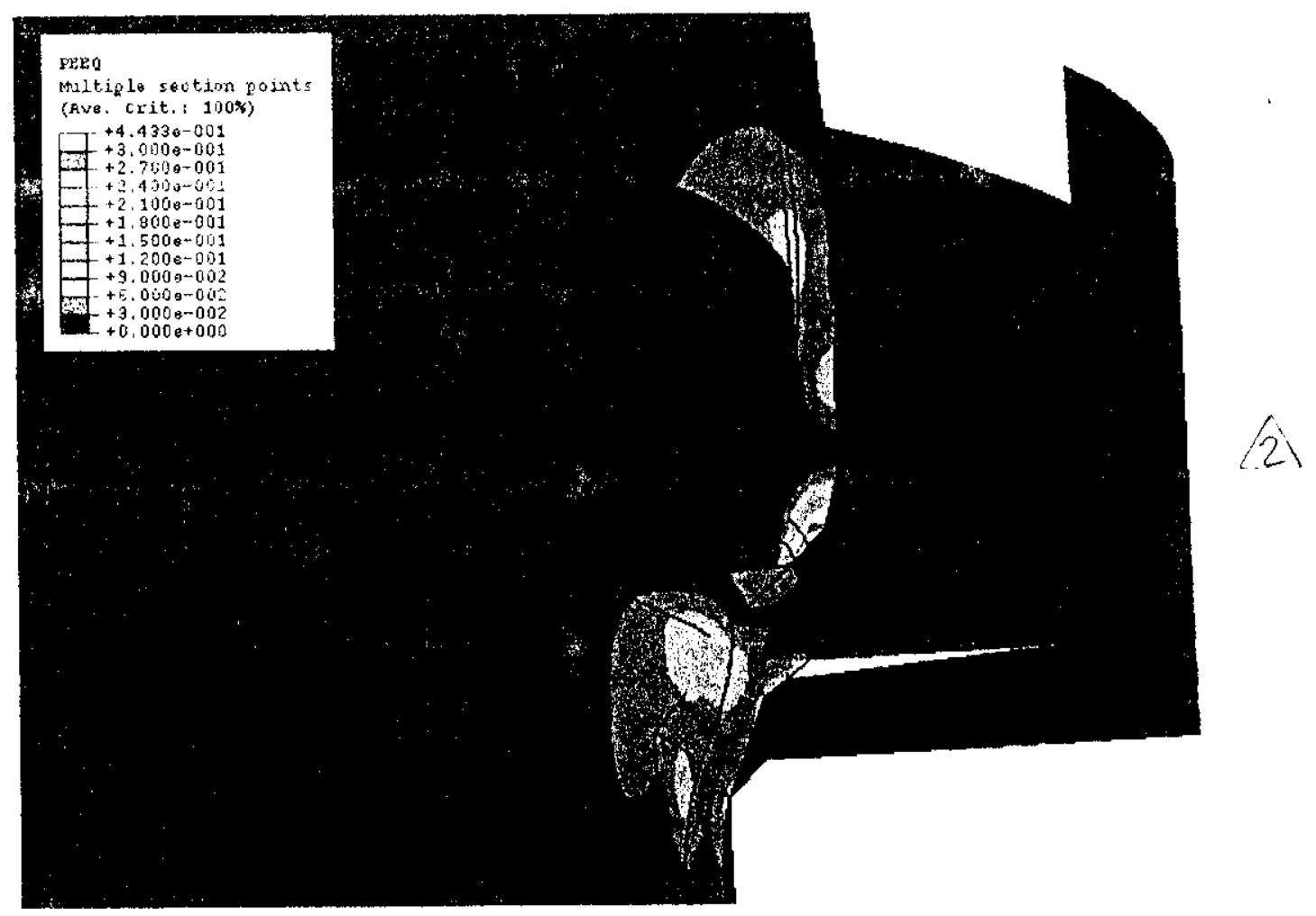

Figure 7.10.d. MCO Drop Animation (Time $=\mathbf{0 . 0 1 1 2 5}$ seconds). 


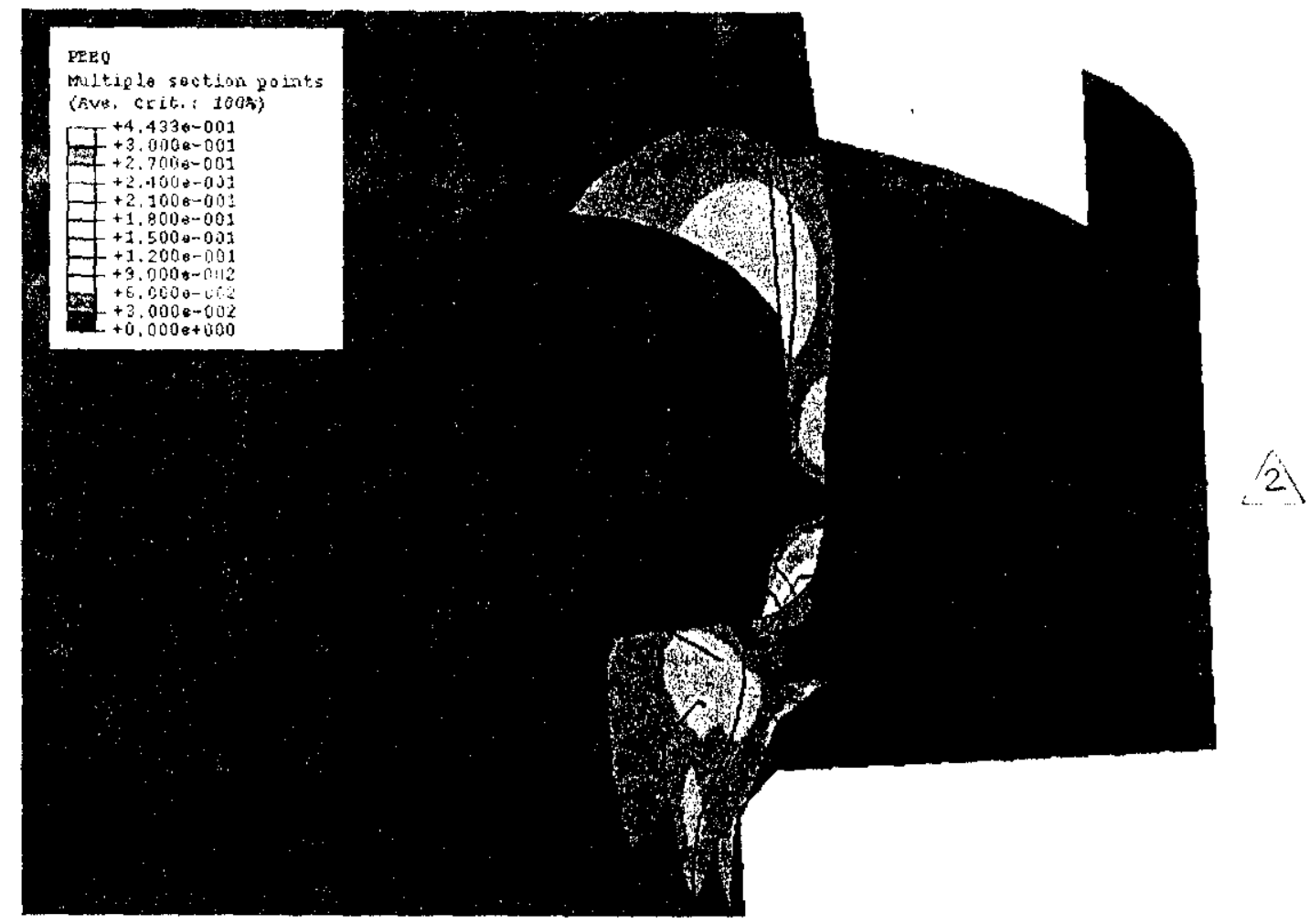

Figure 7.10.e. MCO Drop Animation (Time $=0.015$ seconds). 


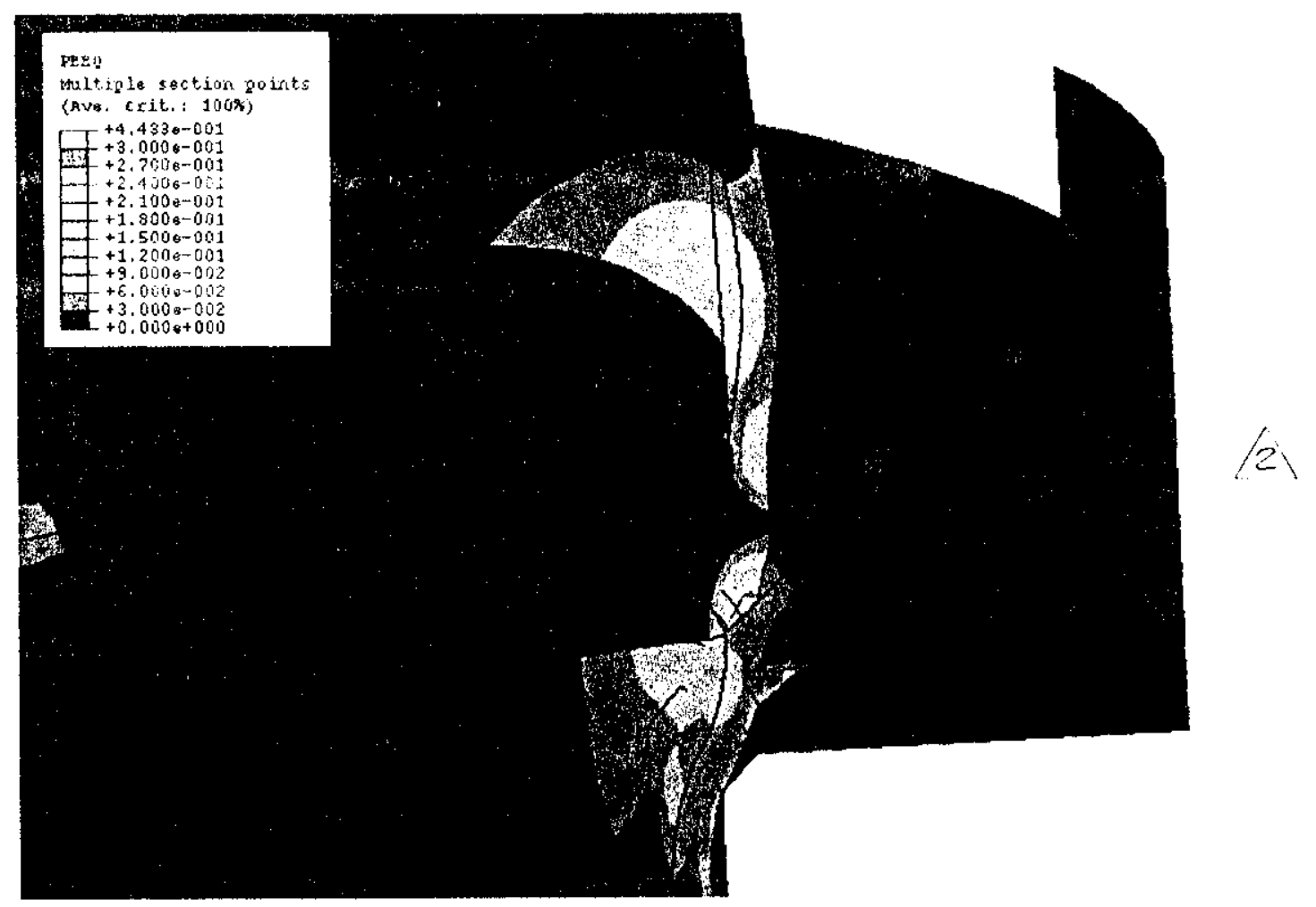

Figure 7.10.f. MCO Drop Animation (Time $=0.01875$ seconds). 


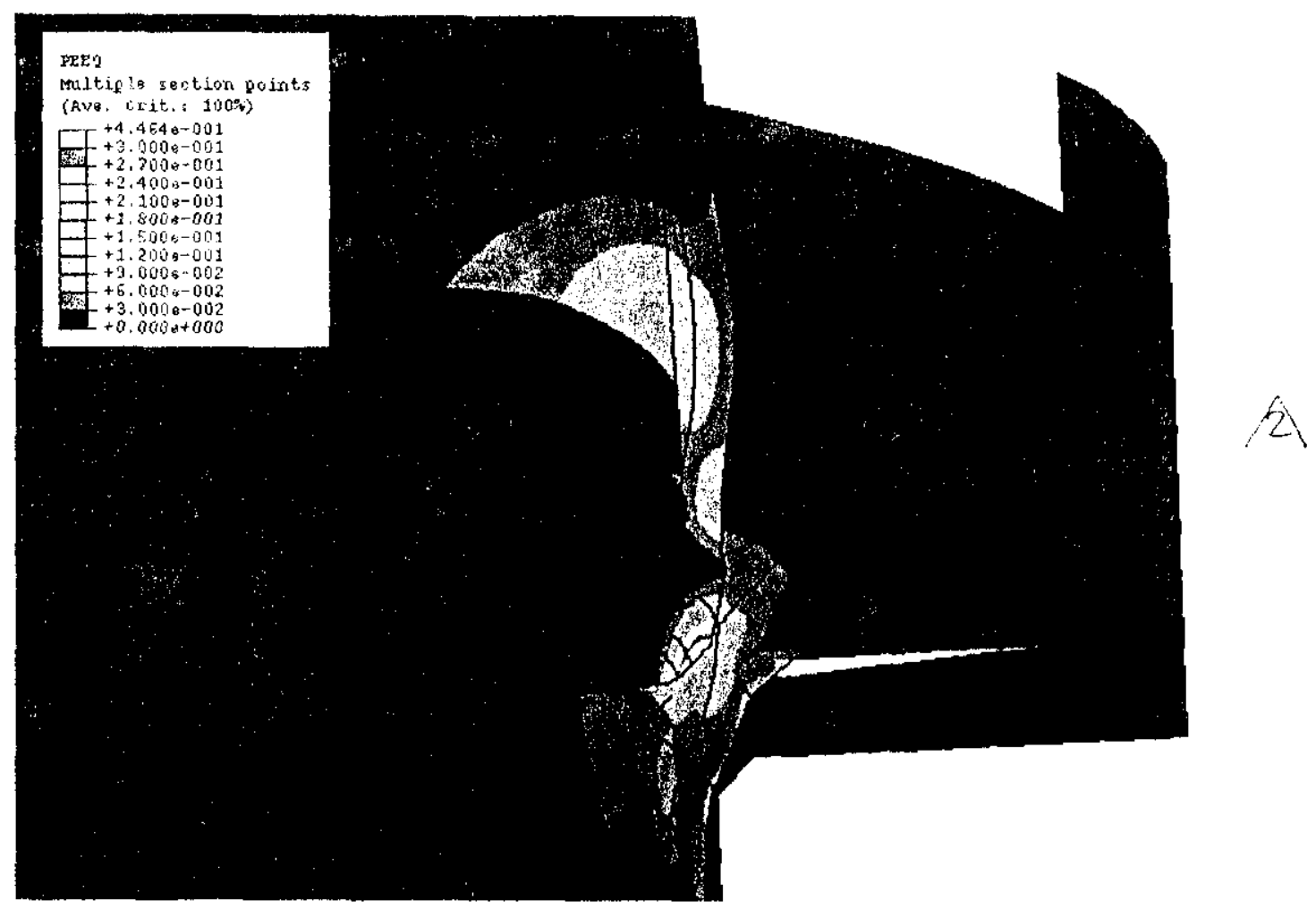

Figure 7.10.g. MCO Drop Animation (Time $=0.0225$ seconds). 


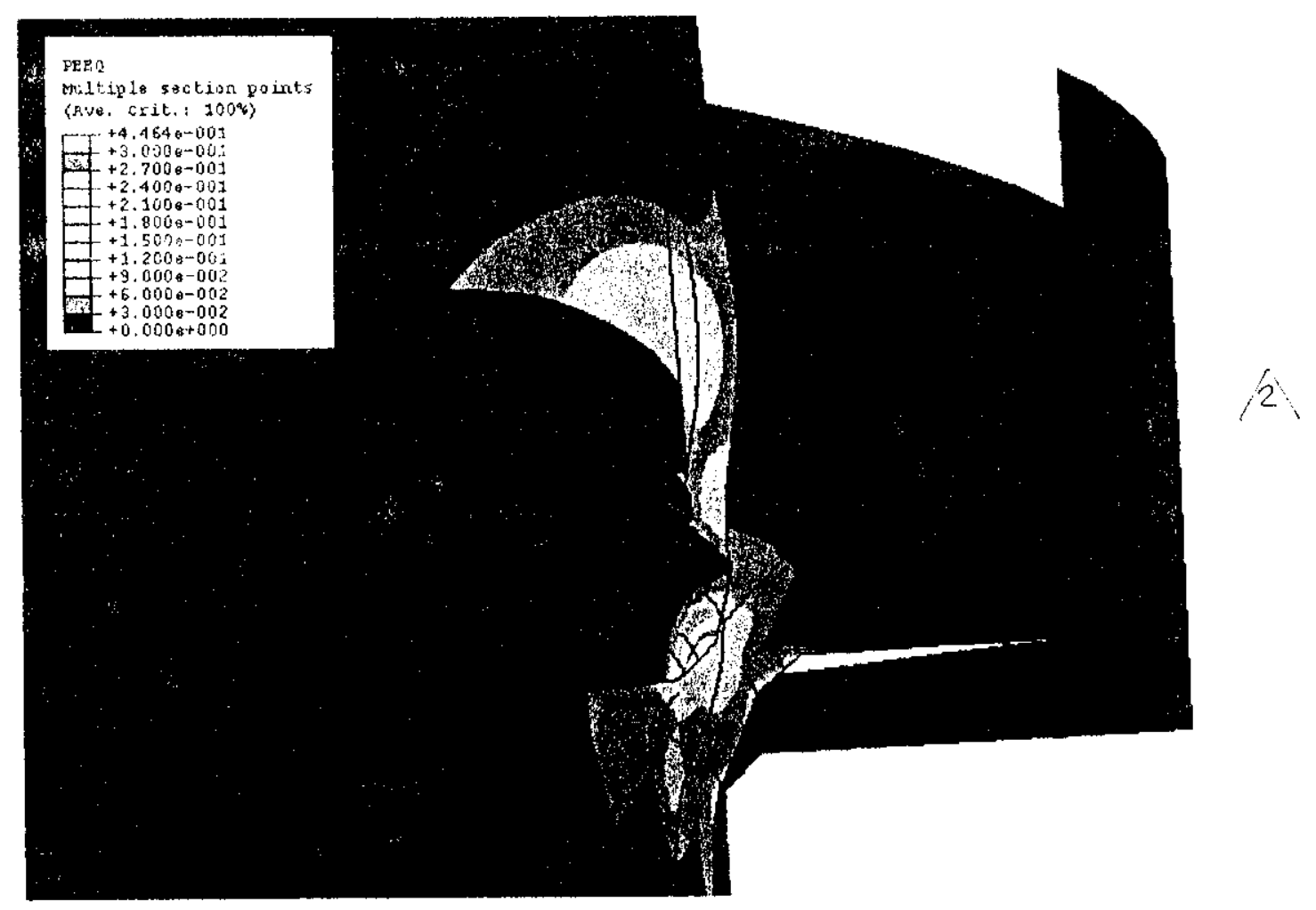

Figure 7.10.h. MCO Drop Animation (Time $=\mathbf{0 . 0 2 6 2 5}$ seconds). 


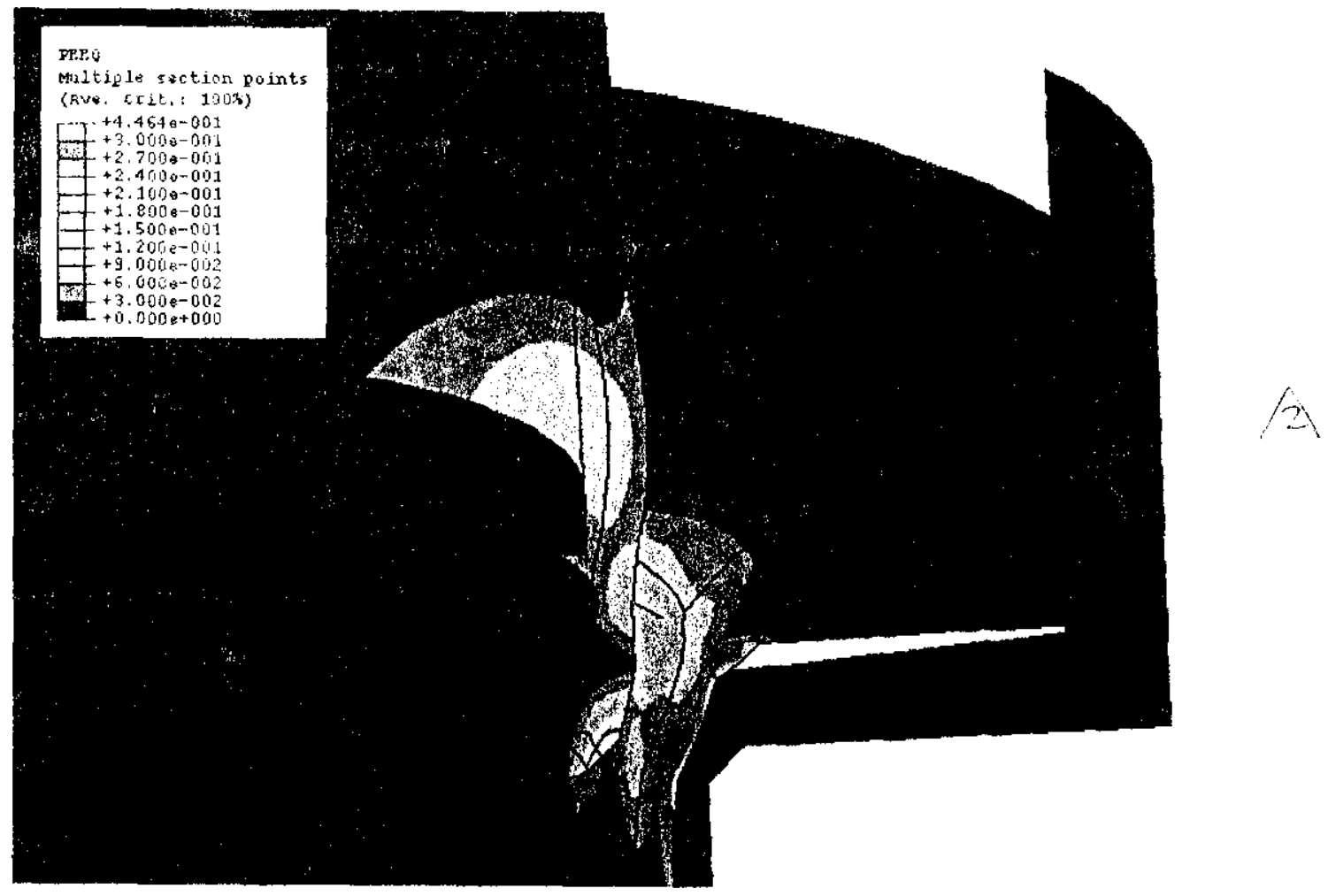

Figure 7.10.i. MCO Drop Animation (Time $=0.03$ seconds) 
WISES E: 70159 IP: 1

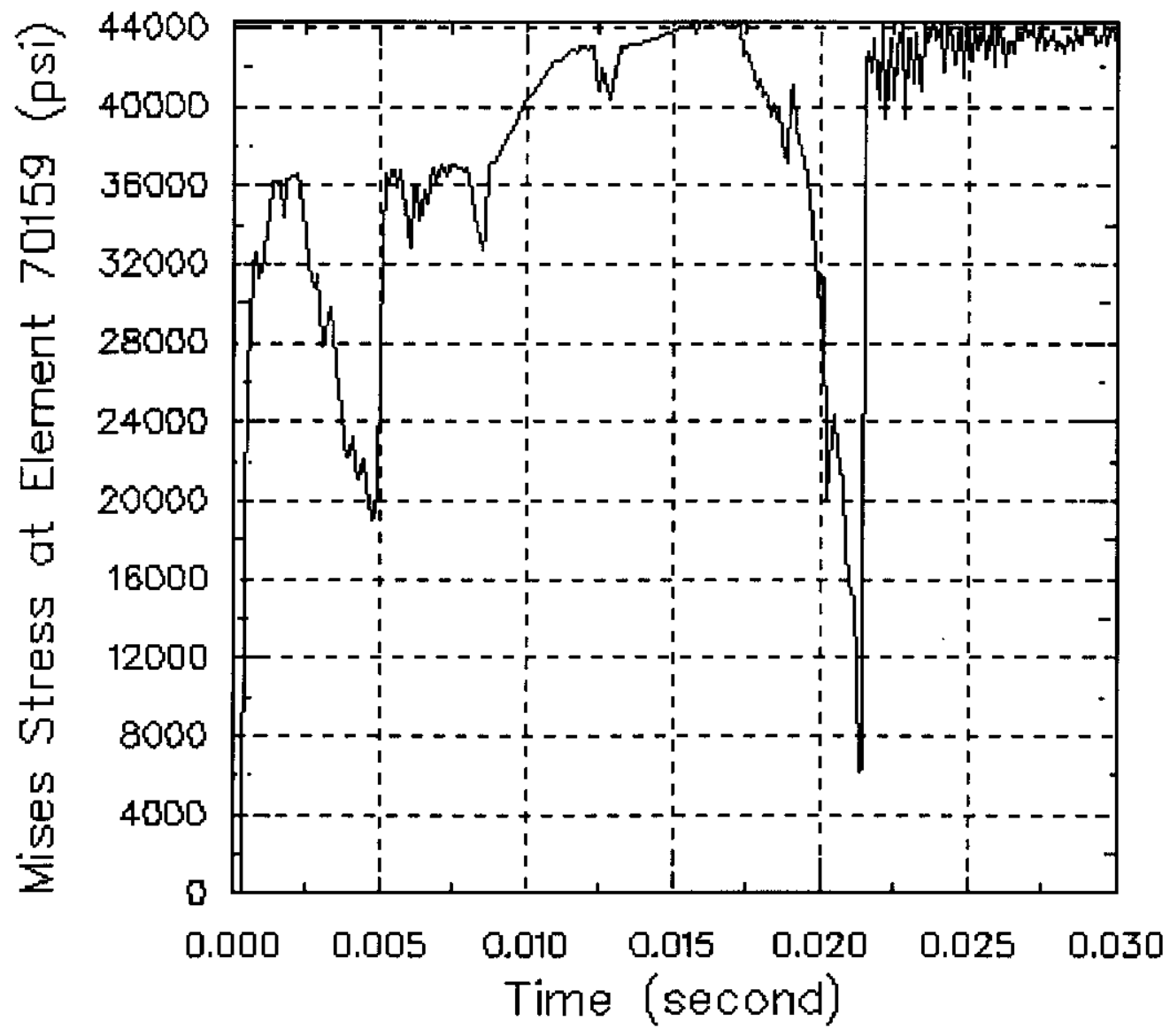

2

Figure 7.11. Mises Equivalent Stress Time History Plot of Element 70159 near Outside weld. 

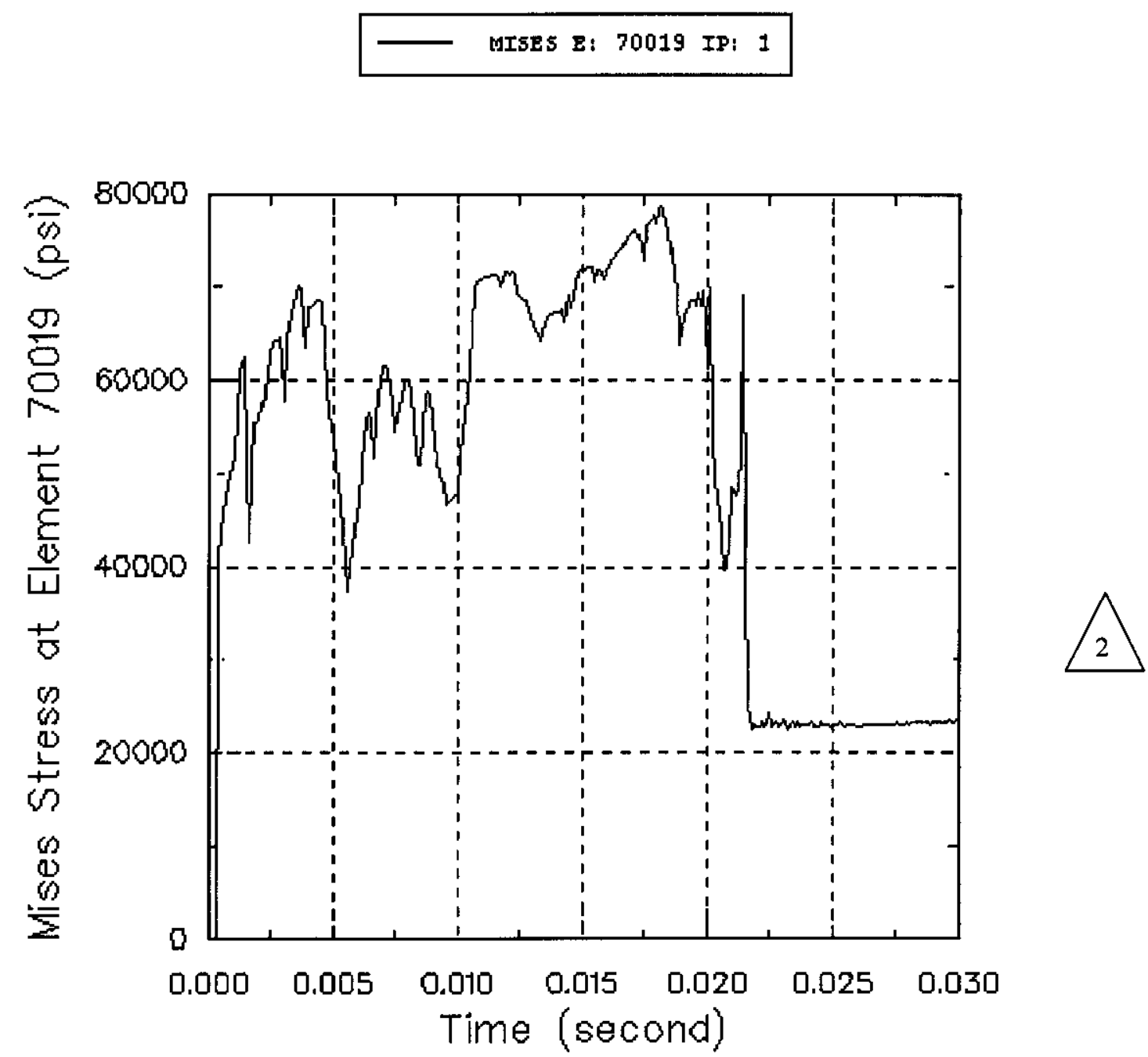

Figure 7.12. Mises Equivalent Stress Time History Plot of Element 70019 at MCO bottom near Impact location. 


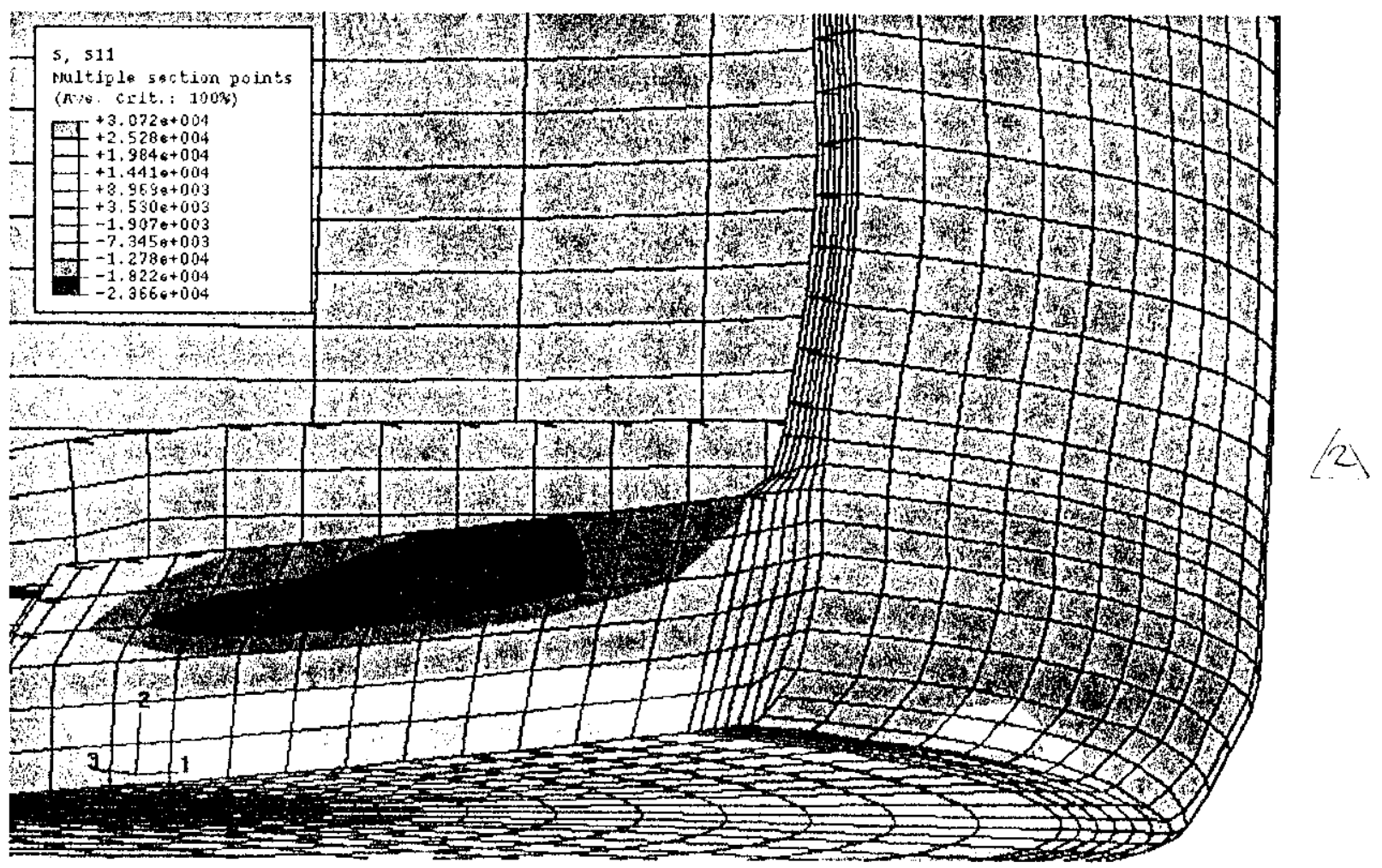

Figure 7.13. Stress in Radial Direction (direction 1) at Time 0.03 Seconds. 


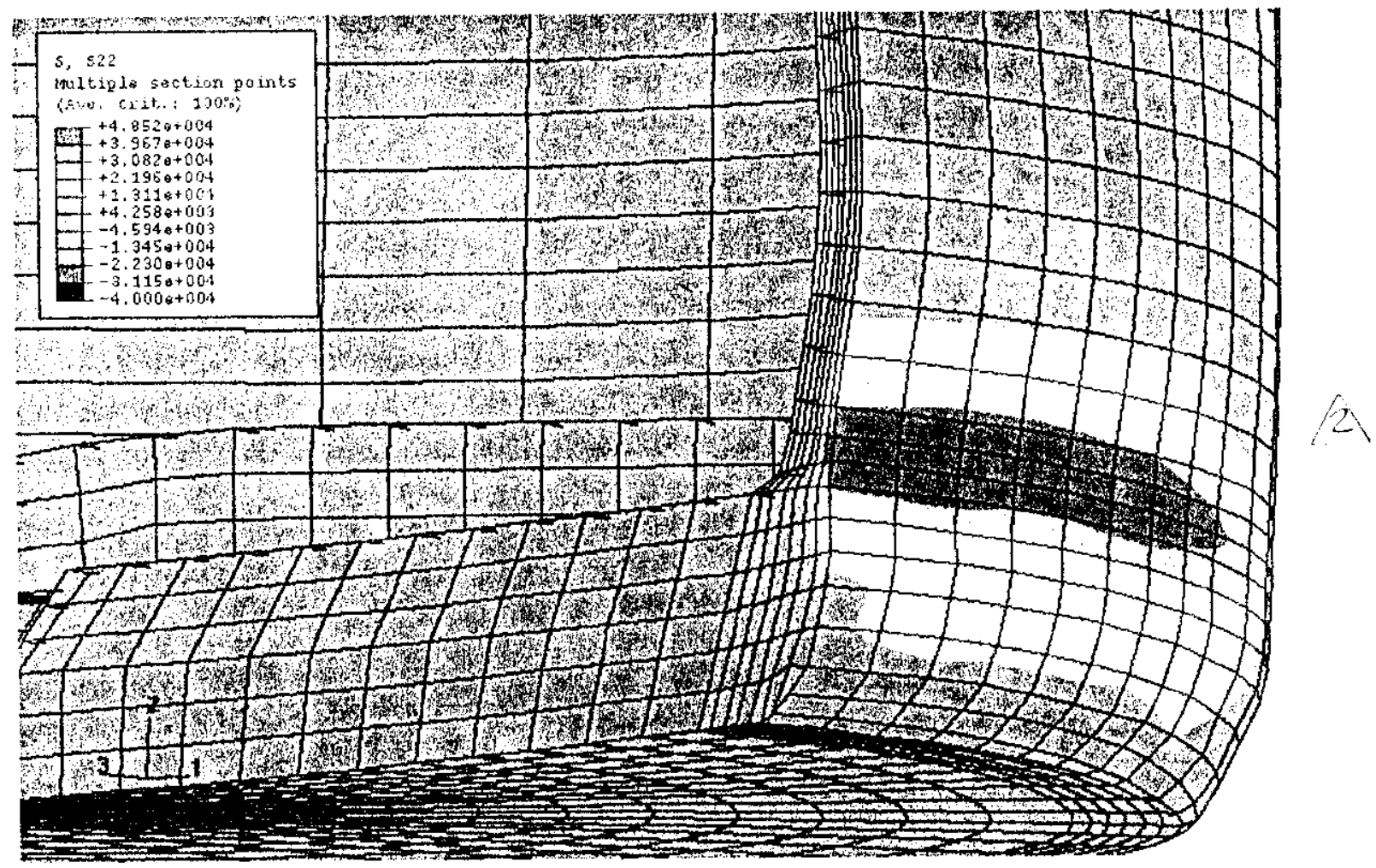

Figure 7.14. Stress in Meridian Direction (direction 2) at Time 0.03 Seconds. 


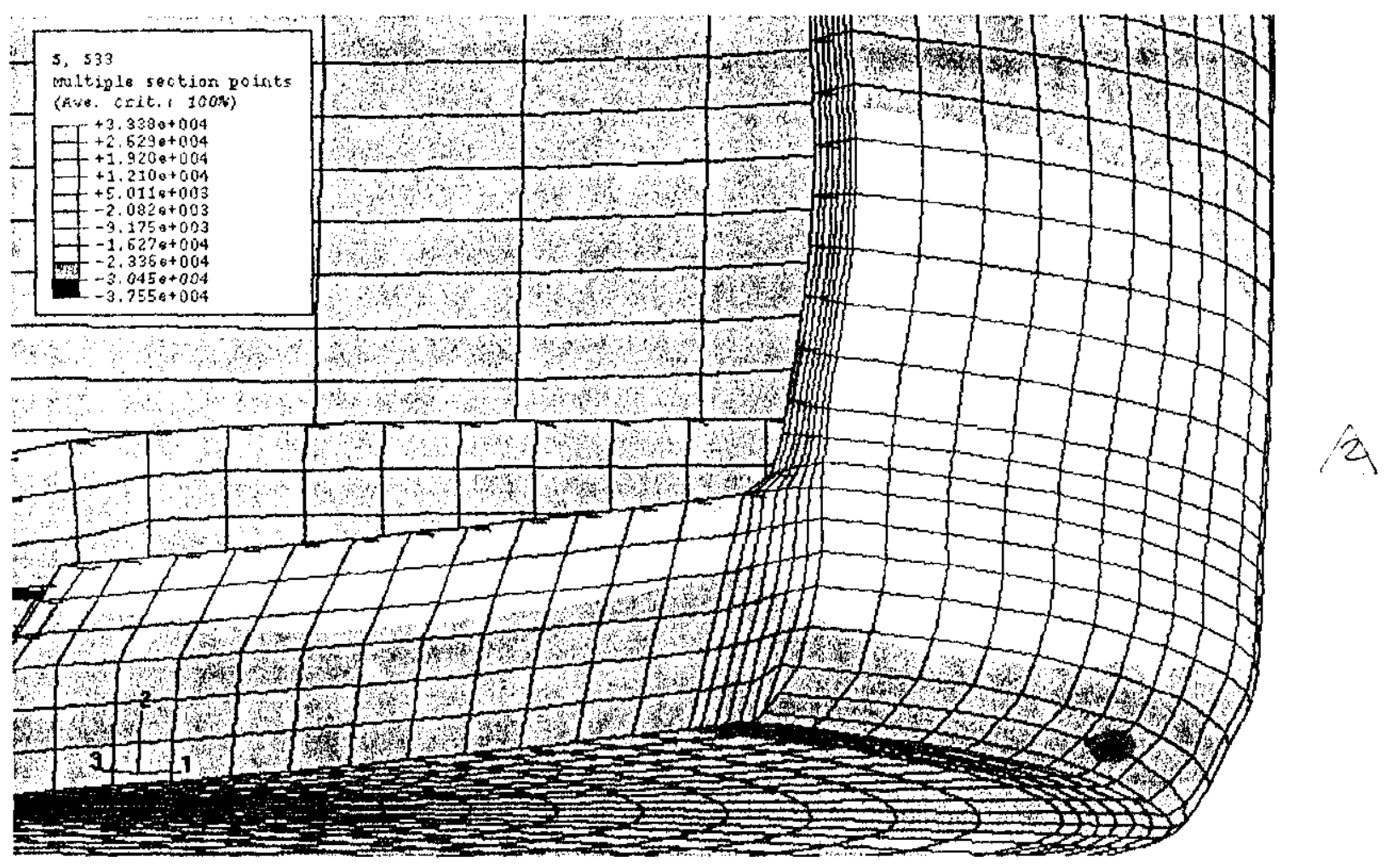

Figure 7.15. Stress in Hoop Direction (direction 3) at Time 0.03 Seconds. 


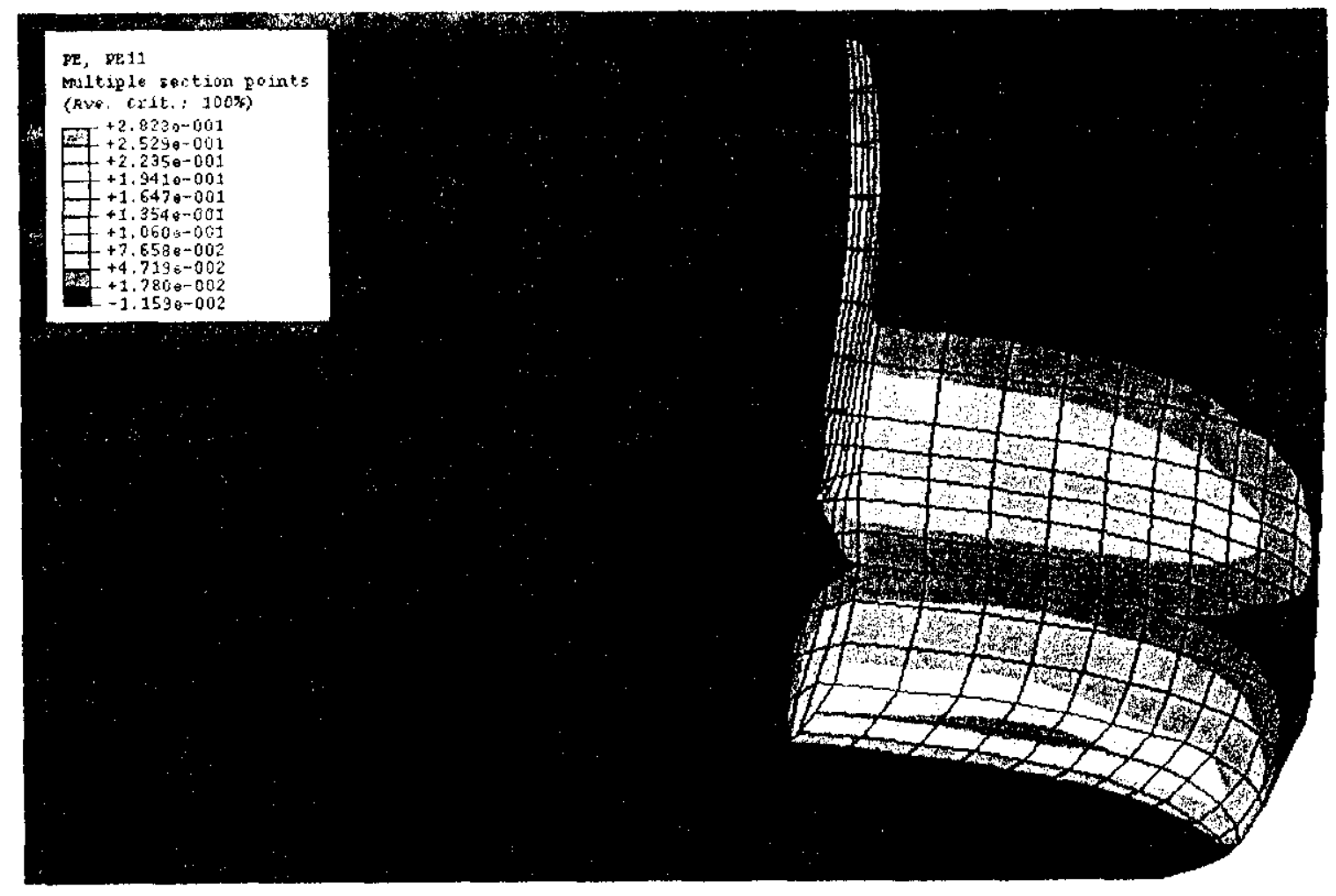

Figure 7.16. Plastic Strain in Radial Direction (direction 1) at Time 0.03 Seconds. 


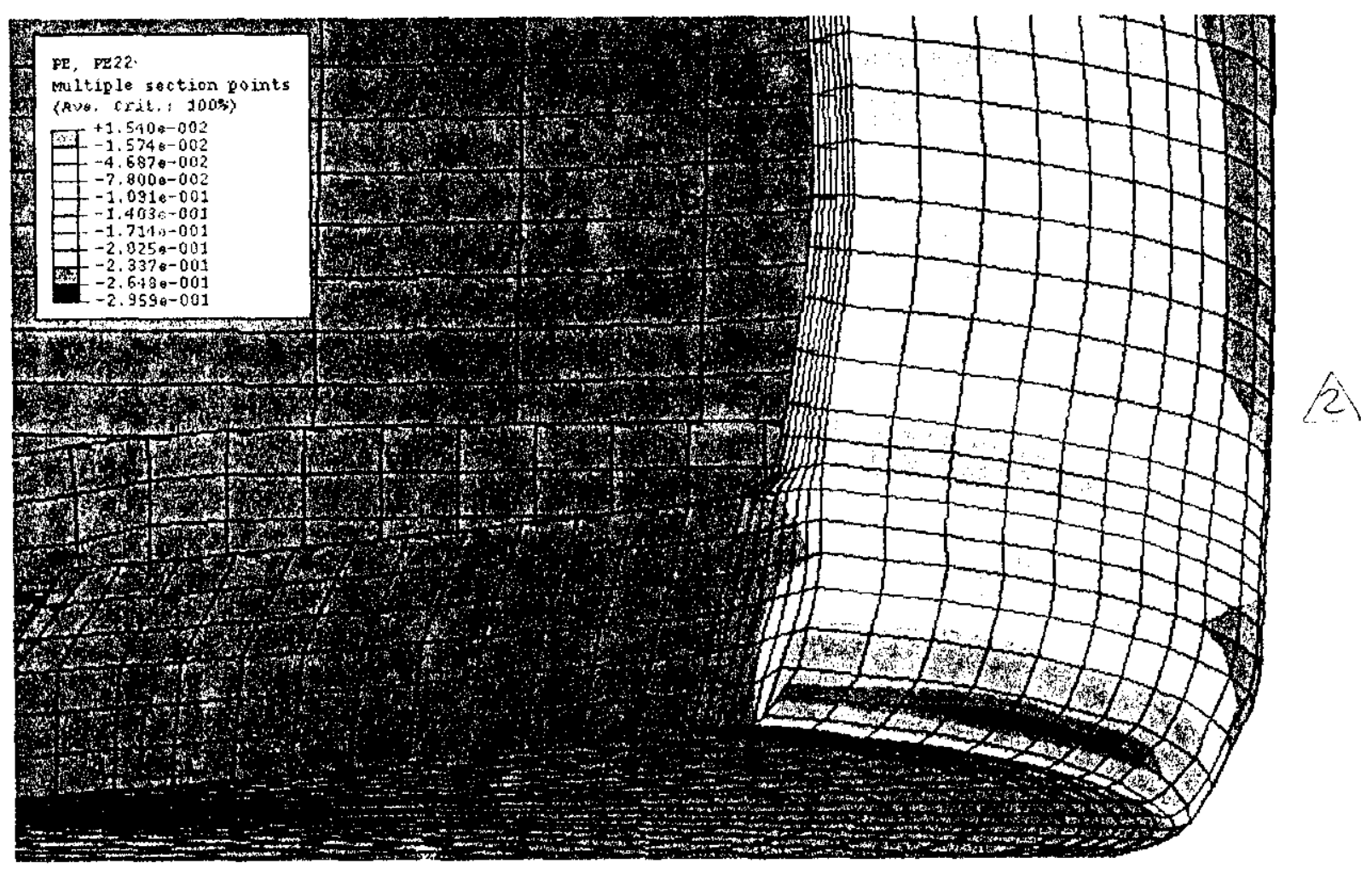

Figure 7.17. Plastic Strain in Meridian Direction (direction 2) at Time 0.03 Seconds. 


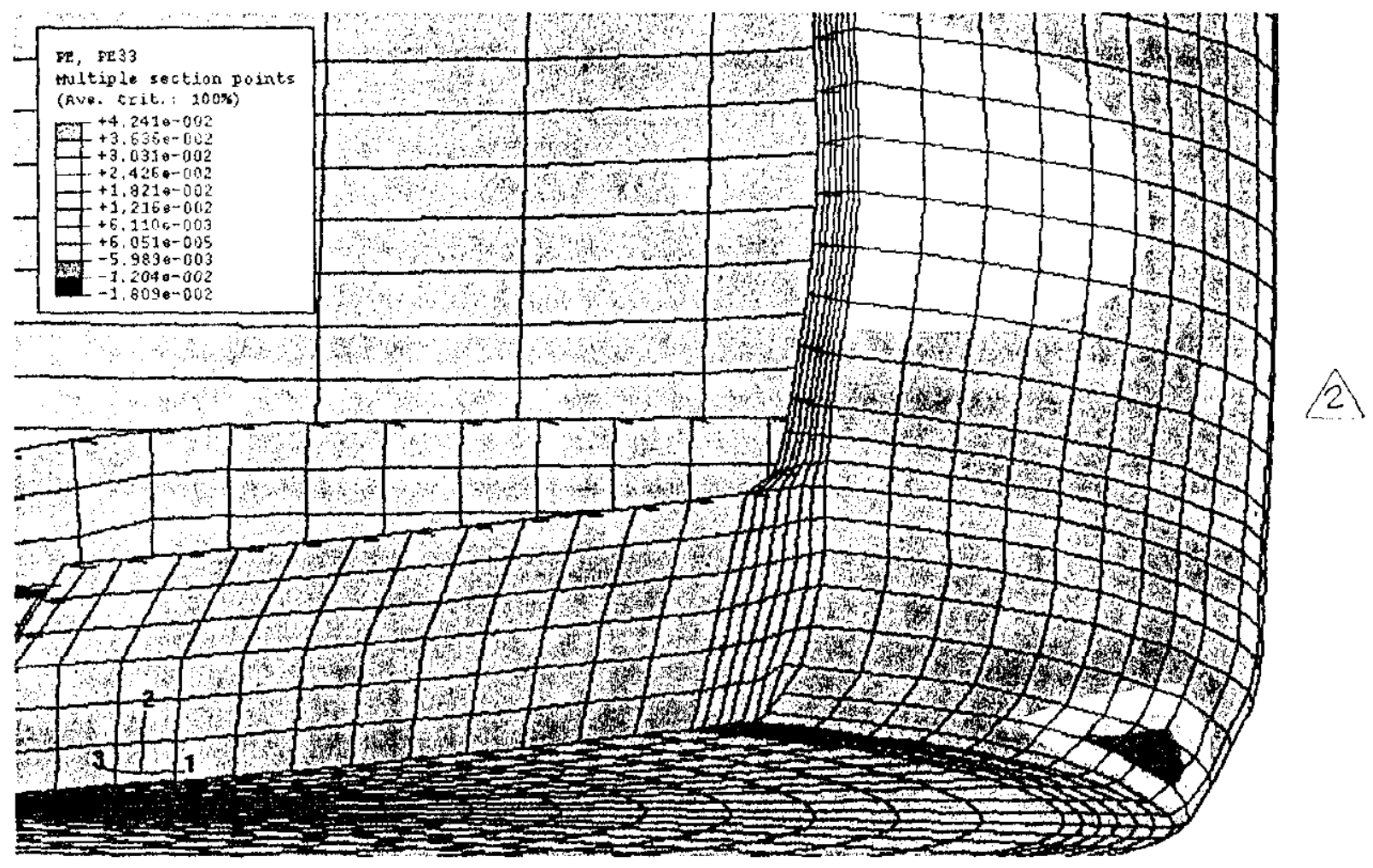

Figure 7.18. Plastic Strain in Hoop Direction (direction 3) at Time 0.03 Seconds. 


\section{- ALLKE Whole Model}

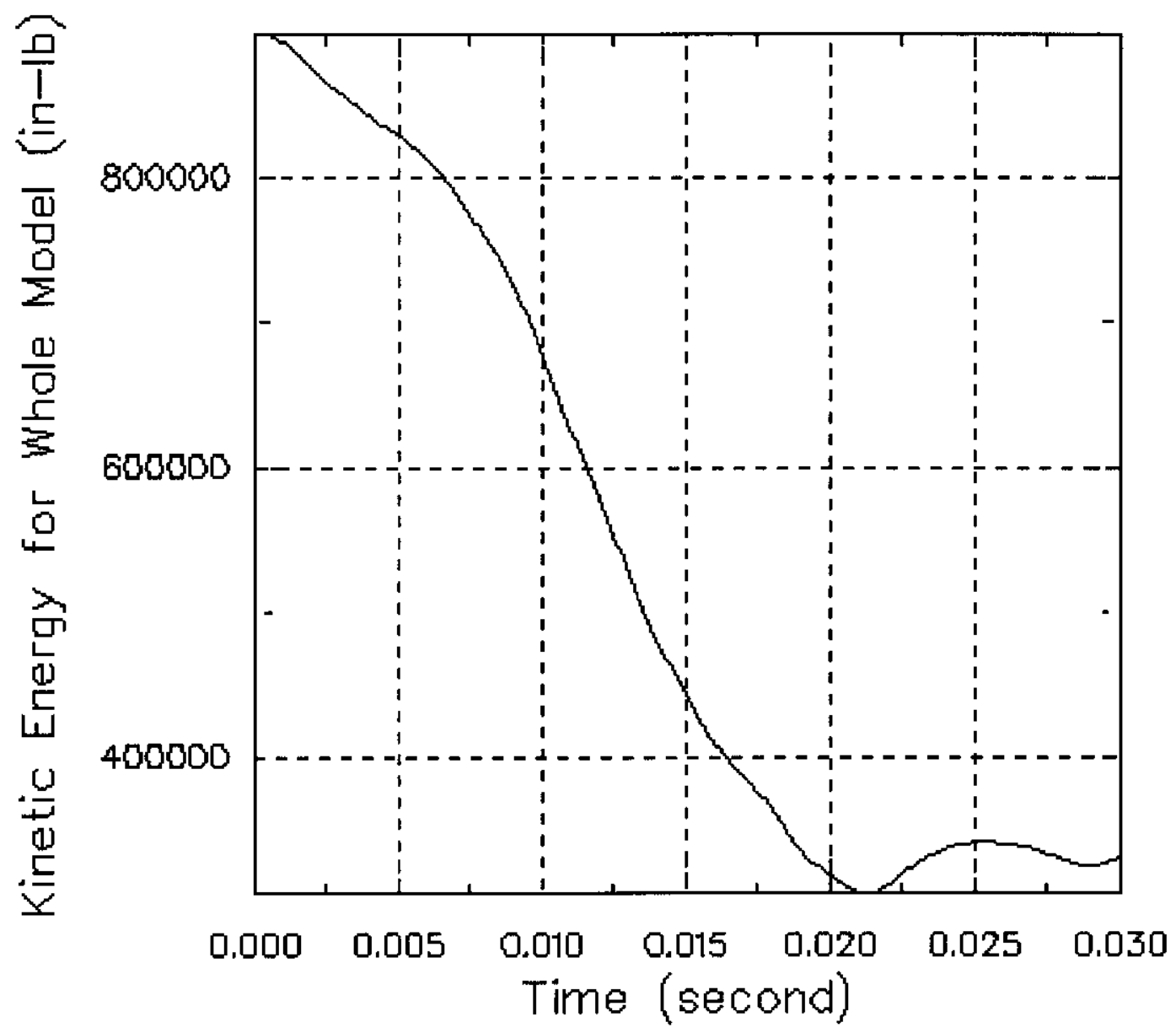

Figure 7.19. Total Kinetic Energy Time History of the MCO Drops onto the Standard Storage Tube Assembly 


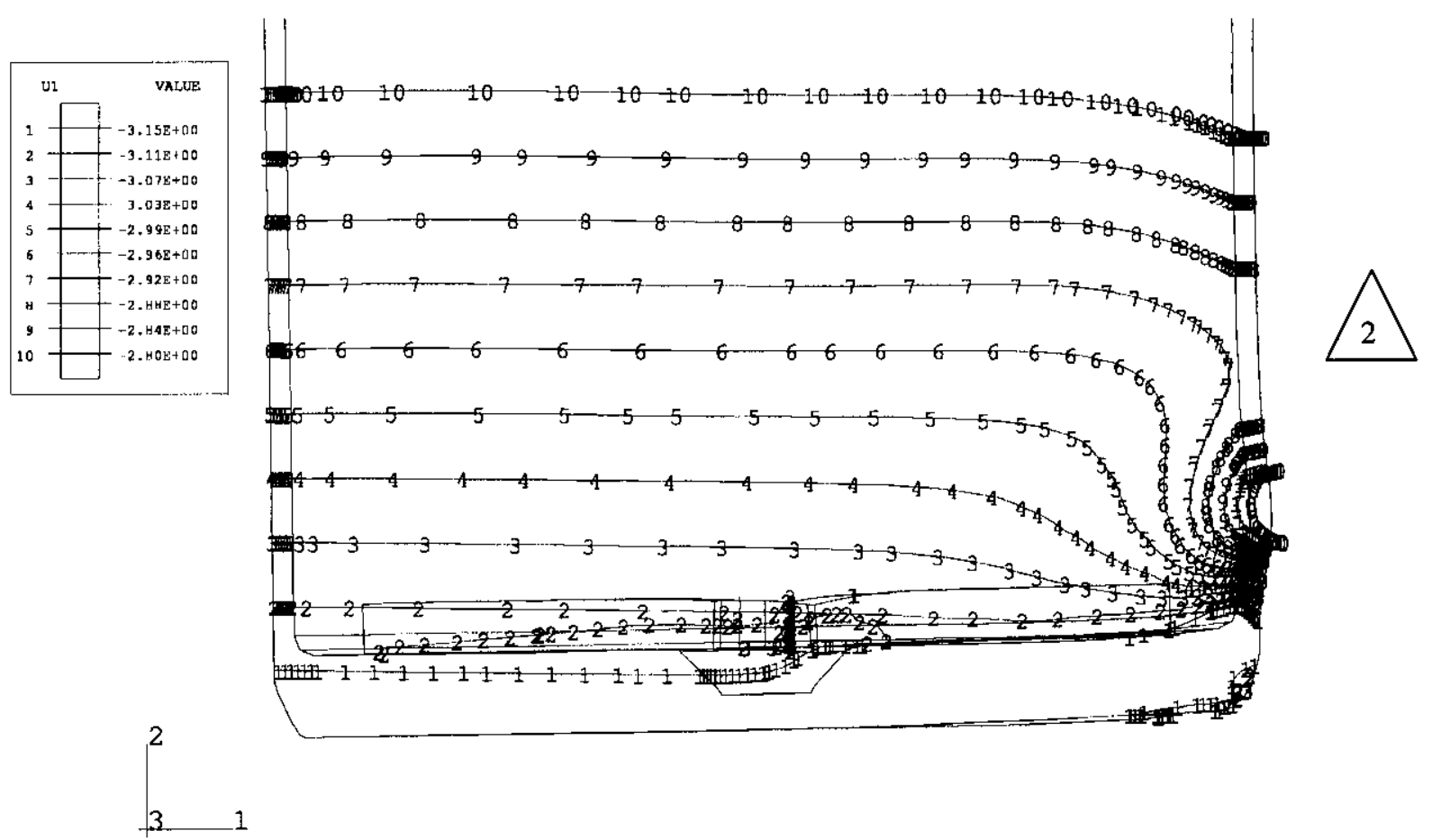

Figure 7.20. MCO Deformations. 


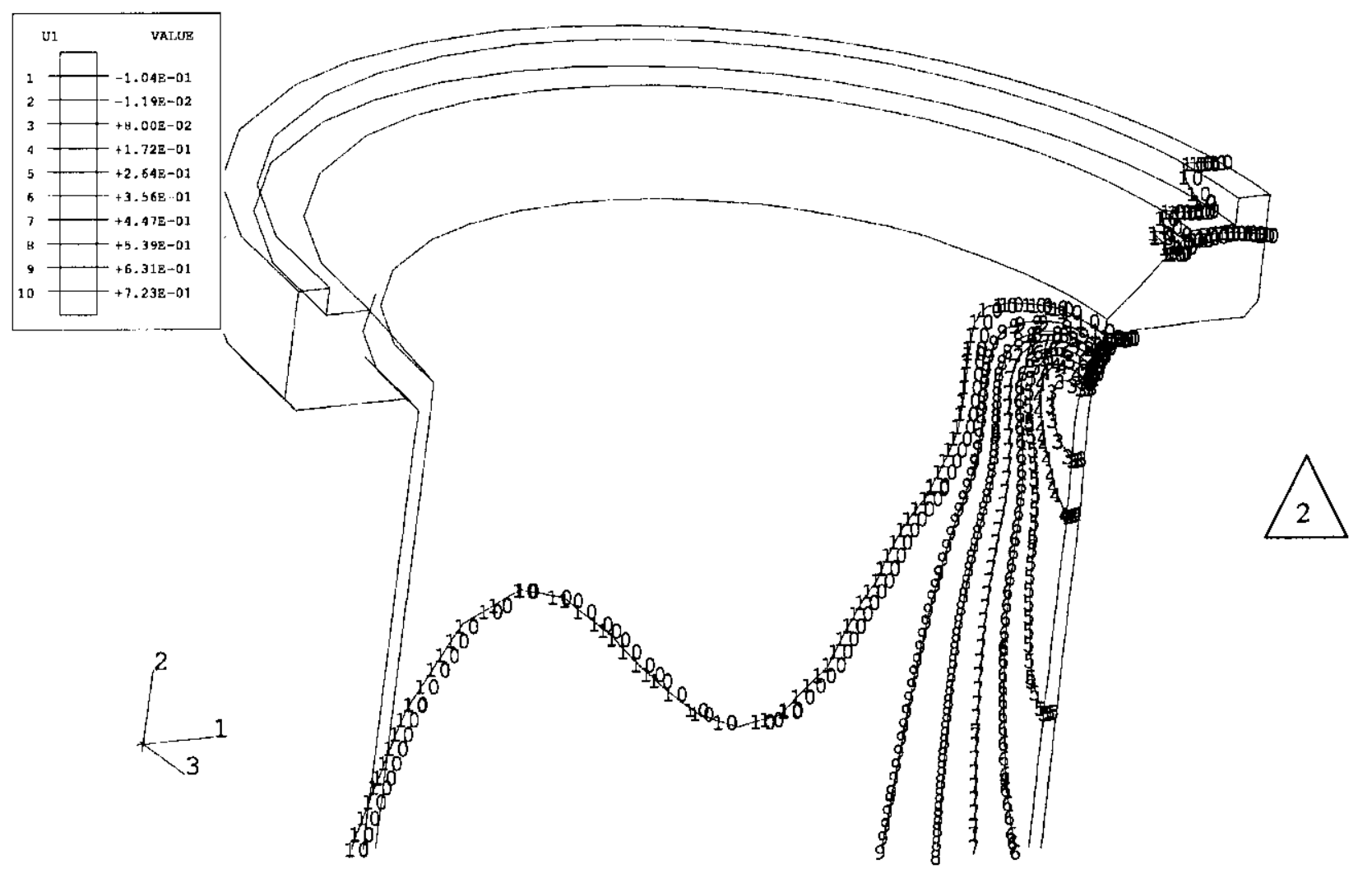

Figure 7.21. Standard Storage Tube Deformations. 


\subsection{FAILURE CRITERIA}

(Discussion and criteria provided by Larry Blackburn, Metallurgy Consultant to DESH/FDH.)

Failure of the MCO will not occur if the maximum principal strain resulting from the drop is below a value that could initiate local cracking. The multi-axial loading and deformation associated with the drop need to be considered in evaluating limits on maximum principal strain. Manjoine (4) has proposed that the tensile elongation measured in a tension test can be adjusted to predict multi-axial failure strain by the relation.

$$
\begin{aligned}
& \frac{\bar{\epsilon}}{e_{\imath}}=2^{(1-T F)} \text { for } T F \geq 0, \text { and } \\
& \frac{\bar{\epsilon}}{e_{i}}=2 \text { for } T F \leq 0
\end{aligned}
$$

where $\bar{\epsilon}$ is the effective (Mises) strain at failure,

$e_{t}$ is the tensile elongation from tension test, and

TF is the stress state triaxiality factor.

The ratio of the Mises strain at failure divided by the uniaxial tensile elongation is a measure of relative ductility between multi-axial and uniaxial stress states. Ductility given by Equation (1) increases as the Triaxiality factor decreases from one and decreases as the triaxiality factor increases from one as shown in Figure 8.1.

The effective strain and triaxiality factor is defined by the relations

$$
\bar{\epsilon}=\frac{\sqrt{2}}{3}\left[\left(\epsilon_{1}-\epsilon_{2}\right)^{2}+\left(\epsilon_{2}-\epsilon_{3}\right)^{2}+\left(\epsilon_{3}-\epsilon_{1}\right)^{2}\right]^{1 / 2}
$$

where $\epsilon_{1}, \epsilon_{2}$, and $\epsilon_{3}$ are the principal strains, and

$$
T F=\frac{\sqrt{2}\left(\sigma_{1}+\sigma_{2}+\sigma_{3}\right)}{\left[\left(\sigma_{1}-\sigma_{2}\right)^{2}+\left(\sigma_{2}-\sigma_{3}\right)^{2}+\left(\sigma_{3}-\sigma_{1}\right)^{2}\right]^{1 / 2}}
$$

where $\sigma_{1}, \sigma_{2}$, and $\sigma_{3}$ are the principal stresses. 

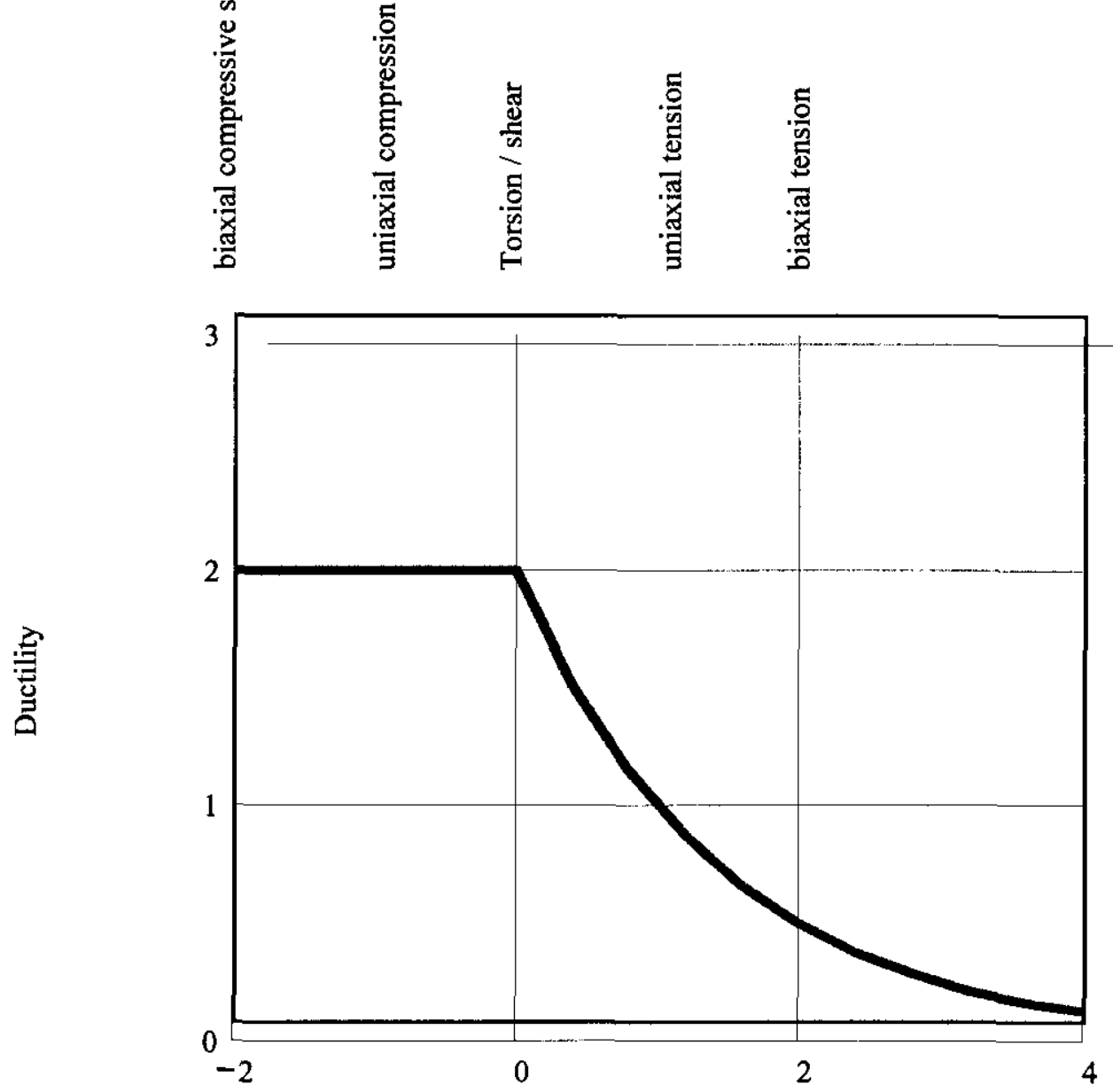

Triaxiality Factor

Figure 8.1 Ductility vs. Triaxiality Factor.

Manjoine indicates support for the correlation from several alloys, but does not cite the specific references for the test data. A pressure vessel burst test program sponsored by the Pressure Vessel Research Committee (PVRC) provides support for the Manjoine correlation. Boyer and Rolfe (5) report that the effective strain measured after bursting by internal pressure of a smooth pressure vessel made of carbon steel was 0.236 , while $e_{t}$ was 0.33 . These results are in good agreement with Equation (1a). A test on a second pressure vessel containing an intentional notch reduced the effective strain to 0.125 . Goller et al (6) report failure strains in pressurized discs (both smooth and 
reinforced) of alloy steel that are twice as large as the tensile elongation. These multi-axial failure strains in discs are much higher than would be predicted by the Manjoine correlation. Several researchers (Blejwas [7], Clauss [8], and Horschel [9]) report results for bursting of sub-scale models of nuclear reactor containment structures of carbon steel. In a simple 1/32-scale model, failure strains were about 0.21 for a smooth geometry, and about 0.16 for geometry containing penetrations (Reference 7). The tensile elongation for the steel was not reported, but the multi-axial failure strains are similar to those cited above for the PVRC vessels. Containment models that were $1 / 8$ and $1 / 6$ scale (References 8 \& 9) were geometrically more complex and contained various penetrations, hatches, and stiffening rings. Localized failure strains were not measured directly, but indicated strain gage readings for the $1 / 8$ scale test would suggest local failure strain exceeded 0.08 . In these models, failures initiated at a formed stiffener adjacent to the reinforcement at an equipment hatch penetration ( $1 / 8$ scale model), and at a thickened region around a penetration ( $1 / 6$ scale model). Both models were loaded beyond general yielding, and the free-field strains (i.e.; away from geometric discontinuities) were in the range 0.013 to 0.031 when ultimate failure occurred.

The MCO being analyzed in the present evaluation exhibits a smooth geometry without any discontinuities or notches that would reduce failure strains below those predicted from the Manjoine correlation.

For assessment of the weld region, the tensile elongation should be based on tests of weld metal. Results from thirteen different welds (References 10 \& 11) tested at room temperature were used to determine tensile elongation. These welds were produced using various welding procedures and represent $308,16-$ $8-2$, and 316 stainless steel weld metal compositions. For a total of 27 tension tests on as-deposited welds, the mean value of $e_{t}$ is 0.37 with a standard deviation of 0.078 . Defining the minimum value of $e_{t}$ as the mean value minus twice the standard deviation, $e_{t}$ (min.) is 0.214 .

For assessment of base metal regions, the specification minimum value for $e_{t}$ of $304 \mathrm{~L}$ stainless steel base metal is $40 \%$ based on uniaxial tensile test at "low" (nominal) strain rate. The maximum acceptable value of $e_{t}$ for $304 \mathrm{~L}$ stainless steel base metal is therefore about twice that for the weld metal.

\subsection{DISCUSSION}

Results of the inelastic analysis calculations include the following significant findings.

- Failure Criteria.

Conservative estimated failure strain levels were predicted for both welds and parent 304L stainless steel material, accounting for scatter in properties and multi-axial stresses and strains, using the methods in Section 8 . For a triaxiality factor of 1.0 (uniaxial tension), the above values are $21 \%$ for the weld metal and $40 \%$ for the base metal. The failure strains are reduced to account for the $270^{\circ} \mathrm{F}$ design temperature and for dynamic strain rate effects. 
For a triaxiality factor of 2.0 (maximum value for biaxial tension at surface) the failure strain levels are estimated to be $8 \%$ for the weld and its adjacent area and $15 \%$ for parent steel material. For negative values of triaxiality factor (significant compressive stress) that are characteristic of the major portion of the strain accumulation in the drop, the failure strain values are $32 \%, 60 \%$, and $48 \%$ for weld metal, base metal and base metal using high strain rate material properties respectively.

- Drop onto Storage Tube.

Improving the model for the MCO internals and impact locations, using the refined finite element model of the wall (7 solid elements through the wall), gives the highest weld region predicted strain of $15 \%$ with TF of less than 0 at outer surface and $4.6 \%$ with TF of 2 at inner surface. The computed values are less than the estimated failure strain levels, $32 \%$ and $8 \%$ respectively. Moreover, the maximum tensile principal strain is in a radial direction, the maximum at the outer surface and any failure would be by spalling or flaking rather than crack formation and propagation through the wall. For the $1 / 2$ " shell area, the maximum computed strain levels are less than the maximum values of the welded area and the estimated failure strains are higher than the failure strain of the welded area.

With the improved models of above, the results indicate the MCO bottom plate area-of-impact sustains a high triaxial compressive stress state (triaxiality factor is negative) with a maximum computed strain of about $45 \%$ and $40 \%$ for the cases using low and high strain rate effects. Since Triaxiality Factor is 2 and the predicted failure strains are $60 \%$ and $48 \%$ accounting high strain rate, no cracking is expected to occur. However, the maximum tensile principal strain, which is very local and exists only a small way into the wall thickness, is perpendicular to the base surface and is a Poisson's ratio effect, therefore any failure would be through spalling or flaking.

The above results also show that the areas of MCO not discussed above are structurally acceptable since the strains are much lower (mostly in the elastic range). No structural instabilities are indicated, and the vertical deceleration of the MCO baskets is $34 \mathrm{~g}$ within a conservative allowable of $35 \mathrm{~g}$ 's from the MCO design criteria and conservatively less than the calculated design capacity of $54 \mathrm{~g}$ for the basket.

The deformation of the support tube where the flange attaches to the tube cylinder is much less than that of the MCO-to-tube clearance, thus, no adverse wedging of the $\mathrm{MCO}$ in the tube is expected.

- Drop onto Service Station Guide Ring.

The finite element model gives the highest weld region effective strain of about $1 \%$. Comparing this strain to the bounding $8 \%$ failure strain estimated in table 7.1 indicated that no cracking would occur. Moreover, the maximum tensile principal strain is in a radial direction, maximum at the outer surface and any failure would be by spalling or flaking rather than crack formation and propagation through the wall. 
and any failure would be by spalling or flaking rather than crack formation and propagation through the wall.

The results indicate the MCO bottom plate area-of-impact sustains a triaxial compressive stress state (triaxiality factor is negative) with a maximum effective strain of about $18 \%$, which is less than the storage tube case. Since the predicted failure strain is $60 \%$ (or $48 \%$ when including strain rate effect reduction factor), no cracking is expected to occur. Moreover, the maximum tensile principal strain is again perpendicular to the base surface and is a Poisson's ratio effect, therefore, any failure would be through spalling or flaking.

The above results also show that the areas of MCO not discussed above are structurally acceptable as the strains are much lower (mostly in the elastic range). No structural instabilities are indicated, and the vertical deceleration of the MCO baskets are about $\mathbf{4} \mathrm{g}$ 's, well within a conservative allowable of $35 \mathrm{~g}$ 's from the MCO design criteria.

\subsection{REFERENCES}

1. Tu, K. C. MCO Drop Impacts on the Standard Storage Tubes, Calculation Number CSB-S-0067, January 15, 1999.

2. Tu, K. C. MCO Drop Impacts on the Overpack Storage Tube, Calculation Number CSB-S-0068, April 1999.

3. Avallone, E. A. and T. Baumeister, III. Marks' Standard Handbook for Mechanical Engineers, New York, McGraw-Hill Book Company, 1987.

4. Manjoine, M. J. Creep-Rupture Behavior of Weldments, Welding Journal, Research Supplement, February 1982.

5. Boyer, C. P. and S. T. Rolfe, Effect of Strain - Hardening Exponent and Strain Concentrations on the Bursting Behavior of Pressure Vessels, ASME Paper No. 74MAT-1, 1974.

6. Goller, B., R. Krieg, and G. Messemer. Failure of Reinforced Sections of Spherical Steel Containments Under Excessive Internal Pressure, Transactions of $8^{\text {th }}$ International. Conference On Structural Mechanics in Reactor Technology, North Holland Physics Publishing, 1985, Paper J3/6.

7. Blejwas, T. E. Ibid, Paper J2/3.

8. Clauss, D. B. Nuclear Engineering and Design, 90 (1985), pp. 241-260.

9. Horschel, D. S. Containment Model-Test Program and Results, SAND88 -1747C, May 1989. 
10. Ward, A. L. and L. D. Blackburn, Journal of Engineering Materials and Technology, 98, p. $213,1976$.

11. Blackburn, L. D. and D. L. Greenslade, Mechanical Properties of Type 316 Stainless Steel Materials after Irradiation at $515^{\circ} \mathrm{C}$ and $585^{\circ} \mathrm{C}$, HEDL-TME 81-4, Hanford Engineering Development Laboratory, Richland, Washington, April 1981.

12. Drawing No. H-2-828043 and Drawing No. H-2-828044.

13. Snow, S. D. Analytical Evaluation of Preliminary Puncture-Drop Tests Performed to Develop a Robust and Drop Resistant Design Concept for the Standardized DOE Spent Nuclear Fuel Canister, EDF No. AMG-06-98, June 15, 1999.

14. Snow, S. D. Analytical Evaluation of Preliminary Drop Tests Performed to Develop a Robust and Drop Resistant Design Concept for the Standardized DOE Spent Nuclear Fuel Canister, EDF No. AMG-01-99, September 1998.

15. Steichen, J. M., High Strain Rate Mechanical Properties of Types 304 Stainless Steel and Nicke/ 200 (RM-14), HEDL-TME 71-145, Hanford Engineering Development Laboratory, September 1971

16. Steichen, J. M., High Strain Rate Mechanical Properties of Types 304 and 316 Stainless Steel (RM-17), HEDL-TME 71-164, Hanford Engineering Development Laboratory, November 1971.

17. HNF-SD-SNF-DR-003, Appendix 5, MCO Design Report [Revised Appendices 1 \& 4 \& 5 \& 6 \& 10], Revision 2, by K. E. Smith, DE\&S Hanford, Inc., Richland, WA, May 1999.

18. V. K. Sikka, B. L. P. Booker, M. K. Booker and J. W. McEnerney, Tensile and Creep Data on Type 316 Stainless Steel, ORNL/TM-7110, Oak Ridge National Laboratory, Oak Ridge, TN, January 1980. 


\section{EXPERT PANEL REPORT}

Prepared for SNF-5204, Revision 1 


\section{Conclusions of Expert Panel on Analysis for Eccentric MCO Drops at CSB September 15, 1999 Richland.WA}

Earlier analysis of a postulated eccentric drop at a CSB tube indicated that significant inelastic deformation in the MCO may occur and a breach of the MCO could not be ruled out. In addition, criticality configuration contingency control for the spent nuclear fuel could not be assured. The radiological dose consequences from such a breach had not been shown to meet evaluation guidelines. Accordingly, a plan of action to resolve this issue was undertaken. This plan included the assembly of an expert panel to provide guidance for further work including modeling activities, preliminary calculations, refining the resolution strategy, and implementing the resolution. The drop of the MCO was assessed for the drop on storage tube and for the drop on the service station guide ring. The Expert Panel has met a number of times and the current conclusions reported herein are the results and findings of the new modeling and calculations.

The Expert Panel members were:

LD Blackburn - Metallurgy

RD Crowe - Safety Analysis

LH Goldmann - MCO Design Authority

RP Kennedy - Structural Analysis

LK Severud - Engineering Management \& Structural Analysis

The Expert Panel, after review of the earlier analysis, made recommendations for improving the modeling and reducing the conservatism in the earlier model and calculations. These included better modeling of the MCO internals and impact locations, accounting for the strain rate effects on the material stress-strain properties, refinement of the finite element model in the areas of the high strains, and inclusion of appropriate predictions of the failure strain levels. Results of the inelastic analysis calculations with these changes include the following significant findings:

Failure Criteria. Conservative failure strain levels were predicted for both welds and parent 304L stainless steel material, accounting for scatter in properties and multi-axial stresses and strains, and using the methods in Attachment 1. For a triaxiality factor of 1.0 (uniaxial tension), the above values are $21 \%$ for weld metal and $40 \%$ base metal. For a triaxiality factor of 2.0 (maximum value for biaxial tension at surface) the above values are $10 \%$ and $20 \%$. For negative values of triaxiality factor (significant compressive stress) that are characteristic of the major portion of the strain accumulation in the drop, the values are $42 \%$ and $80 \%$, again for weld metal and base metal respectively.

\section{Drop onto Storage Tube.}

1. Improving the model for the MCO internals and impact locations, using the refined finite element model of the wall ( 7 solid elements through the wall), and maximizing the strain rate effects gives the highest weld region effective strain of less than $0.6 \%$. If the minimum strain rate effects are used, the value is increased but is still less than $3 \%$ with a triaxiality factor less than 2.0. Comparing these to the bounding $10 \%$ failure strain predicted above indicates to the Expert Panel that no cracking will occur. Moreover, the maximum tensile principal strain is in a 
radial direction, maximum at the outer surface and any failure would be by spalling or flaking rather than crack formation and propagation through the wall.

2. With the improved models of above, the calculations indicate the MCO bottom plate arc-ofimpact sustains a high triaxial compressive stress state (triaxiality factor is negative) with a maximum effective strain of about $45 \%$ and $40 \%$ for the cases using maximum and minimum strain rate effects. Since the predicted failure strain is $80 \%$, no cracking is expected to occur. Moreover, the maximum tensile principal strain is perpendicular to the base surface and is a Poisson's ratio effect, so that any failure would be through spalling or flaking.

3. The above calculations also show that the areas of MCO not discussed above are structurally acceptable as the strains are much lower, mostly in the elastic range, no structural instabilities are indicated, and the vertical deceleration of the MCO baskets is about 20G's, well within a conservative allowable of $35 \mathrm{G}$ 's from the MCO design criteria.

4. The deformation of the support tube where the flange attaches to the tube cylinder is much less than that of the MCO-to-tube clearance and so, no adverse sticking of the MCO is expected.

\section{Drop onto Service Station Guide Ring.}

1. The finite element model gives the highest shell weld region effective strain, located at the outer surface, of less than $1 \%$. Comparing this strain to the bounding $10 \%$ failure strain predicted above indicates to the Expert Panel that no cracking will occur. Moreover, the maximum tensile principal strain is in a radial direction, maximum at the outer surface and any failure would be by spalling or flaking rather than crack formation and propagation through the wall.

2. The calculations indicate the MCO bottom plate arc-of-impact sustains a triaxial compressive stress state (triaxiality factor is negative) with a maximum effective strain of about $18 \%$, which is less than that for the storage tube case. Since the predicted failure strain is $80 \%$, no cracking is expected to occur. Moreover, the maximum tensile principal strain is again perpendicular to the base surface and is a Poisson's ratio effect, so that any failure would be through spalling or flaking.

3. The above calculations also show that the areas of $\mathrm{MCO}$ not discussed above are structurally acceptable as the strains are much lower, mostly in the elastic range, no structural instabilities are indicated, and the maximum vertical deceleration of the MCO baskets is about 4G's, well within a conservative allowable of $35 \mathrm{G}$ 's from the MCO design criteria. 
Although the drop analysis report is yet to be drafted, checked and reviewed, the Expert Panel judges that the ongoing work and final report will show that the MCO is not breached in the event of a postulated drops on either the support tube or service station guide ring. The results of the drop on the service station guide ring are also applicable to the drop of the MCO at the sample/weld station.
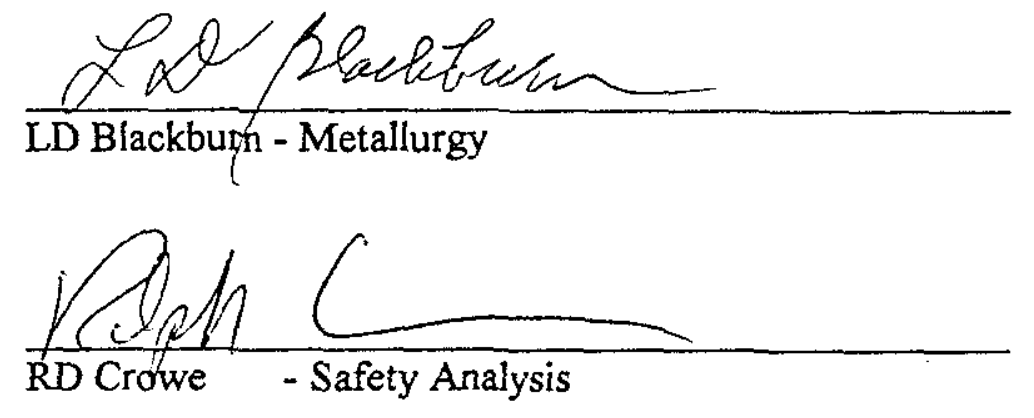

Guis Heltwom

LH Goldmann - MCO Design Authority
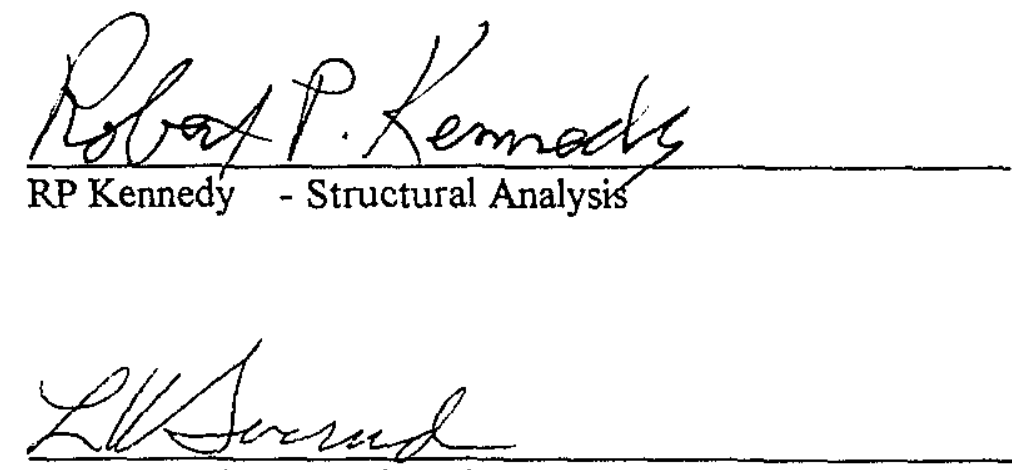

LK Severud - Engineering Management \& Structural Analysis 


\section{PREDICTION OF FAILURE STRAIN}

Failure of the MCO will not occur if the maximum principal strain resulting from the drop is below a value that could initiate local cracking. The multi-axial loading and deformation associated with the drop need to be considered in evaluating limits on maximum principal strain. Manjoine (1) has proposed that the tensile elongation measured in a tension test can be adjusted to predict multi-axial failure strain by the relation.

$$
\begin{aligned}
& \frac{\bar{E}}{e_{1}}=2^{(1-T F)} \text { for } T F \geq 0, \text { and } \\
& \frac{\bar{\epsilon}}{e_{1}}=2 \text { for } T F \leq 0
\end{aligned}
$$

where $\bar{\epsilon}$ is the effective (Mises) strain at failure

$e_{t}$ is the tensile elongation from tension test, and

TF is the triaxiality factor.

The effective strain and triaxiality factor are defined by the relations.

$\bar{\epsilon}=\frac{\sqrt{2}}{3}\left[\left(\epsilon_{1}-\epsilon_{2}\right)^{2}+\left(\epsilon_{2}-\epsilon_{3}\right)^{2}+\left(\epsilon_{3}-\epsilon_{1}\right)^{2}\right]^{1 / 2}$

where $\epsilon_{1}, \epsilon_{2}$, and $\epsilon_{3}$ are the principal strains, and

$$
T F=\frac{\sqrt{2}\left(\sigma_{1}+\sigma_{2}+\sigma_{3}\right)}{\left[\left(\sigma_{1}-\sigma_{2}\right)^{2}+\left(\sigma_{2}-\sigma_{3}\right)^{2}+\left(\sigma_{3}-\sigma_{1}\right)^{2}\right]^{\frac{1}{2}}}
$$

where $\sigma_{1}, \sigma_{2}$, and $\sigma_{3}$ are the principal stresses.

Manjoine indicates support for the correlation from several alloys, but does not cite the specific references for the test data. A pressure vessel burst test program sponsored by the Pressure Vessel Research Committee (PVRC) provides support for the Manjoine correlation. Boyer and Rolfe (2) report that $\bar{\epsilon}$ measured after bursting by internal pressure of a smooth pressure vessel made of carbon steel was 0.236 , while $e_{1}$ was 0.33 . These results are in good agreement with equation 1a. A test on a second pressure vessel containing an intentional notch reduced $\bar{E}$ to 0.125 . Goller et al (3) report failure strains in pressurized discs (both smooth and reinforced) of alloy steel that are twice as large as the tensile elongation. These multi-axial failures strains in discs are much higher than would be predicted by the Manjoine correlation. Several 
researchers (Blejwas [4], Clauss [5], and Horschel [6]) report results for bursting of subscale models of nuclear reactor containment structures of carbon steel. In a simple 1/32 scale model, failure strains were about 0.21 for a smooth geometry, and about 0.16 for a geometry containing penetrations (Ref. 4). The tensile elongation for the steel was not reported, but the multi-axial failure strains are similar to those cited above for the PVRC vessels. Containment models that were $1 / 8$ and $1 / 6$ scale (Ref. 5,6 ) were geometrically more complex and contained various penetrations, hatches, and stiffening rings.

Localized failure strains were not measured directly, but indicated strain gage readings for the $1 / 8$ scale test would suggest local failure strain exceeded 0.08 . In these models, failures initiated at a formed stiffener adjacent to the reinforcement at an equipment hatch penetration ( $1 / 8$ scale model), and at a thickened region around a penetration (1/6 scale model). Both models were loaded beyond general yielding, and the free-field strains (i.e.; away from geometric discontinuities) were in the range 0.013 to 0.031 when ultimate failure occurred.

The MCO being analyzed in the present evaluation exhibits a smooth geometry without any discontinuities or notches that would reduce failure strains below those predicted from the Manjoine correlation.

For assessment of the weld region, the tensile elongation should be based on tests of weld metal. Results from thiteen different welds $(7,8)$ tested at room temperature were used to determine tensile elongation. These welds were produces using various welding procedures and represent $308,16-8-2$, and 316 stainless steel weld metal compositions. For a total of 27 tension tests on as-deposited welds, the mean value of $e_{t}$ is 0.37 with a standard deviation of 0.078 . Defining the minimum value of $e_{t}$ as the mean value minus twice the standard deviation, $\mathrm{e}_{\mathrm{t}}(\mathrm{min}$.$) is 0.214$.

For assessment of base metal regions, the specification minimum value for $e_{t}$ of $304 \mathrm{~L}$ stainless steel base metal is 0.40 . The maximum acceptable value of $e_{\text {f }}$ for $304 \mathrm{~L}$ stainless steel is therefore about twice that for weld metal.

\section{REFERENCES}

1. M. J. Manjoine, Welding J., Research Supplement, February 1982.

2. C. P. Boyer and S. T. Rolfe, "Effect of Strain - Hardening Exponent and Strain Concentrations on the Bursting Behavior of Pressure Vessels", ASME Paper No. 74-MAT-1.

3. B. Goller, R. Krieg, and G. Messemer, Transactions of $8^{\text {th }}$ Intl. Conf, On Strucutral Mechanics in Reactor Technology, North Holland Physics Publishing, 1985, Paper J3/6.

4. T. E. Blejwas, ibid, Paper J2/3.

5. D. B.Clauss, Nucl. Eng and Design, 90 (1985) 241-260.

6. D. S. Horschel, "Containment Model-Test Program and Results", SAND88 1747 C, May 1989.

7. A. L. Ward and L. D. Blackburn, Journal of Engineering Materiais and Technology, 98, p. 213, 1976.

8. L. D. Blackburn and D. L. Greenslade, Mechanical Properties of Type 316 Stainless Steel Materiais After irradiation at $515^{\circ} \mathrm{C}$ and $585^{\circ} \mathrm{C}$, HEDL-TME 81-4, Hanford Engineering Development Laboratory, Richland, Washington, April 1981. 


\section{APPENDIX - A \\ MATERIAL PROPERTIES \\ FOR ABAQUS/EXPLICIT INPUT}

Originator: M.B. LAsota L Lob Date: $\frac{9 / 27 / 99}{9 / 27 / 99}$ 


\section{MATERIAL PROPERTIES FOR ABAQUS/EXPLICIT INPUT Engineering stress-strain curve for 316 SS heat $T$.}

On the basis of data provided in table A-3 contained in Blackburn 1981, engineering stress-strain curve can be constructed by linear interpolation. Stress values in the table are given in mega Pascals. Further the values are converted to psi.

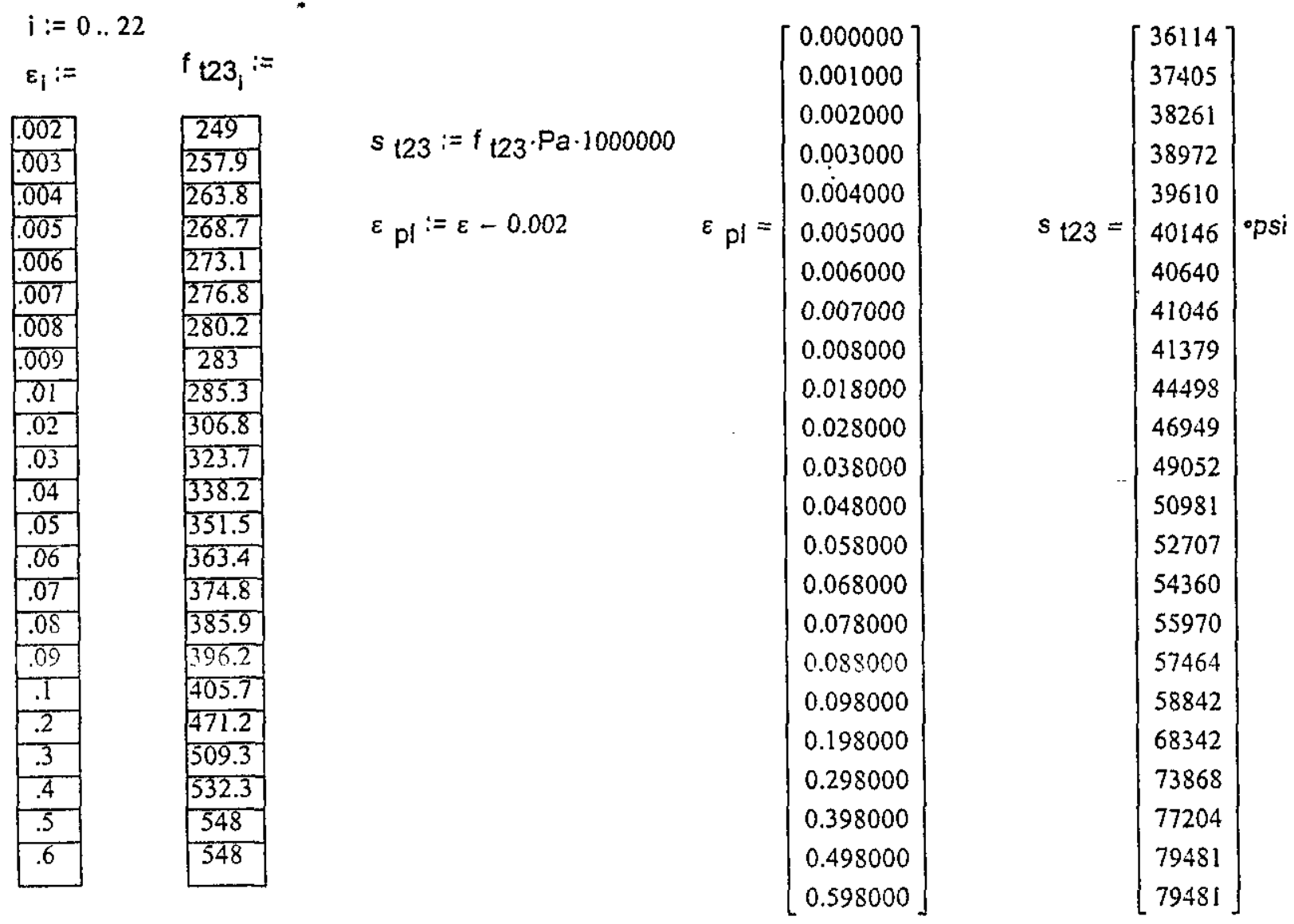

Using the term "Engineering stress-strain" it is implied that cross section of the specimen during uniaxial tension test remains unchanged.

$$
v \varepsilon_{p l}:=\overrightarrow{\varepsilon p l} \quad \text { vs } t 23:=\overrightarrow{s t 23} \quad \text { vs } t 23(\varepsilon):=\text { linterp } v \varepsilon_{p l}, \text { vs } t 23, \varepsilon
$$

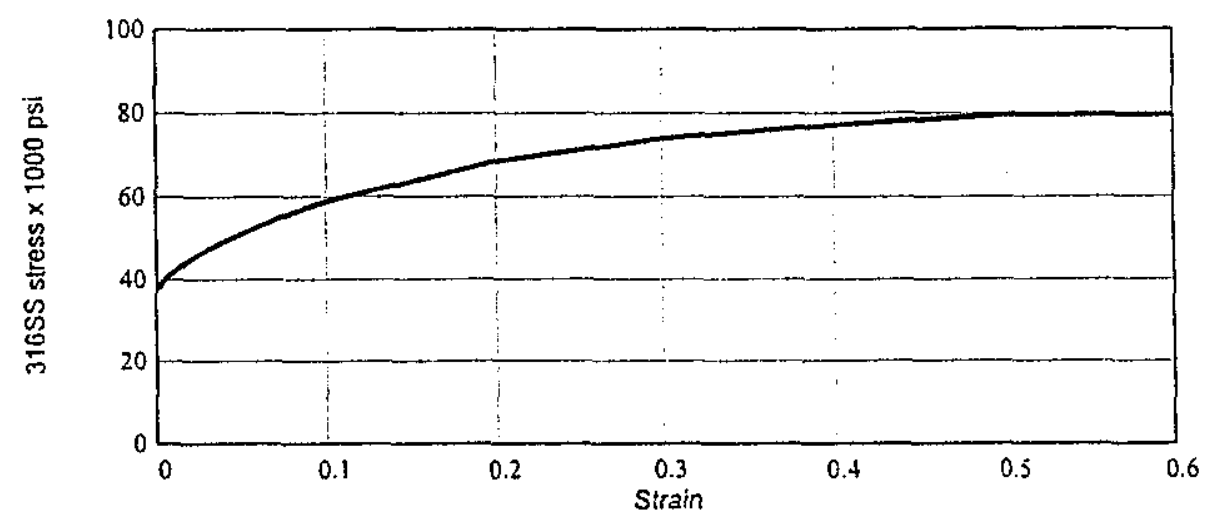

ENGINEERING STRESS-STRAIN CURVE FOR 316 SS STEEL

INELASTIC RANGE 


\section{MATERIAL PROPERTIES FOR ABAQUS/EXPLICIT INPUT}

\section{True stress-strain curve for 316 SS heat T.}

Most materials that exhibit ductile behavior ((large inelastic strains) yield at stress levels that are orders of magnitude less than the elastic modulus of material, which implies that the relevant stress and strain measures are "true" stress (Cauchy stress) and logaritmic strain. Material data for all of these models should, therefore, be given in these measures. The engineering (nominal) stress-strain data from uniaxial test for isotropic material can be simply converted to true stress and logarithmic plastic strain by use of the following formulas:

$\sigma_{\text {true }}=\sigma_{\text {eng }} \cdot\left(1+\varepsilon_{\text {eng }}\right)$ and $\quad \varepsilon_{\mathrm{pl}}=\ln \left(1+\varepsilon_{\text {eng }}\right)-\frac{\sigma \text { true }}{E}$

Thus for 316 SS heat T steel true stress strain relation can be expressed as follows:

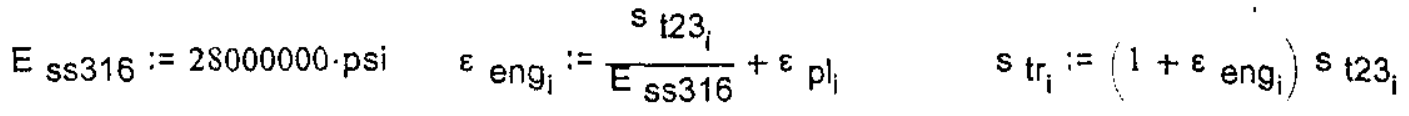

$$
\begin{aligned}
& \varepsilon_{\mathrm{tr}_{i}}:=\ln \left(1+\varepsilon_{\text {eng }}\right)-\frac{s \mathrm{tr}_{\mathrm{i}}}{E_{\mathrm{ss} 316}} \\
& v \varepsilon_{t r}:=\overrightarrow{\varepsilon_{t r}} \quad \text { vs } t r:=\overrightarrow{s t r} \\
& \text { Vs } \operatorname{tr}_{\mathrm{tr}} \varepsilon_{\mathrm{tr}}:=\operatorname{linterp} \mathrm{v} \varepsilon_{\mathrm{tr}}, \mathrm{vs} \mathrm{tr}, \varepsilon_{\mathrm{t} r}
\end{aligned}
$$$$
\varepsilon_{\text {eng }}=\left[\begin{array}{l}
0.001290 \\
0.002336 \\
0.003366 \\
0.004392 \\
0.005415 \\
0.006434 \\
0.007451 \\
0.008466 \\
0.009478 \\
0.019589 \\
0.029677 \\
0.039752 \\
0.049821 \\
0.059882 \\
0.069941 \\
0.079999 \\
0.090052 \\
0.100101 \\
0.200441 \\
0.300638 \\
0.400757 \\
0.500839 \\
0.600839
\end{array}\right] s_{t r}=\left[\begin{array}{l}
36161 \\
37493 \\
38390 \\
39143 \\
39824 \\
40405 \\
40942 \\
41393 \\
41771 \\
45369 \\
48342 \\
51002 \\
53521 \\
55863 \\
58162 \\
60448 \\
62639 \\
64732 \\
82040 \\
96075 \\
108143 \\
119288 \\
127236
\end{array}\right] \varepsilon_{t r}=\left[\begin{array}{c}
-0.000 \\
0.001 \\
0.002 \\
0.003 \\
0.004 \\
0.005 \\
0.006 \\
0.007 \\
0.008 \\
0.018 \\
0.028 \\
0.037 \\
0.047 \\
0.056 \\
0.066 \\
0.075 \\
0.084 \\
0.093 \\
0.180 \\
0.259 \\
0.333 \\
0.402 \\
0.466
\end{array}\right]
$$ 


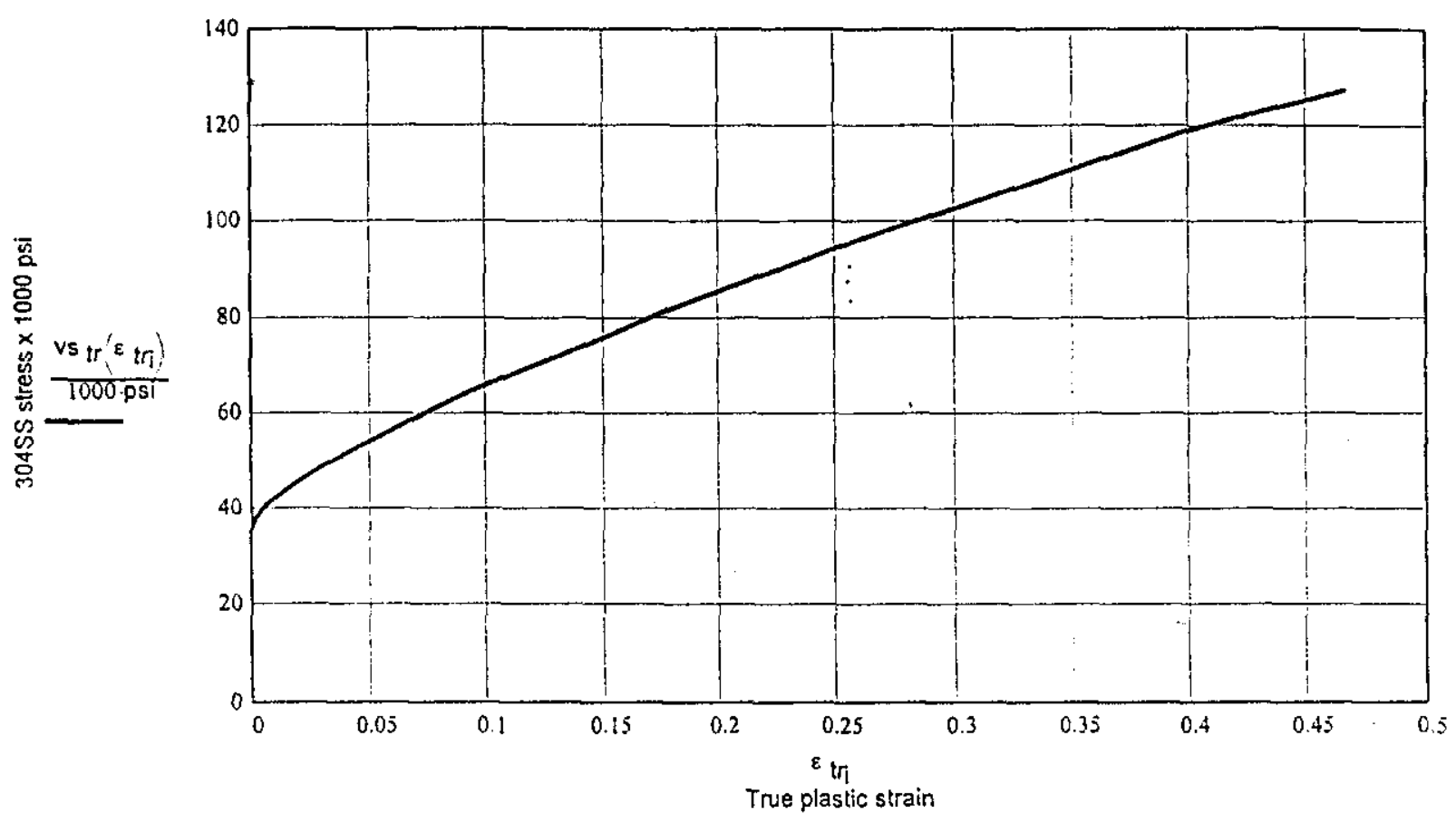

TRUE STRESS-STRAIN CURVE FOR 316 SS STEEL

\section{True stress-strain curve for 304 SS @ specific strain rate.}

From ABAQUS output an estimated strain rate can be computed as follows:

Dependent upon how fast the the strain is applied to the material, the material exhibits varying value of $2 \%$ yield stress. This behavior of Type 304 Stainless Steel is captured in Steinken, 1971. Using actual strain rate from ABAQUCS/EXPLICIT run the material properties are adjusted accordingly.

Time interval for which plastic strain can be approximated as straight line is:

$\Delta t:=\frac{11.3}{19} \cdot 5 \cdot 10^{-3} \cdot \sec -\frac{4}{19} \cdot 5 \cdot 10^{-3} \cdot \sec$

$\Delta t=0.0019 \cdot \mathrm{sec}$

Corresponding plastic strain increase is:

$\Delta \varepsilon_{p l}:=0.1633-0.0475 \quad \Delta \varepsilon_{p l}=0.1158$

$\frac{\Delta \varepsilon p 1}{\Delta t}=60.28 \cdot \mathrm{sec}^{-1}$

The effect of the strain rate on the value of "0.2\% Yield Stress" (Steicken, 1971, Figure 2.) for $304 S S$.

s yss $304:=51820 \cdot$ psi $\quad\left(\frac{4}{22} \cdot 10+50\right) \cdot 1000=51818$ 


\section{MATERIAL PROPERTIES FOR ABAQUS/EXPLICIT INPUT}

The stress-strain curves for 316 SS steel and 304 SS steel are similar. Due to similarity the final plastic strain curve can be estimated by adjusting the $316 \mathrm{SS}$ curve by a difference in the value of the yield stress for $316 S S$ and 304SS @ formerly computed strain rate.

$$
\begin{aligned}
& \Delta s_{y}:=s_{y s s 304}-s_{t_{0}} \quad \Delta s_{y}=15659.02 \circ p s i \quad s:=s_{t 23} \quad s=36114.4 \circ p s i
\end{aligned}
$$

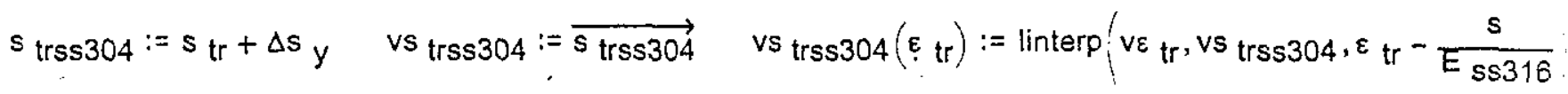

$$
\begin{aligned}
& \varepsilon \text { elss304 }:=\frac{s}{E s s 316} \\
& \varepsilon_{\text {tr }}^{\prime}:=0,0.0001 \ldots 0.5
\end{aligned}
$$

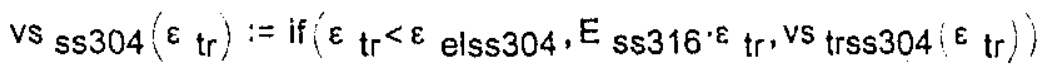

$$
\begin{aligned}
& E_{s s 316 \cdot \varepsilon} \text { elss304 }=36114.4 \text { opsi } \\
& v_{\operatorname{trss} 304}(.00127)=51796.88 \cdot p s i \\
& \mathrm{j}:=0 . .3 \\
& \varepsilon_{\text {in }_{\mathrm{j}}}:=\quad \mathrm{f}_{\text {tin }_{\mathrm{j}}}:=
\end{aligned}
$$

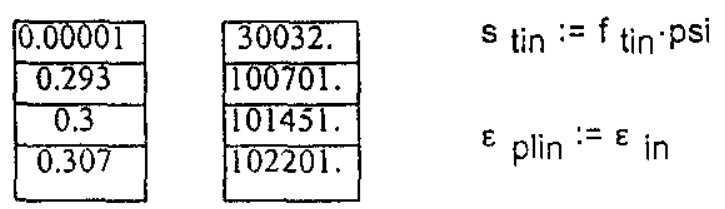

$$
\begin{aligned}
& s_{\text {tin }}=\left[\begin{array}{l}
30032 \\
100701 \\
101451 \\
102201
\end{array}\right] \text { opsi } \quad \varepsilon \text { plin }=\left[\begin{array}{l}
0.000010 \\
0.293000 \\
0.300000 \\
0.307000
\end{array}\right] \\
& v \varepsilon_{\text {plin }}:=\vec{\varepsilon}_{\text {plin }} \quad \text { vs tin }:=\overrightarrow{s \text { tin }}_{\text {tin }_{0}}=30032 \circ p \text { os } \\
& \varepsilon^{\prime} \text { elss304 }:=\frac{s \operatorname{tin}_{0}}{E s s 316} \quad \varepsilon^{\prime} \text { elss304 }=0.001073 \\
& \text { vs tin } \varepsilon_{\text {plin }}:=\text { linterp } v \varepsilon_{\text {plin }}, \text { vs }_{\text {tin }}, \varepsilon_{\text {plin }} \\
& \text { vs tel }\left(\varepsilon_{\text {plin }}\right):=E_{\text {ss316 }}{ }^{\circ} \text { plin } \quad v s_{\text {tin }}(.3)=101451 \text { opsi }
\end{aligned}
$$




$$
\begin{aligned}
& \text { vs orig }(\varepsilon \text { plin }):=\text { if }\left(\varepsilon \text { plin }<\varepsilon^{\prime} \text { eiss304, vs tel }(\varepsilon \text { plin }) \text {,vs tin }(\varepsilon \text { plin })\right) \\
& \varepsilon_{\text {plin }}:=0,0.0001 \ldots 0.466
\end{aligned}
$$

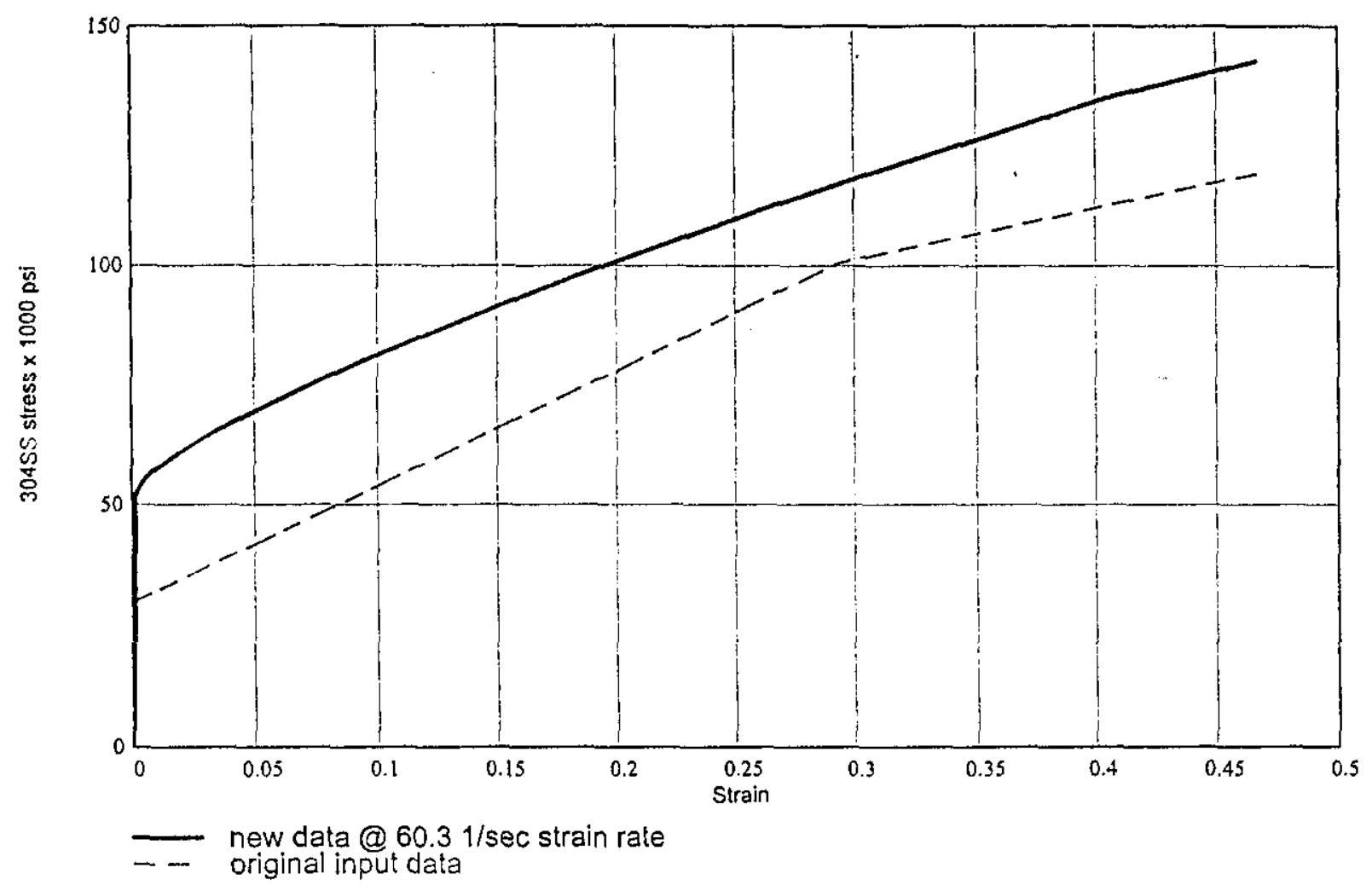

Figure 2sr-0a. TRUE STRESS-STRAIN CURVES FOR 304SS STEEL

\begin{tabular}{|c|c|}
\hline & $v s \operatorname{trss} 304(\varepsilon)$ \\
\hline$\varepsilon$ & $1000 \cdot p s i$ \\
\hline 0 & 50.10 \\
\hline 0.01 & 57.77 \\
\hline 0.02 & 61.31 \\
\hline 0.03 & 64.33 \\
\hline 0.04 & 67.07 \\
\hline 0.05 & 69.68 \\
\hline
\end{tabular}

$\varepsilon:=0,0.01 \ldots 0.05$

\begin{tabular}{|c|c|}
\hline$\varepsilon \mathrm{tr}$ & $\frac{v_{\mathrm{trss}} 304 \varepsilon \mathrm{tr}}{1000 \cdot \mathrm{psi}}$ \\
\hline 0.05 & 69.68 \\
\hline 0.7 & 81.51 \\
\hline 0.15 & 97.50 \\
\hline 0.2 & 107.04 \\
\hline 0.25 & 109.85 \\
\hline 0.3 & 1188.16 \\
\hline 0.35 & 126.33 \\
\hline 0.4 & 134.45 \\
\hline 0.45 & 140.76 \\
\hline 0.5 & 146.95 \\
\hline
\end{tabular}

$\varepsilon_{\mathrm{tr}}:=0.05,0.10 . .0 .5$ 
MATERIAL PROPERTIES FOR ABAQUS/EXPLICIT INPUT

$$
\begin{aligned}
& \varepsilon^{\prime} \operatorname{tr}_{i}:=\ln \left(1+\varepsilon \text { eng }_{i}\right)-\frac{s_{t_{i}}}{E_{s s 316}} \\
& s^{\prime} t_{r}:=s_{t r}+\Delta s_{y} .
\end{aligned}
$$

\begin{tabular}{|c|c|c|c|}
\hline & 51820 & & {$\left[-0.0000^{\circ}\right.$} \\
\hline & 53152 & & 0.0010 \\
\hline & 54049 & & 0.0020 \\
\hline & $54 S 02$ & & 0.0030 \\
\hline & 55483 & & 0.0040 \\
\hline$s^{\prime} t r=$ & 56064 & opsi $\quad \varepsilon^{\prime}{ }_{\mathrm{tr}}=$ & 0.0050 \\
\hline & 56601 & & 0.0060 \\
\hline & 57052 & & 0.0070 \\
\hline & 57430 & & 0.0079 \\
\hline & 61028 & & 0.0178 \\
\hline & 64001 & & 0.0275 \\
\hline & 66661 & & 0.0372 \\
\hline & 69180 & & 0.0467 \\
\hline & 71522 & & 0.0562 \\
\hline & 73821 & & 0.0655 \\
\hline & 76107 & & 0.0748 \\
\hline & 78298 & & 0.0840 \\
\hline & 80391 & & 0.0931 \\
\hline & 97699 & & 0.1798 \\
\hline & 111734 & & 0.2594 \\
\hline & 123803 & & 0.3332 \\
\hline & 134947 & & 0.4018 \\
\hline & 142895 & & 0.4660 \\
\hline
\end{tabular}




\section{MATERIAL PROPERTIES FOR ABAQUS/EXPLICIT INPUT}

Engineering stress-strain curve for SA36.

$j:=0 . .3$

$\varepsilon_{c s_{j}}:=\quad f_{c s t 23_{j}} \vdots=$

$E_{\operatorname{cs} 36}:=29500000 \cdot p s i$

\begin{tabular}{|l|}
\hline .00 \\
\hline .02 \\
\hline .095 \\
\hline .161 \\
\hline
\end{tabular}

36044

37786

55085

64728

$s_{\operatorname{cst} 23}:=f_{\operatorname{cst} 23} \cdot \mathrm{psi}$

$\varepsilon_{\mathrm{cspl}}:=\varepsilon_{\mathrm{cs}}$

$\varepsilon \dot{e l c s 36}:=\frac{s \operatorname{cst} 23_{0}}{E \operatorname{cs} 36}$

$\varepsilon_{\text {elcs } 36}=0.00122183$

$\varepsilon_{\mathrm{cspl}}=\left[\begin{array}{l}0.000000 \\ 0.020000 \\ 0.095000 \\ 0.161000\end{array}\right]$

$s_{\text {cst23 }}=\left[\begin{array}{l}36044 \\ 37786 \\ 55085 \\ 64728\end{array}\right] \cdot p s i$

$v \varepsilon_{\operatorname{cspl}}:=\overrightarrow{\varepsilon_{\operatorname{cspl}}}$ vs $\operatorname{cst23}:=\overrightarrow{\operatorname{sest}_{\cos }}$ vs $\operatorname{cst} 23(\varepsilon):=$ linterp $v \varepsilon_{\operatorname{cspl}}, v_{\operatorname{cst} 23}, \varepsilon \varepsilon:=0,0.0001 .0 .161$

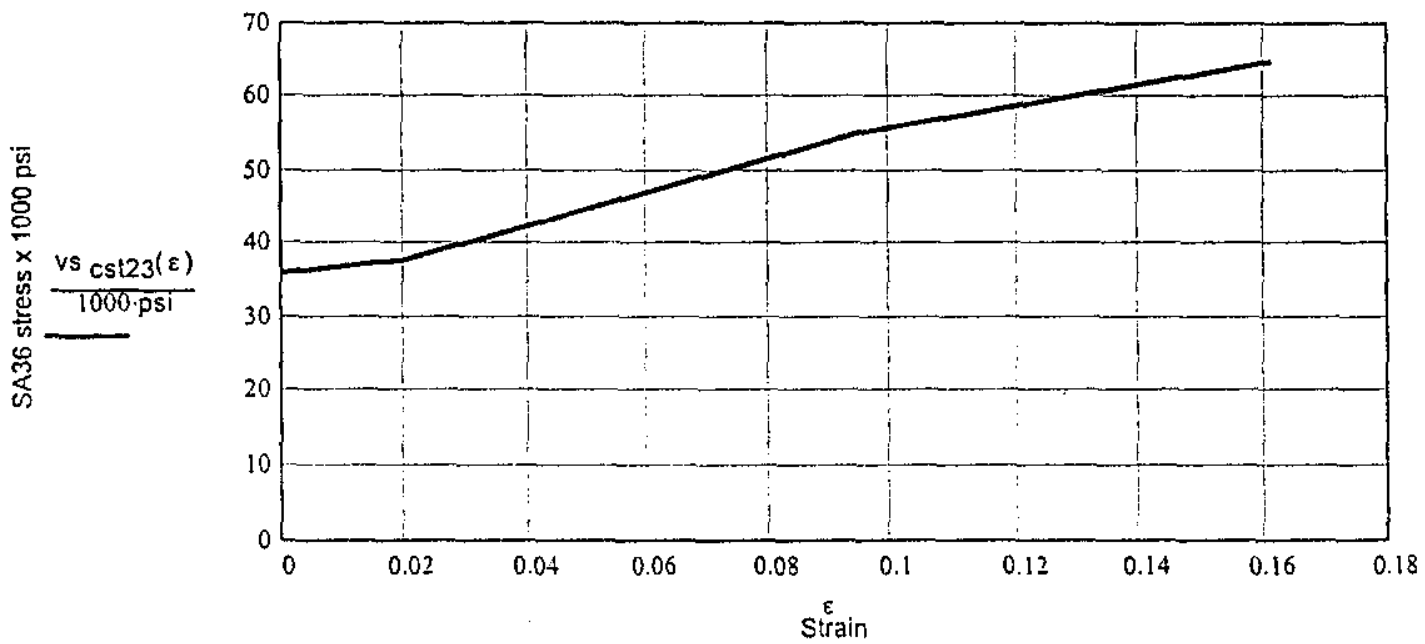

ENGINEERING STRESS-STRAIN CURVE FOR SA36 CS STEEL 
MATERIAL PROPERTIES FOR ABAQUS/EXPLICIT INPUT

True stress-strain curve for SA36 CS.

$$
\begin{aligned}
& E_{\operatorname{cs} 36}=295000000_{s} \text { si } \quad \varepsilon_{\operatorname{cseng}_{j}}:=\frac{s_{\operatorname{cst} 23_{j}}}{E_{\operatorname{cs} 36}}+\varepsilon_{p_{j}} \quad s_{\operatorname{cstr}}:=\left(1+\varepsilon_{\text {cseng }}\right) s_{\operatorname{cst} 23_{j}} \\
& \varepsilon_{\operatorname{cstr}_{j}}:=\ln \left(1+\varepsilon_{\text {cseng }_{j}}\right)-\frac{s_{\operatorname{cstr}}}{E_{\operatorname{cs} 36}} \quad \frac{s \operatorname{cstr}_{0}}{E_{\operatorname{cs} 36}} \cdot 10^{-3}=0.000001 \\
& v \varepsilon_{\text {cstr }}:=\overrightarrow{\left(\varepsilon_{\text {cstr }}\right)} \quad \text { vs } \operatorname{cstr}:=\overrightarrow{\mathrm{s} \text { cstr }} \\
& \text { vs } \operatorname{cstr}(\varepsilon):=\operatorname{linterp}\left(v \varepsilon_{\text {cstr }}, v_{\text {cstr }}, \varepsilon\right. \\
& \varepsilon_{\text {cseng }}=\left[\begin{array}{l}
0.001222 \\
0.002281 \\
0.003867 \\
0.005194
\end{array}\right] \\
& s_{\text {cstr }}=\left[\begin{array}{l}
36088 \\
37872 \\
55298 \\
65064
\end{array}\right] \cdot p s i \quad \varepsilon \text { cstr }=\left[\begin{array}{c}
-0.000002 \\
0.000994 \\
0.001985 \\
0.002975
\end{array}\right] \\
& \varepsilon:=0,0.0001 . .0 .161
\end{aligned}
$$

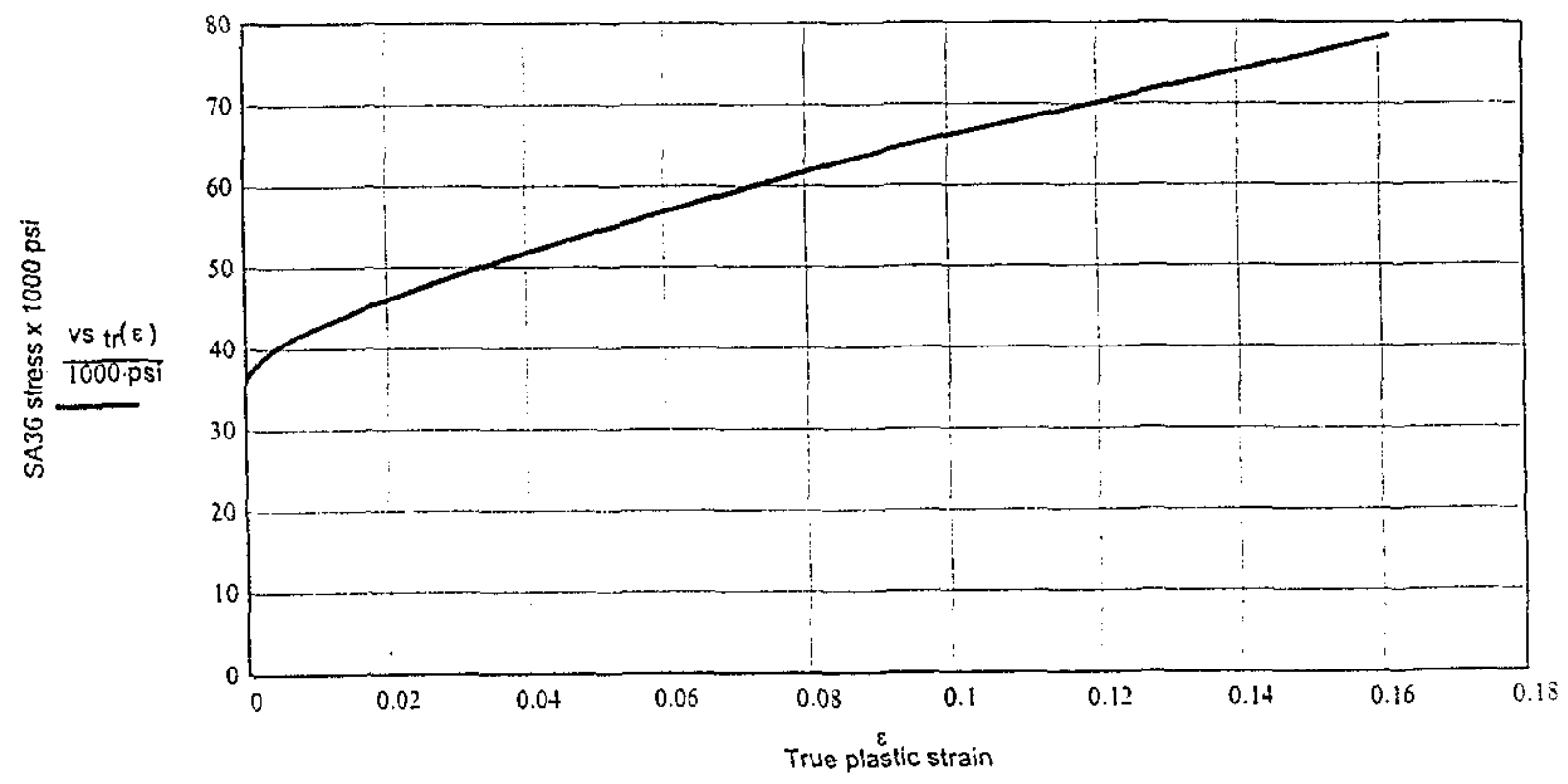

TRUE STRESS-STRAIN CURVE FOR SA36 CS STEEL. 


\section{MATERIAL PROPERTIES FOR ABAQUS/EXPLICIT INPUT}

\section{True stress-strain curve for SA36 @ specific strain rate.}

From ABAQUS output.an estimated strain rate can be computed as follows:

Time interval for which plastic strain can be approximated as straight line is:
$\Delta t:=\frac{11.3}{19} \cdot 5 \cdot 10^{-3} \cdot \sec -\frac{4}{19} \cdot 5 \cdot 10^{-3} \cdot \sec$
$\Delta \mathrm{t}=0.0019 \cdot \mathrm{sec}$

Corresponding plastic strain increase is:

$$
\begin{aligned}
& \Delta \varepsilon_{\mathrm{pl}}:=0.1633-0.0475 \quad \Delta \varepsilon_{\mathrm{pl}}=0.1158 \\
& \frac{\Delta \varepsilon \mathrm{pl}}{\Delta \mathrm{t}}=60.28 \cdot \mathrm{sec}^{-1}
\end{aligned}
$$

The effect of the strain rate on the value of $0.2 \%$ Yield Stress (Figure 2. ref......) for SA36.

$$
s_{\text {ysa36 }}:=57820 \cdot \mathrm{psi} \quad\left(\frac{17.2}{22} \cdot 10+50\right) \cdot 1000=57818
$$

The stress-strain curves for SA36 steel and 304 SS steel are similar. Due to similarity the final plastic strain curve can be estimated by adjusting the 316SS curve by a difference in the value of the yield stress for 316SS and 304SS@ formerly computed strain rate.

$$
\begin{aligned}
& \Delta s_{y}:=s_{y s a 36}-s_{t r} \quad \Delta s_{y}=21659.02 \circ p s i
\end{aligned}
$$

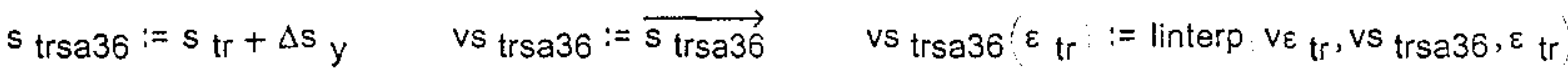

$$
\begin{aligned}
& \Delta s_{y}=21659.02 \text { opsi } \quad s:=s t_{2} 3_{0} \quad s=36 i 14.4 \text { opsi }
\end{aligned}
$$

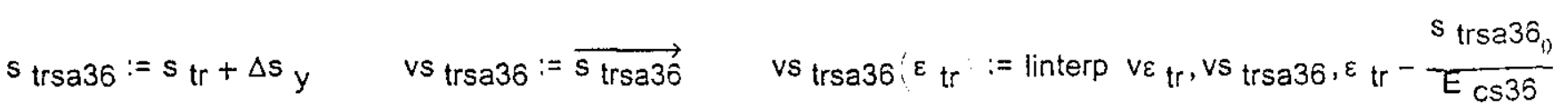

$$
\begin{aligned}
& \varepsilon_{\text {elcs } 36}:=\frac{s \operatorname{trsa} 36_{0}}{E \operatorname{cs} 36} \\
& \varepsilon_{\mathrm{tr}}:=0,0.0001 \ldots 0.5
\end{aligned}
$$

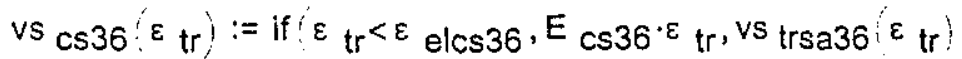

$$
\begin{aligned}
& E_{\operatorname{cs} 36^{\circ} \cdot \varepsilon_{\text {elcs } 36}=57820 \circ \mathrm{psi}} \varepsilon_{\text {elcs } 36}=0.00196 \\
& \text { vs } \operatorname{cs} 36(0.00122183)=36043.99 \circ p s i
\end{aligned}
$$

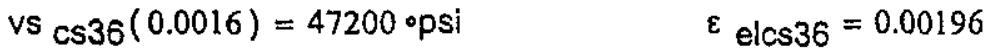




\section{MATERIAL PROPERTIES FOR ABAQUS/EXPLICIT INPUT}

$$
\begin{aligned}
& \varepsilon^{\prime} \text { elcs } 36:=\frac{s \mathrm{t} 23_{0}}{E \operatorname{cs} 36}, \quad \varepsilon^{\prime} \text { elcs } 36=0.00122422 \\
& v^{\prime} \mathrm{t} 23(\varepsilon):=\mathrm{if}\left(\varepsilon<\varepsilon^{\prime} \text { elcs } 36, E \operatorname{cs} 36^{\circ} \varepsilon, v_{\mathrm{t}} \mathrm{t} 23(\varepsilon)\right) \\
& \varepsilon_{\text {plin }}:=0,0.00001 . .0 .16
\end{aligned}
$$

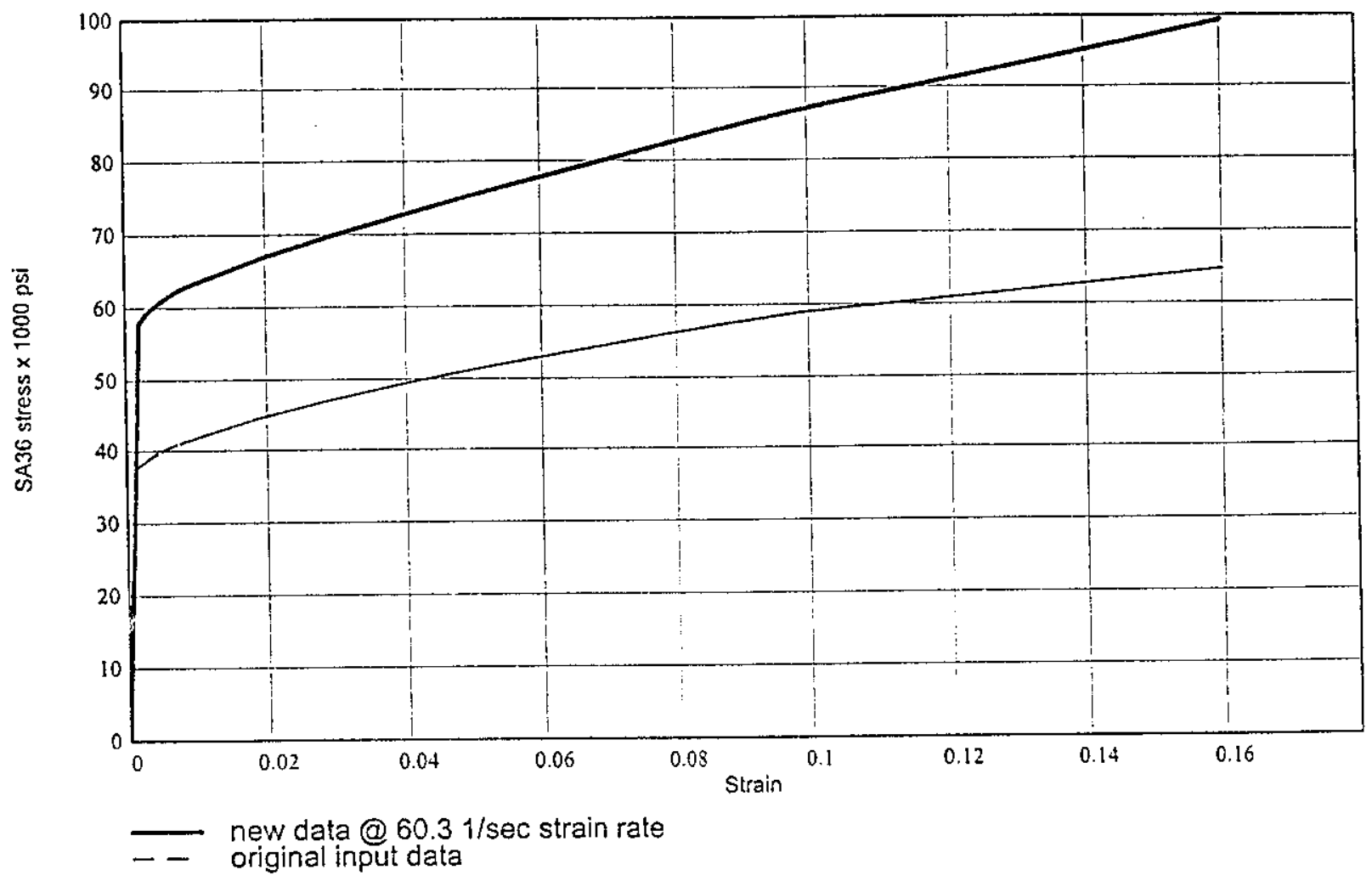

Figure 2sr-0b. TRUE STRESS-STRAIN CURVES FOR SA36 STEEL 


\section{MATERIAL PROPERTIES FOR ABAQUS/EXPLICIT INPUT}

\begin{tabular}{|c|c|}
\hline & vs trsa36(E) \\
\hline$\varepsilon$ & $1000 \cdot \mathrm{psi} \cdot$ \\
\hline 0 & 55.2 \\
\hline 0.01 & 63.5 \\
\hline 0.02 & 67.1 \\
\hline 0.03 & 70.1 \\
\hline 0.04 & 72.9 \\
\hline 0.05 & 75.5 \\
\hline 0.06 & 78.0 \\
\hline 0.07 & 80.4 \\
\hline 0.08 & 82.9 \\
\hline 0.09 & 85.2 \\
\hline 0.1 & 87.4 \\
\hline 0.11 & 89.4 \\
\hline 0.12 & 91.4 \\
\hline 0.13 & 93.4 \\
\hline 0.14 & 95.4 \\
\hline 0.15 & 97.4 \\
\hline 0.16 & 99.4 \\
\hline
\end{tabular}

$$
\varepsilon^{\prime} \operatorname{tr}_{j}:=\ln \left(1+\varepsilon \text { eng }_{j}\right)-\frac{s^{\operatorname{tr}}}{E \operatorname{cs} 36} \quad s^{\prime} t r:=s_{t r}+\Delta s_{y}
$$

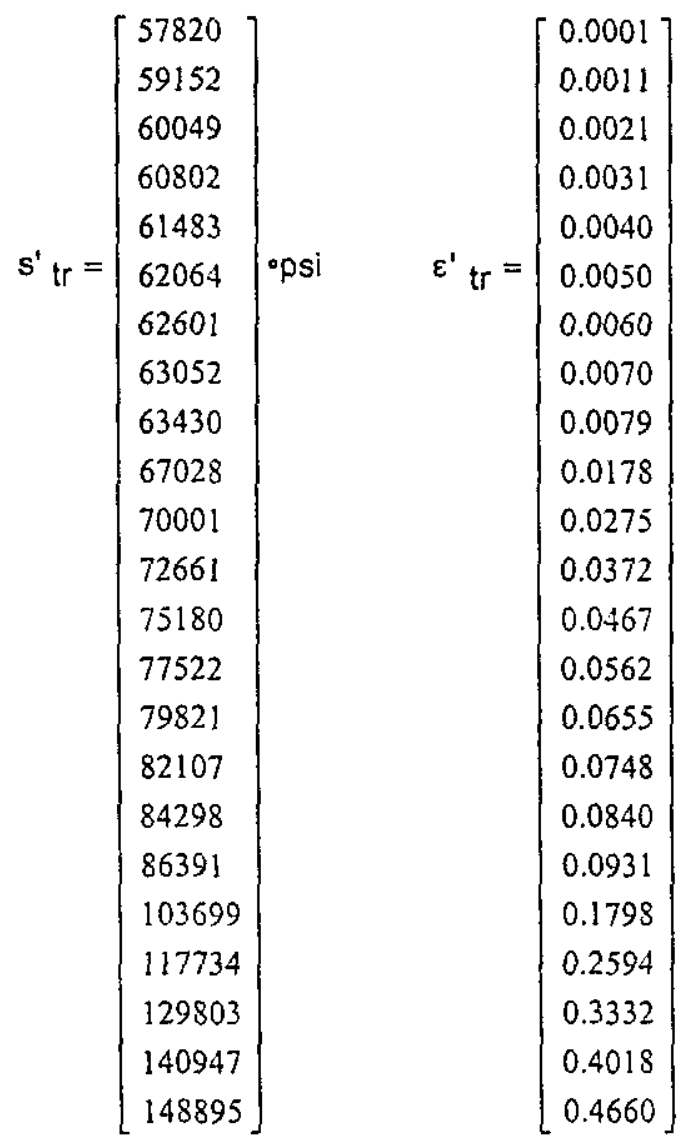

REFERENCES:

Blackburn, L.D., Granslade, D.L. Mechanical Properties of Type 316 Stainless Steel Materials After Irradiation at $515^{\circ} \mathrm{C}$ and $585^{\circ} \mathrm{C}$. HEDL-TME 81-4, April 1981. Hanford Engineering Development Laboratory, Richland, WA.

Steicken, J.M., High Strain Rate Mechanical Properties of Type 304 Stainless Steel and Nickel 200 (RM-14). HEDL-TME 71-145, September 1971. Hanford Engineering Development Laboratory, Richland, WA. 


\section{APPENDIX B}

\section{STRESS, STRAIN, and TRIAXIALITY FACTOR PLOTS}

originator: K.C.Tu beofur Date:1/24/2000 Checked by:M.B. LAsotA 35 Date:1/24/2000 


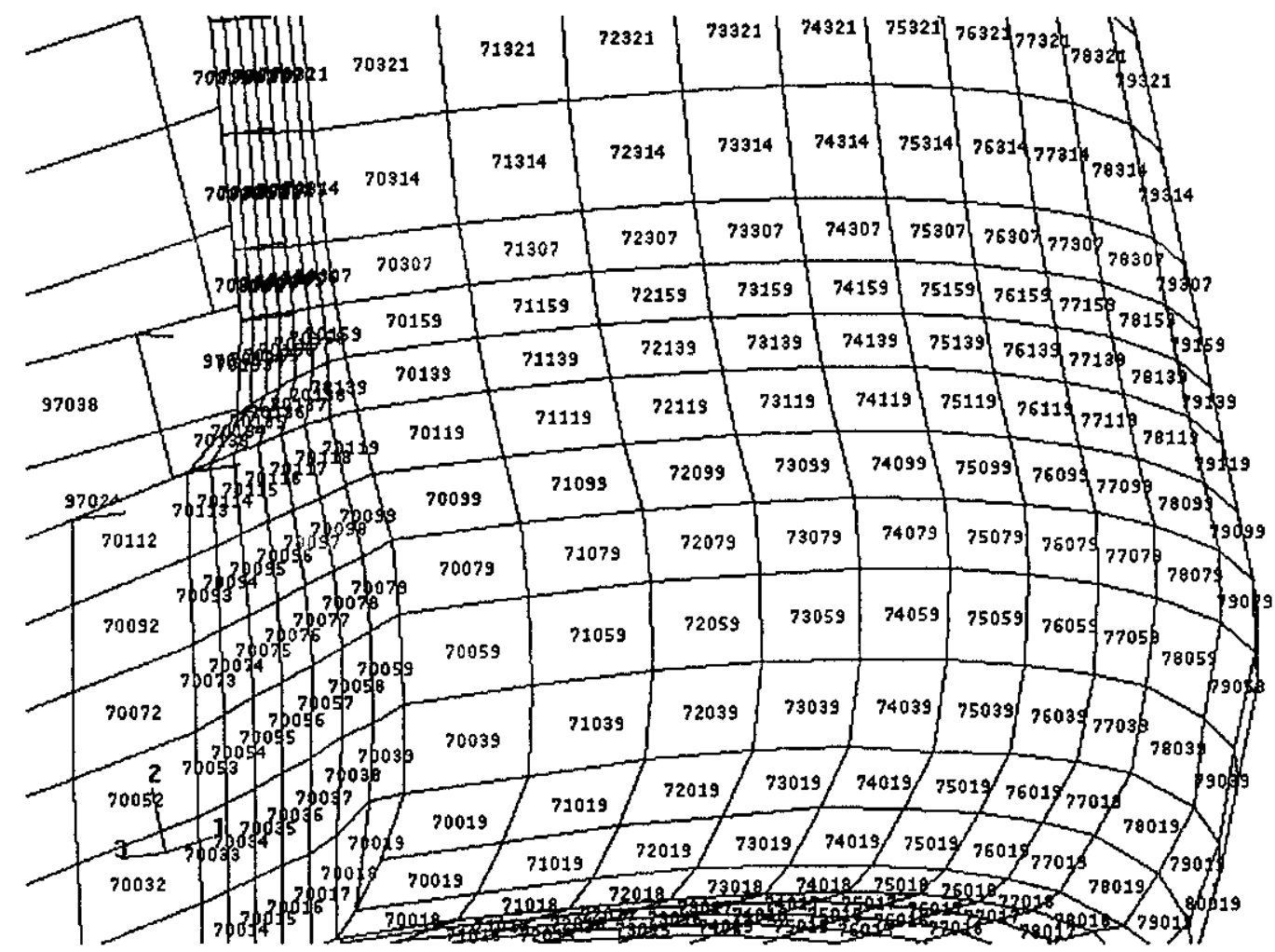

Figure B.1. MCO Bottom Region - Location of Solid Elements 


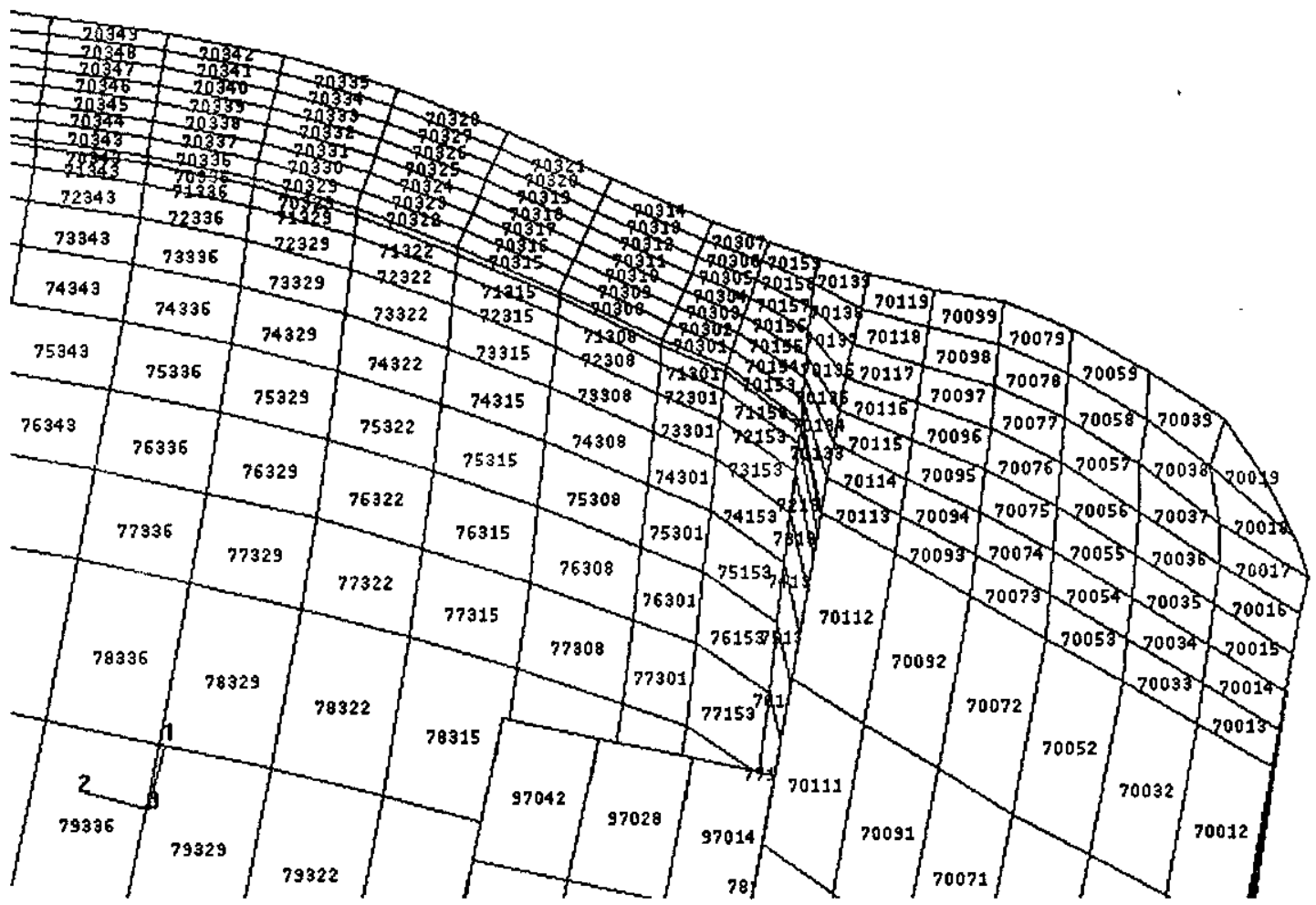

Figure B.2. MCO Weld and Shell Region - Location of Solid Elements 


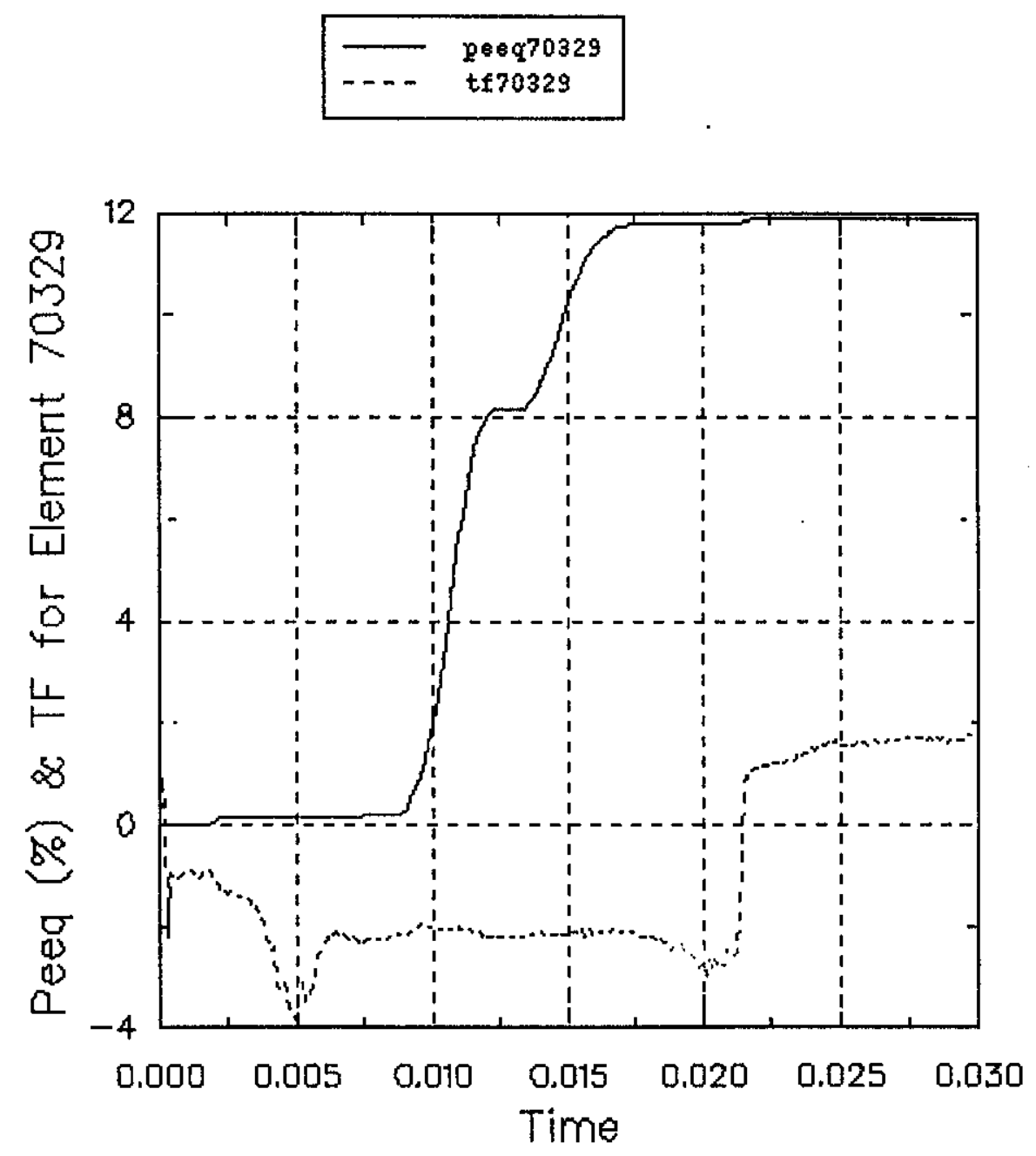

Figure B.3. Equivalent Plastic Strain and Triaxiality Factor At Element 70329 With Respect To Time (Seconds). 


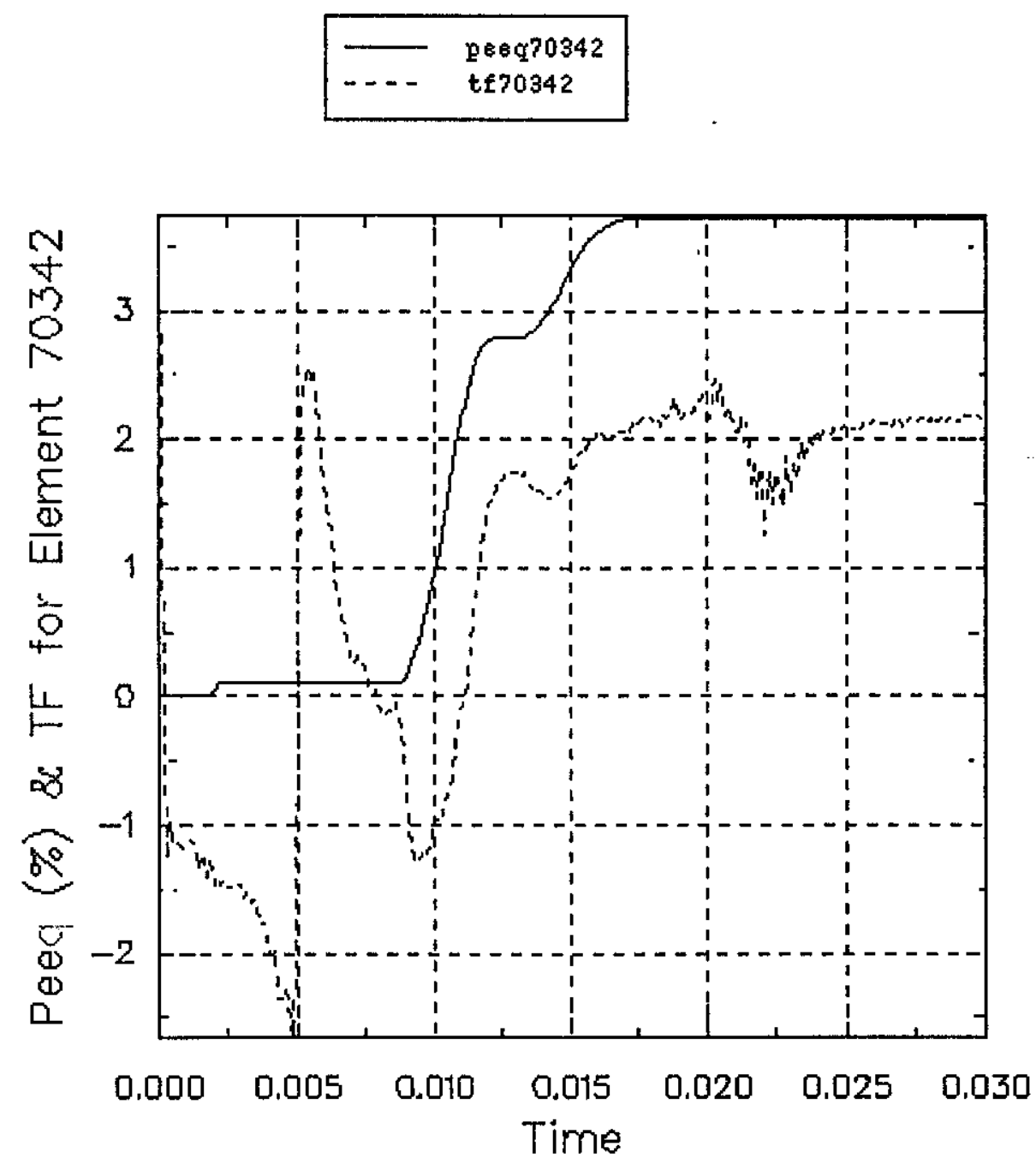

Figure B.4. Equivalent Plastic Strain and Triaxiality Factor At Element 70342 With Respect To Time (Seconds). 


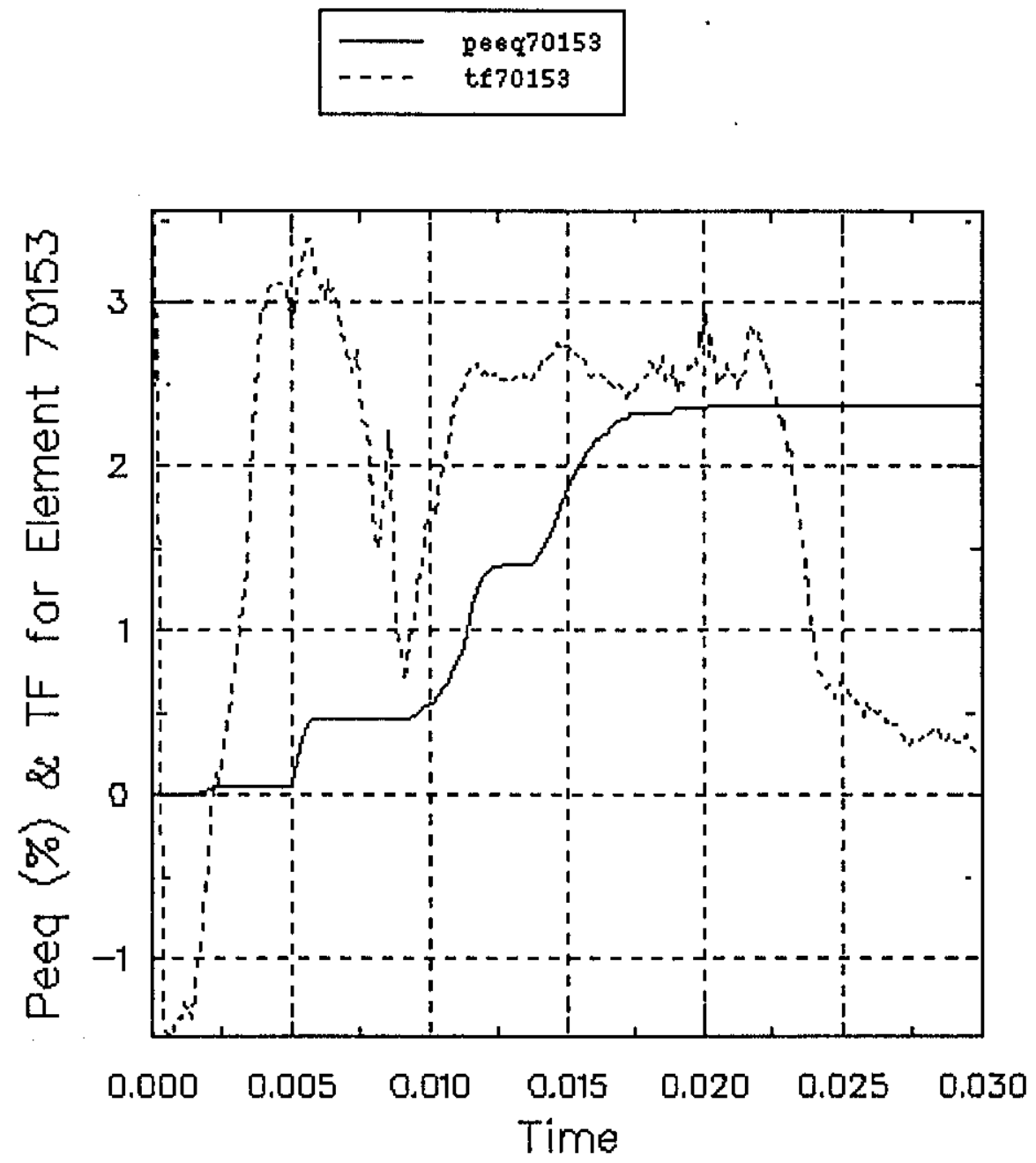

Figure B.5. Equivalent Plastic Strain and Triaxiality Factor At Element 70153 With Respect To Time (Seconds). 

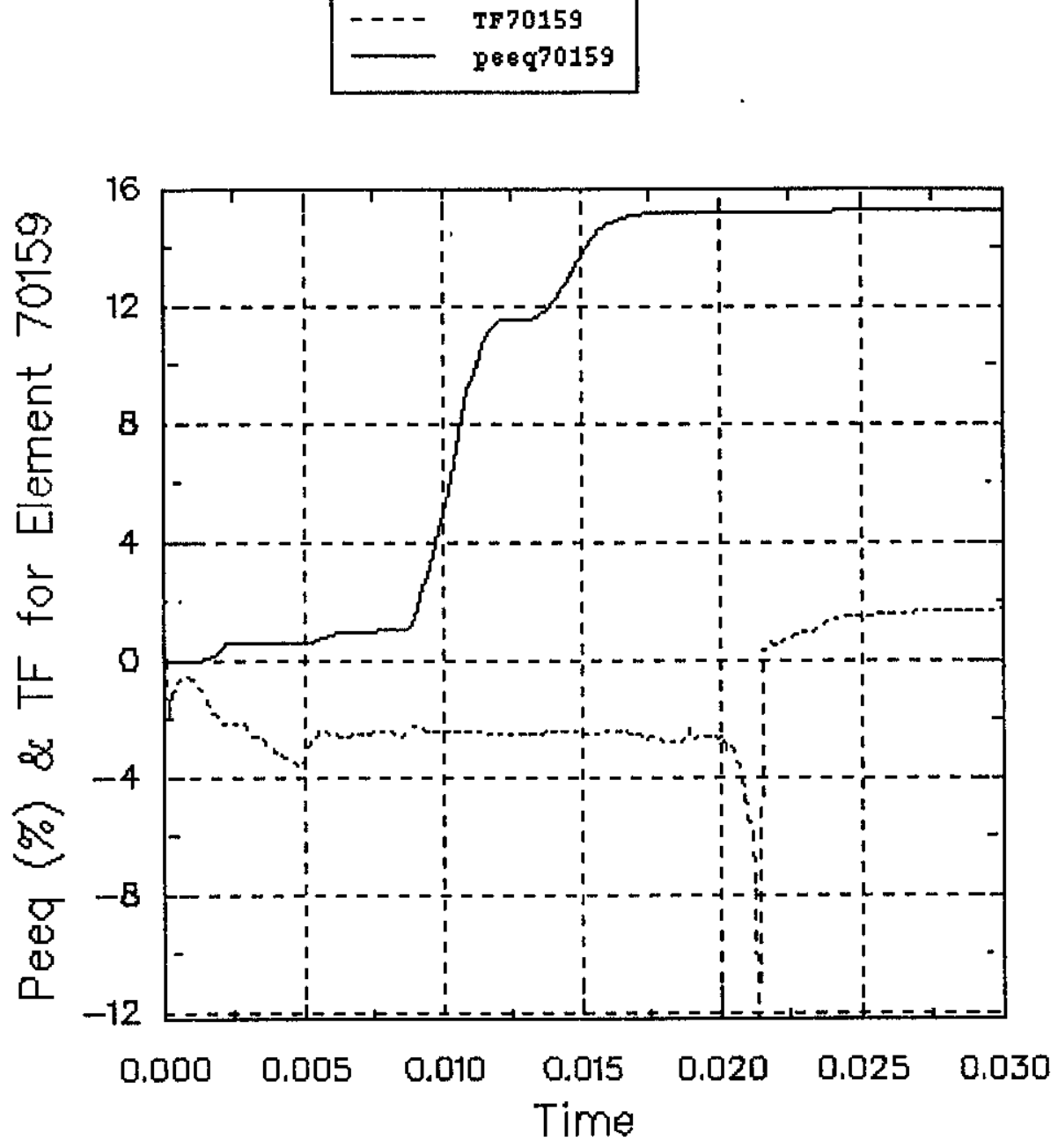

Figure B.6. Weld Outside Face - Equivalent Plastic Strain and Triaxiality Factor At Element 70159 With Respect To Time (Seconds). 


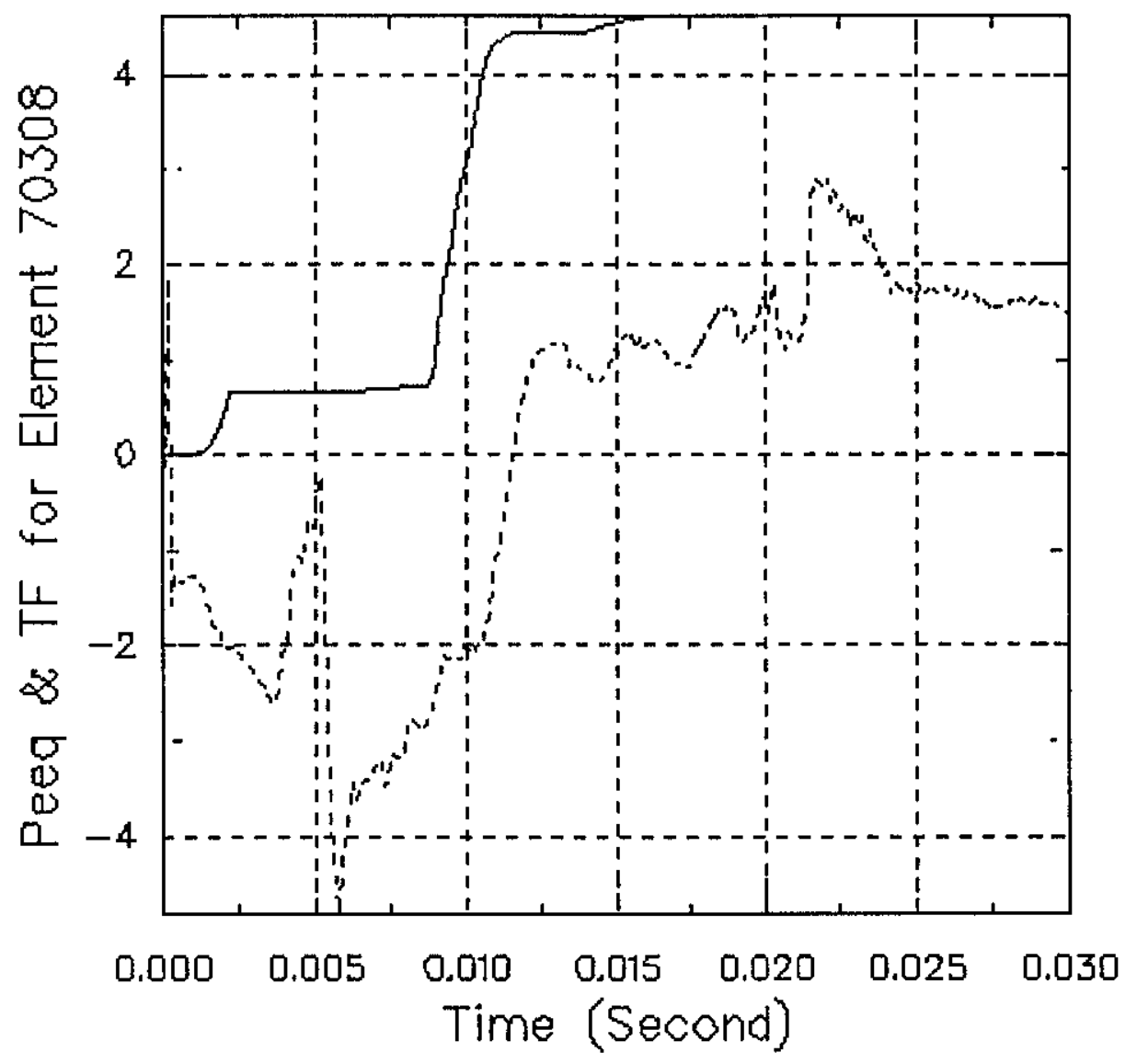

Figure B.7. Weld Inside Face - Equivalent Plastic Strain and Triaxiality Factor At Element 70308 With Respect To Time (Seconds). 


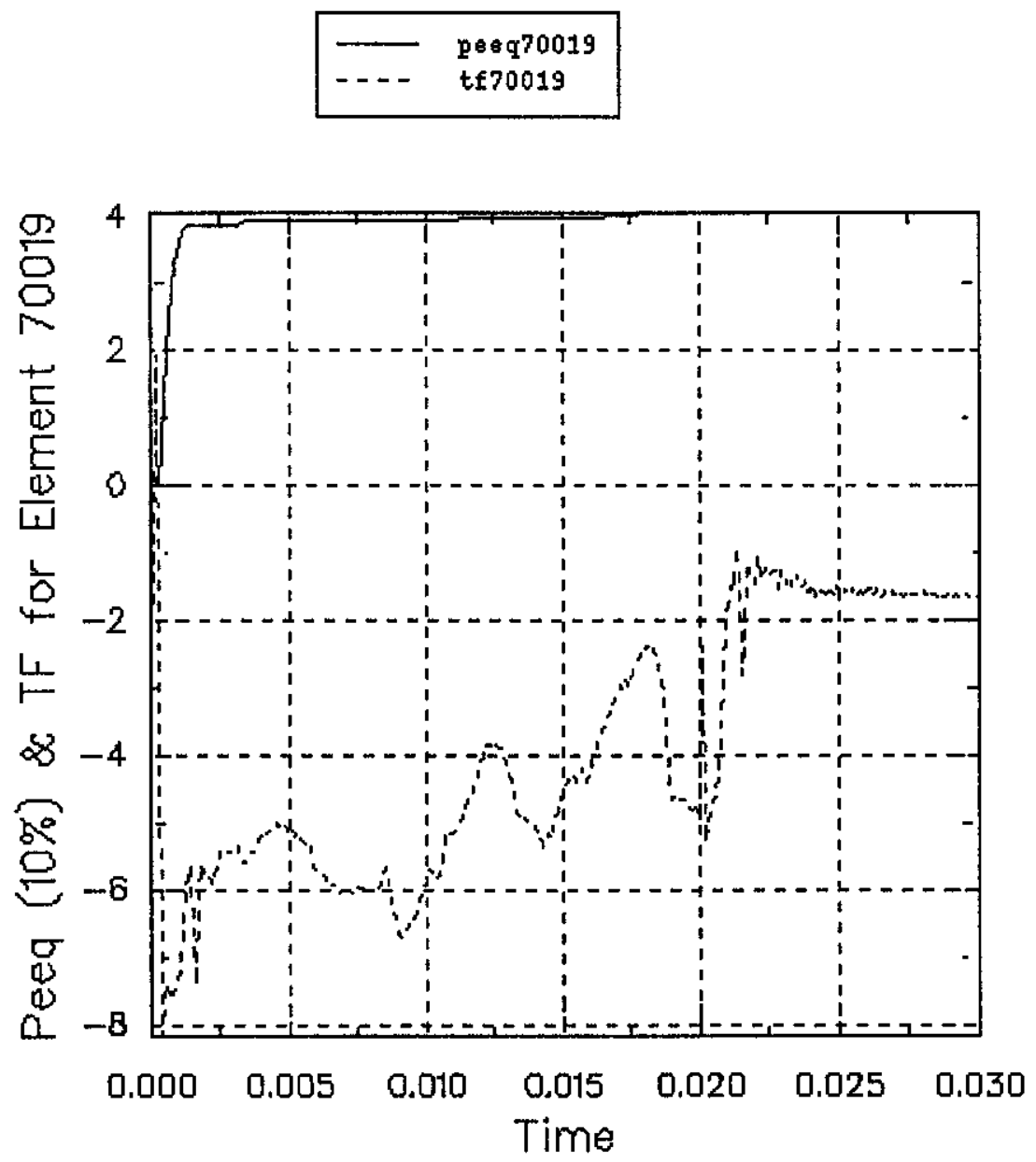

Figure B.8. Equivalent Plastic Strain (Scaled To 10\%) And Triaxiality Factor At Element 70019 With Respect To Time (Seconds). 


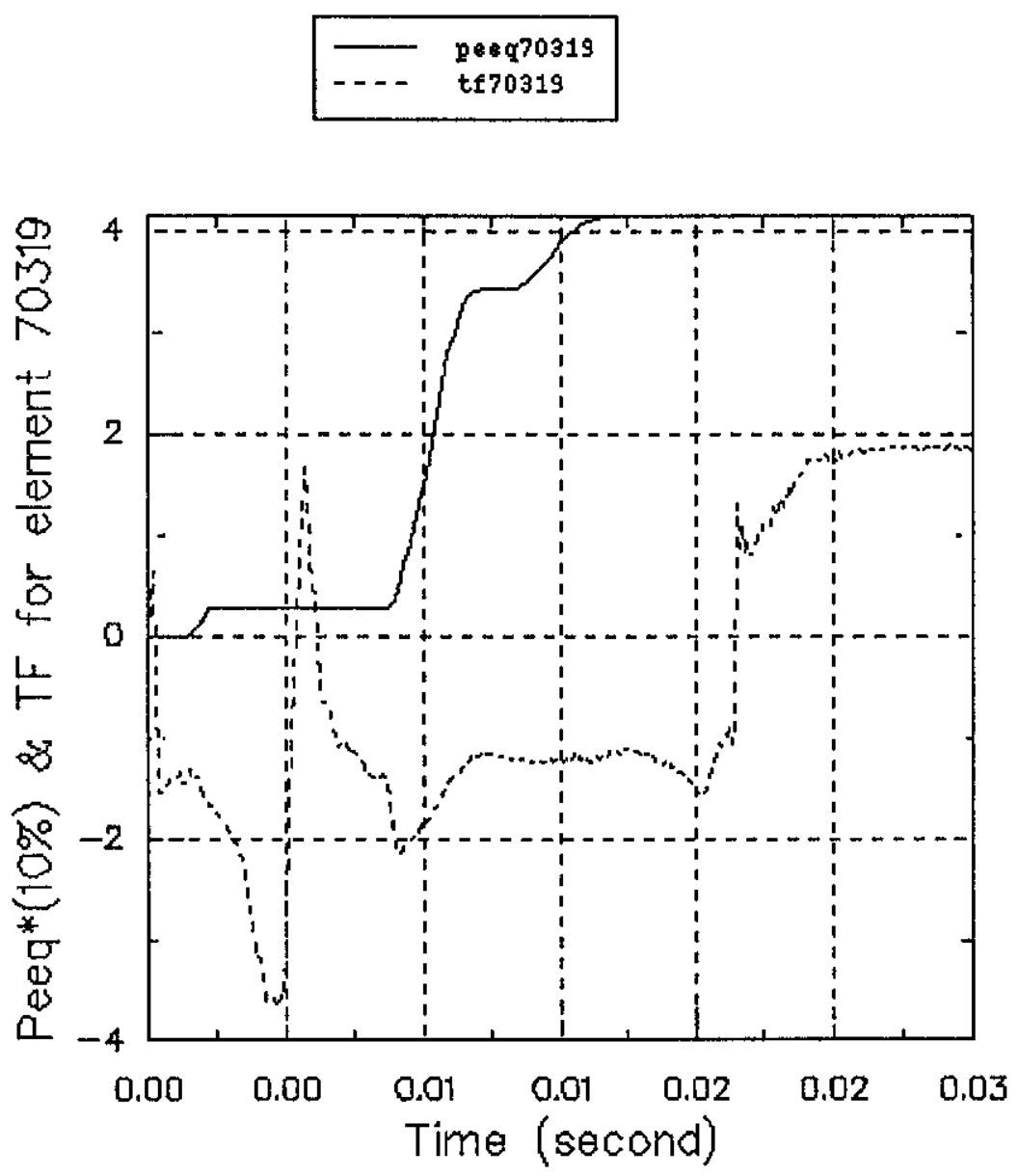

Figure B.9. Equivalent Plastic Strain (Scaled To 10\%) And Trlaxiality Factor At Element 70319 With Respect To Time (Seconds). 


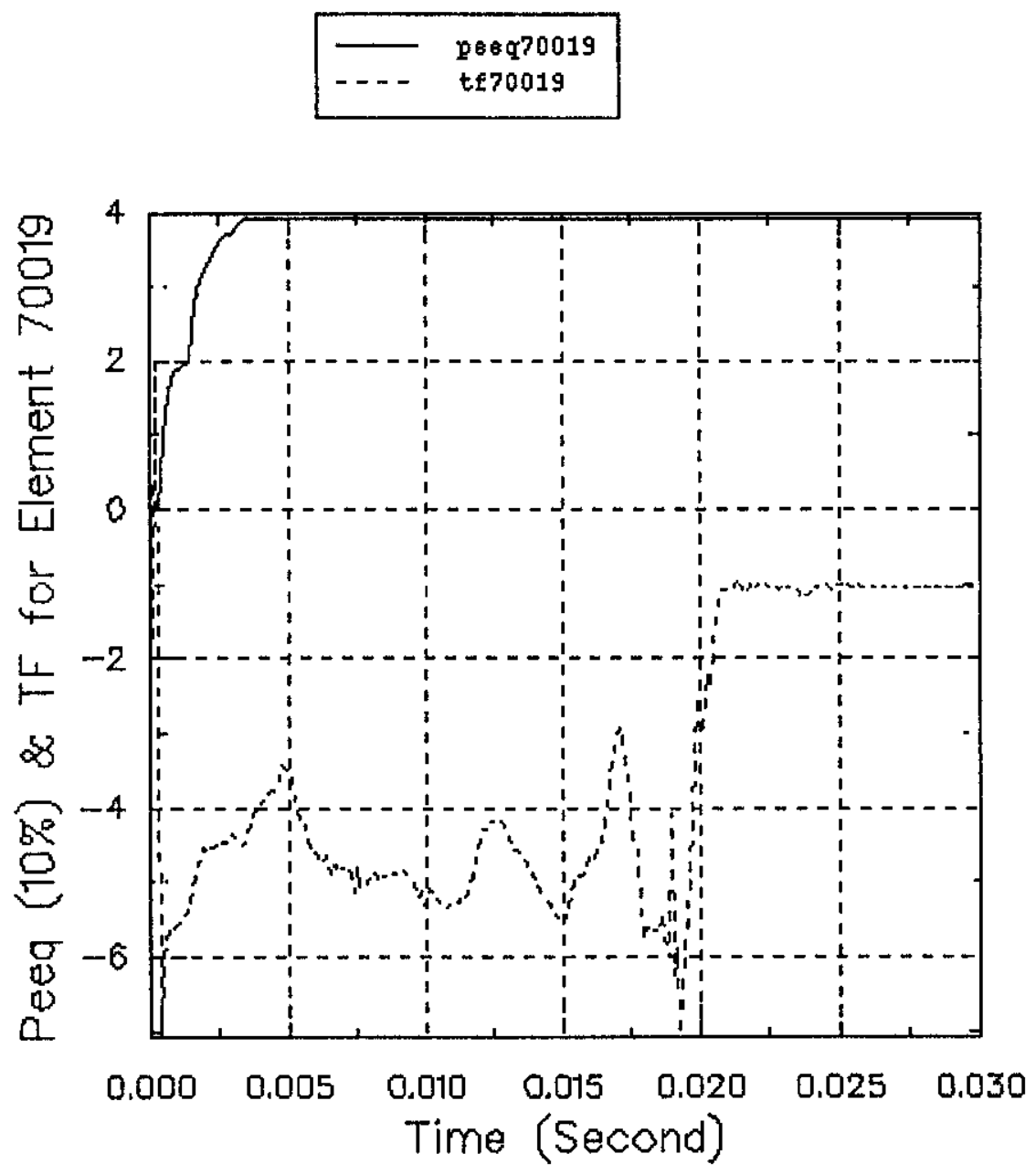

Figure B.10. Equivalent Plastic Strain (Scaled To 10\%) And Triaxiality Factor At Element 70019 With Respect To Time (Seconds),

For High Strain Rate Run. 


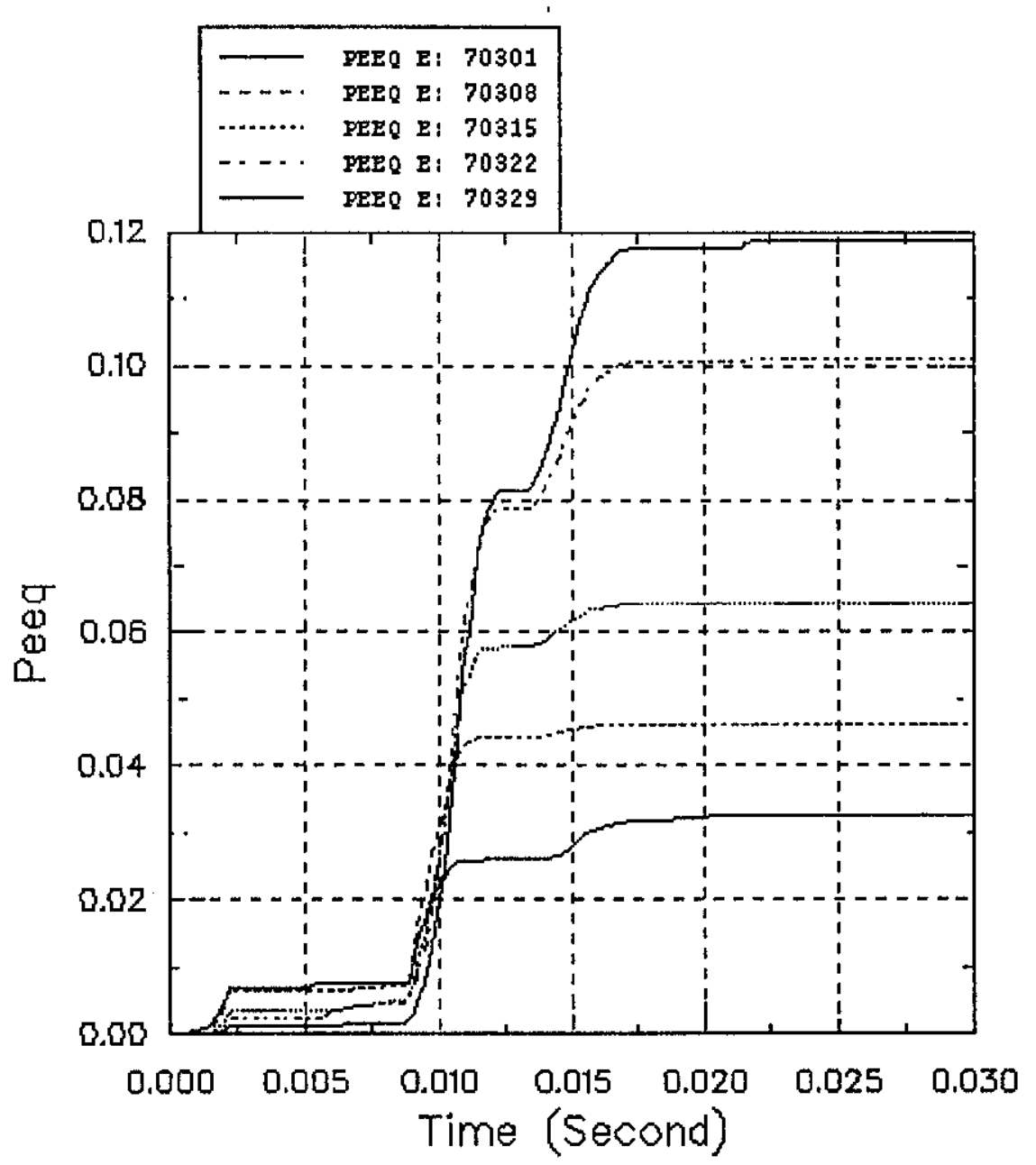

Figure B.11. Weld Region - Equivalent Plastic Strain At Five Inside Face Elements With Respect To Time (Seconds). 


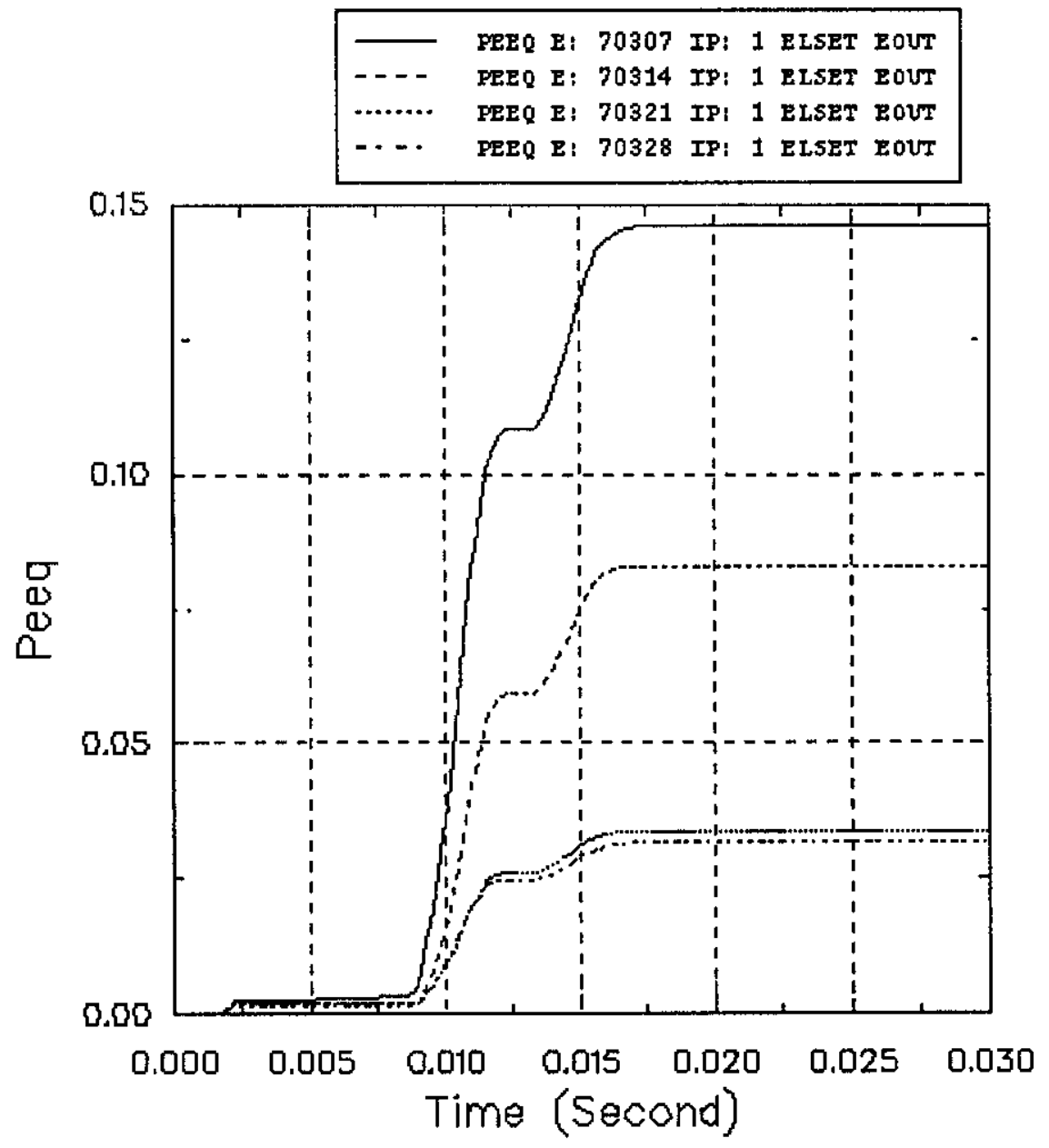

Figure B.12. Weld Region - Equivalent Plastic Strain At Four Outside Face Elements With Respect To Time (Seconds). 


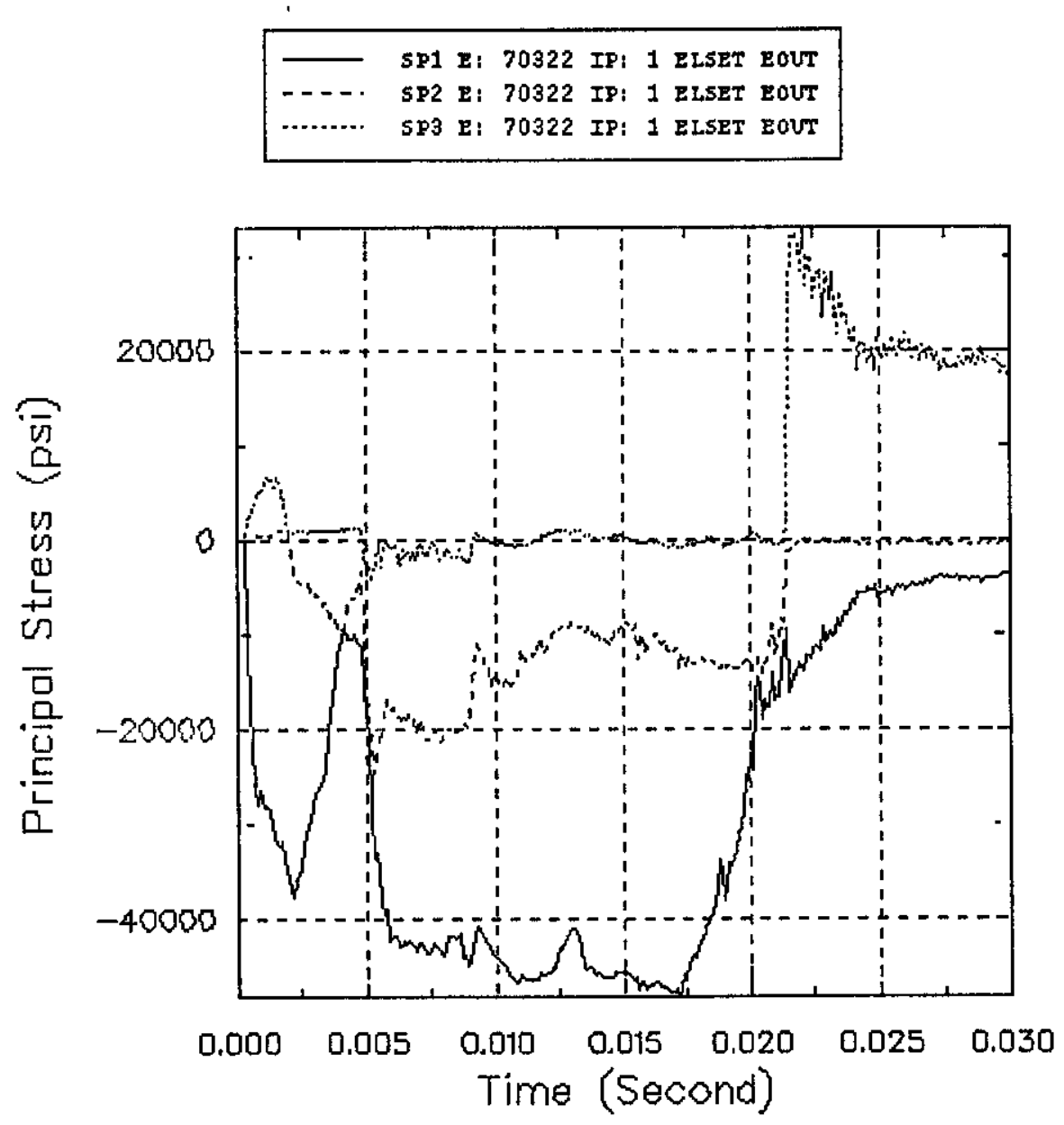

Figure B.13. Set Of Principal Stresses at Element 70322 With Respect To Time (Seconds). 
DP1 E: 70315 (minimum)

--.. SP2 EI 70315 (intermediate)

S........ SP E: 70315 (maximum)

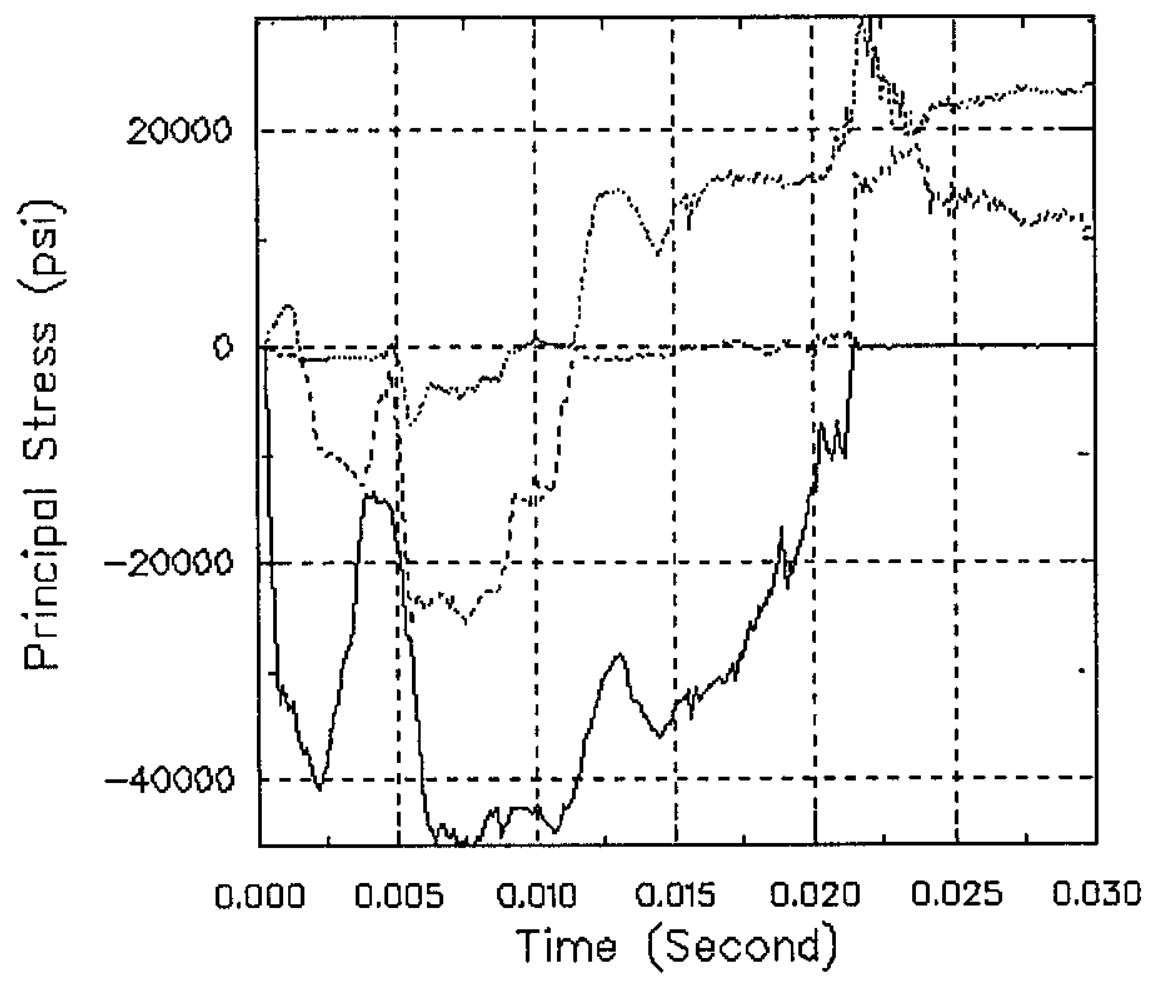

Figure B.14. Set Of Principal Stresses at Element 70315 With Respect To Time (Seconds). 


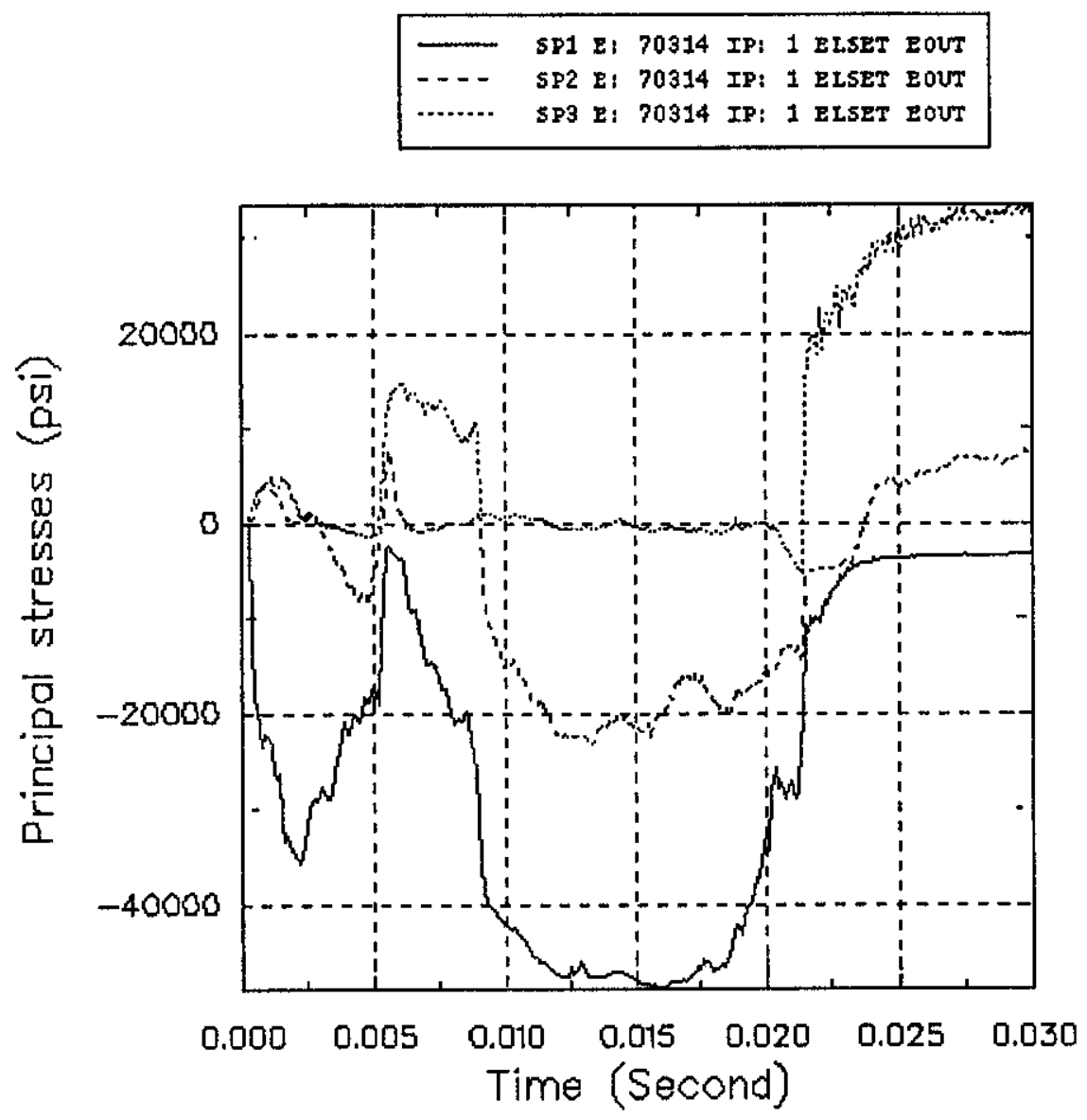

Figure B.15. Set Of Principal Stresses at Element 70314 With Respect To Time (Seconds). 


$\begin{array}{llll}- & \text { SP1 I: } & 70308 \text { (minimum) } \\ -\ldots . & \text { SP2 E: } 70308 \text { IP (inte Imediate) } \\ \cdots \cdots & \text { SP3 E: } 70308 \text { (max imum) }\end{array}$

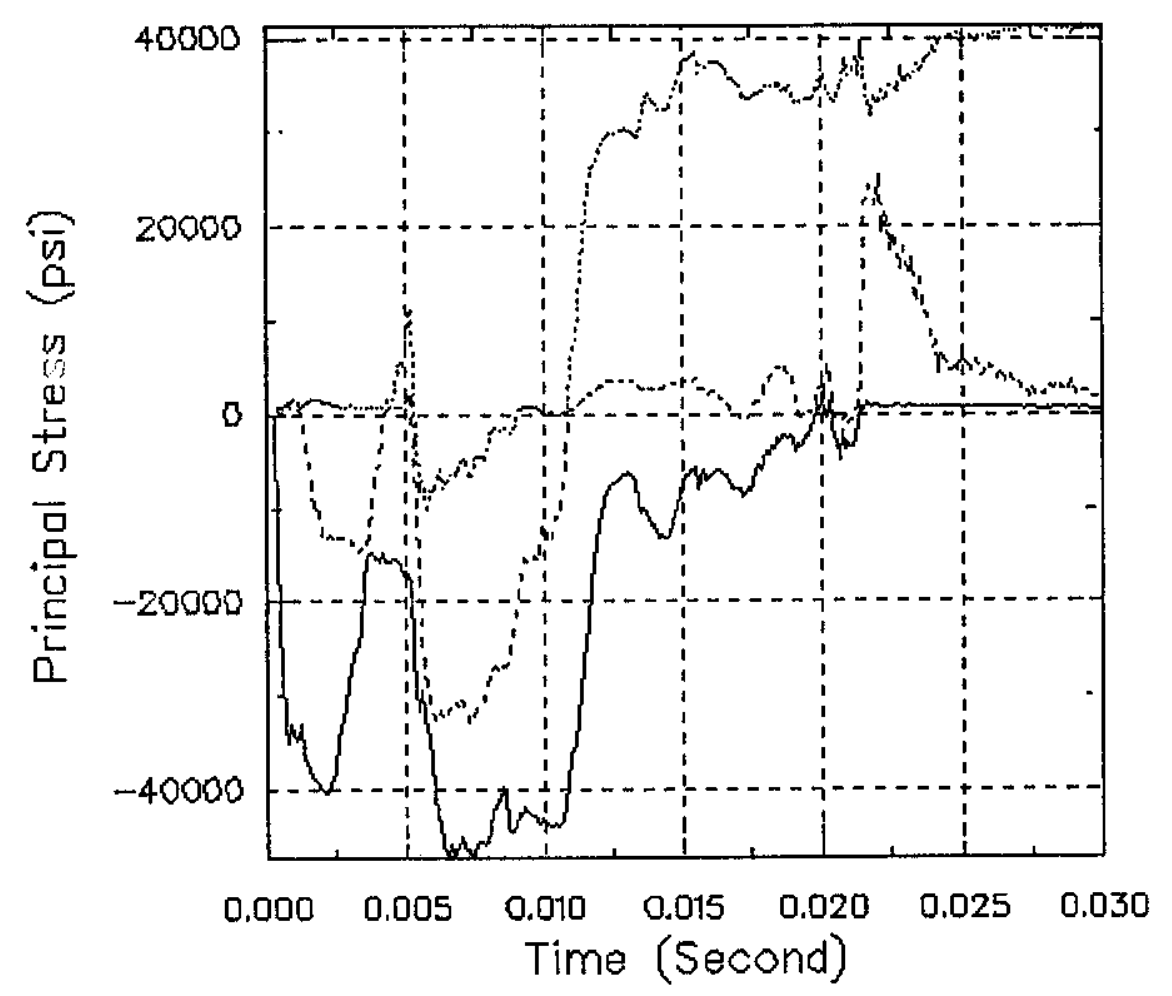

Figure B.16. Set Of Principal Stresses at Element 70308 With Respect To Time (Seconds). 


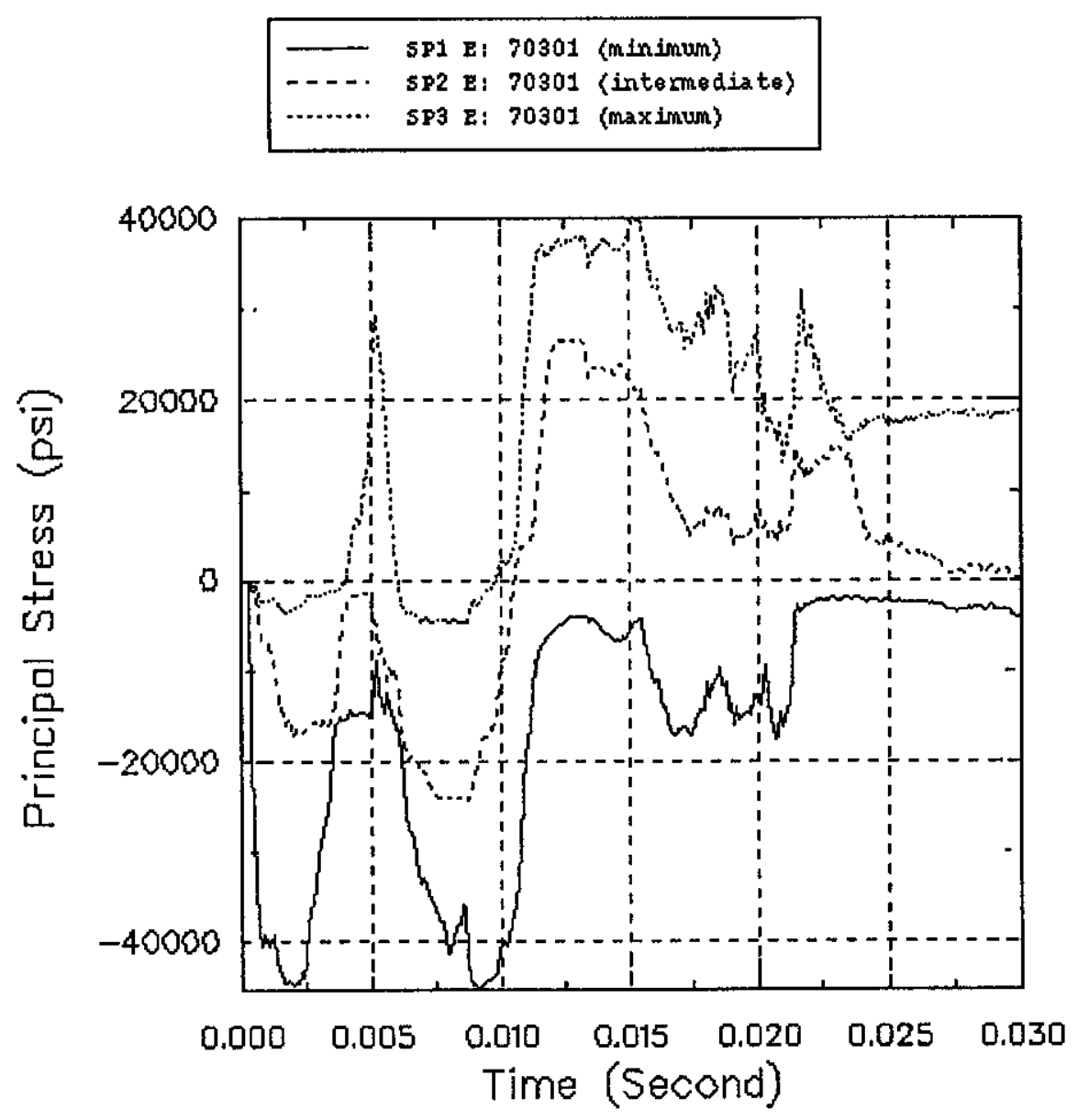

Figure B.17. Set Of Three Principal Stresses at Element 70301 With Respect To Time (Seconds). 


\section{APPENDIX - C COMPUTER INPUT FILES}




\title{
APPENDIX C
}

\section{ABAQUS INPUT FILE}

\author{
SECTION ONE
}

MCO DROP ON STANDARD STORAGE TUBE

Originator: K.C.Tu \&dy Date: 1/24/2000 Checked by:M.B. Lasota of \&ts Date:1/24/2000 
** file "rev2.inp"

*HEADING

MCO DROP ONTO TUBE(MCO shell w/ 7 solid el \& basket support)

* INCLUDE, INPUT=mco7.txt.

*INCLUDE, INPUT =bsk1a4. t $x t$

*SYSTEM

*INCLUDE, INPUT=stdstd2.txt

*SYSTEM

$-1,22.75$

*NODE, NSET $=$ RGD 1

$95001,-17.5,55,0$

$95003,-17.5,114.15,0$

$95005,-13.625,128.91,0$

$95007,-13.625,160,0$

*NODE, NSET $=$ RGD 2

$95011,17.5,55,0$

$95013,17.5,114.15,0$

$95015,13.625,128.91,0$

$95017,13.625,160 ., 0$

*SYSTEM

*NODE, NSET=RGD3

$95031,14.5,-34.5,0$

$95041,14.5,-2.25,0$

$95051,15.0,-1.75,0$

$95061,20.625,-1.75,0$

$95071,20.625,6,0$

*NCOPY, CHANGE NUMBER $=1$, OLD SET $=$ RGD3, SHIFT, NEW

SET $T=R G D 3$, mul $t$ ipl $e=6$

0 ,

$0,0,0,0,1,0,3.44$

*NCOPY, CHANGE NUMBER $=1$, OLD SET $=R G D 2, S H I F T$, NEW SET $=R$ RD2

0 ,

$0,0,0,0,1,0,3.75$

*NCOPY, CHANGE NUMBER=1, OLD SET=RGD1, SHIFT, NEW SE T $=$ RGD 1

$\dot{0}, 0$

$0,0,0,0,1,0,-15$.

*node

$95020,-12.625,100$. ,

$95099,23.625,-10,0$

*el ement, type $=R 304$, el set $=r g d 1$

95001,95001, 95002, 95004, 95003

$95002,95003,95004,95006,95005$

$95003,95005,95006,95008,95007$

* el ement, type $=R 3 D 4$, el set $=$ rgd?

$95004,95011,95012,95014,95013$

$95005,95013,95014,95016,95015$

$95006,95015,95016,95018,95017$

*el ement , type $=R 304$, el set $=$ rgd3

95007, 95031, 95032, 95042, 95041

*elgen, el set $=$ rgd3

$95007,4,10,1,5,1,4$

*ELSET, ELSET=SSTA

FLANG, TUBES, TUBEP

ॠELSET, ELSET $=$ TTT

MCO, EBSK, SSTA

**

*SOLID SECTION, ELSET=FLANG, MATERIAL=SA36

*SOLID SECTION, ELSET=TUBES, MATERIAL=SA36

*SHELL SECTION, ELSET=TUBEP, MATERIAL=SA36

0.5

* rigid body, elset $=$ rgd1, ref node $=95020$

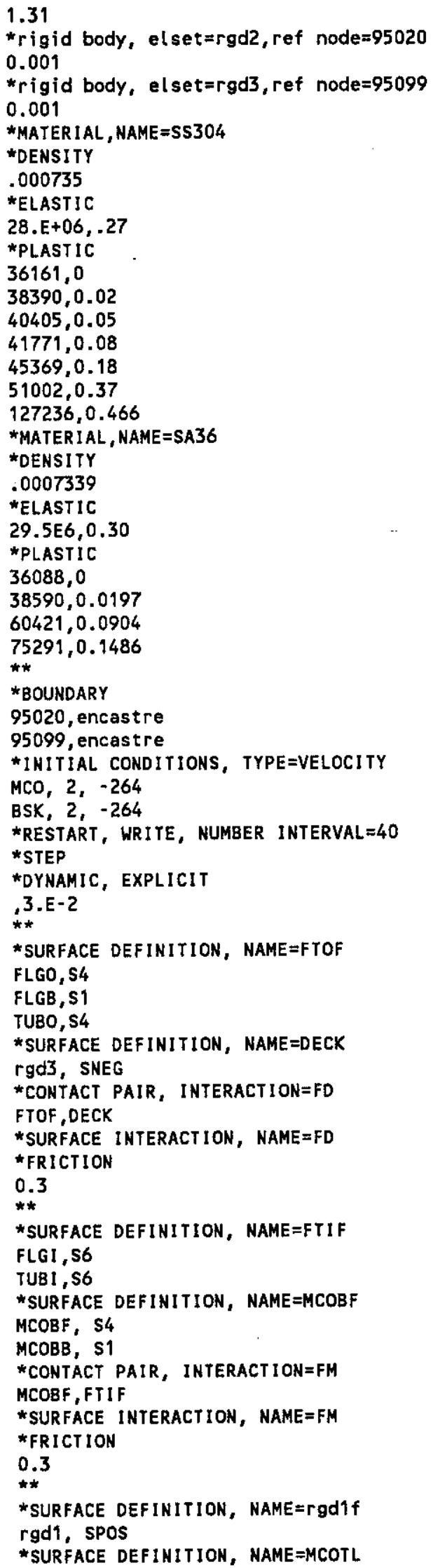

1.31

*rigid body, elset=rgd2, ref node $=95020$

0.001

*rigid body, elset=rgd3, ref node $=95099$

0.001

*MATERIAL, NAME $=\$ S 304$

*DENSITY

.000735

*ELASTIC

$28 . E+06, .27$

*PLASTIC

36161,0

$38390,0.02$

40405, 0.05

$41771,0.08$

$45369,0.18$

$51002,0.37$

$127236,0.466$

*MATERIAL, NAME=SA36

*OENSITY

.0007339

*ELASTIC

29.5E6, 0.30

*PLASTIC

36088,0

$38590,0.0197$

$60421,0.0904$

$75291,0.1486$

*BOUNDARY

95020, encastre

95099, encastre

* INITIALL CONDITIONS, TYPE=VELOCITY

MCO, 2, -264

BSK, 2, -264

*RESTART, WRITE， NUMBER INTERVAL $=40$

*STEP

*DYNAMIC, EXPLICIT

, 3.E-2

*SURFACE DEFINITION, NAME=FTOF

FLGO, 54

FLGB, S1

TUBO, 54

*SURFACE DEFINITION, NAME=DECK rgd3, SNEG

*CONTACT PAIR, INTERACTION=FD

FTOF, DECK

*SURFACE INTERACTION, NAME=FD

ॠFRICTION

0.3

**

*SURFACE DEFINITION, NAME=FTIF

FLGI, S6

TUB1, S6

*SURFACE DEFINITION, NAME=MCOBF

MCOBF, S4

$M C O B B, S 1$

*CONTACT PAIR, INTERACTION=FM

MCOBF, FTIF

*SURFACE INTERACTION, NAME=FM

*FRICTION

0.3

$\star *$

*SURFACE DEFINITION, NAME=rgdif

rgd1, SPOS

*surface definition, name=mcotl. 
MCOTL, SPOS

*CONTACT PAIR, INTERACTION=FMTL rgdif, MCOTL

*SURFACE INTERACTION, NAME=FMTL *FRICTION

0.3

**

"SURFACE DEFINITION, NAME=rgd2f rgd2, SNEG

*SURFACE DEFINITION, NAME $=$ MCOTR MCOTR, SPOS

*CONTACT PAIR, INTERACTION=FMTR rgd2f, MCOTR

*SURFACE INTERACTION, NAME=FMTR

*FRICTION

0.3

**

* SURFACE DeFINITION, NAME=bskb1 bskb1, s1

bskc1,s1

bskb1, s4

*SURFACE DEFINITION, NAME=bskb2 bskb2, $s 1$

bskc2, s1

bskb2, $\$ 4$

"SURFACE DEFINITION， NAME=bskb3

bskb3, s1

bskc3, s1

bskb3, s4

*SURFACE DEFINITION, NAME=bskb4

bskb4,s1

bskc4, s1

bskb4, s4

*SURFACE DEFINITION， NAME=bskb5

bskb5, s1

bske5, s1

bskb5, s4

*SURFACE DEFINITION, NAME=bskb6

bskb6, 1

bskc6, s1

bskb6, 54

*CONTACT NODE SET, NAME=bspb

bspb

*SURFACE DEFINITION, NAME=mcos $i$

mcobt, 52

meosi, s6

*CONTACT PAIR, INTERACTION=BSmCO

bspb, mcos $i$

* SURFACE INTERACTION, NAME=BSmCO

*FRICTION

0.3

*CONTACT NODE SET, NAME=bspt

bspt

*CONTACT PAIR, INTERACTION=BSKO 1 bspt, BSKB1

* SURFACE INTERACTION, NAME=BSKO1

*FRICTION

0.3

*SURFACE DEFINITION, NAME=mcotb mcot, 51

*elset, el set=mcopi , generate

$70205,70240,1$

$71205,71240,1$

$72205,72240,1$

$73205,73240,1$

$74205,74240,1$

$75205,75240,1$

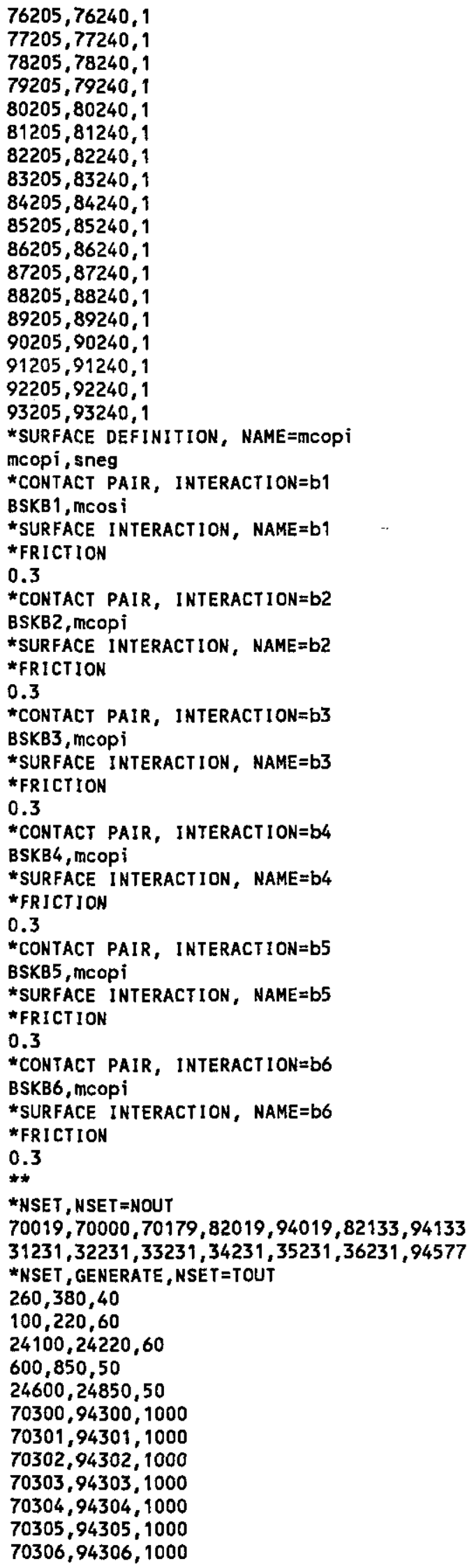


$70307,94307,1000$

$70308,94308,1000$

$70309,94309,1000$

*OUTPUT, HISTORY, TIME INTERVAL=1.E-4

*NODE OUTPUT, NSET=NOUT *

$U, V, A$

*NODE OUTPUT, NSET=TOUT

$\mathrm{U}$

*NODE OUTPUT, NSET=PFLR

$R F$

*nset, nset $=$ rgdn

95020,95099

*NODE OUTPUT, NSET $=$ rgdn

RF

*ELSET, ELSET =EOUT

70301,70304,70307,70019

*el set, elset=eout, generate

$70133,70139,1$

$70153,70159,1$

$70301,70349,1$

*ELEMENT OUTPUT, ELSET=EOUT

$S, S P, P E, M I S E S, P E E Q$

*ENERGY outPUt

ALLKE

*elset, elsetzst

flang, tubes, tubep

*energy output, elset=st

allie, allpd

*output, field, number interval=40

*element output

$S, S P, M I S E S, P E, P E E Q, E, E P$

*node output

$u, v, r f$

*MONITOR, NODE $=70019$, DOF $=2$

*END STEP

** end of file 


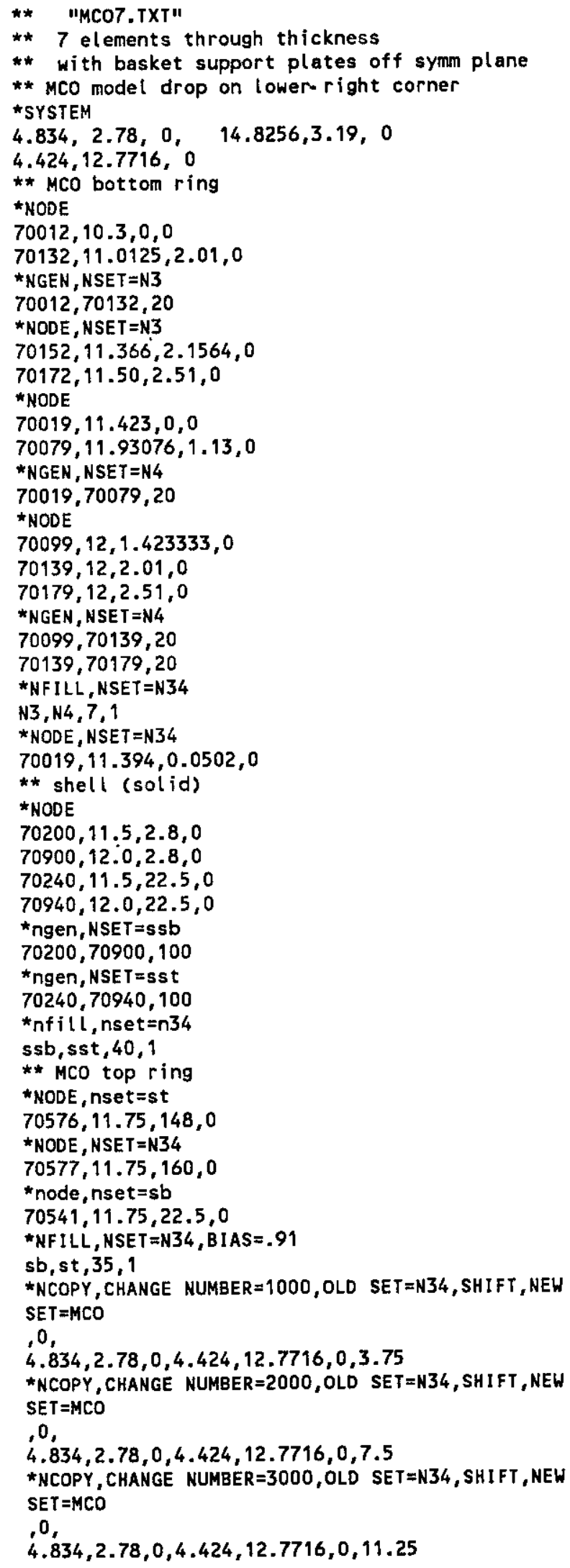

*NCOPY, CHANGE NUM8ER $=4000$, OLD SET $=N 34$, SHIFT, NEW SET $=M C O$

0 ,

$4.834,2.78,0,4.424,12.7716,0,15$.

*NCOPY, CHANGE NUMBER $=5000$, OLD SET $=N 34$, SHIFT, NEW SET $=$ MCO

0 ,

$4.834,2.78,0,4.424,12.7716,0,18.75$

*NCOPY, CHANGE NUMBER $=6000$, OLD SET $=$ N34, SHIFT, NEH SET $=M C O$

0 ,

$4.834,2.78,0,4.424,12.7716,0,22.5$

*NCOPY, CHANGE NUMBER $=7000,0 L D$ SET $=N 34$, SHIFT, NEW SET $=$ MCO

0 ,

$4.834,2.78,0,4.424,12.7716,0,26.25$

$* N C O P Y, C H A N G E$ NUMBER $=8000$, OLD SET $=N 34$, SHIFT, NEW SET $=M C O$

0 ,

4.834,2.78,0,4.424, 12.7716,0,30.

*NCOPY, CHANGE NUMBER $=9000$, OLD SET $=N 34$, SHIFT, NEW SET $=$ MCO

0 , 4.834, 2.78,0,4.424, 12.7716,0,36.

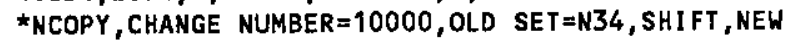
SET $=\mathrm{MCO}$

.0 ,

$4.834,2.78,0,4.424,12.7716,0,42$.

*NCOPY, CHANGE NUMBER $=11000$, OLD SET $=N 34$, SHI FT, NEW SET $=$ MCO

0 ,

$4.834,2.78,0,4.424,12.7716,0,48$.

*NCOPY, CHANGE NUMBER $=12000$, OLD SET $=$ N34, SHIFT, NEW SET $=$ MCO

0 ,

$4.834,2.78,0,4.424,12.7716,0,54$.

$\star_{N C O P Y}$, CHANGE NUMBER $=13000$, OLD SET $=N 34$, SHIFT, NEW SET $=M C O$

0 ,

$4.834,2.78,0,4.424,12.7716,0,60$.

*NCOPY, CHANGE NUMBER $=14000$, OLD SET $=N 34$, SHI FT, NEW SET $=$ MCO

0 ,

4.834,2.78,0,4.424, 12.7716,0,67.5

*NCOPY, CHANGE NUMBER $=15000$, OLD SET $=N 34$, SHIFT, NEW $S E T=M C O$

0 ,

$4.834,2.78,0,4.424,12.7716,0,75$.

*NCOPY, CHANGE NUMBER $=16000$, OLD SET $=N 34, S H I F T, N E W$ SET $=M C O$

0 ,

$4.834,2.78,0,4.424,12.7716,0,82.5$

$\star_{N C O P Y, C H A N G E ~ N U M B E R}=17000$, OLD SET $=N 34$, SHI FT, NEW $S E T=M C O$

0 ,

$4.834,2.78,0,4.424,12.7716,0,90$.

*NCOPY, CHANGE NUMBER $=18000$, OLD SET $=N 34$, SHIFT, NEW SET $=M C O$

0 ,

$4.834,2.78,0,4.424,12.7716,0,100$

*NCOPY, CHANGE NUMBER $=19000$, OLD SET $=N 34$, SHIFT, NEW SET $=M C O$

0 ,

$4.834,2.78,0,4.424,12.7716,0,110$.

$*$ NCOPY, CHANGE NUMBER $=20000$, OLD SET $=N 34$, SHI FT, NEW SET $=$ MCO

0 , 
$4.834,2.78,0,4.424,12.7716,0,120$. *NCOPY, CHANGE NUMBER $=21000$, OLD SET $=N 34$, SHIFT, NEW SET $=M C O$

0 ,

$4.834,2.78,0,4,424,12.7716,0,135$.

*NCOPY, CHANGE NUMBER $=22000$, OLD SET $=N 34$, SHIFT, NEW $S E T=M C O$

0 ,

$4.834,2.78,0,4.424,12.7716,0,150$.

*NCOPY, CHANGE NUMBER $=23000$, OLD SET $=N 34$, SHIFT, NEW SET $=M C O$

0 ,

$4.834,2.78,0,4.424,12.7716,0,165$

*NCOPY, CHANGE NUMBER $=24000$, OLD SET=N34, SHIFT, NEW SET $=M C O$

.0 ,

$4.834,2.78,0,4.424,12.7716,0,180$

* NODE

$70000,1.25,0,0$

$70060,1.25,1.13,0$

*NGEN, NSET $=$ N1

$70000,70060,20$

*NODE

$70120,2.13,2.01,0$

*NGEN, NSET $=$ N 1

$70060,70120,20$

*NCOPY, CHANGE NUMBER $=1000$, OLD SET $=N 1$, SHIFT, NEH SE T $=$ N 1, MULT I PLE $=24$

, 0 ,

$4.834,2.78,0,4.424,12.7716,0,7.5$

*NSET, NSET $=$ N2, GENERATE

$70012,94012,1000$

$70032,94032,1000$

$70052,94052,1000$

$70072,94072,1000$

$70092,94092,1000$

$70112,94112,1000$

$70132,94132,1000$

$*_{N F I L L, N S E T}=N 12$, BIAS $=1.01$

N1,N2, 12,1

*ELEMENT, TYPE $=$ C3D8R, ELSE T $=M C O B$

$70001,70000,70001,71001,71000,70020,70021,71021,7$ 1020

*ELGEN, ELSET $T=M C O B$

$70001,19,1,1,6,20,20,24,1000,1000$

$70113,2,20,20$

$70133,7,1,9,2,20,20,24,1000,1000$

*ELEMENT, TYPE $=C 3 D 8 R$, ELSET $=$ MCOPS

$70301,70172,70173,71173,71172,70200,70300,71300,7$ 1200

$70302,70173,70174,71174,71173,70300,70400,71400,7$ 1300

$70303,70174,70175,71175,71174,70400,70500,71500,7$ 1400

$70304,70175,70176,71176,71175,70500,70600,71600,7$ 1500

$70305,70176,70177,71177,71176,70600,70700,71700,7$ 1600

$70306,70177,70178,71178,71177,70700,70800,71800,7$ 1700

$70307,70178,70179,71179,71178,70800,70900,71900,7$ 1800

$70308,70200,70300,71300,71200,70201,70301,71301,7$ 1201

*ELGEN, ELSET T=MCOPS

$70301,24,1000,1000$

$70302,24,1000,1000$
$70303,24,1000,1000$ $70304,24,1000,1000$ $70305,24,1000,1000$ $70306,24,1000,1000$ $70307,24,1000,1000$ $70308,7,100,1,40,1,7,24,1000,1000$ $\star_{\text {mpc }}$

beam, 70541,70240

beam, 71541,71240

beam, 72541,72240

beanf, 73541,73240

beam, 74541, 74240

beam, 75541,75240

beam, 76541, 76240

beam, 77541,77240

beam, 78541,78240

beam, 79541,79240

beam, 80541,80240

beam, 81541,81240

beam, 82541,82240

beam, 83541,83240

beam, 84541,84240

beam, 85541,85240

beam, 86541,86240

beam, 87541,87240

beam, 88541,88240

beam, 89541, 89240

beam, 90541,90240

beam, 91541,91240

beam, 92541,92240

beam, 93541,93240

beam, 94541,94240

beam, 70541,70240

beam, 71541, 71340

beam, 72541,72340

beam, 73541,73340

beam, 74541,74340

beam, 75541,75340

beam, 76541,76340

beam, 77541,77340

bean, 78541,78340

beam, 79541,79340

beam, 80541,80340

beam, 81541,81340

beam, 82541,82340

beam, 83541,83340

beam, 84541,84340

beam, 85541,85340

beam, 86541,86340

beam, 87541,87340

beam, 88541,88340

bean, 89541,89340

beam, 90541,90340

beam, 91541,91340

beam, 92541,92340

beam, 93541,93340

beam, 94541,94340

beam, 70541,70440

beam, 71541,71440

beam, 72541,72440

beam, 73541,73440

beam, 74541,74440

beam, 75541,75440

beam, 76541,76440

beam, 77541,77440

beam, 78541,78440

beam, 79541,79440 
beam, 80541,80440

beam, 81541,81440

beam, 82541,82440

beam, 83541,83440

bean, 84541,84440

beam, 85541,85440

beam, 86541,86440

beam, 87541,87440

beam, 88541, 88440

beam, 89541,89440

beam, 90541,90440

beam, 91541,91440

beam, 92541,92440

beam, 93541,93440

bean, 94541,94440

beam, 70541,70540

beam, 71541,71540

beam, 72541,72540

beam, 73541,73540

beam, 74541,74540

beam, 75541,75540

beam, 76541,76540

beam, 77541,77540

beam, 78541,78540

bean, 79541,79540

beam, 80541,80540

beam, 81541,81540

beam, 82541,82540

beam, 83541,83540

beam, 84541,84540

beam, 85541,85540

beam, 86541,86540

beam, 87541,87540

beam, 88541,88540

beam, 89541,89540

beam, 90541,90540

beam, 91541,91540

beam, 92541,92540

beam, 93541,93540

bean, 94541,94540

beam, 70541,70640

beam, 71541,71640

beam, 72541,72640

bean, 73541,73640

beam, 74541,74640

beam, 75541,75640

beam, 76541,76640

beam, 77541,77640

beam, 78541,78640

beam, 79541,79640

beam, 80541,80640

beam, 81541, 81640

beam, 82541,82640

beam, 83541,83640

beam, 84541,84640

beam, 85541,85640

beam, 86541,86640

beam, 87541,87640

beam, 88541,88640

beam, 89541,89640

beam, 90541,90640

beam, 91541,91640

beam, 92541,92640

beam, 93541,93640

beant, 94541,94640

bearn, 70541,70740

beam, 71541,71740 beam, 72541,72740

beam, 73541,73740

beam, 74541,74740

beam, 75541,75740

beam, 76541,76740

beam, 77541,77740

beam, 78541,78740

beam, 79541,79740

beam, 80541,80740

beam, 81541,81740

beam, 82541,82740

beam, 83541,83740

beam, 84541,84740

beam, 85541,85740

beam, 86541,86740

beam, 87541,87740

bean, 88541,88740

beam, 89541,89740

beam, 90541,90740

beam, 91541,91740

beam, 92541,92740

beam, 93541,93740

beam, 94541,94740

beam, 70541,70840

beam, 71541,71840

beam, 72541,72840

beam, 73541,73840

beam, 74541,74840

beam, 75541,75840

beam, 76541,76840

beam, 77541,77840

beam, 78541,78840

beam, 79541,79840

beam, 80541,80840

beam, 81541,81840

beam, 82541,82840

beam, 83541,83840

beam, 84541,84840

beam, 85541,85840

beam, 86541, 86840

beam, 87541,87840

beam, 88541,88840

beam, 89541,89840

beam, 90541,90840

beam, 91541,91840

beam, 92541,92840

beam, 93541,93840

beam, 94541,94840

beam, 70541,70940

beam, 71541,71940

beam, 72541,72940

beam, 73541,73940

beam, 74541,74940

beam, 75541,75940

beam, 76541,76940

beam, 77541,77940

beam, 78541,78940

beam, 79541,79940

beam, 80541,80940

beam, 81541,81940

beam, 82541,82940

beam, 83541,83940

beam, 84541,84940

beam, 85541,85940

beam, 86541,86940

beam, 87541,87940

beam, 88541,88940 
beam, 89541,89940

beam, 90541,90940

beam, 91541,91940

beam, 92541,92940

beam, 93541,93940

beam, 94541,94940

*ELEMENT, TYPE $=\$ 4 R S, E L S E T=M C O P L$

$70205,70540,71540,71541,70541$

*ELGEN, ELSE T =MCOPL

$70205,36,1,1,24,1000,1000$

** MCO bottom center

\#NODE

$60000,-1.08,0,0$

$66000,-.7637,0,-.7637$

*NGEN, NSET $=$ L?

$60000,66000,1000$

*NODE

$60012,1.08,0,0$

$66012, .7637,0,-.7637$

*NGEN, NSET $=\mathrm{L} 2$

$60012,66012,1000$

* NODE

$60006,0,0,0$

$66006,0,0,-1.08$

*NGEN, NSET $T=13$

$60006,66006,1000$

*NFILL, NSET $T=L 12$

$L 1, L 3,6,1$

$13, L 2,6,1$

*NCOPY, CHANGE NUMBER $=60$, OLD SET $=L 12$, SHIFT, NEW

$S E T=L 13$

$-0.0262,0.8796,0$

*NFILL, NSET $=L \mathrm{~L} 14$

$L 12, L 13,3,20$

*ELEMENT, TYPE $=$ C3D8R, ELSET $=$ MCOB

$60101,60000,60001,61001,61000,60020,60021,61021,6$ 1020

*ELGEN, ELSET $=M C O B$

$60101,12,1,1,6,1000,12,3,20,72$

*ELEMENT, TYPE $=C 3 D 8 R$, ELSET $=E B 1$

$60001,60012,70000,71000,61012,60032,70020,71020,6$

1032

*ELGEN , ELLSET =EB2

$60001,6,1000,1,3,20,6$

ॠELEMENT, TYPE $=C 3 D 8 R, E L S E T=E B 3$

$60019,66012,76000,77000,66011,66032,76020,77020,6$

6031

$60020,66011,77000,78000,66010,66031,77020,78020,6$

6030

$60021,66010,78000,79000,66009,66030,78020,79020,6$

6029

$60022,66009,79000,80000,66008,66029,79020,80020,6$

6028

$60023,66008,80000,81000,66007,66028,80020,81020,6$

6027

$60024,66007,81000,82000,66006,66027,81020,82020,6$

6026

$60025,66006,82000,83000,66005,66026,82020,83020,6$

6025

$60026,66005,83000,84000,66004,66025,83020,84020,6$

6024

$60027,66004,84000,85000,66003,66024,84020,85020,6$

6023

$60028,66003,85000,86000,66002,66023,85020,86020,6$ 6022
$60029,66002,86000,87000,66001,66022,86020,87020,6$ 6021

$60030,66001,87000,88000,66000,66021,87020,88020,6$ 6020

$60031,66000,88000,89000,65000,66020,88020,89020,6$ 5020

$60032,65000,89000,90000,64000,65020,89020,90020,6$ 4020

$60033,64000,90000,91000,63000,64020,90020,91020,6$ 3020

$60034,63000,91000,92000,62000,63020,91020,92020,6$ 2020

$60035,62000,92000,93000,61000,62020,92020,93020,6$ 1020

$60036,61000,93000,94000,60000,61020,93020,94020,6$ 0020

*ELCOPY,ELEMENT SHIFT $=18$, OLD SET $=E 83$, SHIFT

NODES $=20$, NEW SET $=E B 4$

*ELCOPY,ELEMENT SHIFT=18, OLD SET=EB4, SHIFT

NODES $=20, N E W$ SET $=E B 5$

*ELSET, ELSET $=M C O B$

$E B 2, E B 3, E B 4, E B 5$

** MCO top center

*NODE

$50000,-8 ., 148,0$

$56000,-1 ., 148,-8.5$

*NGEN, NSET $=$ T?

$50000,56000,1000$

NODE

$50012,10.8,148,0$

$56012,9.1,148,-3.77$

*NGEN, NSET $=$ T2

$50012,56012,1000$

NODE

$50006,5.8,148,0$

$56006,5.8,148,-7.97$

*NGEN, NSET $=$ T3

$50006,56006,1000$

NNFILL, NSET $=T 12$

$T 1, T 3,6,1$

$T 3, T 2,6,1$

*NCOPY, CHANGE NUMBER $=20$, OLD SET $=T 12$, SHIFT, NEW SET $=\mathrm{T} 13$

$-0.4920,11.9899,0$

*ELEMENT $, T Y P E=C 308 R, E L S E T=M C O T$

$60601,50000,50001,51001,51000,50020,50021,51021,5$ 1020

*ELGEN, ELSET $=$ MCOT

$60601,12,1,1,6,1000,12$

*ELEMENT, TYPE $=$ C3DBR, ELSET $=E B 11$

$50001,50012,70576,71576,51012,50032,70577,71577,5$ 1032

*ELGEN, ELSET $=E B 11$

$50001,6,1000,1$

*ELEMENT, TYPE $=C 308 R$, ELSET $=E B 12$

$50007,56012,76576,77576,56011,56032,76577,77577,5$ 6031

$50008,56011,77576,78576,56010,56031,77577,78577,5$ 6030

$50009,56010,78576,79576,56009,56030,78577,79577,5$ 6029

$50010,56009,79576,80576,56008,56029,79577,80577,5$ 6028

$50011,56008,80576,81576,56007,56028,80577,81577,5$ 6027 


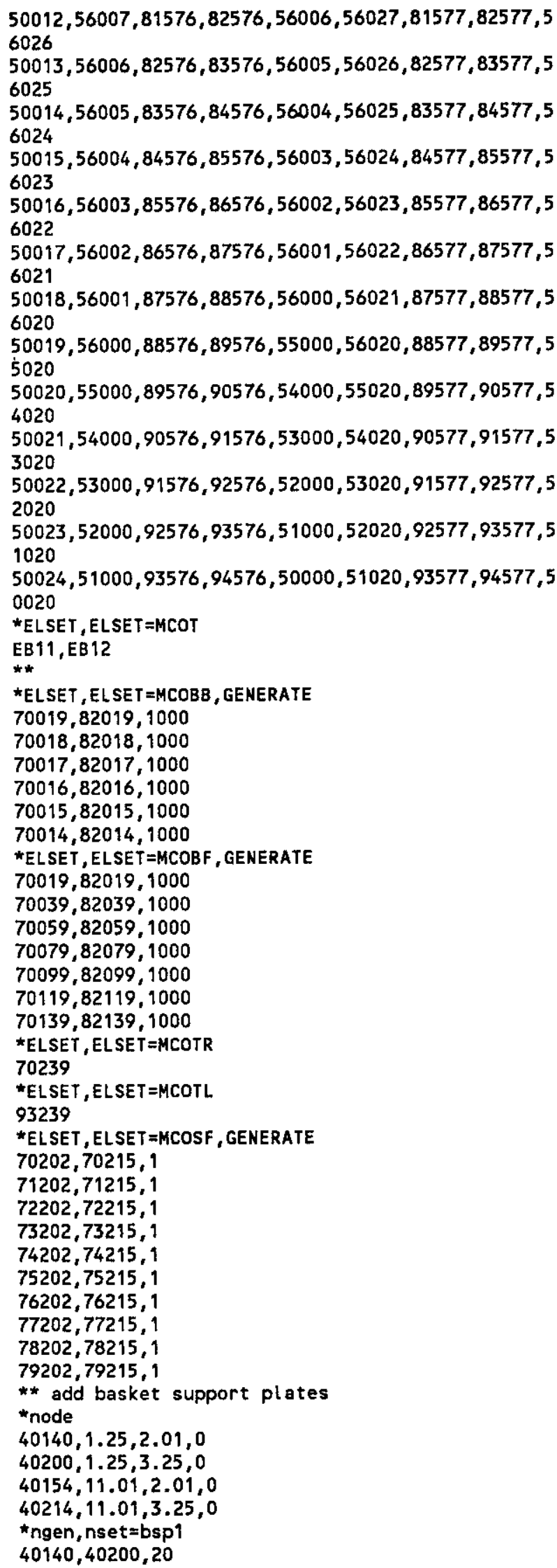

*ngen, nset $=$ bsp2

40154, 40214,20

*NCOPY, CHANGE NUMBER $=1000$, OLD SET $=$ bsp1, SHIFT, NEH SET $=b s p 3$

0 ,

*NCOPY, CHANGE NUMBER $=2000$, OLD SET $=b S p 1$, SHIFT, NEW SET $=$ bsp3

, 0 ,

$4.834,2.78,0,4.424,12.7716,0,30$

*NCOPY, CKANGE NUMBER $=3000$, OLD SET=bSP1, SHIFT, NEW SET $=$ bsP3

0 ,

$4.834,2.78,0,4.424,12.7716,0,60$

*NCOPY, CHANGE NUMBER $=4000,0 L D$ SET $=$ bSP1 , SHIFT, NEW SET $=$ bsp3

0 ,

$4.834,2.78,0,4.424,12.7716,0,60$

*NCOPY, CHANGE NUMBER $=5000$, OLD SET $=b S P 1$, SHIFT, NEW SET $=$ bSP3

0 ,

$4.834,2.78,0,4.424,12.7716,0,90$

*NCOPY, CHANGE NUMBER $=6000$, OLD SET=bSP1, SHI FT, NEW SET $=$ bsp3

0 ,

$4.834,2.78,0,4.424,12.7716,0,120$

* NCOPY, CHANGE NUMBER $=7000$, OLD SET=bsP1, SHI FT, NEW SET $=b s p 3$

0

$4.834,2.78,0,4.424,12.7716,0,120$

${ }^{\text {NCOPY }}$, CHANGE NUMBER $=8000$, OLD SET=bsp1, SHIFT, NEW SET $=$ bsp3

0 ,

$4.834,2.78,0,4.424,12.7716,0,150$

* NCOPY, CHANGE NUMBER $=9000,0$ LD SET=bsP1, SHIFT, NEW SET $=$ bsp3

0 ,

$4.834,2.78,0,4.424,12.7716,0,180$

*NCOPY, CHANGE NUMBER $=1000$, OLD SET $=b S P 2, S H I F T$, NEW SET $=b s p 4$

0 ,

$4.834,2.78,0,4.424,12.7716,0,26.7458$

*NCOPY, CHANGE NUMBER=2000, OLD SET=bSP2, SHIFT, NEW SET $=b s p 4$

0

$4.834,2.78,0,4.424,12.7716,0,30$

*NCOPY, CHANGE NUMBER $=3000$, OL.D SET $=b S P 2$, SHIFT, NEW SET $=$ bsp4

0 ,

$4.834,2.78,0,4.424,12.7716,0,33.2542$

* NCOPY, CHANGE NUMBER $=4000$, OLD SET $=b S P 2$, SHIFT, NEW $\mathrm{SET}=\mathrm{bSP} 4$

0 ,

$4.834,2.78,0,4,424,12.7716,0,86.7458$

*NCOPY, CHANGE NUMBER $=5000$, OLD SET $=b S P 2, S H I F T, N E H$ SET $=$ bsp4

0 ,

$4.834,2.78,0,4.424,12.7716,0,90$

*NCOPY, CHANGE NUMBER $=6000$, OLD SET $=b S P 2$, SHIFT, NEW SET $=$ bsp4

0 ,

$4.834,2.78,0,4.424,12.7716,0,93.2542$

*NCOPY, CHANGE NUMBER $=7000$, OLD SET=bSP2, SHIFT, NEW SET $=b s p 4$

0 ,

$4.834,2.78,0,4.424,12.7716,0,146.7458$ 
*NCOPY, CHANGE NUMBER $=8000,0 L D$ SET=bSP2, SHIFT, NEW SET $=$ bsp4

0 ,

$4.834,2.78,0,4.424,12.7716,0,150$

*NCOPY, CHANGE NUMBER $=9000$, OLD SET $=b S P 2$, SHIFT, NEW SET $\mathrm{T}=\mathrm{bSp} 4$

0 ,

$4.834,2.78,0,4.424,12.7716,0,153.2542$

*nset, nset $=b s p 3$

bsp1

*nset, nset $=b s p 4$

bsp2

*nfill, nset $=$ mco

bsp3, bsp4, 14, 1

*ELEMENT, TYPE $=$ C3DBR, ELSET $=b s p$

$97001,41140,41141,42141,42140,41160,41161,42161,4$

2160

$97101,42140,42141,43141,43140,42160,42161,43161,4$

3160

*ELGEN, ELSET $=$ bsP

$97001,14,1,1,3,20,14,3,3000,200$

$97101,14,1,1,3,20,14,3,3000,200$

*mpc

l ink, 43140,44140

link, 43160,44160

link, 43180,44180

link, 43200,44200

link, 46140,47140

link, 46160,47160

link, 46180,47180

link, 46200,47200

*ELSET, ELSET=MCOSL

MCOT, MCOB

*SOLID SECTION, ELSET=MCOSL, MATERIAL=SS304

*SOLID SECTION, ELSET=MCOPS, MATERIAL=SS304

*SHELL. SECTION, ELSET $=M C O P L$, MATERIAL $=5 \$ 304$

0.5

* SOLID SECTION, ELSET=bSP, MATERIAL=SS304

*nset, nset $=b s p b$, generate

$40140,40154,1$

$41140,41154,1$

$42140,42154,1$

$43140,43154,1$

$44140,44154,1$

$45140,45154,1$

$46140,46154,1$

$47140,47154,1$

$48140,48154,1$

$49140,49154,1$

*nset, nset=bspt, generate

$40200,40214,1$

$41200,41214,1$

$42200,42214,1$

$43200,43214,1$

$44200,44214,1$

$45200,45214,1$

$46200,46214,1$

$47200,47214,1$

$48200,48214,1$

$49200,49214,1$

*NSET, NSET $=$ MCO

N34, SB, ST, N12, L14, T12, T13

bspt, bspb

*ELSET, ELSET $=M C O$

MCOPL, MCOSL, mcops, bsp

*elset, el set=mcobt, generate

$70101,93101,1000$
$70102,93102,1000$

$70103,93103,9000$

$70104,93104,1000$

$70105,93105,1000$

$70106,93106,1000$

$70107,93107,1000$

$70108,93108,1000$

$70109,93109,1000$

$70110,93110,1000$

$70111,93111,1000$

$70112,93112,1000$

*elset, el set =mcos $i$, generate

$70133,93133,1000$

$70153,93153,1000$

$70301,93301,1000$

$70308,93308,1000$

$70315,93315,1000$

$70322,93322,1000$

$70329,93329,1000$

$70336,93336,1000$

*NSET, NSET $=$ MCOSY, GENERATE

$70000,70999,1$

$94000,94999,1$

$50000,50999,1$

$60000,60999,1$

$79140,79200,20$

*BOUNDARY

MCOSY, ZSYMM

** end of file 
** mark1a4.txt

*SYSTEM

$4.7003,6.0373,0,14.6919,6.4473,0$

$4.4240,12.7716,0$

*node, nset $=$ nbsk 0

$31000,11.3125,0,0$

*NCOPY, CHANGE NUMBER $=1$, OLD SET $=n b s k 0$, SHIFT, NEW

SET $=$ nbsk 1

0 ,

$4.7003,6.0373,0,4.4240,12.7716,0,3.75$

*NCOPY, CHANGE NUMBER=2, OLD SET=nbskO, SHIFT, NEH

SET $=$ nbsk 1

0 ,

4.7003,6.0373,0,4.4240,12.7716,0,7.5

*NCOPY, CHANGE NUMBER=3,OLD SET=nbskO, SHIFT, NEW SET $=$ nbsk 1

, 0 ,

$4.7003,6.0373,0,4.4240,12.7716,0,11.25$

*NCOPY, CHANGE NUMBER $=4$, OLD SET=nbSkO, SHIFT, NEW SET $T=$ nbsk 1

0 ,

$4.7003,6.0373,0,4.4240,12.7716,0,15$.

*NCOPY, CHANGE NUMBER $=5$, OLD SET $=n b S k O$, SHIFT, NEW SE T $=n b s k 1$

0 ,

$4.7003,6.0373,0,4.4240,12.7716,0,18.75$

*NCOPY, CHANGE NUMBER $=6$, OLD SET $=n b S k O, S H I F T, N E W$

SET =nbsk1

0 ,

$4.7003,6.0373,0,4.4240,12.7716,0,22.5$

*NCOPY, CHANGE NUMBER =7, OLD SET=nbskO, SHIFT, NEW

SET $=$ nbsk 1

0 ,

$4.7003,6.0373,0,4.4240,12.7716,0,26.25$

*NCOPY, CHANGE NUMBER $=8$, OLD SET $=n b s k 0$, SHIFT, NEW

SET $=$ nbsK 1

0 ,

$4.7003,6.0373,0,4.4240,12.7716,0,30$.

NCOPY, CHANGE NUMBER=9, OLD SET=nbsk0, SHIFT, NEW SET =nbsk 1

0 ,

$4.7003,6.0373,0,4.4240,12.7716,0,36$.

*NCOPY, CHANGE NUMBER $=10$, OLD SET=nbskO, SHIFT, NEW SET $=$ nbsk 1

, 0 ,

$4.7003,6.0373,0,4.4240,12.7716,0,42$

* NCOPY, CHANGE NUMBER $=11$, OLD SET=nbskO, SHIFT, NEW SET $=$ nbsk 1

0 ,

$4.7003,6.0373,0,4.4240,12.7716,0,48$.

* NCOPY, CHANGE NUMBER $=12$, OLO SET =nbskO, SHI FT, NEW SET=nbsk 1

0 ,

$4.7003,6.0373,0,4.4240,12.7716,0,54$.

$\star_{N C O P Y}$, CHANGE NUMBER $=13$, OLD SET=nbskO, SHIFT, NEW SET $=$ nbsk 1

0 ,

$4.7003,6.0373,0,4.4240,12.7716,0,60$

${ }^{*}$ NCOPY, CHANGE NUMBER $=14$, OLD SET $=$ nbskO, SHIFT, NEW SET $=$ nbsk 1

0 ,

$4.7003,6.0373,0,4.4240,12.7716,0,67.5$

*NCOPY, CHANGE NUMBER $=15$, OLD SET=nbskO, SHIFT, NEW

SET $=$ nbsk 1

0 ,

$4.7003,6.0373,0,4.4240,12.7716,0,75$.
*NCOPY, CHANGE NUMBER $=16$, OLD SET $=n b s k 0$, SHIFT, NEW SET=nbs 1

0 ,

$4.7003,6.0373,0,4.4240,12.7716,0,82.5$

$N$ COPY, CHANGE NUMBER $=17$, OLD SET $=$ nbskO, SHIFT, NEW SET $=$ nbsk1

0 ,

$4.7003,6.0373,0,4.4240,12.7716,0,90$.

* NCOPY, CHANGE NUMBER $=18$, OLD SET $=n b S K O, S H I F T$, NEW SET $=n$ bsk 1

0 ,

$4.7003,6.0373,0,4.4240,12.7716,0,100$

* NCOPY, CHANGE NUMBER=19, OLD SET=nbskO, SHIFT, NEW SET $=$ nbSk1

0 ,

$4.7003,6.0373,0,4.4240,12.7716,0,110$.

*NCOPY, CHANGE NUMBER=20, OLD SET=nbskO, SHI FT, NEW SET $=n b s k 1$

0 ,

$4.7003,6.0373,0,4.4240,12.7716,0,120$

*NCOPY, CHANGE NUMBER $=21$, OLD SET=nbSKO, SHIFT, NEH SET $=$ nbsk ?

0 ,

$4.7003,6.0373,0,4.4240,12.7716,0,135$.

* NCOPY, CHANGE NUMBER $=22$, OLD SET=nbskO, SHIFT, NEW SET $=n b s k 1$

0 ,

$4.7003,6.0373,0,4.4240,12.7716,0,150$.

${ }^{*}$ NCOPY, CHANGE NUMBER $=23$, OLD SET $=n b s k O, S H I F T, N E W$ SET $=$ nbsk 1

0 ,

$4.7003,6.0373,0,4.4240,12.7716,0,165$.

*NCOPY, CHANGE NUMBER $=24$, OLD SET $=$ nbSkO, SHIFT, NEW SET $=$ nbsk 1

0 ,

$4.7003,6.0373,0,4.4240,12.7716,0,180$.

*nset, nset $=$ nbsk1

nbsko

*node

$31037,-8 ., 0,0$

$31115,-1 ., 0,-8.5$

*ngen, nset=bskt 1

$31037,31115,13$

*node

$31025,10.6,0,0$

$31103,9 ., 0,-3.76$

*ngen, nset $=$ bskt2

31025, 31103, 13

*node

$31031,0,0,0$

$31109,5.7,0,-7.9$

*ngen, nset $=$ bskt3

$31031,31109,13$

*nfill, nset=nbsk 1

bskt2, bskt3, 6, 1

bskt3, bskt1, 6, 1

*NCOPY, CHANGE NUMBER $=200$, OLD

SET=nbsk1, SH1 FT, NEW SET=nbsk1

$-0.041,0.9992$

*node, nset $=b s k p 0$

$31410,11.3125,8,0$

$31411,11.3125,16,0$

$31412,11.3125,23.166,0$

*NCOPY, CHANGE NUMBER=10, OLD SET=bskpO, SHIFT, NEW SET=nbskp, mul $t$ iple $=3$

0 , 
$4.7003,6.0373,0,4.4240,12.7716,0,60$.

*node, nset $=$ nbskp

$31400,8,0$

$31401,16,0$

$31402,23.166,0$

*nset, nset=nbsk1

noskp, bskpo

*NCOPY, CHANGE NUMBER $=1000$, OLD SET=nbsk 1 , SHIFT, NEW SET T=nbsk

$-0.9499,23.1465$

*NCOPY, CHANGE NUMBER $=2000$, OLD SET $=n b S k 1$, SHIFT, NEW SET $=$ nbsk

$-1.8998,46.2930$

*NCOPY, CHANGE NUMBER $=3000$, OLD SET $=n b S k 1$, SHIFT, NEW SET $=$ nbsk

$-2.8497,69.4396$

*NCOPY, CHANGE NUMBER $=4000$, OLD SET $=n b s k 1$, SH I FT, NEW SET $=$ nbsk

$-3.7996,92.5861$

*NCOPY, CHANGE NUMBER $=5000$, OLD SET=nbsk 1 , SHIFT, NEW SET $=$ nbsK

$-4.7495,115.7326$

*nset, nset $=$ bsk

nbsk, nbsk 1

*ELEMENT, TYPE $=C 308 R$, ELSET $T=b s k 0$

$31001,31025,31000,31001,31038,31225,31200,31201,3$ 1238

$31002,31038,31001,31002,31051,31238,31201,31202,3$ 1251

$31003,31051,31002,31003,31064,31251,31202,31203,3$ 1264

$31004,31064,31003,31004,31077,31264,31203,31204,3$ 1277

$31005,31077,31004,31005,31090,31277,31204,31205,3$ 1290

$31006,31090,31005,31006,31103,31290,31205,31206,3$ 1303

$31007,31103,31006,31007,31104,31303,31206,31207,3$ 1304

$31019,31115,31018,31019,31102,31315,31218,31219,3$

1302

$31020,31102,31019,31020,31089,31302,31219,31220,3$

1289

$31021,31089,31020,31021,31076,31289,31220,31221,3$

1276

$31022,31076,31021,31022,31063,31276,31221,31222,3$

1263

$31023,31063,31022,31023,31050,31263,31222,31223,3$

1250

$31024,31050,31023,31024,31037,31250,31223,31224,3$

1237

$31025,31026,31025,31038,31039,31226,31225,31238,3$

1239

*ELGEN, ELSET $=b s k 0$

$31007,12,1,1$

$31025,12,1,1,6,13,12$

*ELcopy, el ement shift=1000, old set=bsk0, shift nodes $=1000$, new SET $=$ bsk

*ELcopy, element shift=2000, old set=bsk0, shift nodes $=2000$, new SET $=$ bsk

*ELcopy, el ement shift=3000, old set $=b s k 0$, shift

nodes $=3000$, new SE $\mathrm{T}=$ bsk
*ELcopy, element shift $=4000$, old set $=b$ sk0, shift nodes $=4000$, new SET $=$ bsk

*ELcopy, element shift $=5000$, old set $=b s k 0$, shift nodes $=5000$, new SET $=$ bsk

*ELEMENT, TYPE $=B 31, E L S E T=$ pos tc

$31101,31031,31231$

$31102,31231,31400$

$31103,31400,31401$

*ELEMENT, TYPE $=831$, ELSET $=$ pos th

$31111,31000,31200$

$31112,31200,31410$

$31113,31410,31411$

*ELEMENT, TYPE $=B 31$, ELSET $T=$ pos $t f$

$31121,31013,31213$

$31122,31213,31420$

$31123,31420,31421$

$31131,31020,31220$

$31132,31220,31430$

$31133,31430,31431$

*ELEMENT, TYPE $=B 31$, ELSET $=$ pos th

$31141,31024,31224$

$31142,31224,31440$

$31143,31440,31441$

*ELGEN, ELSET=pos tc

$31101,6,1000,1000$

$31102,6,1000,1000$

$31103,2,1,1,6,1000,1000$

*ELGEN, ELSET =posth

$31111,6,1000,1000$

$31112,6,1000,1000$

$31113,2,1,1,6,1000,1000$

$31141,6,1000,1000$

$31142,6,1000,1000$

$31143,2,1,1,6,1000,1000$

*ELGEN, ELSET=pos tf

$31121,6,1000,1000$

$31122,6,1000,1000$

$31123,2,1,1,6,1000,1000$

$31131,6,1000,1000$

$31132,6,1000,1000$

$31133,2,1,1,6,1000,1000$

*elset, el set $=b s k$

bsko

*elset, el set =ebsk

posth, postf, pos tc, bsk

*SOLIO SECTION, ELSET=bsK, MATERIAL=bsk

*BEAM SECTION, ELSET=postc, MATERIAL=bskp,

SECTION=arbi trary

$4,1.906,0,1.348,1.348,2.4375$

$0,1.906,2.4375$

$-1.348,-1.348,2.4375$

$-1.906,0,2.4375$

*BEAM SECTION, ELSET=postf , MATER IAL=bskp, SECTION=trapezoid

$3.114,1.45,1.23,0$

*BEAM SECTION, ELSET=posth, MATERIAL=bskp。 SECTION= trapezoid

$1.557,1.45,0.615,0$

*MATER I AL, , NAME =bsk

*DENSITY

.01556

*ELASTIC

28.E+06, .27

ॠPLASTIC

30032 . 0.0

100701.0 .293

101451.0 .300 
$102201,0.307$

*MATERIAL , NAME=bskp

*DENSITY

.000735

*ELASTIC

28.E+06, .27

$\pitchfork$ PLASTIC

30032.,0.0

100701.0 .293

101451.0 .300

$102201 ., 0.307$

*mpc

link,32031,31402

link, 32000,31412

link, 32013,31422

link, 32020, 31432

link, 32024, 31442

l ink, 33031,32402

link, 33000, 32412

link, 33013,32422

l ink, 33020,32432

link, 33024, 32442

link, 34031,33402

link, 34000,33412

link, 34013,33422

link, 34020, 33432

link, 34024, 33442

link, 35031,34402

link, 35000, 34412

l ink, 35013, 34422

link, 35020, 34432

link, 35024, 34442

link, 36031, 35402

link, 36000,35412

l ink, 36013,35422

link, 36020,35432

link, 36024, 35442

*elset, elset=bskb1, generate $31001,31024,1$

*elset, el set=bskb2, generate $32001,32024,1$

*elset, el set=bskb3, generate $33001,33024,1$

*elset, el set=bskb4, generate $34001,34024,1$

*elset, el set=bskb5, generate $35001,35024,1$

*el set, el set=bskb6, generate $36001,36024,1$

* el set, el set =bskc1, generate 31025,31096, 1

*el set, el set=bskc2, generate $32025,32096,1$

*el set, elset=bskc3, generate $33025,33096,1$

*elset, elset=bskc4, generate 34025, 34096, 1

*elset, elset=bskc5, generate $35025,35096,1$

*el set, el set=bskc6, generate $36025,36096,1$

*nset, nset=BSKSY, generate

$31000,36000,1000$

$31024,36024,1000$

$31025,31037,1$

$31225,31237,1$

$32025,32037,1$
INPUT FILE Bsk1a4.txt

$32225,32237,1$

$33025,33037,1$

$33225,33237,1$

$34025,34037,1$

$34225,34237,1$

$35025,35037,1$

$35225,35237,1$

$36025,36037,1$

$36225,36237,1$

$31400,36400,1000$

$31401,36401,1000$

$31402,36402,1000$

$31410,36410,1000$

$31411,36411,1000$

$31412,36412,1000$

$31440,36440,1000$

$31441,36441,1000$

$31442,36442,1000$

*BOUNDARY

BSKSY, ZSYMM

** end of file 


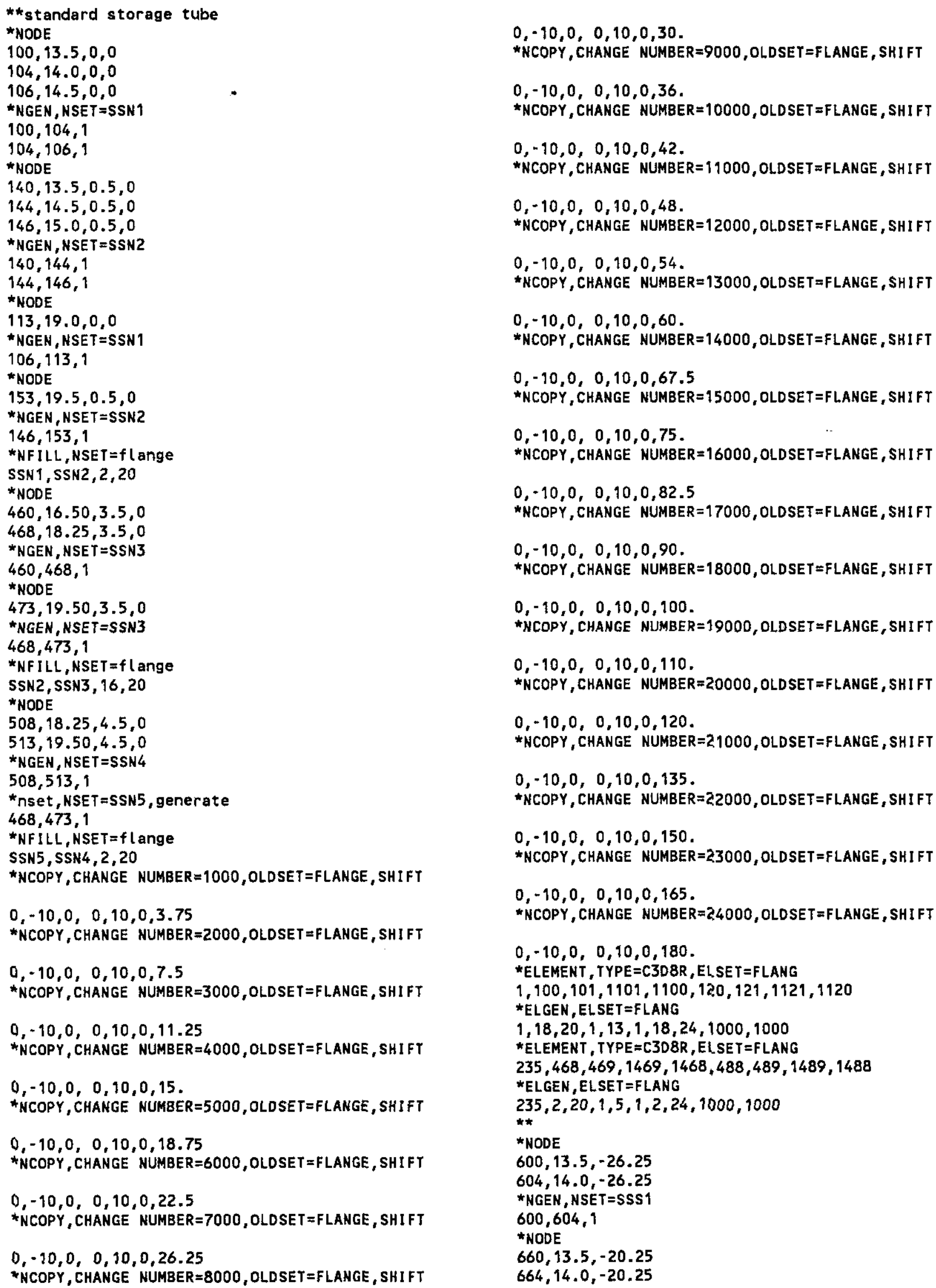


*NGEN , NSET $=$ SSS2

$660,664,1$

*NFILL, NSET $=S S 12$

SSS1, SSS2, 12,5

*NODE

$665,13.5,-20$.

$669,14.0,-20$.

*NGEN , NSET $=\$ S \$ 3$

$665,669,1$

*NODE

$860,13.5,-0.5$

$864,14.0,-0.5$

*NGEN, NSET $=$ SSS 4

$860,864,1$

*NF ILL, NSET $=S S 34$

SSS3, SSS $4,39,5$

* NODE

$865,13.50,-0.25$

$869,14.00,-0.25$

$870,14.25,-0.25$

*NGEN , NSET $=$ SSS5

$865,869,1$

*NSET, NSET T TUBES

SS12, SS34, SSS5, 870

*NCOPY, CHANGE NUMBER $=1000$, OLDSET $=$ TUBES, SHIFT

$0,-10,0,0,10,0,3.75$

$\star N C O P Y$, CHANGE NUMBER $=2000$, OLDSET $=$ TUBES, SHIF T

$0,-10,0,0,10,0,7.5$

$\star$ NCOPY, CHANGE NUMBER $=3000$, OLDSET $=$ TUBES, SHIFT

$0,-10,0,0,10,0,11.25$

*NCOPY, CHANGE NUMBER $=4000$, OLDSET $=$ TUBES , SH I FT

$0,-10,0,0,10,0,15$.

${ }^{*}$ COPY, CHANGE NUMBER $=5000$, OLDSET $=$ TUBES, SHIFT

$0,-10,0,0,10,0,18.75$

*NCOPY, CHANGE NUMBER $=6000$, OLDSET $=$ TUBES, SH I FT

$0,-10,0,0,10,0,22.5$

*NCOPY, CHANGE NUMBER $=7000$, OLDSET $=$ TUBES, SHIFT

$0,-10,0,0,10,0,26.25$

* NCOPY, CHANGE NUMBER $=8000$, OLDSET $=$ TUBES, SH I F T

$0,-10,0,0,10,0,30$.

*NCOPY, CHANGE NUMBER $=9000$, OLDSET $=$ TUBES, SHIFT

$0,-10,0,0,10,0,36$

*NCOPY, CHANGE NUMBER $=10000,0$ LDSET $=$ TUBES, SHIFT

$0,-10,0,0,10,0,42$.

* NCOPY, CHANGE NUMBER $=11000$, OLDSET $=$ TUBES, SHIFT

$0,-10,0,0,10,0,48$.

*NCOPY, CHANGE NUMBER $=12000$, OLDSET $=$ TUBES, SH I F T

$0,-10,0,0,10,0,54$.

${ }^{*}$ NCOPY, CHANGE NUMBER $=13000$, OLDSET $T=$ TUBES, SHI FT

$0,-10,0,0,10,0,60$.

*NCOPY, CHANGE NUMBER $=14000$, OLDSET $=$ TUBES, SHIFT

$0,-10,0,0,10,0,67.5$

* $N$ COPY, CHANGE NUMBER $=15000$, OLDSET $=$ TUBES, SHIFT
$0,-10,0,0,10,0,75$

* $\mathrm{NCOPY}$, CHANGE NUMBER $=16000$, OLDSET $=$ TUBES, SH I FT

$0,-10,0,0,10,0,82.5$

*NCOPY, CHANGE NUMBER $=17000$, OLDSET $=$ TUBES, SH I FT

$0,-10,0,0,10,0,90$.

*NCOPY, CHANGE NUMBER $=18000$, OLDSET $=$ TUBES, SHI FT

$0,-10,0,0,10,0,100$.

*NCOPY, CHANGE NUMBER $=19000$, OLDSET $=$ TUBES, SH I FT

$0,-10,0,0,10,0,110$.

${ }_{\text {NCOPY }}$ CHANGE NUMBER $=20000$, OLDSET $=$ TUBES, SHIFT

$0,-10,0,0,10,0,120$.

${ }_{\text {NCOPY }}$ CHANGE NUMBER $=21000$, OLDSET T=TUBES, SHIFT

$0,-10,0,0,10,0,135$.

*NCOPY, CHANGE NUMBER $=22000$, OLDSET $=$ TUBES, SHIFT

$0,-10,0,0,10,0,150$.

$*$ NCOPY, CHANGE NUMBER $=23000$, OLDSET $=$ TUBES, SH IF T

$0,-10,0,0,10,0,165$.

*NCOPY, CHANGE NUMBER $=24000$, OLDSET $=$ TUBES, SHI F T

$0,-10,0,0,10,0,180$.

*ELEMENT, TYPE $=C 3 D 8 R$, EL SET $T=T$ TUBES

$301,600,601,1601,1600,605,606,1606,1605$

*ELGEN, ELSET $=$ TUBES

$301,53,5,1,4,1,53,24,1000,1000$

*ELEMENT, TYPE $=$ C3D8R, ELSET $=$ TUBES

$550,865,866,1866,1865,100,101,1101,1100$

^ELGEN, ELSET $=$ TUBES

$550,5,9,1,24,1000,1000$

*ELEMENT, TYPE $=$ C3D 6, ELSET $=$ TUBES

$556,869,870,864,1869,1870,1864$

*ELGEN, ELSET T=TUBES

$556,24,1000,1000$

^ELEMENT, TYPE $=$ C3D6, ELSET $=$ TUBES

$557,105,106,870,1105,1106,1870$

*ELGEN, ELSET $=$ TUBES

$557,24,1000,1000$

**

*NODE , NSET $=$ SSP 1

$900,13.75,-475,0$

*NODE, NSET $=$ SSP2

$997,13.75,-27,0$

*NFILL, B [ IAS $=1.03$, NSE T $=$ TUBEP

SSP1, SSP2, 97, 1

*NCOPY, CHANGE NUMBER $=1000$, OLDSET $=$ TUBEP, SHI FT

$0,-10,0,0,10,0,3.75$

${ }^{N}$ COPY, CHANGE NUMBER $=2000,0$ OLDSET $=$ TUBEP, SH I FT

$0,-10,0,0,10,0,7.5$

* $C O P Y$, CHANGE NUMBER $=3000$, OLDSET $=$ TUBEP, SH I FT

$0,-10,0,0,10,0,11.25$

*NCOPY, CHANGE NUMBER $=4000$, OLDSET $=$ TUBEP, SHIFT

$0,-10,0,0,10,0,15$.

$*$ NCOPY, CHANGE NUMBER $=5000$, OLDSET $=$ TUBEP, SHI FT

$0,-10,0,0,10,0,18.75$ 
\#COPY, CHANGE NUMBER $=6000$, OLDSET $=$ TUBEP, SH IFT

$0,-10,0,0,10,0,22.5$

* NCOPY, CHANGE NUMBER $=7000$, OLDSET $=$ TUBEP, SHI FT

$0,-10,0,0,10,0,26.25$

$*$ NCOPY, CHANGE NUMBER $=8000,0$ LDSET $=$ TUBEP, SHI FT

$0,-10,0,0,10,0,30$

* MCOPY, CHANGE NUMBER=9000, OLDSET $=$ TUBEP, SHIFT

$0,-10,0,0,10,0,36$

*NCOPY, CHANGE NUMBER $=10000$, OLDSET $=$ TUBEP, SHI FT

$0,-10,0,0,10,0,42$.

* $N$ COPY, CHANGE NUMBER $=11000$, OLDSET $=$ TUBEP, SHIFT

$0,-10,0,0,10,0,48$.

*NCOPY, CHANGE NUMBER $=12000$, OLDSET $=$ TUBEP, SHIFT

$0,-10,0,0,10,0,54$.

${ }^{*}$ NCOPY, CHANGE NUMBER $=13000$, OLDSET $=$ TUBEP, SH I F T

$0,-10,0,0,10,0,60$.

* $N$ COPY, CHANGE NUMBER $=14000$, OLDSET $=$ TUBEP, SHI F T

$0,-10,0,0,10,0,67.5$

*NCOPY, CHANGE NUMBER $=15000$, OLDSET $=$ TUBEP, SHIFT

$0,-10,0,0,10,0,75$.

* NCOPY, CHANGE NUMBER $=16000$, OLDSET $=$ TUBEP, SHIFT

$0,-10,0,0,10,0,82.5$

* $\mathrm{NCOPY}$, CHANGE NUMBER $=17000$, OLDSET $=$ TUBEP, SHIFT

$0,-10,0,0,10,0,90$.

* $N$ COPY, CHANGE NUMBER $=18000$, OLDSET $=$ TUBEP, SHI F T

$0,-10,0,0,10,0,100$

*NCOPY, CHANGE NUMBER $=19000$, OLDSET $=$ TUBEP, SH IFT

$0,-10,0,0,10,0,110$

*NCOPY, CHANGE NUMBER $=20000$, OLDSET $=$ TUBEP, SH I FT

$0,-10,0,0,10,0,120$.

* $\mathrm{NCOPY}$, CHANGE NUMBER $=21000$, OLDSET $=$ TUBEP, SHI FT

$0,-10,0,0,10,0,135$.

*NCOPY, CHANGE NUMBER $=22000$, OLDSET $=$ TUBEP, SHIFT

$0,-10,0,0,10,0,150$.

*NCOPY, CHANGE NUMBER $=23000$, OLDSET $=$ TUBEP, SHIFT

$0,-10,0,0,10,0,165$.

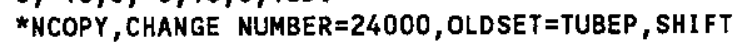

$0,-10,0,0,10,0,180$.

*ELEMENT, TYPE $=\$ 4 R S$, ELSET $=$ TUBEP

$600,900,1900,1901,901$

*ELGEN , ELSET = TUBEP

$600,97,1,1,24,1000,1000$

*ELEMENT, TYPE $=\$ 4 R S$, ELSET $=$ TUBEP

$698,997,1997,1602,602$

^ELGEN, ELSET = TUBEP

$698,24,1000,1000$

^ELEMEN $T, T Y P E=\$ 4 R S$, EL.SE $T=$ TUBEP

$699,602,1602,1607,607$
•ELGEN, ELSET = TUBEP

$699,24,1000,1000$

*nset, nset $=$ f sym, generate

$1,513,1$

$24001,24513,1$

$600,870,1$

$24600,24870,1$

$901,997,1$

$24901,24997,1$

*nset, nset $=P F L R$, generate $900,24900,1000$

*elset, elset=FLGI, generate

$1,18,1$

$1001,1018,1$

$2001,2018,1$

$3001,3018,1$

$4001,4018,1$

$5001,5018,1$

$6001,6018,1$

$7001,7018,1$

$8001,8018,1$

$9001,9018,1$

*elset, elset $=F L G O$, generate

$217,234,1$

$1217,1234,1$

$243,1243,1000$

$244,1244,1000$

* elset, el set=FLGB, generate

$109,217,18$

$1109,1217,18$

*elset, el set =TUB I, generate

$301,353,1$

$1301,1353,1$

$2301,2353,1$

$3301,3353,1$

$4301,4353,1$

$5301,5353,1$

$6301,6353,1$

$7301,7353,1$

$8301,8353,1$

$9301,9353,1$

$550,9550,1000$

*elset, el set $=$ TUBO, generate

$460,511,1$

$1460,1511,1$

$556,1556,1000$

$557,1557,1000$

*BOUNDARY

FSYM, ZSYMM

PFLR, ENCASTRE

**END OF FILE 


\title{
APPENDIX C
}

\section{ABAQUS INPUT FILE}

\author{
SECTION TWO
}

\section{MCO DROP ON SERVICE STATION}

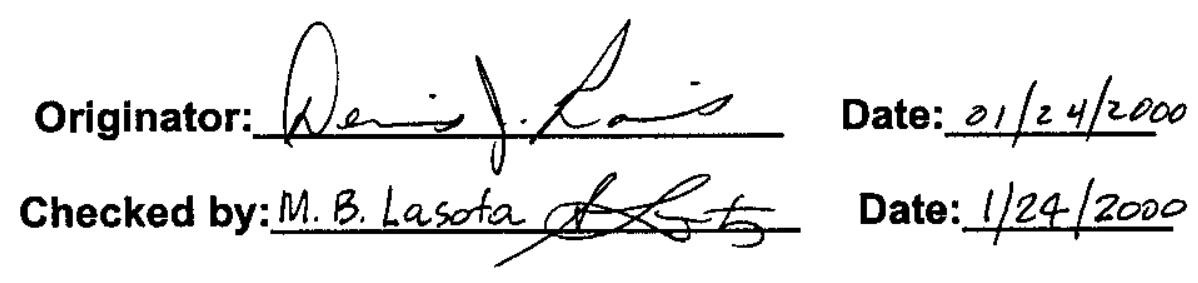




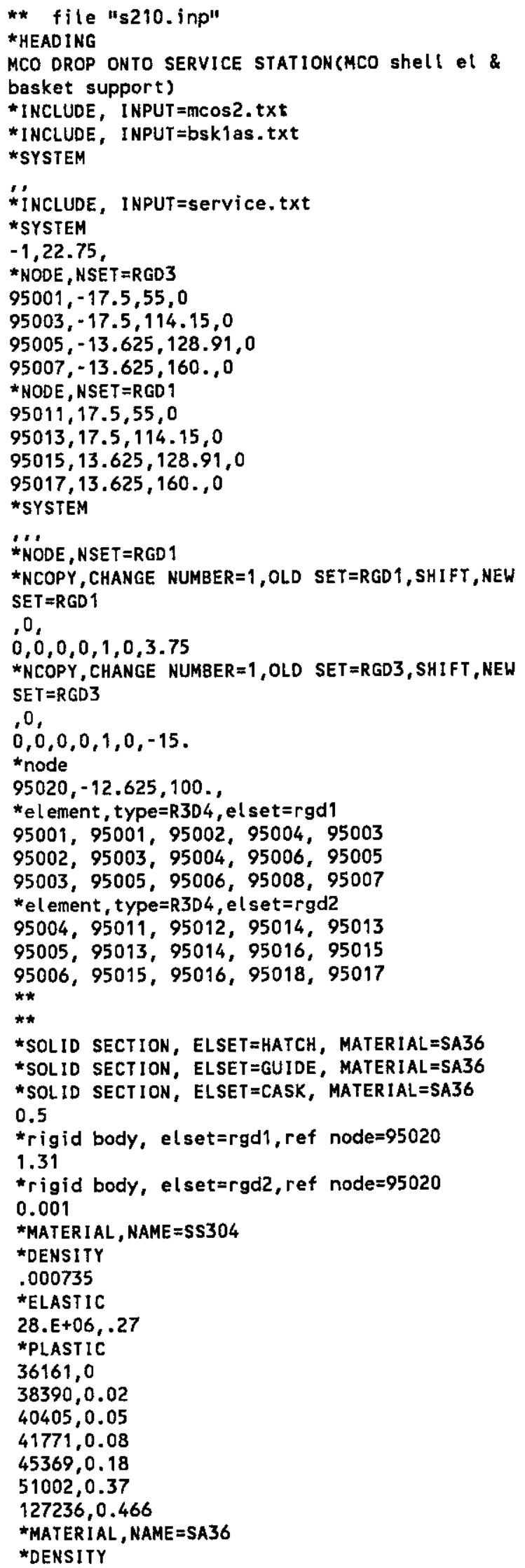


* SURFACE DEFINITION, NAME=rgd1f rgd1, SPOS

* SURFACE DEFINITION, NAME=MCOTL MCOTL, SPOS

*CONTACT PAIR, INTERACT bON=FMTL rgd1 I, MCOTL

*SURFACE INTERACTION, NAME $=$ FMTL

*FRICTION

0.3

**

*SURFACE DEFINITION, NAME $=r g d 2 f$ rgd2, SNEG

*SURFACE DEFINITION, NAME=MCOTR MCOTR, SPOS

*CONTACT PAIR, INTERACTION=FMTR rgd2f,MCOTR

*SURFACE INTERACTION, NAME=FMTR

* FRICTION

0.3

**

*SURFACE DEFINITION, NAME=bskb1 bskb1, s1

bskc1, s1

bskb1, 54

*SURFACE DEFINITION, NAME=bskb2 bskb2, s1

bskc2, s1

bskb2, 54

*SURFACE DEFINITION, NAME=bskb3

bskb3,s1

bskc3,s1

bskb3, 54

*SURFACE DEFINITION, NAME=bskb4

bskb4,s1

bskc4,s1

bskb4, $\$ 4$

*SURFACE DEFINITION, NAME=bskb5

bskb5, s1

bskc5, s1

bskb5, s4

*SURFACE DEFINITION, NAME=bskb6

bskb6, s1

bskc6, s1

bskb6, s4

*CONTACT NODE SET, NAME=bspb

$$
\text { bspb }
$$

"SURFACE DEFINITION, NAME=mcosi

mcobt, $\mathbf{S 2}$

mcosi, s6

*CONTACT PAIR, INTERACTION=BSmCO

bspb, mcos $i$

* SURFACE INTERACTION, NAME=BSmCO

*FRICTION

0.3

*CONTACT NODE SET, NAME=bspt

bspt

"CONTACT PAIR, INTERACTION=BSK01

bsPt, BSKB 1

*SURFACE INTERACTION, NAME=BSK01

*FRICTION

0.3

*SURFACE DEFINITION, NAME=mcotb mCOt, s1

*SURFACE DEFINITION, NAME=mcopi

mcopl, sneg

*CONTACT PAIR, INTERACTION=b1

BSKB1, mCOPi

\section{INPUT FILE S210.inp}

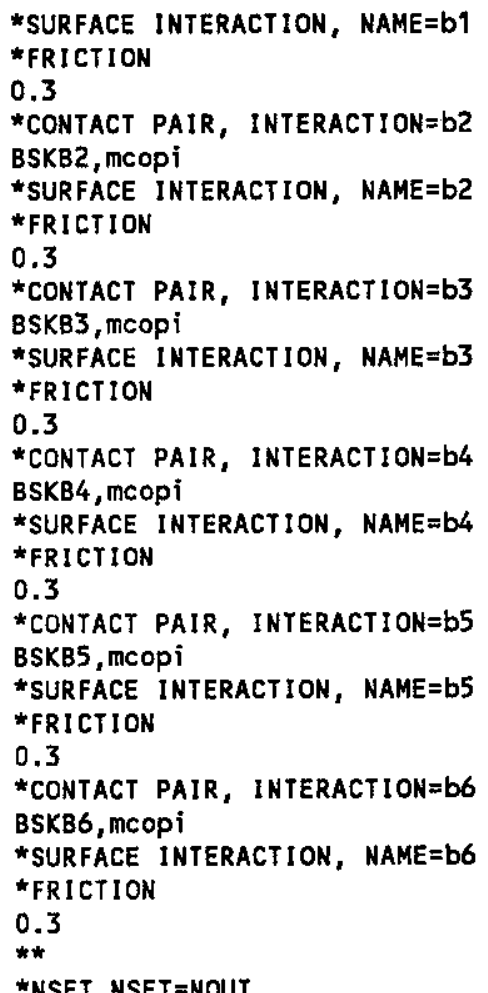

WNET NSET=NOUT

$70019,70000,70179,82019,94019,82133,94133$

$31231,32231,33231,34231,35231,36231,94577$

*nset, nset=nout, generate

$31000,36000,1000$

$31024,36024,1000$

$31025,31037,1$

$32025,32037,1$

$33025,33037,1$

$34025,34037,1$

$35025,35037,1$

$36025,36037,1$

*NSET, GENERATE, NSET $=$ TOUT

**

** nodes for Service station output

$\star *$

$100,800,20$

$\star \star 100,220,60$

$24100,24220,60$

$600,850,50$

$24600,24850,50$

$70300,94300,1000$

$70301,94301,1000$

$70302,94302,1000$

$70303,94303,1000$

$70304,94304,1000$

$70305,94305,1000$

$70306,94306,1000$

$70307,94307,1000$

$70308,94308,1000$

$70309,94309,1000$

*ELSET, ELSET=EOUT, generate

70016,70156, 20

$70017,70157,20$

$70018,70158,20$

$70019,70159,20$

$70160,70175,1$

$71016,71456,20$ 


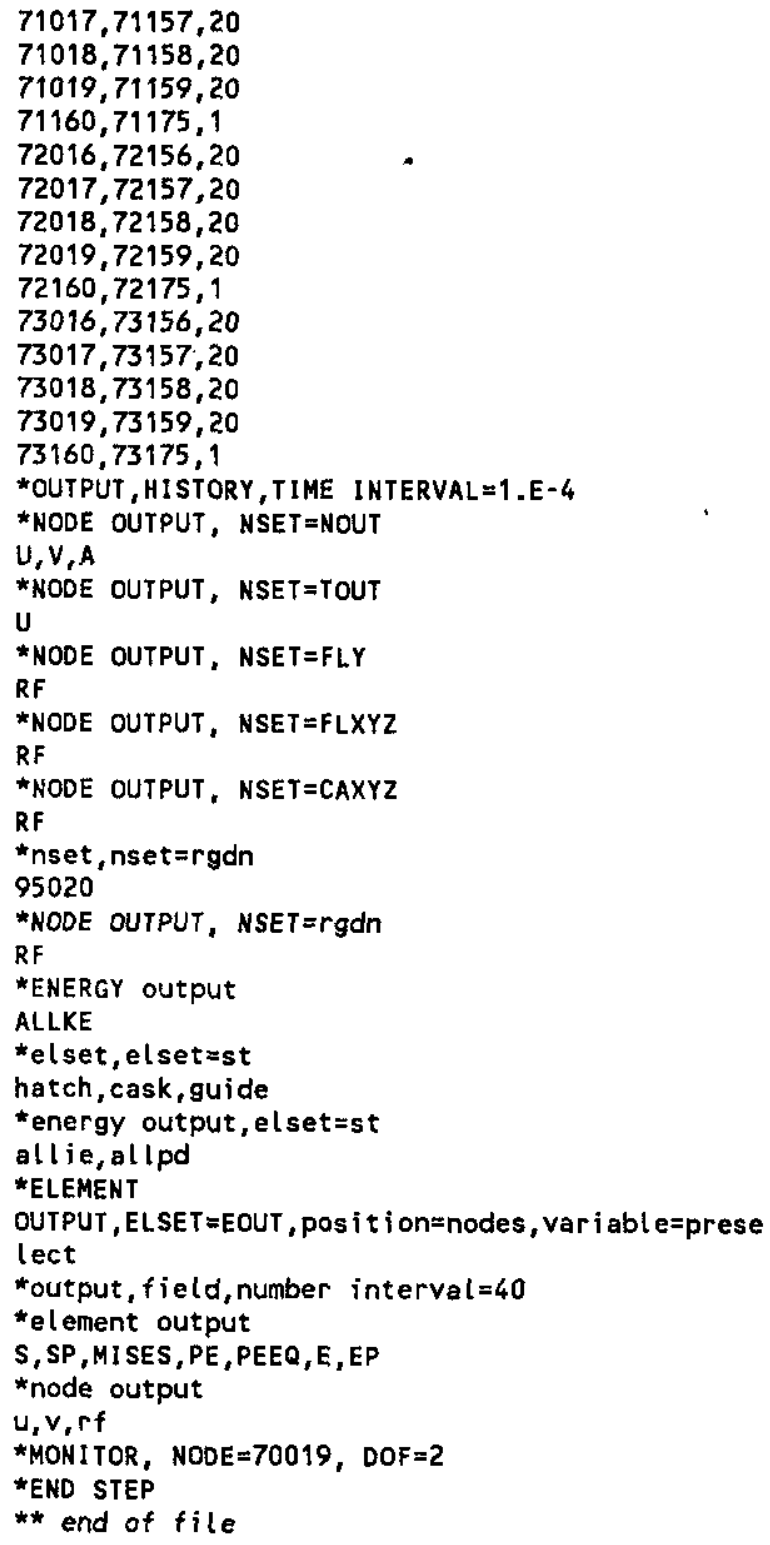




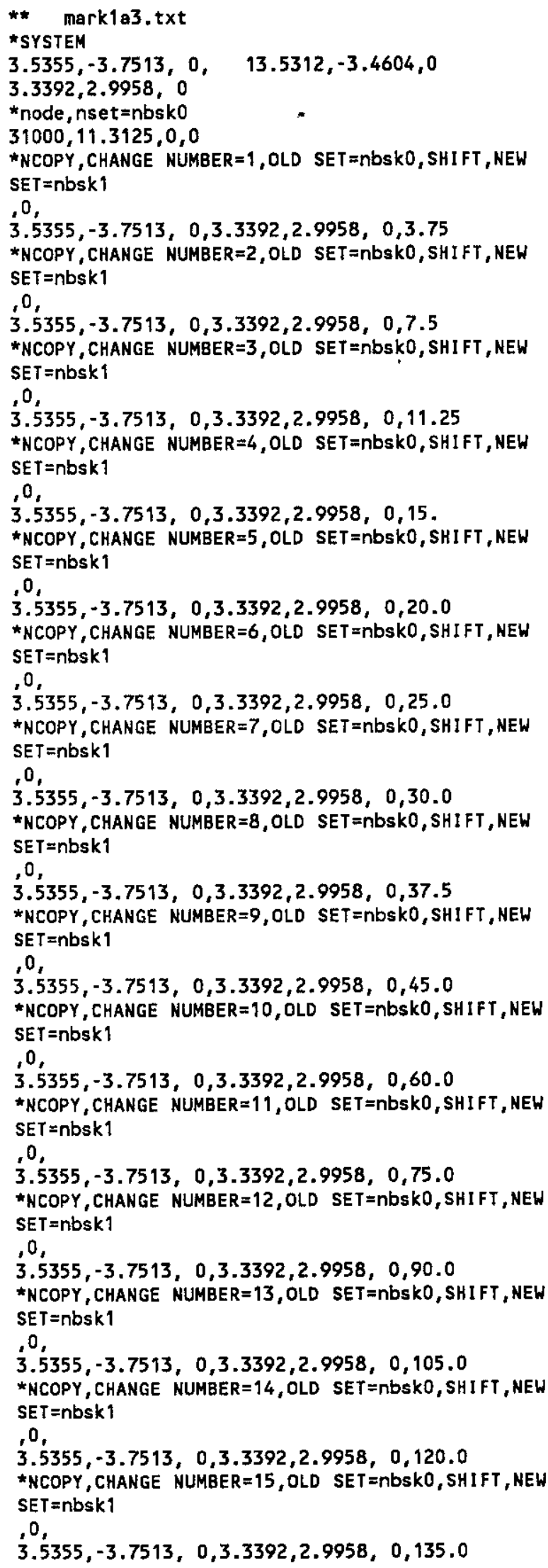

*NCOPY, CHANGE NUMBER $=16$, OLD SET $=n b s k 0$, SHIFT, NEW SET $=$ nbsk 1

, 0 ,

$3.5355,-3.7513,0,3.3392,2.9958,0,142.5$

*NCOPY, CHANGE NUMBER $=17$, OLD SET $=n b s k 0$, SHIFT, NEW SET $=$ nbsk 1

0 ,

$3.5355,-3.7513,0,3.3392,2.9958,0,150.0$ *NCOPY, CHANGE NUMBER $=18$, OLD SET $=n b s k 0$, SH I FT, NEW SET=nbsk1

0 ,

$3.5355,-3.7513,0,3.3392,2.9958,0,155.0$ *NCOPY, CHANGE NUMBER $=19,0 L O$ SET $=n b s k O$, SHIFT, NEW SET $=$ nbsk 1

0 ,

$3.5355,-3.7513,0,3.3392,2.9958,0,160.0$ * NCOPY, CHANGE NUMBER $=20$, OLD SET $=n b s k 0$, SHIFT, NEW SET=nbsk 1

0 ,

$3.5355,-3.7513,0,3.3392,2.9958,0,165.0$ *NCOPY, CHANGE NUMBER $=21$, OLD SET $=n b S k O$, SHIFT, NEW SET $=$ nbsk 1

0 , $3.5355,-3.7513,0,3.3392,2.9958,0,168.75$ *NCOPY, CHANGE NUMBER $=22$, OLD SET $=n b S k O$, SH IFT, NEW SET $=$ nbsk 1

0 ,

$3.5355,-3.7513,0,3.3392,2.9958,0,172.5$

*NCOPY, CHANGE NUMBER $=23$, OLD SET =nbSkO, SHIFT, NEW SET $=$ nbsk 1

. 0 ,

$3.5355,-3.7513,0,3.3392,2.9958,0,176.25$

*NCOPY, CHANGE NUMBER $=24$, OLD SET=nbsKO, SHIFT, NEW SET=nbsK 1

0 ,

$3.5355,-3.7513,0,3.3392,2.9958,0,180$.

*nset, nset=nbsk1

nbsko

*node

$31037,-10.3,0,0$

$31115,-8.9,0,-5.1$

*ngen, nset=bskt 1

31037,31115, 13

*node

$31025,10.3,0,0$

$31103,8.9,0,-5.1$

*ngen, nset =bskt2

31025, 31103, 13

*node

$31031,0,0,0$

$31109,0,0,-10.3$

*ngen, nset $=$ bskt3

31031,31109, 13

*nfill, nset=nbsk1

bskt2, bskt3, 6, 1

bskt3, bskt1,6,1

*NCOPY, CHANGE NUMBER $=200$, OLD SET $=n b s k 1$, SHIFT, NEW SET T =nbsk1

$-0.0291,0.9996$

*node, nset $=$ bskp0

$31410,11.3125,7,0$

$31411,11.3125,13,0$

$31412,11.3125,19,0$

*NCOPY, CHANGE NUMBER $=10$, OLD SET $=b s k p O$, SHIFT, NEW SET $=$ nbskp, mul $t$ ipl $e=3$

, 0 , 
$3.5355,-3.7513,0,3.3392,2.9958,0,60$.

*node, nset =nbskp

$31400, .7,0$

$31401,13,0$

$31402, .19,0$

*nset, nset =nbsk1

nbskp, bskpo

*NCOPY, CHANGE NUMBER $=1000$, OLD SET $=n b s k 1$, SH I FT, NEW SET $=$ nbsk

$-0.6738,23.1562$

*NCOPY, CHANGE NUMBER $=2000$, OLD SET=nbsk1, SHIFT, NEW SET $=$ nbsk

$-1.3476,46.3124$

*NCOPY, CHANGE NUMBER $=3000$, OLD SET $=$ nbSK 1, SHIFT, NEW SET $=$ nbsk

$-2.0213,69.4686$

*NCOPY, CHANGE NUMBER $=4000$, OLD SET=nbsk 1, SHIFT, NEW SET $=$ nbsk

$-2.6951,92.6248$

*NCOPY, CHANGE NUMBER $=5000$, OLD SET $=n b s k 1$, SH I FT, NEW SET $=$ nbsk

$-3.3689,115.7810$

*nset, nset $=$ bsk

nbsk, nbsk1

*ELEMENT, TYPE $=$ C3D8R, ELSET $\mathrm{T}=\mathrm{b} S \mathrm{~K} 0$

$31001,31025,31000,31001,31038,31225,31200,31201,3$ 1238

$31002,31038,31001,31002,31051,31238,31201,31202,3$

1251

$31003,31051,31002,31003,31064,31251,31202,31203,3$

1264

$31004,31064,31003,31004,31077,31264,31203,31204,3$ 1277

$31005,31077,31004,31005,31090,31277,31204,31205,3$ 1290

$31006,31090,31005,31006,31103,31290,31205,31206,3$ 1303

$31007,31103,31006,31007,31104,31303,31206,31207,3$ 1304

$31019,31115,31018,31019,31102,31315,31218,31219,3$ 1302

$31020,31102,31019,31020,31089,31302,31219,31220,3$ 1289

$31021,31089,31020,31021,31076,31289,31220,31221,3$

1276

$31022,31076,31021,31022,31063,31276,31221,31222,3$

1263

$31023,31063,31022,31023,31050,31263,31222,31223,3$

1250

$31024,31050,31023,31024,31037,31250,31223,31224,3$

1237

$31025,31026,31025,31038,31039,31226,31225,31238,3$

1239

*ELGEN, ELSET $=$ bskO

$31007,12,1,1$

$31025,12,1,1,6,13,12$

*ELcopy, el ement shift $=1000$, old set $=b s k 0$, shift nodes $=1000$, new SET $=$ bsk

$\star E L$ copy, element shift $=2000$, old set=bsk0, shift nodes $=2000$, new SET $=$ bsk

*ELcopy, el ement shif $t=3000$, old set=bsk0, shift nodes $=3000$, new SET $=b s k$
*ELcopy, element shift $=4000$, old set $=b s k 0$, shift nodes $=4000$, new $S E T=b s k$

*ELcopy, el ement shif $t=5000$, old set $=b s k 0$, shift nodes $=5000$, new SET $=$ bsk

*elset, elset $=$ bsk

bskO

*ELEMENT, TYPE $=B 31$, ELSET $=$ pos tc

$31101,31031,31231$

$31102,31231,31400$

$31103,31400,31401$

$31105,31402,32031$

*ELEMENT, TYPE=B31, ELSET=pos th

$31111,31000,31200$

$31112,31200,31410$

$31113,31410,31411$

$31115,31412,32000$

*ELEMENT , TYPE $=B 31$, ELSET $=$ pos $t f$

$31121,31010,31210$

$31122,31210,31420$

$31123,31420,31421$

$31125,31422,32010$

$31131,31014,31214$

$31132,31214,31430$

$31133,31430,31431$

$31135,31432,32014$

*ELEMENT, TYPE $=B 31$, ELSET $=$ pos th

$31141,31024,31224$

$31142,31224,31440$

$31143,31440,31441$

$31145,31442,32024$

*ELGEN, ELSET=pos tc

$31101,6,1000,1000$

$31102,6,1000,1000$

$31103,2,1,1,6,1000,1000$

$31105,5,1000,1000$

*ELGEN, ELSET $=$ pos th

$31111,6,1000,1000$

$31112,6,1000,1000$

$31113,2,1,1,6,1000,1000$

$31115,5,1000,1000$

$31141,6,1000,1000$

$31142,6,1000,1000$

$31143,2,1,1,6,1000,1000$

$31145,5,1000,1000$

*ELGEN, ELSET $=$ post $f$

$31121,6,1000,1000$

$31122,6,1000,1000$

$31123,2,7,1,6,1000,1000$

$31125,5,1000,1000$

$31131,6,1000,1000$

$31132,6,1000,1000$

$31133,2,1,1,6,1000,1000$

$31135,5,1000,1000$

*elset, elset=ebsk

posth, post $f$, postc

*SOLID SECTION, ELSET=bsk, MATERIAL=bsk

*BEAM SECTION, ELSET=postc, MATER IAL=bskp.

SECTION=pipe

$3.125,2.4375$

*BEAM SECTION, ELSET=postf， MATERIAL=bskp, SECTION= TrapeZoid

$3.114,1.45,1.23,0$

*BEAM SECTION, ELSET=posth, MATERIAL=bskp, SECTION= 5 rapezoid

$1.557,1.45,0.615,0$

*MATERIAL, NAME $=b s k$

*DENSITY 
APPENDIX C SECTION TWO INPUT FILE Bsk1as.txt

BSKSY, ZSYMM

.01472

*ELASTIC

** end of file

28.E+06, . 27

«PLASTIC

30032.0 .0

$100701 ., 0.293$

$101451 ., 0.300$

102201.0 .307

*MATER I AL , NAME =bskp

*DENSITY

.000735

*ELASTIC

28.E+06, .27

*PLASTIC

30032.0 .0

100701.0 .293

$101451 ., 0.300$

$102201 ., 0.307$

*elset, el set=bskb1, generate $31001,31024,1$

*el set, el set=bskb2, generate $32001,32024,1$

*elset, el set=bskb3, generate $33001,33024,1$

*el set, el set $=b s k b 4$, generate $34001,34024,1$

*elset, el set=bskb5, generate 35001,35024, 1

*elset, el set=bskb6, generate $36001,36024,1$

*elset, elset =bskc1, generate 31025,31096, 1

* elset, el set=bskc2, generate 32025,32096, 1

*el set, el set =bskc3, generate 33025, 33096, 1

*elset, el set=bskc4, generate $34025,34096,1$

*el set, el set=bskc5, generate 35025, 35096, 1

*elset, el set=bskc6, generate $36025,36096,1$

*nset, nset=BSKSY, generate

$31000,36000,1000$

$31024,36024,1000$

$31025,31037,1$

$31225,31237,1$

$32025,32037,1$

$32225,32237,1$

$33025,33037,1$

$33225,33237,1$

$34025,34037,1$

$34225,34237,1$

$35025,35037,1$

$35225,35237,1$

$36025,36037,1$

$36225,36237,1$

$31400,36400,1000$

$31401,36401,1000$

$31402,36402,1000$

$31410,36410,1000$

$31411,36411,1000$

$31412,36412,1000$

$31440,36440,1000$

$31441,36441,1000$

$31442,36442,1000$

*BOUNDARY 
INPUT FILE Mcos2.txt

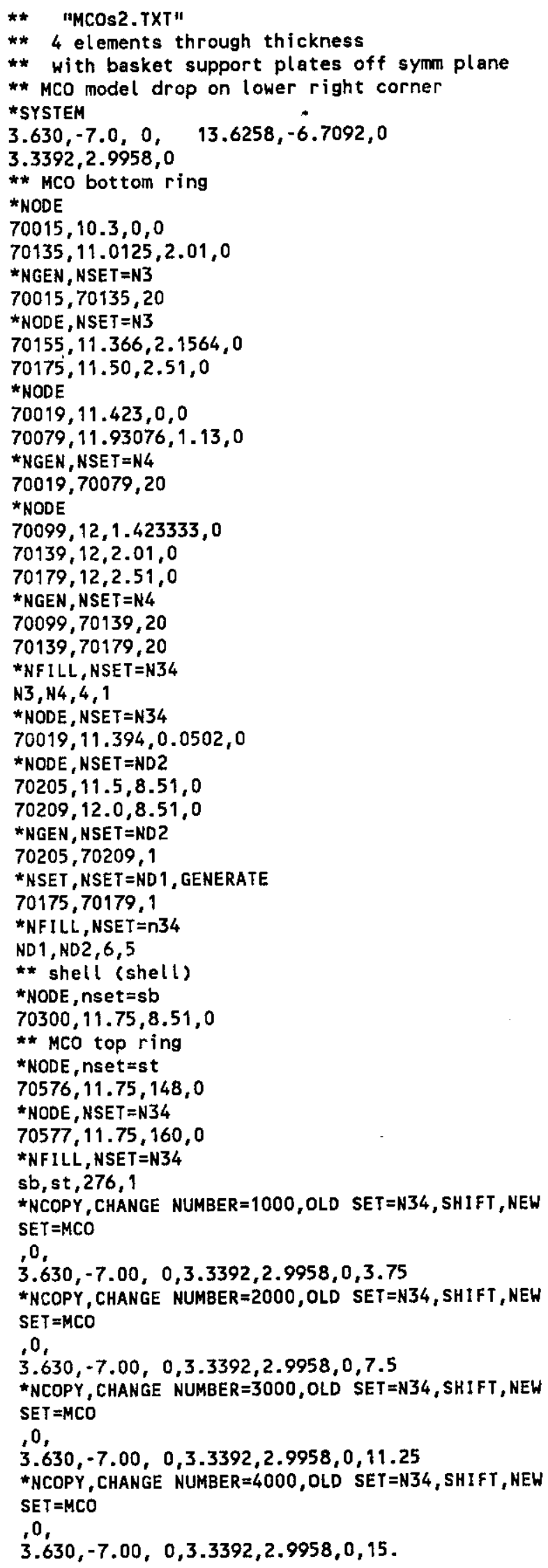

*NCOPY, CHANGE NUMBER $=5000$, OLD SET $=N 34$, SHIFT, NEH $S E T=M C O$

0 , $3.630,-7.00,0,3.3392,2.9958,0,20.0$ *NCOPY, CHANGE NUMBER $=6000$, OLD SET $=N 34,5 H I F T, N E W$ $S E T=M C O$

0 ,

$3.630,-7.00,0,3.3392,2.9958,0,25.0$

* NCOPY, CHANGE NUMBER $=7000$, OLD SET $=$ N34, SHIFT, NEW $S E T=M C O$

$\therefore$,

$3.630,-7.00,0,3.3392,2.9958,0,30.0$

*NCOPY, CHANGE NUMBER $=8000$, OLD SET $=N 34$, SHIFT, NEW SET $=M C O$

0 ,

$3.630,-7.00,0,3.3392,2.9958,0,37.5$

*NCOPY, CHANGE NUMBER $=9000$, OLD SET $=N 34$, SHIFT, NEW SET $=M C O$

0 ,

$3.630,-7.00,0,3.3392,2.9958,0,45.0$

*NCOPY, CHANGE NUMBER $=10000$, OLD SET $=N 34$, SHIFT, NEW SET $=$ MCO

0 ,

$3.630,-7.00,0,3.3392,2.9958,0,60.0$

* NCOPY, CHANGE NUMBER $=11000$, OLD SET $=N 34$, SHIFT, NEW SET $=M C O$

0 ,

$3.630,-7.00,0,3.3392,2.9958,0,75.0$

*NCOPY, CHANGE NUMBER $=12000$, OLD SET $=$ N34, SHIFT, NEW SET $T=M C O$

0 ,

$3.630,-7.00,0,3.3392,2.9958,0,90.0$

*NCOPY, CHANGE NUMBER $=13000$, OLD SET $=N 34$, SHIFT, NEH SET $=M C O$

0 ,

$3.630,-7.00,0,3.3392,2.9958,0,105.0$

*NCOPY, CHANGE NUMBER $=14000$, OLD SET $=N 34$, SHIFT, NEW $S E T=M C O$

0 ,

$3.630,-7.00,0,3.3392,2.9958,0,120.0$

*NCOPY, CHANGE NUMBER $=15000$, OLD SET $=N 34$, SHIFT, NEW SET $=M C O$

0 ,

$3.630,-7.00,0,3.3392,2.9958,0,135.0$

*NCOPY, CHANGE NUMBER $=16000$, OLD SET $=N 34$, SHIFT, NEW SET $=M C O$

0 ,

$3.630,-7.00,0,3.3392,2.9958,0,142.5$

*NCOPY, CHANGE NUMBER $=17000$, OLD SET $=N 34$, SHIFT, NEW $S E T=M C O$

0 ,

$3.630,-7.00,0,3.3392,2.9958,0,150.0$

*NCOPY, CHANGE NUMBER $=18000$, OLD SET $=$ N34, SHI FT, NEW SET $=M C O$

0 ,

$3.630,-7.00,0,3.3392,2.9958,0,155.0$

$\star_{N C O P Y, C H A N G E ~ N U M B E R}=19000$, OLD SET $=N 34, S H I F T, N E W$ $S E T=M C O$

0 .

$3.630,-7.00,0,3.3392,2.9958,0,160.0$

*NCOPY, CHANGE NUMBER $=20000$, OLD SET $=N 34$, SHIFT, NEW SET $=$ MCO

0 ,

$3.630,-7.00,0.3 .3392,2.9958,0,165.0$

$*$ NCOPY, CHANGE NUMBER $=21000$, OLD SET $=N 34$, SHIFT, NEW SET $=M C O$

, 0 , 
$3.630,-7.00,0,3.3392,2.9958,0,168.75$

*NCOPY, CHANGE NUMBER $=22000$, OLD SET $=N 34$, SHIFT, NEH $S E T=M C O$

0 ,

$3.630,-7.00,0,3.3392,2.9958,0,172.5$

*NCOPY, CHANGE NUMBER $=23000$, OLD SET $=N 34$, SHIFT, NEW $S E T=M C O$

.0 ,

$3.630,-7.00,0,3.3392,2.9958,0,176.25$

*NCOPY, CHANGE NUMBER $=24000,0 L D$ SET $=N 34$, SHIFT, NEW SET $=M C O$

.0 ,

$3.630,-7.00,0,3.3392,2.9958,0,180$

*NODE

$70000,1.25,0,0$

$70060,1.25,1.13,0$

*NGEN, NSET $=$ N 1

$70000,70060,20$

*NODE

$70120,2.13,2.01,0$

"NGEN, NSET $=$ N 1

$70060,70120,20$

* NCOPY, CHANGE NUMBER $=1000$, OLD SET $=N 1$, SHIFT, NEW

SE $T=N 1$, MUL T IPLE $=24$

0 ,

$3.630,-7.00,0,3.3392,2.9958,0,7.5$

*NSET, NSET $=$ N2, GENERATE

$70015,94015,1000$

$70035,94035,1000$

$70055,94055,1000$

$70075,94075,1000$

$70095,94095,1000$

$70115,94115,1000$

$70135,94135,1000$

*NFILL, NSET $=N 12$, BIAS $=1.01$

N1, N2, 15, 1

*ELEMENT, TYPE $=C 308 R$, ELSET $=M C O B$

$70001,70000,70001,71001,71000,70020,70021,71021,7$ 1020

$70160,70175,70176,71176,71175,70180,70181,71181,7$ 1180

*ELGEN, ELSET $T=M C O B$

$70001,19,1,1,6,20,20,24,1000,1000$

$70116,2,20,20$

$70136,4,1,1,2,20,20,24,1000,1000$

$70160,4,1,1,6,5,4,24,1000,1000$

*mpc

beam, 70300,70205

beam, 71300,71205

beam, 72300,72205

beam, 73300,73205

beam, 74300,74205

bean, 75300,75205

beam, 76300,76205

beam, 77300,77205

bean, 78300,78205

bean, 79300,79205

beam, 80300,80205

beam, 81300,81205

beam, 82300,82205

beam, 83300,83205

beam, 84300,84205

beam, 85300,85205

beam, 86300,86205

beam, 87300,87205

beam, 88300,88205

beam, 89300,89205 beam, 90300,90205

beam, 91300,91205

beam, 92300,92205

beam, 93300,93205

beam, 94300,94205

beam, 70300,70206

beam, 71300,71206

beam, 72300,72206

beam, 73300,73206

beam, 74300,74206

beam, 75300,75206

beam, 76300,76206

beam, 77300,77206

beam, 78300,78206

beam, 79300,79206

beam, 80300,80206

beam, 81300,81206

beam, 82300,82206

beam, 83300,83206

beam, 84300,84206

beam, 85300,85206

beam, 86300,86206

beam, 87300,87206

beam, 88300,88206

beam, 89300,89206

beam, 90300,90206

beam, 91300,91206

beam, 92300,92206

beam, 93300,93206

beam, 94300,94206

pin, 70300,70207

pin, 71300,71207

pin, 72300,72207

pin, 73300,73207

pin, 74300,74207

pin, 75300,75207

pin, 76300,76207

pin, 77300,77207

pin, 78300,78207

pin, 79300,79207

pin, 80300,80207

pin, 81300,81207

pin, 82300,82207

pin, 83300,83207

pin, 84300,84207

pin, 85300,85207

pin, 86300,86207

pin, 87300,87207

pin, 88300,88207

pin, 89300,89207

pin, 90300,90207

pin, 91300,91207

pin, 92300,92207

pin, 93300,93207

pin, 94300,94207

beam, 70300,70208

beam, 71300,71208

beam, 72300,72208

beam, 73300,73208

beam, 74300,74208

beam, 75300,75208

beam, 76300,76208

beam, 77300,77208

beam, 78300,78208

beam, 79300,79208

beam, 80300,80208

beam, 81300,81208 
beam, 82300,82208

beam, 83300,83208

beam, 84300,84208

beam, 85300,85208

beam, 86300,86208

beam, 87300,87208

bean, 88300,88208

beam, 89300,89208

beam, 90300,90208

beam, 91300,91208

beam, 92300,92208

beam, 93300,93208

beam, 94300,94208

beam, 70300,70209

beam, 71300,71209

beam, 72300,72209

beam, 73300,73209

beam, 74300,74209

beam, 75300,75209

beam, 76300,76209

beam, 77300,77209

beam, 78300,78209

beam,79300,79209

beam, 80300,80209

beam, 81300,81209

beam, 82300,82209

beam, 83300,83209

beam, 84300,84209

beam, 85300,85209

beam, 86300,86209

beam, 87300,87209

bean, 88300,88209

beam, 89300,89209

beam, 90300,90209

beam, 91300,91209

beam, 92300,92209

beam, 93300,93209

beam, 94300,94209

*ELEMENT, TYPE $=\$ 4 R S, E L S E T=M C O P L$

$70300,70300,71300,71301,70301$

*ELGEN, ELSET $=$ MCOPL

$70300,277,1,1,24,1000,1000$

** MCO bottom center

*NODE

$60000,-1.08,0,0$

$66000,-.7637,0,-.7637$

*NGEN, NSET $=19$

$60000,66000,1000$

*NODE

$60012,1.08,0,0$

$66012, .7637,0,-.7637$

*NGEN, NSET $=$ L2

$60012,66012,1000$

*NODE

$60006,0,0,0$

$66006,0,0,-1.08$

*NGEN, NSET $=$ L3

$60006,66006,1000$

*NFILL, NSET $=L 12$

$L 1, L 3,6,1$

$L 3, L 2,6,1$

*NCOPY, CHANGE NUMBER $=60$, OLD SET $=L 12$, SHIFT, NEW SET $=L 13$

$-0.0256,0.8796,0$

*NFILL, NSET $=\mathrm{L} 14$

$L 12, L 13,3,20$
*ELEMENT, TYPE $=C 3 D 8 R$, ELSE T $=M C O B$

$60101,60000,60001,61001,61000,60020,60021,61021,6$ 1020

*ELGEN, ELSET = MCOB

$60101,12,1,1,6,1000,12,3,20,72$

*ELEMENT, TYPE $=$ C3D8R, ELSET=EB 1

$60001,60012,70000,71000,61012,60032,70020,71020,6$ 1032

*ELGEN, ELSET $=$ EB2

$60001,6,1000,1,3,20,6$

*ELEMENT, TYPE $=$ C3D8R , ELSET $=E B 3$

$60019,66012,76000,77000,66011,66032,76020,77020,6$ 6031

$60020,66011,77000,78000,66010,66031,77020,78020,6$ 6030

$60021,66010,78000,79000,66009,66030,78020,79020,6$ 6029

$60022,66009,79000,80000,66008,66029,79020,80020,6$ 6028

$60023,66008,80000,81000,66007,66028,80020,81020,6$ 6027

$60024,66007,81000,82000,66006,66027,81020,82020,6$ 6026

$60025,66006,82000,83000,66005,66026,82020,83020,6$ 6025

$60026,66005,83000,84000,66004,66025,83020,84020,6$ 6024

$60027,66004,84000,85000,66003,66024,84020,85020,6$ 6023

$60028,66003,85000,86000,66002,66023,85020,86020,6$ 6022

$60029,66002,86000,87000,66001,66022,86020,87020,6$ 6021

$60030,66001,87000,88000,66000,66021,87020,88020,6$ 6020

$60031,66000,88000,89000,65000,66020,88020,89020,6$

5020

$60032,65000,89000,90000,64000,65020,89020,90020,6$ 4020

$60033,64000,90000,91000,63000,64020,90020,91020,6$ 3020

$60034,63000,91000,92000,62000,63020,91020,92020,6$ 2020

$60035,62000,92000,93000,61000,62020,92020,93020,6$ 1020

$60036,61000,93000,94000,60000,61020,93020,94020,6$ 0020

*ELCOPY, ELEMENT SHIFT $=18$, OLD SET=EB3, SHIFT

NODES $=20$, NEW SET $=E B 4$

*ELCOPY, ELEMENT SHIFT=18, OLD SET=EB4, SHIFT

NOOES $=20, N E W$ SET $=E B 5$

*ELSET, ELSET $=$ MCOB

$E B 2, E B 3, E B 4, E B 5$

** MCO top center

*NODE

$50000,-10.8,148,0$

$56000,-9.3,148,-5.4$

*NGEN, NSET $=$ T 1

$50000,56000,1000$

*NODE

$50012,10.8,148,0$

$56012,9.3,148,-5.4$

*NGEN, NSET $=T 2$

$50012,56012,1000$

*NODE

$50006,0,148,0$

$56006,0,148,-10.8$ 
*NGEN, NSET $T=T 3$

$50006,56006,1000$

*NFILL, NSET $=\mathrm{T} 12$

$T 1, T 3,6,1$

$T 3, T 2,6,1$

*NCOPY, CHANGE NUMBER $=20$, OLD SET $=T 12$, SHIFT, NEW

SET $=T 13$

$-0.3490,11.9949,0$

*ELEMENT, TYPE $=C 3 D 8 R$, ELSET $=M C O T$

$60601,50000,50001,51001,51000,50020,50021,51021,5$

1020

*ELGEN, ELSET $=M C O T$

$60601,12,1,1,6,1000,12$

*ELEMENT, TYPE $=$ C3D $8 R$, ELSET $=E B 11$

$50001,50012,70576,71576,51012,50032,70577,71577,5$ 1032

*ELGEN, ELSET=EB11

$50001,6,1000,1$

*ELEMENT, TYPE $=C 308 R, E L S E T=E B 12$

$50007,56012,76576,77576,56011,56032,76577,77577,5$

6031

$50008,56011,77576,78576,56010,56031,77577,78577,5$ 6030

$50009,56010,78576,79576,56009,56030,78577,79577,5$

6029

$50010,56009,79576,80576,56008,56029,79577,80577,5$

6028

$50011,56008,80576,81576,56007,56028,80577,81577,5$ 6027

$50012,56007,81576,82576,56006,56027,81577,82577,5$ 6026

$50013,56006,82576,83576,56005,56026,82577,83577,5$ 6025

$50014,56005,83576,84576,56004,56025,83577,84577,5$ 6024

$50015,56004,84576,85576,56003,56024,84577,85577,5$ 6023

$50016,56003,85576,86576,56002,56023,85577,86577,5$ 6022

$50017,56002,86576,87576,56001,56022,86577,87577,5$

6021

$50018,56001,87576,88576,56000,56021,87577,88577,5$

6020

$50019,56000,88576,89576,55000,56020,88577,89577,5$

5020

$50020,55000,89576,90576,54000,55020,89577,90577,5$

4020

$50021,54000,90576,91576,53000,54020,90577,91577,5$

3020

$50022,53000,91576,92576,52000,53020,91577,92577,5$

2020

$50023,52000,92576,93576,51000,52020,92577,93577,5$

1020

$50024,51000,93576,94576,50000,51020,93577,94577,5$ 0020

*ELSET, EL.SET $=$ MCOT

EB11, EB12

**

*ELSET , ELSET $=$ MCOBB, GENERATE

$70019,82019,1000$

$70018,82018,1000$

$70017,82017,1000$

$70016,82016,1000$

$70015,82015,1000$

$70014,82014,1000$

*ELSET, ELSET $=$ MCOBF, GENERATE
$70019,82019,1000$

$70039,82039,1000$

$70059,82059,1000$

$70079,82079,1000$

$70099,82099,1000$

$70119,82119,1000$

$70139,82139,1000$

*ELSET, ELSET $=$ MCOTR

70576

*ELSET, ELSET =MCOTL

93576

***ELSET, ELSET $=M \operatorname{MCOSF}$, GENERATE

**70202,70215, 1

$* * 71202,71215,1$

$\star * 72202,72215,1$

$* * 73202,73215,1$

**74202,74215, 1

$\star * 75202,75215,1$

$\star \star 76202,76215,1$

**77202,77215, 1

$* * 78202,78215,1$

**79202,79215, 1

** add basket support plates

* node

$40140,0.5,2.01,0$

$40200,0.5,3.25,0$

$40154,11.00,2.01,0$

$40214,11.00,3.25,0$

*ngen, nset $=$ bsp 1

$40140,40200,20$

*ngen, nset $=$ bsp2

40154,40214, 20

${ }^{*}$ NCOPY, CHANGE NUMBER $=1000$, OLD SET $=$ bSP1, SHIFT, NEW SET $=b s p 3$

.0 ,

$3.630,-7.00,0,3.3392,2.9958,0,0$

*NCOPY, CHANGE NUMBER $=2000$, OLD SET $=b s p 1$, SHIFT, NEW SET $=$ bsp3

0 ,

$3.630,-7.00,0,3.3392,2.9958,0,30$

*NCOPY, CHANGE NUMBER $=3000$, OLD SET=bsp1, SHIFT, NEW SET $=b s p 3$

0 ,

$3.630,-7.00,0.3 .3392,2.9958,0,60$

*NCOPY, CHANGE NUMBER $=4000,0 L D$ SET $=b S P 1$, SHIFT, NEW SET $=$ bsp3

0 ,

$3.630,-7.00,0,3.3392,2.9958,0,60$

*NCOPY, CHANGE NUMBER $=5000$, OLD SET $=b S P 1$, SHIFT, NEW SET $=$ bsp3

0 ,

$3.630,-7.00,0,3.3392,2.9958,0,90$

*NCOPY, CHANGE NUMBER $=6000,0 L D$ SET $=b s p 1$, SHIFT, NEW SET $=$ bsP3

0 ,

$3.630,-7.00,0,3.3392,2.9958,0,120$

*NCOPY, CHANGE NUMBER $=7000$, OLD SET $=b S P 1$, SH $1 F T, N E W$ SET $=$ bsp3

0 ,

$\dot{3} .630,-7.00,0,3.3392,2.9958,0,120$

*NCOPY, CHANGE NUMBER $=8000,0$ LD SET $=b S P 1$, SHIFT, NEW SET $=b s p 3$

0 ,

$3.630,-7.00,0,3.3392,2.9958,0,150$

*NCOPY, CHANGE NUMBER $=9000,0 L D$ SET=bsP1, SHI FT, NEW SET $=b s p 3$

0 . 
$3.630,-7.00,0,3.3392,2.9958,0,180$

* NCOPY, CHANGE NUMBER $=1000,0 L D$ SET $=b s p 2$, SH I FT, NEW SET $=$ bsp4

0 ,

$3.630,-7.00,0,3.3392,2.9958,0,28.69805$

*NCOPY, CHANGE NUMBER $=2000,0 L 0$ SET $=b s p 2$, SHIFT, NEW SET $=$ bSP4

0 ,

$3.630,-7.00,0,3.3392,2.9958,0,30$

*NCOPY, CHANGE NUMBER $=3000$, OLD SET=bsP2, SHI I FT, NEW SET $=$ bsp4

0 ,

$3.630,-7.00,0,3.3392,2.9958,0,31.30195$

*NCOPY, CHANGE NUMBER $=4000$, OLD SET $=b s P 2$, SHIFT, NEW

SET $=$ bSP4

0 ,

$3.630,-7.00,0,3.3392,2.9958,0,88.69805$

*NCOPY, CHANGE NUMBER $=5000$, OLD SET=bsp2, SHIFT, NEW

SET $=$ bsp4

0 ,

$3.630,-7.00,0,3.3392,2.9958,0,90$

*NCOPY, CHANGE NUMBER $=6000$, OLD SET $=b s p 2$, SH1FT, NEW SET $\mathrm{T}=\mathrm{bsp4}$

0 ,

$3.630,-7.00,0,3.3392,2.9958,0,91.30195$

*NCOPY, CHANGE NUMBER $=7000$, OLD SET $=b s p 2$, SHIFT, NEW

SET $=$ bsp4

0 ,

$3.630,-7.00,0,3.3392,2.9958,0,148.69805$

*NCOPY, CHANGE NUMBER $=8000,0$ LD SET=bSP2, SHIFT, NEW SE T $=$ bsp4

0 ,

$3.630,-7.00,0,3.3392,2.9958,0,150$

*NCOPY, CHANGE NUMBER $=9000$, OLD SET $=b S P 2$, SHIFT, NEW SET $=$ bsp4

0 ,

$3.630,-7.00,0,3.3392,2.9958,0,151.30195$

*nset, nset $=$ bsp3

bsp1

*nset, nset $=\mathrm{bsp} 4$

bsp2

*nfill, nset $=$ mco

bsp3, bsp4, 14, 1

*ELEMENT , TYPE $=c 308 R$, EL SET $=b S P$

$97001,41140,41141,42141,42140,41160,41161,42161,4$ 2160

$97101,42140,42141,43141,43140,42160,42161,43161,4$ 3160

*ELGEN , ELSET $=$ bSP

$97001,14,1,1,3,20,14,3,3000,200$

$97101,14,1,1,3,20,14,3,3000,200$

*mpc

link, 43140,44140

link, 43160,44160

link, 43180,44180

link, 43200,44200

l ink, 46140,47140

l ink, 46160,47160

link, 46180,47180

link, 46200,47200

*ELSET, ELSET $=$ MCOSL

MCOT, MCOB

*SOL ID SECTION, ELSET=MCOSL, MATERIAL=\$S304

*SHELL SECTION, ELSET=MCOPL， MATERIAL=SS304

0.5

*SOLID SECTION, ELSET=bSp, MATERIAL=SS304

*nset, nset=bspb, generate
$41140,41154,1$

$42140,42154,1$

$43140,43154,1$

$44140,44154,1$

$45140,45154,1$

$46140,46154,1$

$47140,47154,1$

$48140,48154,1$

$49140,49154,1$

*nset, nset=bspt, generate

41200,$41214 ; 1$

$42200,42214,1$

$43200,43214,1$

$44200,44214,1$

$45200,45214,1$

$46200,46214,1$

$47200,47214,1$

$48200,48214,1$

$49200,49214,1$

*NSET, NSET $=$ MCO

N34, SB, ST, N12, L14, T12,T13

bspt, bspb

^ELSET, ELSET=MCO

MCOPL, MCOSL, bsp

*elset, el set=mcobt, generate

$70101,93101,1000$

$70102,93102,1000$

$70103,93103,1000$

$70104,93104,1000$

$70105,93105,1000$

$70106,93106,1000$

$70107,93107,1000$

$70108,93108,1000$

$70109,93109,1000$

$70110,93110,1000$

$70111,93111,1000$

$70112,93112,9000$

$70113,93113,1000$

$70114,93114,1000$

$70115,93115,1000$

*elset, el set=mcos $i$, generate

$70136,93136,1000$

$70156,93156,1000$

$70160,93160,1000$

$70164,93164,1000$

$70168,93168,1000$

$70172,93172,1000$

$70176,93176,1000$

$70180,93180,1000$

*NSET, NSET = MCOSY, GENERATE

$70000,70999,1$

$94000,94999,1$

$50000,50999,1$

$60000,60999,1$

$79140,79200,20$

*BOUNDARY

MCOSY, ZSYMM

** end of file 


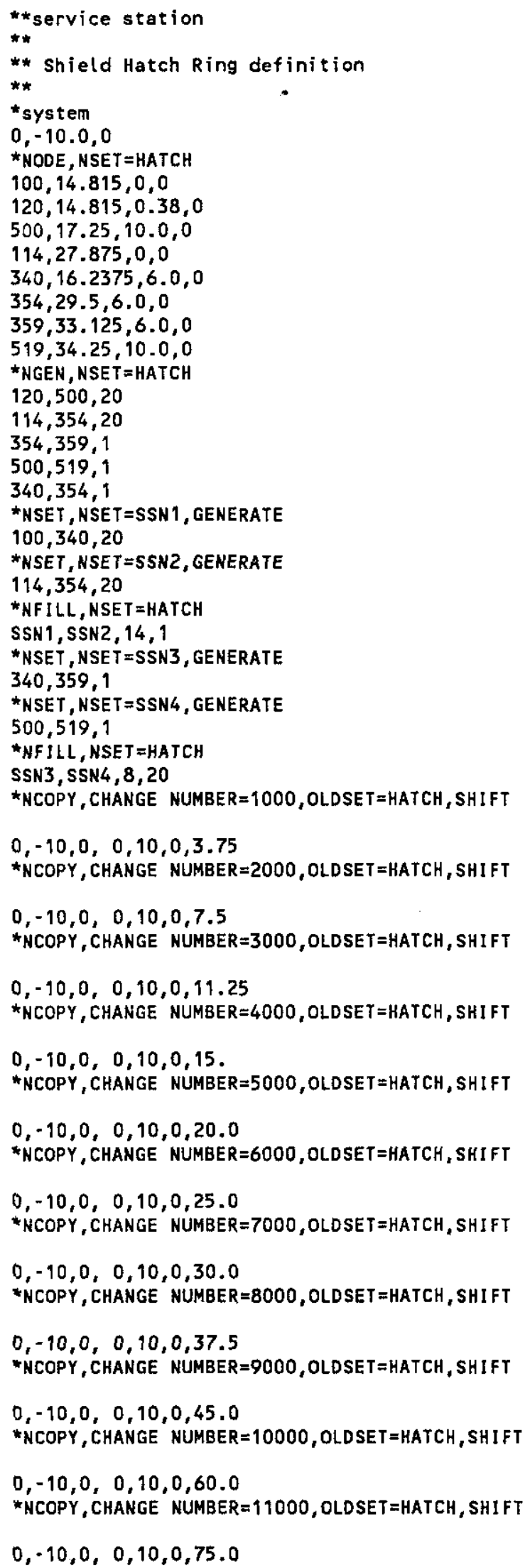

*NCOPY, CHANGE NUMBER $=12000$, OLDSET $=$ HATCH, SHIFT $0,-10,0,0,10,0,90.0$

*NCOPY, CHANGE NUMBER $=13000$, OLDSET $=$ HATCH , SHIFT

$0,-10,0,0,10,0,105.0$

$*$ NCOPY, CHANGE NUMBER $=14000$, OLDSET $=$ HATCH, SHI FT

$0,-10,0,0,10,0,120.0$

*NCOPY, CHANGE NUMBER $=15000$, OLDSET $=$ HATCH, SHIFT

$0,-10,0,0,10,0,135,0$

*NCOPY, CHANGE NUMBER $=16000$, OLDSET $=H A T C H, S H I F T$

$0,-10,0,0,10,0,142.5$

*NCOPY, CHANGE NUMBER $=17000$, OLOSET $=$ HATCH, SHIFT

$0,-10,0,0,10,0,150.0$

$*$ NCOPY, CHANGE NUMBER $=18000$, OLDSET $=$ HATCH, SHIFT

$0, \cdots 10,0,0,10,0,155.0$

* NCOPY, CHANGE NUM8ER $=19000$, OLDSET $=$ HATCH, SH $1 \mathrm{FT}$

$0,-10,0,0,10,0,160.0$

* NCOPY, CHANGE NUMBER $=20000$, OLDSET $=$ HATCH, SH IFT

$0,-10,0,0,10,0,165.0$

* NCOPY, CHANGE NUMBER $=21000$, OLDSET $=$ HATCH, SHIFT

$0,-10,0,0,10,0,168.75$

*NCOPY, CHANGE NUMBER $=22000$, OLDSET $=$ HATCH , SHIFT

$0,-10,0,0,10,0,172.5$

*NCOPY, CHANGE NUMBER $=23000$, OLDSET $=$ HATCH, SHIFT

$0,-10,0,0,10,0,176.25$

*NCOPY, CHANGE NUMBER $=24000$, OLDSET $=$ HATCH, SHIFT

$0,-10,0,0,10,0,180$

*ELEMENT, TYPE $=$ C3D8R, ELSET $=$ HATCH

$1,100,101,1101,1100,120,121,1121,1120$

*ELGEN, ELSET $=$ HATCH

$1,20,20,1,14,1,20,24,1000,1000$

*ELEMENT, TYPE $=$ C3D8R, ELSE T $=$ HATCH

$281,354,355,1355,1354,374,375,1375,1374$

*ELGEN, ELLSET $=$ HATCH

$281,8,20,1,5,1,8,24,1000,1000$

$\star *$

** Element sets for surfaces

**

*ELSET, ELSET =FLSI, GENERATE

$1,20,1$

$1001,1020,1$

$2001,2020,1$

$3001,3020,1$

$4001,4020,1$

$5001,5020,1$

$6001,6020,1$

$7001,7020,1$

$8001,8020,1$

$9001,9020,1$

**

**

** MCO Guide definition

**

*system 
$0,-18.81,0$

* NODE

$520,14.905,0,0$

$533,20.75,0,0$

$534,14.905, .5,0$

$547,20.75, .5,0$

$548,13.315,1.0,0$

$549,14.11,1.0,0$

$550,14.905,1.0,0$

$563,20.75,1.0,0$

$564,13.315,1.25,0$

$579,20.75,1.25,0$

$772,15.125,8.0,0.0$

$787,20.75,8.0,0$

*NGEN

$520,533,1$

$534,547,1$

$550,563,1$

* NGEN, NSET $=$ SSN 5

$564,579,1$

*NGEN, NSET T=SSNG

$772,787,1$

*NFILL

SSN5, SSN6, 13, 16

**

** Adjust node coordinates to correct element angles

**

*NODE

$565,14.11,1.25,0$

*NGEN

$565,579,1$

*NSET, NSET = GUIDE, GENERATE

$520,787,1$

*NCOPY, CHANGE NUMBER $=1000$, OLDSET $=$ GUIDE, SHIFT

$0,-10,0,0,10,0,3.75$

* $N$ COPY, CHANGE NUMBER $=2000$, OLDSET $=$ GUIDE,$S H I F T$

$0,-10,0,0,10,0,7.5$

*NCOPY, CHANGE NUMBER $=3000$, OLDSET $=$ GUIDE, SH I FT

$0,-90,0,0,10,0,11.25$

* NCOPY, CHANGE NUMBER $=4000$, OLDSET $=$ GUIDE, SHIFT

$0,-10,0,0,10,0,15$.

*NCOPY , CHANGE NUMBER $=5000$, OLDSET $=$ GUIDE, SHIFT

$0,-10,0,0,10,0,20.0$

${ }_{N}$ COPY, CHANGE NUMBER $=6000$, OLDSET $=$ GUIDE, SHIFT

$0,-10,0,0,10,0,25.0$

*NCOPY, CHANGE NUMBER $=7000$, OLDSET $=$ GUIDE, SHIFT

$0,-10,0,0,10,0,30.0$

*NCOPY, CHANGE NUMBER $=8000$, OLDSET $=$ GUIDE, SH I FT

$0,-10,0,0,10,0,37.5$

*NCOPY, CHANGE NUMBER $=9000$, OLDSET $=$ GUIDE, SHIFT

$0,-10,0,0,10,0,45.0$

* NCOPY, CHANGE NUMBER $=10000$, OLDSET $=$ GUIDE, SHIFT

$0,-10,0,0,10,0,60.0$

$\star$ NCOPY, CHANGE NUMBER $=11000$, OLDSET $=$ GUIDE, SHIFT

$0,-10,0,0,10,0,75.0$
*NCOPY, CHANGE NUMBER $=12000$, OLDSET $=$ GUIDE, SHIFT

$0,-10,0,0,10,0,90.0$

*NCOPY, CHANGE NUMBER $=13000,0 L D S E T=$ GUIDE, SHIFT

$0,-10,0,0,10,0,105.0$

*NCOPY, CHANGE NUMBER $=14000$, OLDSET $=$ GUIDE, SHIFT

$0,-10,0,0,10,0,120.0$

*NCOPY, CHANGE NUMBER $=15000$, OLDSET $=$ GUIDE, SHIFT

$0,-10,0,0,10,0,135.0$

*NCOPY, CHANGE NUMBER $=16000$, OLDSET $=$ GUIDE, SHIFT

$0,-10,0,0,10,0,142.5$

*NCOPY, CHANGE NUMBER $=17000$, OLDSET $=$ GUIDE, SH'FT

$0,-10,0,0,10,0,150,0$

*NCOPY, CHANGE NUMBER $=18000$, OLDSET $=$ GUIDE, SHIFT

$0,-10,0,0,10,0,155,0$

* NCOPY, CHANGE NUMBER $=19000$, OLDSET $=$ GUIDE, SHI FT

$0,-10,0,0,10,0,160.0$

* NCOPY, CHANGE NUMBER $=20000$, OLDSET $=$ GUIDE, SHIFT

$0,-10,0,0,10,0,165,0$

* $N$ COPY, CHANGE NUMBER $=21000$, OLDSET $T=G U 1 D E$, SHIF $\mathrm{T}$

$0,-10,0,0,10,0,168.75$

*NCOPY, CHANGE NUMBER $=22000$, OLDSET $=$ GUIDE, SHIFT

$0,-10,0,0,10,0,172.5$

*NCOPY, CHANGE NUMBER $=23000$, OLDSET $=$ GUIDE, SHI F T

$0,-10,0,0,10,0,176.25$

*NCOPY, CHANGE NUMBER $=24000$, OLDSET $=$ GUIDE, SHIFT

$0,-10,0,0,10,0,180$.

*ELEMENT, TYPE $=$ C3DBR, ELSET $=$ GUIDE

$584,520,521,1521,1520,534,535,1535,1534$

*ELGEN, ELSET = GUIDE

$584,13,1,1,24,1000,1000$

*ELEMENT, TYPE $=C 3 D 8 R, E L S E T=G U I D E$

$598,534,535,1535,1534,550,551,1551,1550$

*EL,GEN, ELSET $=$ GUIDE

$598,13,1,1,24,1000,1000$

*ELEMENT, TYPE $=$ C3D8R, ELSET $=$ GUIDE

$612,548,549,1549,1548,564,565,1565,1564$

*ELGEN, ELSET $=$ GUIDE

$612,15,1,1,14,16,16,24,1000,1000$

**

** Element sets for surfaces

**

*ELSET, ELSET $=$ GS I , GENERATE

$612,820,16$

$1612,1820,16$

$2612,2820,16$

$3612,3820,16$

$4612,4820,16$

$5612,5820,16$

$6612,6820,16$

$7612,7820,16$

$8612,8820,16$

$9612,9820,16$

*ELSET, ELSET=GSB1

612,613 


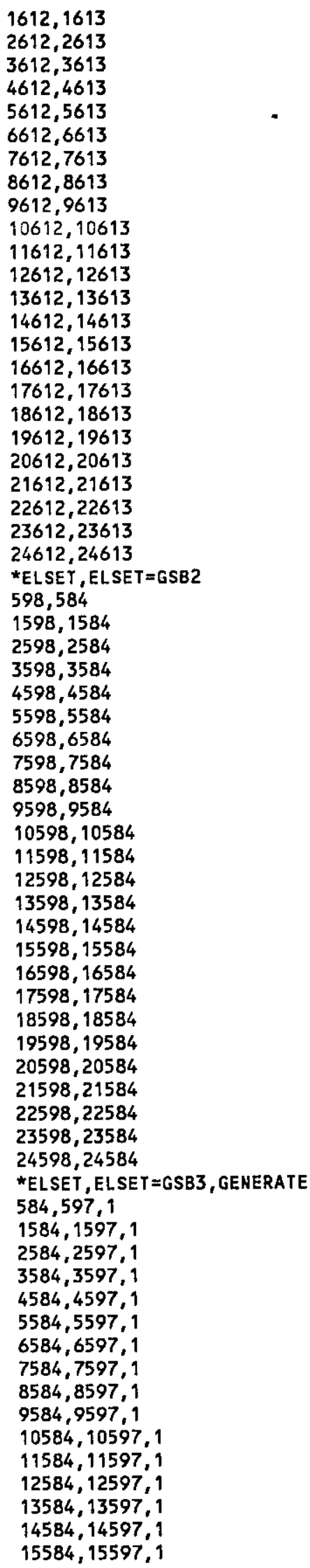

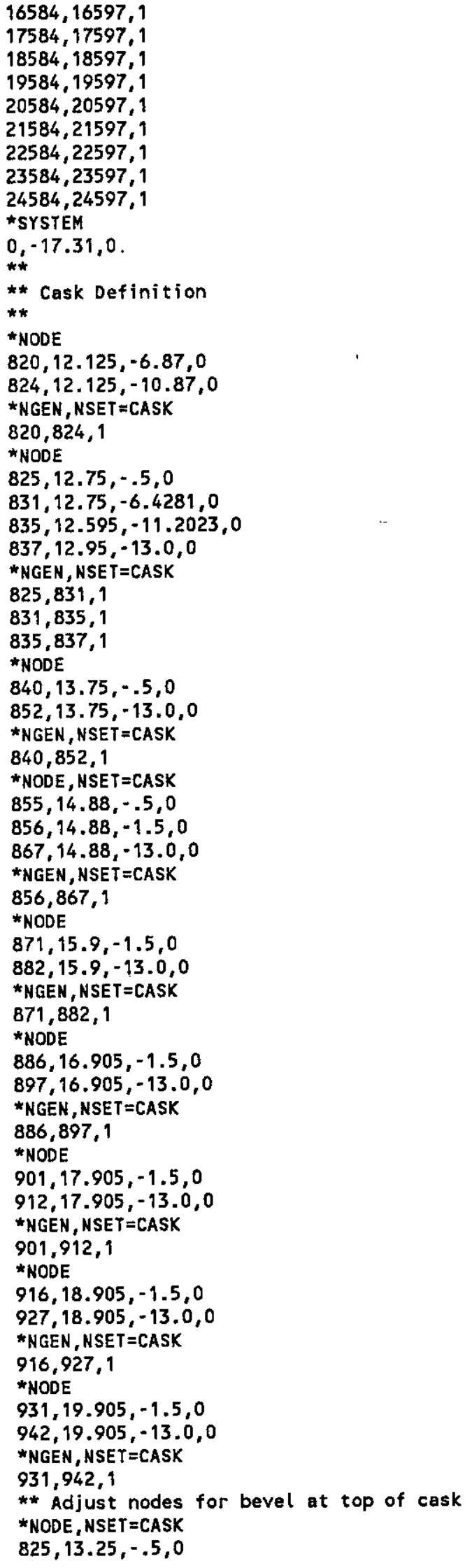


$826,12.9833,-1.5,0$

$827,12.75,-2.375,0$

* $N$ COPY, CHANGE NUMBER $=1000$, OLDSET $=$ CASK, SHIFT

$0,-10,0,0,10,0,3.75$

${ }_{N \text { COPY }}$ CHANGE NUMBER $=2000^{\circ}$, OLDSET=CASK, SHIFT

$0,-10,0,0,10,0,7.5$

*NCOPY, CHANGE NUMBER $=3000$, OLDSET $=$ CASK, SHI I T

$0,-10,0,0,10,0,11.25$

* NCOPY, CHANGE NUMBER $=4000$, OLDSET $T=C A S K$, SHIFT

$0,-10,0,0,10,0,15$.

* NCOPY, CHANGE NUMBER $=5000$, OLDSET $=$ CASK, SHIFT

$0,-10,0,0,10,0,20.0$

$*$ NCOPY, CHANGE NUMBER $=6000$, OLDSET $=$ CASK, SH IFT

$0,-10,0,0,10,0,25.0$

* $N$ COPY, CHANGE NUMBER $=7000$, OL.DSET $=$ CASK, SHIFT

$0,-10,0,0,10,0,30.0$

*NCOPY, CHANGE NUMBER $=8000$, OLDSET $=$ CASK, SHIFT

$0,-10,0,0,10,0,37,5$

* $N$ COPY, CHANGE NUMBER $=9000,0 L D S E T=C A S K$, SHIFT

$0,-10,0,0,10,0,45.0$

$\star$ NCOPY, CHANGE NUMBER $=10000$, OLDSET $=$ CASK, SHIFT

$0,-10,0,0,10,0,60.0$

* NCOPY, CHANGE NUMBER $=11000$, OLDSET $=$ CASK, SHIFT

$0,-10,0,0,10,0,75.0$

$* N C O P Y, C H A N G E$ NUMBER $=12000$, OLDSET $=C A S K$, SHI FT

$0,-10,0,0,10,0,90.0$

$\star$ NCOPY, CHANGE NUMBER $=13000$, OLDSET $=$ CASK, SHIFT

$0,-10,0,0,10,0,105,0$

*NCOPY, CHANGE NUMBER $=14000$, OLDSET $=$ CASK, SH I FT

$0,-10,0,0,10,0,120.0$

* NCOPY, CHANGE NUMBER $=15000$, OLDSET $=$ CASK, SH I FT

$0,-10,0,0,10,0,135.0$

${ }^{*}$ NCOPY, CHANGE NUMBER $=16000$, OLDSET $=$ CASK, SHIFT

$0,-10,0,0,10,0,142.5$

* $N$ COPY, CHANGE NUMBER $=17000$, OLDSET $=$ CASK, SHIFT

$0,-10,0,0,10,0,150.0$

*NCOPY, CHANGE NUMBER $=18000$, OLDSET $=$ CASK, SHIFT

$0,-10,0,0,10,0,155.0$

$\star_{N C O P Y}$, CHANGE NUMBER $=19000$, OLDSE $T=C A S K$, SHI F T

$0,-10,0,0,10,0,160.0$

${ }^{*}$ NCOPY, $C H A N G E$ NUMBER $=20000$, OLDSET $=$ CASK, SHI F T

$0,-10,0,0,10,0,165.0$

*NCOPY, CHANGE NUMBER $=21000$, OLDSET $=$ CASK, SHI FT

$0,-10,0,0,10,0,168.75$

${ }^{*}$ COPY, CHANGE NUMBER $=22000$, OLDSET $=$ CASK, SHI F T
$0,-10,0,0,10,0,172.5$

*COPY, CHANGE NUMBER $=23000$, OLDSET $=$ CASK, SHIFT

$0,-10,0,0,10,0,176.25$

$*$ NCOPY, CHANGE NUMBER $=24000$, OLDSET $=$ CASK, SHI F T

$0,-10,0,0,10,0,180$

**

**

*ELEMENT, TYPE $=$ C3D8R, ELSE T $=$ CASK

$501,821,832,1832,1821,820,831,1831,1820$

*ELGEN, ELSET $=$ CASK

$501,4,1,1,24,1000,1000$

*ELEMENT, TYPE $=$ C3D8R, ELSET $T=$ CASK

$505,826,841,1841,1826,825,840,1840,1825$

*ELGEN, ELSET=CASK

$505,12,1,1,2,15,12,24,1000,1000$

¿ELEMENT, TYPE $=C 3 D 8 R, E L S E T=C A S K$ $529,857,872,1872,1857,856,871,1871,1856$

*ELGEN, ELSET =CASK

$529,11,1,1,5,15,11,24,1000,1000$

$\star \star$

** Element set for surface

**

*ELSET, ELSET =CAI 1, GENERATE

$505,510,1$

$501,504,1$

$515,516,1$

$1505,1510,1$

$1501,1504,1$

$1515,1516,1$

$2505,2510,1$

$2501,2504,1$

$2515,2516,1$

$3505,3510,1$

$3501,3504,1$

$3515,3516,1$

$4505,4510,1$

$4501,4504,1$

$4515,4516,1$

$5505,5510,1$

$5501,5504,1$

$5515,5516,1$

$6505,6510,1$

$6501,6504,1$

$6515,6516,1$

$7505,7510,1$

$7501,7504,1$

$7515,7516,1$

$8505,8510,1$

$8501,8504,1$

$8515,8516,1$

$9505,9510,1$

$9501,9504,1$

$9515,9516,1$

*ELSET, ELSET $=$ CAI 2

501

1501

2501

3501

4501

5501

6501

7501

8501

9501

*ELSET , ELSET $=C A 13$ 
APPENDIX C SECTION TWO INPUT FILE Service.txt

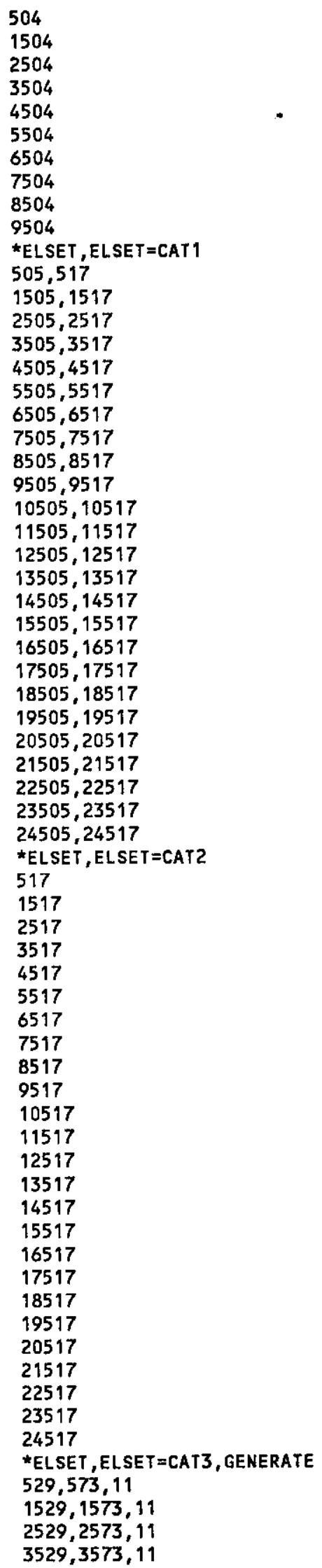

$4529,4573,11$

$6529,6573,11$

$7529,7573,11$

$8529,8573,11$

$9529,9573,11$

$10529,10573,11$

$11529,11573,11$

$12529,12573,11$

$13529,13573,11$

$14529,14573,11$

$15529,15573,11$

$16529,16573,11$

$17529,17573,11$

$18529,18573,11$

19529,$19573 ; 11$

$20529,20573,11$

$21529,21573,11$

$22529,22573,11$

$23529,23573,11$

$24529,24573,11$

**

** Set boundary conditions

**

*NSET, NSE T =FSYM, GENERATE

$100,942,1$

24100,24942,1

*NSET, NSET =FLY, GENERATE

$355,24355,1000$

$356,24356,1000$

$357,24357,1000$

$358,24358,1000$

*NSET, NSET = FLXYZ, GENERATE

$359,24359,1000$

*NSET , NSET $=$ CAXYZ, GENERATE

$837,24837,1000$

$852,24852,1000$

$867,24867,1000$

$882,24882,1000$

$897,24897,1000$

$912,24912,1000$

$927,24927,1000$

$942,24942,1000$

*BOUNDARY

FSYM, ZSYMM

FLY, 2

FLXYZ, 1, 3

CAXYZ, 1, 3

ॠะEND OF FILE 
SNF-5204, Rev. 2/CSB-S-0073

\section{APPENDIX D}

\section{PEER REVIEW COMMENT RECORD}

AND FDNW TRANSMITTAL RECORD

D.1 


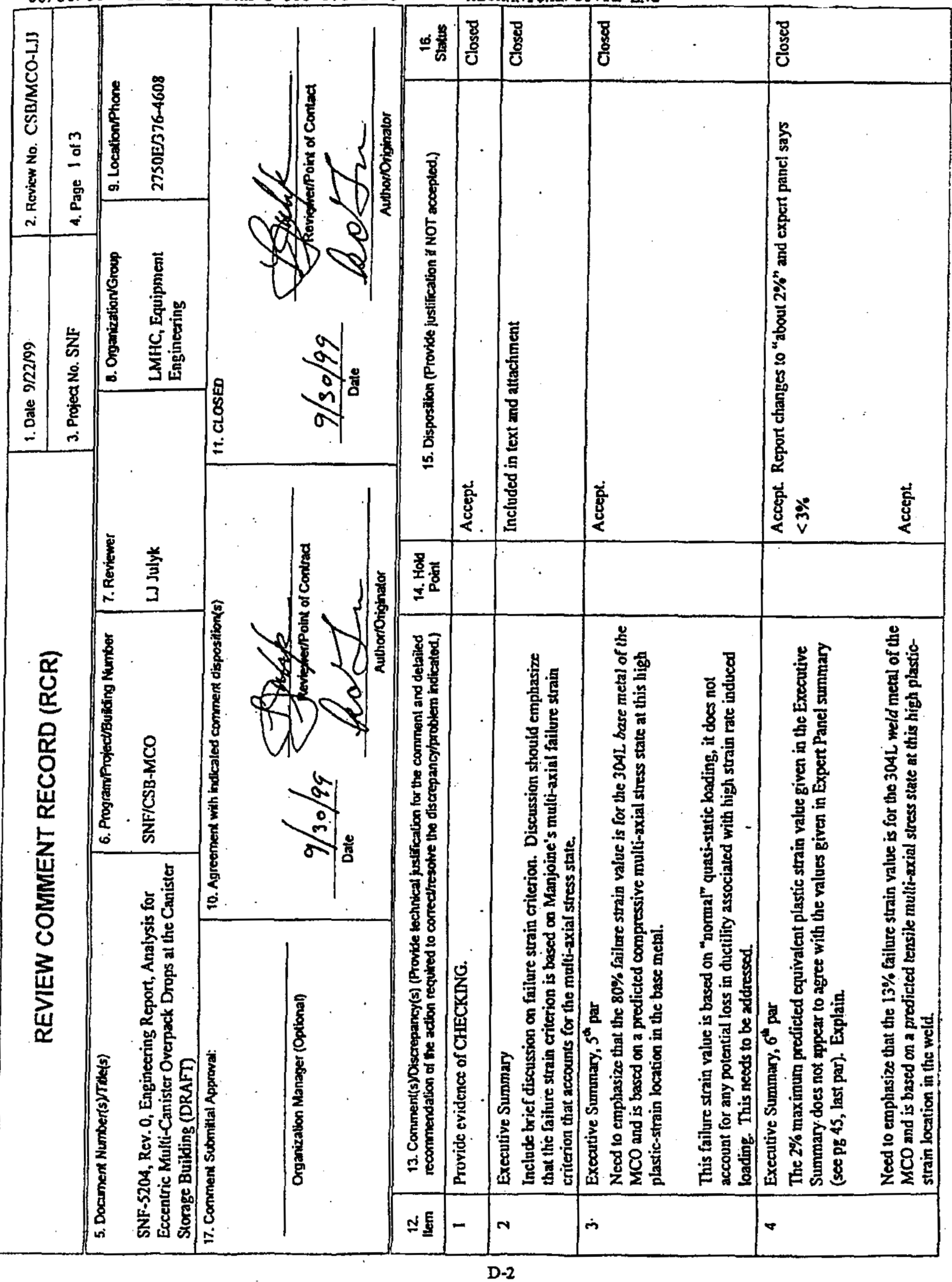




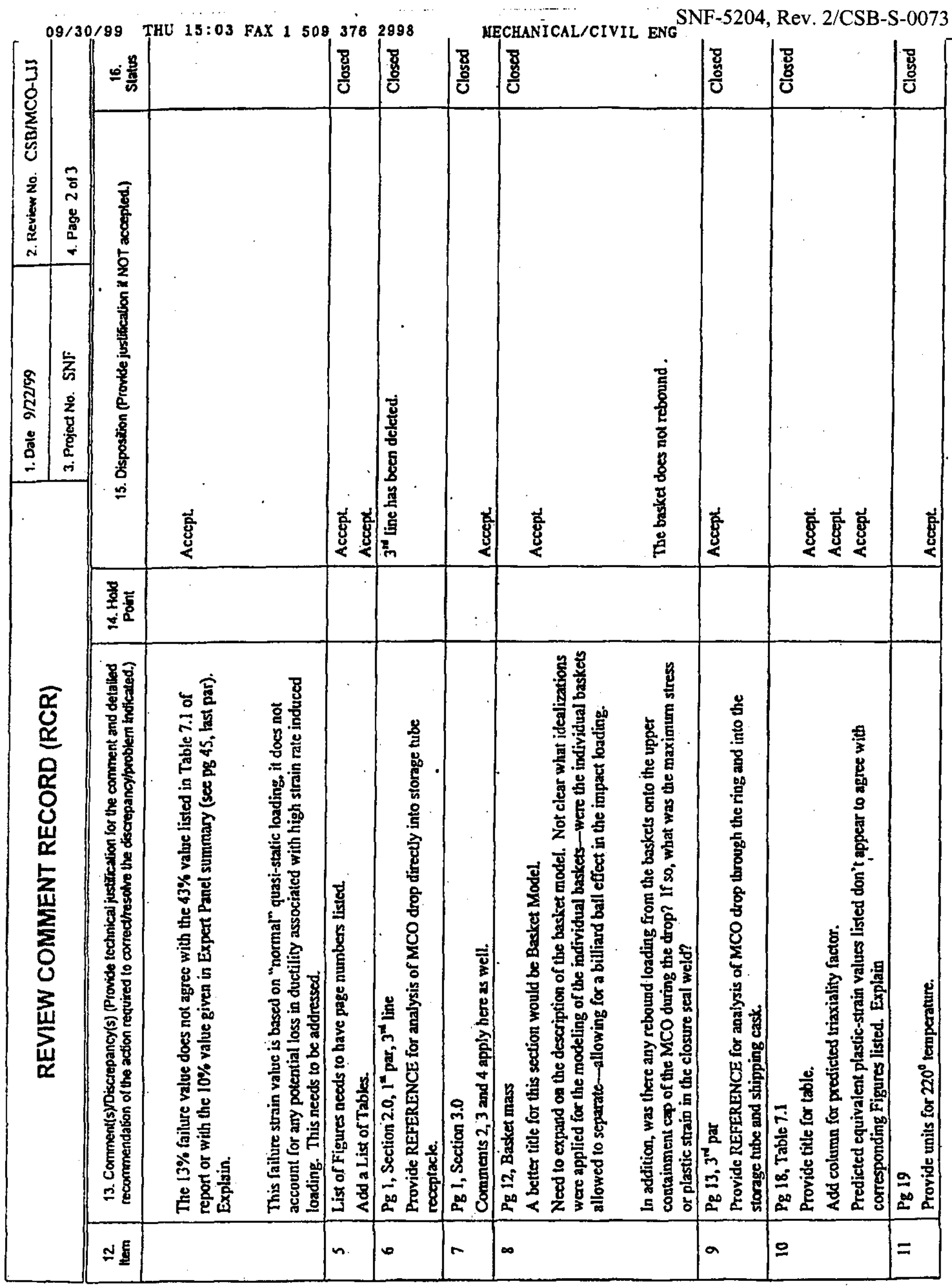


09/30/99 THU 15:04 FAX 15093762998

MECHANICAL/CIVIL ENG

SNF-5204, Rev. 2/CSB-S-0073

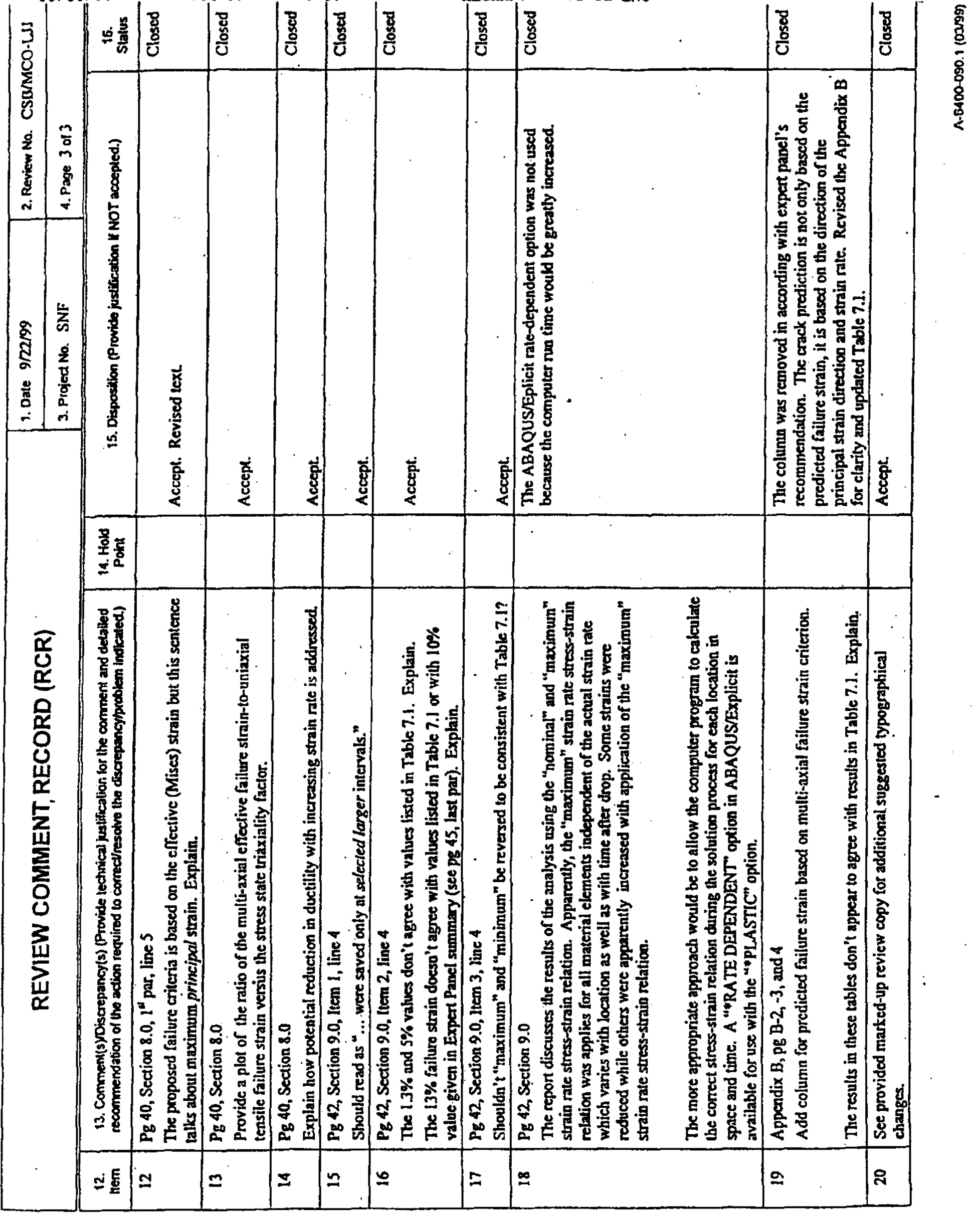

D-4 
KEYWORO DESIGNEE TO INDICATE OISTRIBUTION OF CORRESPONDENCE \& ATTACHMENTS IF REQUIRED $A$ - ACTIONEE KW - KEYWORD DESIGNEEIORIGINATOR

TRANSMITTAL TO: DE \& S

DATE: 1015A99

LOG NUMBER:FDP.1050 FILE LOCATION: 102,5E

\begin{tabular}{|c|c|c|c|c|c|}
\hline 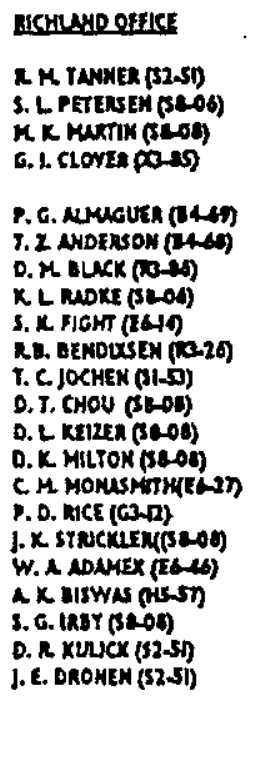 & 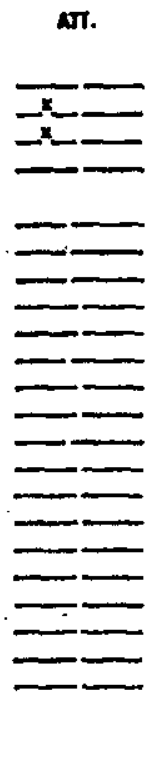 & 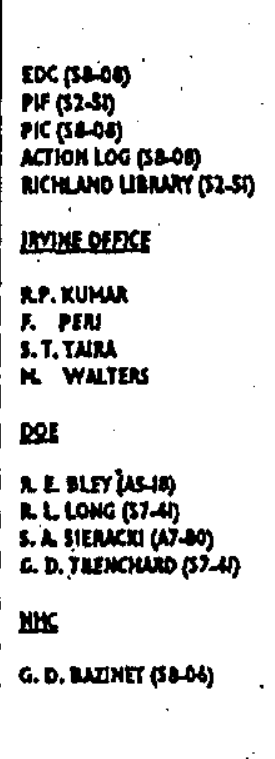 & = & 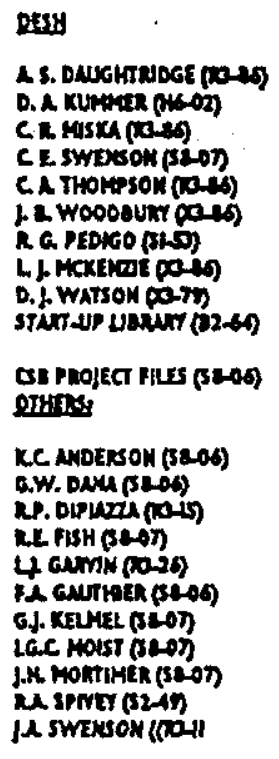 & 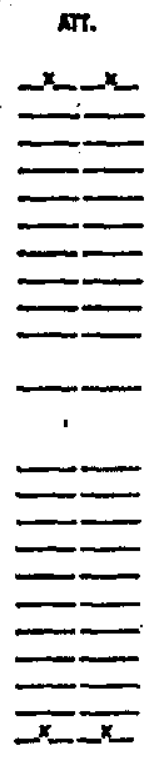 \\
\hline \multicolumn{6}{|c|}{ ACTION ASSIGNMENT/COMMENTS } \\
\hline
\end{tabular}

\section{TITLE/DESCRIPTION}

\section{ANALYSIS FOOR EXCENTRIC MULTI-CANISTER OVERPACK DROPS AT THE CANISTER STORAGE}

BUILDING

\section{KEYWORDS}

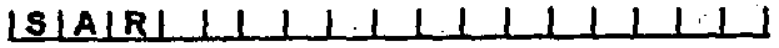

IC IS IB I

IS IN IF IP I ل

لـ 
SNF-5204. Rev. 2/CBS-S-0073

Appendix E

RL Letter of Concurrence

E-1 


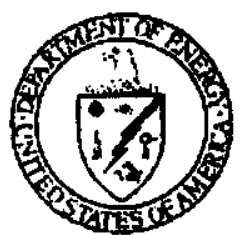

(0)-SFO-014
Department of Energy

Richland Operations Office

P.O. Box 550

Richland, Washington 99352
9907430

CC RFCD: $11 / 23 ; .19$

Mr. R. D. Hanson, President

Fluor Daniel Hanford. Inc.

Richland, Washington 99352

Dear Mr. Hanson:

NOY 181999

\section{CONTRACT NO. DE-AC.06-96RLI3200 - REQUEST FOR PERMISSION TO PERFORM IINAL STANDARD TUBE WELDING}

Fluor Daniel Hanford, Inc. (FDH) letter to P. G. Loscoe, U.S. Department of Energy, Richland Opcrations Office (RL), from R. B. Wilkinson, sanc subject as above, FDH-9957747, dated October 13,1999, requests RL concurrence on the Engineering Data Transmittal 627587. RL concurs that the Engineering Datu Transmittal 627587 dated October 8, 1999, provides sufficicnt technical justification to proced with final seal welding of the standard and overpack tubes with the floor imbeds.

FDH is authorized to procecd with this welding.

If you have any questions, please contact P. (i. Loscoc, Office of Spent Nuclear Fuels, on (509) 376-7465.

SFO:REB

Sincerely,

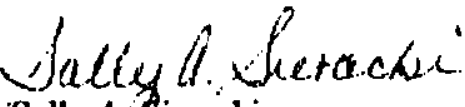

Sally A Sierucki

Contracting Officer

cc: A. S. Daughtridge, DESH

J. W. Ioster, DESH

R. P. Ruth, DESII

J. $\Lambda$. Swenson, DESH

R. B. Wilkinson, DFSH

R. G. Jones, FDH

D. W. Siddoway, FDH

D. B. Van Leuven, FDH

R. B. Willard, FDH 